NATIONAL LABORATORY

MANAGED BY UT-BATTELLE

FOR THE DEPARTMENT OF ENERGY

\title{
Near Net Shape Manufacturing of New, Low Cost Titanium Powders for Industry
}

\section{$03 / 5 / 2013$}

Prepared by

William H. Peter \& Yukinori Yamamoto

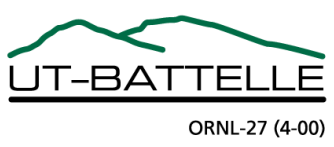




\section{DOCUMENT AVAILABILITY}

Reports produced after January 1, 1996, are generally available free via the U.S. Department of Energy (DOE) Information Bridge.

Web site http://www.osti.gov/bridge

Reports produced before January 1, 1996, may be purchased by members of the public from the following source.

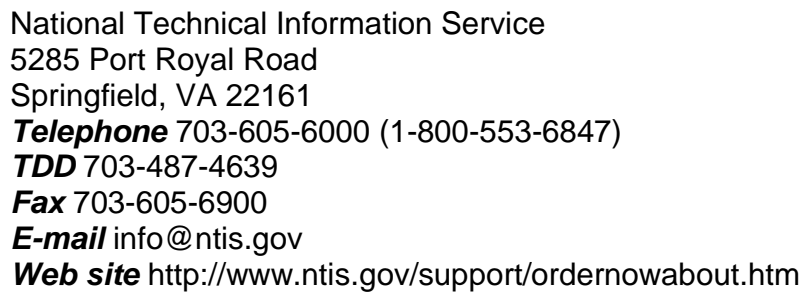

Reports are available to DOE employees, DOE contractors, Energy Technology Data Exchange (ETDE) representatives, and International Nuclear Information System (INIS) representatives from the following source.

Office of Scientific and Technical Information

P.O. Box 62

Oak Ridge, TN 37831

Telephone 865-576-8401

Fax 865-576-5728

E-mail reports@osti.gov

Web site http://www.osti.gov/contact.html

This report was prepared as an account of work sponsored by an agency of the United States Government. Neither the United States Government nor any agency thereof, nor any of their employees, makes any warranty, express or implied, or assumes any legal liability or responsibility for the accuracy, completeness, or usefulness of any information, apparatus, product, or process disclosed, or represents that its use would not infringe privately owned rights. Reference herein to any specific commercial product, process, or service by trade name, trademark, manufacturer, or otherwise, does not necessarily constitute or imply its endorsement, recommendation, or favoring by the United States Government or any agency thereof. The views and opinions of authors expressed herein do not necessarily state or reflect those of the United States Government or any agency thereof.

ORNL/TM-2012/510 
Materials Science and Technology Division

Final Technical Report

\section{Near Net Shape Manufacturing of New, Low Cost Titanium Powders for Industry}

DOE Award Number: CPS Agreement No. 17881

Project Period: July 2008 - May 2012

Primary Investigators:

Dr. William Peter, Dr. Yukinori Yamamoto, Dr. Wei Chen, Dr. Ryan Dehoff, Dr. Stephen Nunn, Dr. Adrian Sabau, Mr. Jim Kiggans, Dr. Thomas Muth,

Oak Ridge National Laboratory

1 Bethel Valley Rd, Oak Ridge, Tennessee 37831

University Participant:

Prof. Glenn Daehn and Mr. Bradley Kabert, The Ohio State University

Industrial Participants:

Mr. Cory Tallman, Mr. Rob Gorham, John Barnes (formerly), and Chad Henry (formerly)

Lockheed Martin Aeronautics

Mr. Joe Capone, Mr. Muktesh Paliwal, and Mr. Ryan Smith, Ametek, Inc.

Dr. Kamal Akhtar, International Titanium Powder

Mr. David Peltier, Avure Technologies, Inc.

Other Laboratory Participants:

Dr. Richard Everett and Dr. Ashraf Imam, Naval Research Laboratory

Date Published: 03/5/2013

Prepared by

OAK RIDGE NATIONAL LABORATORY

Oak Ridge, Tennessee 37831-6283

managed by

UT-BATTELLE, LLC

for the U.S. DEPARTMENT OF ENERGY

under contract DE-AC05-00OR22725 


\section{Acknowledgment}

\section{Acknowledgment:}

This report is based upon work supported by the U. S. Department of Energy, Advanced Manufacturing Office (AMO) as CPS Agreement 17881.

The authors would like to acknowledge Mr. David Harper for coordination of the tasks in the materials processing laboratory, Mr. Mike Clark for handling powder samples and pressing procedure, Mr. Kevin Harper and Mr. Greg Cox for help with heat treatment, Mr. Jackie Mayotte for optical metallography and hardness measurements, Ms. Rita Ayers for her help as administrative support including the formatting the report, and Dr. Alan Liby and Hiram Rogers for their review of the report.

Furthermore, the authors would like to thank the management and guidance of Dr. Steve Sikirica of DOE's Advanced Manufacturing Office and Dr. Mahesh Jha of the Golden Field Office, Dr. Craig Blue (Program Manager of Advanced Manufacturing at ORNL), and Dr. Alan Liby (Deputy Program Manager of Advanced Manufacturing at ORNL). The team would also like to express appreciation to Hiram Rogers for his editing and revision, and Jennifer Palmer for her contributions in media and highlight development. 


\section{TABLE OF CONTENTS}

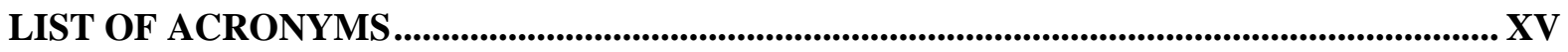

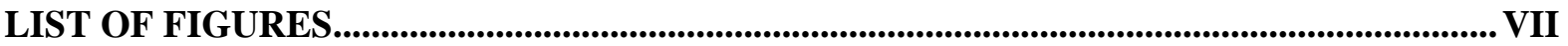

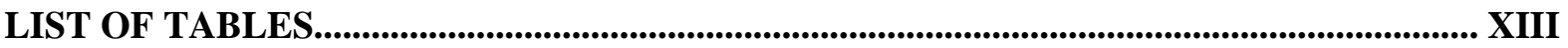

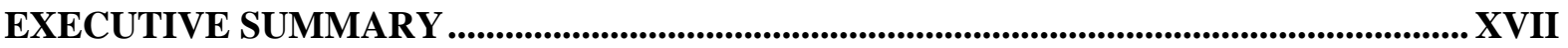

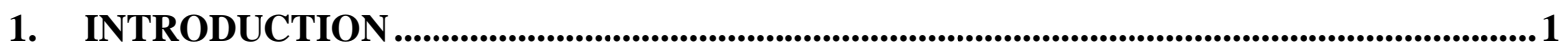

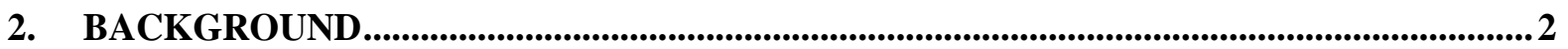

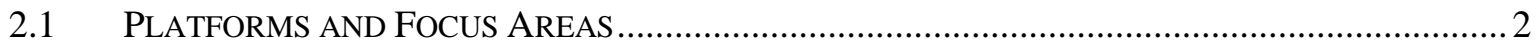

2.2 SUPERIORITY/BENEFITS OF PROPOSED TECHNOLOGY OVER CURRENT PRACTICES.............. 2

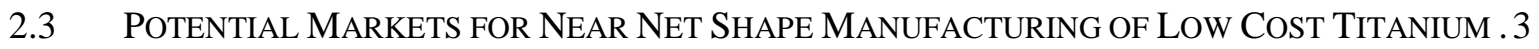

2.4 CURRENT AND TARGET STAGES OF TECHNICAL AND COMMERCIAL DEVELOPMENT ........... 5

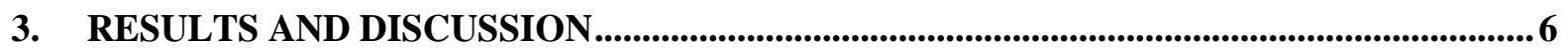

3.1 TASK 1: PRESS AND SinTER OF LOW COST TI AND TI ALLOY POWDERS FOR NEAR NET

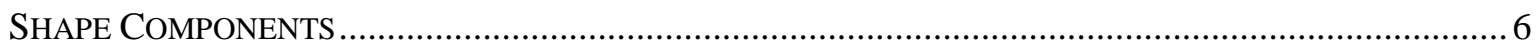

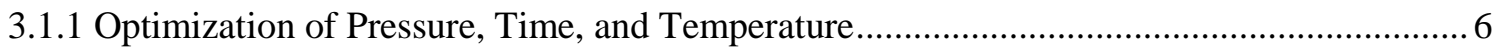

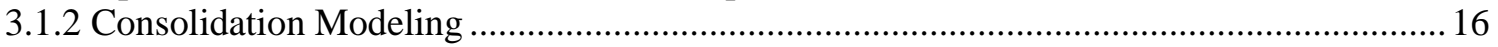

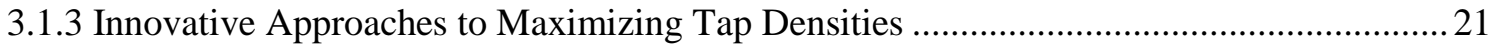

3.1.4 Fabrication of Low Cost Ti and Ti Alloy Net Shape Press and Sintered Parts .................. 31

3.1.5 Characterization and Evaluation of Press and Sintered Low Cost Ti and Ti Alloy .............32

3.1.6 Stamping of Thin Gauge Titanium for Heat Exchangers .................................................. 37

3.2 TASK 2: FULL CONSOLIDATION OF PRESS AND SINTERED PLATES ................................... 38

3.2.1 Pneumatic Isostatic Forging / Hot Isostatic Pressing of Press and Sintered Plates ............. 39

3.2.2 Adiabatic Compaction of Low Cost Ti and Ti Alloys..................................................... 43

3.2.3 Establishing Pressure Density Relationships at High Strain Rates for a Fundamental

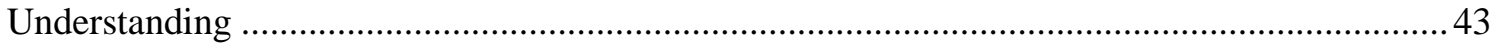

3.2.4 Characterization of Fully Consolidated Plate Produced by Three Methods........................55

3.3 TASK 3: FABRICATION OF PROTOTYPE OF NEAR NET SHAPE COMPONENTS AND OEM

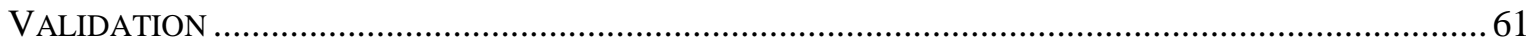

3.3.1 Comprehensive Mechanical Properties Evaluation .....................................................61

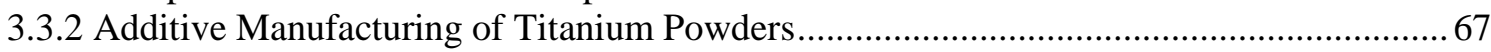

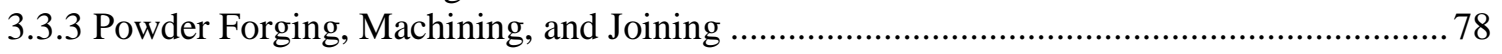

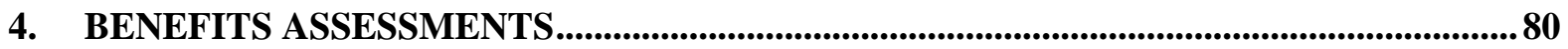

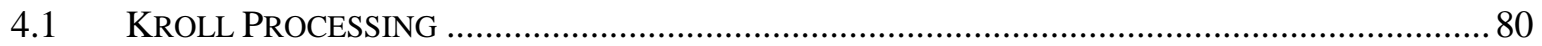

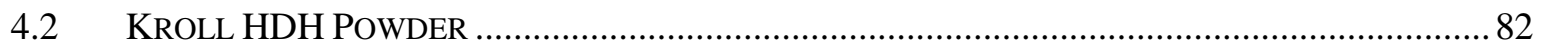

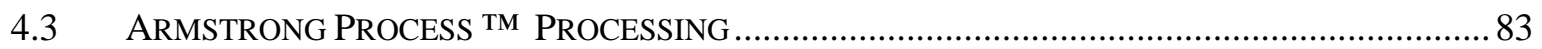

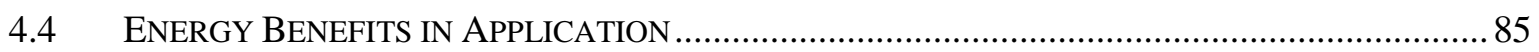

4.5 COST COMPARISON OF POWDER METALLURGY, ADDITIVE MANUFACTURING,

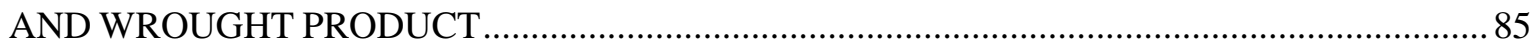

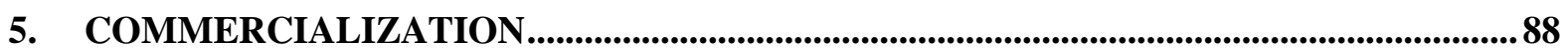

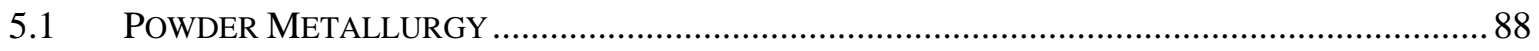

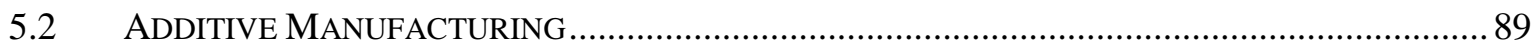

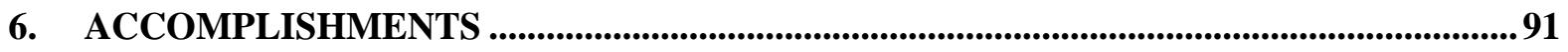

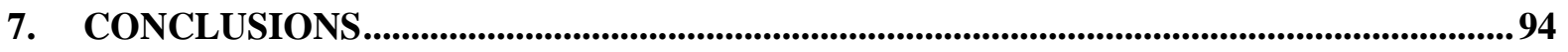




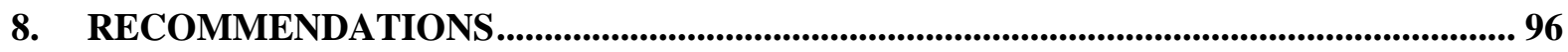

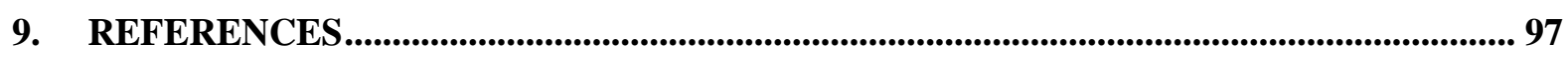




\section{LIST OF FIGURES}

FIGURE 1. SEM-SE IMAGES OF TITANIUM POWDERS STUDIED; (A) ARMSTRONG PROCESSED CPTI, (B) HDH PROCESSED CP-TI, (C) ARMSTRONG PROCESSED TI-6AL-4V, (D) HDH PROCESSED TI-6AL-4V

FIGURE 2. CROSS SECTIONAL SEM-BSE IMAGES OF THE TI-6AL-4V POWDERS STUDIED; (A) ARMSTRONG POWDER, AND (B) HDH POWDER. .8

FIGURE 3. TITANIUM DISCS PRESSED USING A STEEL DIE AND CARVER PRESS FOR THE STUDY (1/2” DIAMETER); (A) SINGLE ACTION DIE, AND (B) DOUBLE ACTION DIE. ..............................

FIGURE 4. THEORETICAL DENSITIES OF CPTI AND TI-6AL-4V BEFORE AND AFTER SINTERING AT $1300^{\circ} \mathrm{C} / 1 \mathrm{H}$, PLOTTED AS A FUNCTION OF PRESSURE AT ROOM TEMPERATURE; (A) CPTIARMSTRONG, (B) CP TI-HDH, (C) TI-6AL-4V-ARMSTRONG, AND (D) TI-6AL-4V-HDH POWDERS.

FIGURE 5. SINTERING TEMPERATURE DEPENDENCE OF THE DENSITY OF ARMSTRONG POWDERS: (A) CP-TI, AND (B) TI-6AL-4V. 10

FIGURE 6. SEM BSE IMAGES OF ARMSTRONG POWDERS AFTER CONSOLIDATION PROCESS (PRESSED AT 100KSI, AND THEN SINTERED FOR 1H); (A, B, AND C) CP-TI, SINTERED AT 925, 1100, AND 1300OC, RESPECTIVELY, AND (D, E, AND F) TI-6AL-4V, SINTERED AT 925, 1100, AND 1300OC, RESPECTIVELY. THE NUMBERS IN THE PICTURES CORRESPOND TO THE MEASURED DRY DENSITIES (CONVERTED TO THE THEORETICAL DENSITIES).

FIGURE 7. TEMPERATURE DEPENDENCES OF (A) VOLUME FRACTION OF PORES MEASURED FROM CROSS-SECTIONAL IMAGES AND (B) THEORETICAL DENSITIES. ................................11

FIGURE 8. OM MICROSTRUCTURE OF ARMSTRONG CP-TI PRESSED AT 100KSI; (A) NO HOLD AT 100 KSI PRESSING, AND (B) 2 MIN HOLD DURING PRESSING AT 100 KSI. CIRCLES IN THE PICTURES CORRESPOND TO AGGLOMERATES OF LARGE PORES.

FIGURE 9. OM MICROSTRUCTURE OF ARMSTRONG CP-TI PRESSED AT 100KSI WITH DIFFERENT HOLD TIMES, FOLLOWED BY SINTERING AT $1100^{\circ} \mathrm{C}$ FOR $2 \mathrm{H}$; (A) NO HOLD AT 100KSI PRESSING, AND (B) 2 MIN HOLD DURING PRESSING AT 100 KSI.

FIGURE 10. EFFECT OF SINTERING TIME AND TEMPERATURE ON THE DENSITY OF ARMSTRONG CP-TI PRESSED AT 10 OKSI.

FIGURE 11. THEORETICAL DENSITY OF PRESSED AND SINTERED HDH TI-6AL-4V POWDERS PLOTTED AS A FUNCTION OF PRESSURE: (A) SINTERED FOR 1H, AND (B) FOR 5H...............14

FIGURE 12. THEORETICAL DENSITY OF PRESSED AND SINTERED HDH TI-6AL-4V POWDERS PLOTTED AS A FUNCTION OF SINTERING TIME: (A) PRESSED AT 75 KSI, AND (B) AT 100 KSI.

FIGURE 13. OM MICROSTRUCTURE OF HDH TI-6AL-4V PRESSED AT 100 KSI, TOGETHER WITH A HIGH MAGNIFICATION OM PICTURE SHOWING THE LOCAL POWDER DEFORMATION INDICATED BY ARROWS.

FIGURE 14. OM MICROSTRUCTURE OF HDH TI-6AL-4V PRESSED AT 100KSI, FOLLOWED BY SINTERING AT $1300^{\circ} \mathrm{C}$; (A) SINTERED FOR 1H, AND (B) FOR 5H................................................ 16

FIGURE 15. UNIAXIAL COMPRESSION TESTS LOADING AND UNLOADING FOR RD=3.12 G/CM ${ }^{3}$,

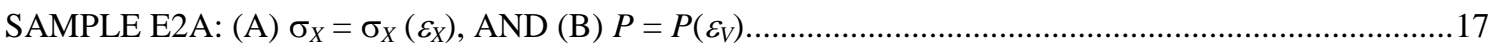

FIGURE 16. CYCLES CHOSEN FOR LINEAR REGRESSION ANALYSIS TO OBTAIN E AND K FOR $\mathrm{RD}=3.12 \mathrm{G} / \mathrm{CM}^{3}$

FIGURE 17. FAILURE LINE OBTAINED FROM THE TWO COMPRESSION TESTS. ............................17

FIGURE 18. SCHEMATIC OF VERTICAL CROSS SECTION THROUGH THE CYLINDRICAL PART THAT IS SUBJECT TO DUAL-ACTION PRESSING SHOWING THE CYLINDER VERTICAL AXIS

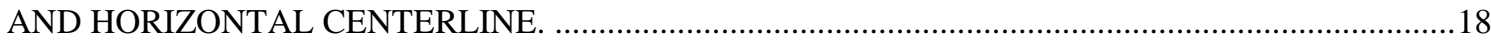

FIGURE 19. THE EFFECTIVE STRESS [KSI] FOR DISK SAMPLES WITH COMPACTION PRESSURES OF (A) 25 KSI (172.4 MPA) AND (B) 75 KSI (517.1 MPA) AND FOR CYLINDER SAMPLES WITH COMPACTION PRESSURES OF (C) 25 KSI (172.4 MPA) AND (D) 75 KSI (517.1 MPA). DEFORMED MESHES ARE SHOWN. 
FIGURE 20. THE DISTRIBUTION OF HYDROSTATIC STRESS [KSI] FOR DISK SAMPLES WITH COMPACTION PRESSURES OF (A) 25 KSI (172.4 MPA) AND (B) 75 KSI (517.1 MPA) AND FOR CYLINDER SAMPLES WITH COMPACTION PRESSURES OF (C) 25 KSI (172.4 MPA) AND (D) 75 KSI (517.1 MPA). DEFORMED MESHES ARE SHOWN...

FIGURE 21. EXAMPLES OF THE SIMULATION RESULTS: (A) DEFORMED MESH SHOWING THE DISTRIBUTION OF RELATIVE DENSITY FOR SIMULATION OF CIP OF THE SAMPLE S2. INITIAL (WHITE) AND DEFORMED (GREEN) MESHES SHOWING THE DENSIFICATION DURING SINTERING: (B) AT THE END OF THE HOLD TIME AND (C) AFTER COOLING TO ROOM TEMPERATURE.

FIGURE 22. DISTRIBUTION OF RELATIVE DENSITY DURING SINTERING FOR THE SAMPLE IN FIGURE 21, (A) AT THE END OF THE HOLD TIME AND (B) AFTER COOLING TO ROOM TEMPERATURE.

FIGURE 23. (A) POWDER SIZE DISTRIBUTION AND (B) TAP DENSITY OF ARMSTRONG CP-TI POWDER BEFORE AND AFTER BALL-MILLING IN ETHANOL

FIGURE 24. SEM IMAGES OF (A) ARMSTRONG CP-TI POWDER AND (B) ARMSTRONG TI-6AL-4V POWDER AFTER BALL-MILLING IN ETHANOL FOR 1H. ARROWS INDICATE FLATTENED PARTICLES FORMED BY DIRECT COMPACTION OF BALLS.

FIGURE 25. OM PICTURES OF BALL-MILLED ARMSTRONG CP-TI PRESSED AT 100KSI; (A) HOLD FOR 30 SEC AT 100KSI, AND (B) HOLD FOR 2 MIN AT 100KSI, TOGETHER WITH (C) A HIGH

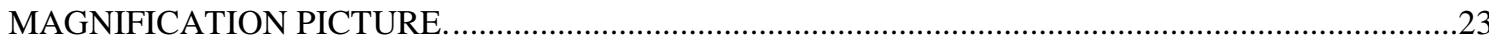

FIGURE 26. OM PICTURES OF AS-PRESSED THE ARMSTRONG AND THE HDH CP-TI POWDERS BLENDED WITH DIFFERENT RATIO (A) ARMSTRONG: HDH = 90:10, AND (B) 50:50...............24

FIGURE 27. DENSITY OF BLENDED CP-TI POWDER PRESSED AT 100KSI, PLOTTED AS A FUNCTION OF VOLUME FRACTION OF HDH POWDER.

FIGURE 28. THEORETICAL DENSITIES OF ARMSTRONG PROCESS TI-6AL-4V POWDER BEFORE AND AFTER SINTERING AT $1300^{\circ} \mathrm{C}$ FOR $1 \mathrm{H}$ PLOTTED AS A FUNCTION OF (A) DIE PRESSURE AND (B) COLD-ISOSTATIC PRESSURE.

FIGURE 29. CHANGES IN OXYGEN CONTENTS DURING CONSOLIDATION PROCESS OF ARMSTRONG TITANIUM POWDERS MILLED IN DIFFERENT TYPES OF MEDIA; (A) TI-6AL4V, AND (B) CP-TI..

FIGURE 30. COMPOSITION PROFILES OF C AND O NEAR THE SURFACE OF ARMSTRONG CP-TI POWDER BEFORE AND AFTER BALL-MILLING, MEASURED BY PHYSICAL ELECTRONIC

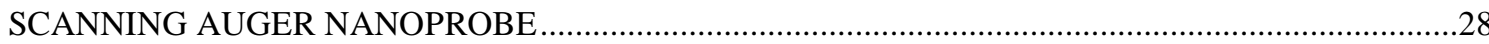

FIGURE 31. EFFECT OF BALL-MILLING ATMOSPHERE (AIR, AR, AND N $_{2}$ OF ARMSTRONG CP-TI POWDER ON THE CHEMISTRY AFTER LONG TIME EXPOSURE IN AIR; (A) OXYGEN AND (B) NITROGEN.

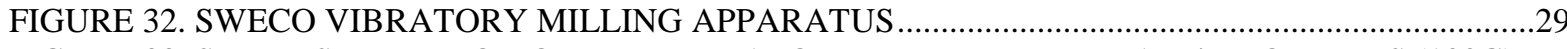

FIGURE 33. SIZE DISTRIBUTION OF THE VIBRATORY MILLED ITP TI-6AL-4V POWDERS (100G) WITH TUNGSTEN CARBIDE MEDIA (19KG) IN AR GAS. NOTE THAT THE SIEVE SIZE OF

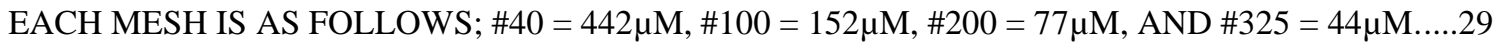

FIGURE 34. (A) TAP DENSITY OF THE VIBRATORY MILLED ITP TI-6AL-4V POWDERS, AND (B) CHEMICAL ANALYSIS RESULTS OF THE VIBRATORY MILLED ITP TI-6AL-4V POWDERS PLOTTED AS A FUNCTION OF MILLING TIME.

FIGURE 35. SLURRY OF VIBRATORY-MILLED ARMSTRONG CP-TI POWDER WITH DEIONIZED WATER

FIGURE 36. AS-PRESSED NET SHAPE DISCS OF HDH POWDER (LEFT) AND ARMSTRONG POWDER (RIGHT)

FIGURE 37. EXAMPLES OF PRESSED AND SINTERED ARMSTRONG POWDERTI-6AL-4V COMPONENTS. A COMPONENT BLANK IS SHOWN AT TOP RIGHT AND TWO COMPONENTS MACHINED FROM BLANKS ARE PICTURED. ...........................................................................

FIGURE 38. EXAMPLES OF PRESSED AND SINTERED ARMSTRONG TI-6AL-4V COMPONENTS. CYLINDRICAL ISOPRESSING ON A MANDRIL AND SINTERING AT $1300^{\circ} \mathrm{C}$ HAVE BEEN

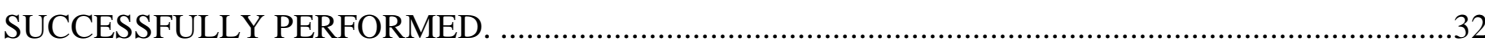

FIGURE 39. AS-RECEIVED TUBES AFTER REMOVING THE OUTER CU TUBES.................................32 
FIGURE 40. GREEN DENSITY DISTRIBUTION IN ARMSTRONG TI-6AL-4V SAMPLES PRESSED AT 345 MPA AND 517 MPA. (A) AXIAL DENSITY OF SAMPLES WITH ASPECT RATIO 2, AND (B)

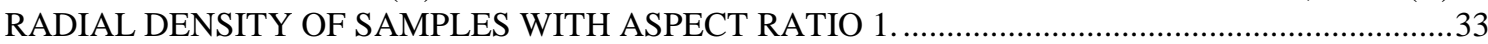

FIGURE 41. GREEN DENSITY VERSUS ASPECT RATIO PLOT FOR THE ARMSTRONG TI-6AL-4V SAMPLES PRESSED AT 6 DIFFERENT PRESSURES. 34

FIGURE 42. GREEN DENSITY VERSUS DIE-PRESSURE FITTED TO THE PANELLI EQUATION FOR

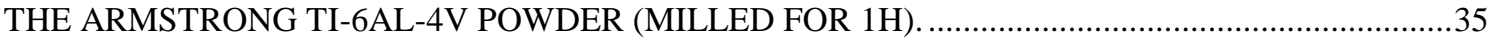

FIGURE 43. AN IMAGE OF X-RAY TOMOGRAPHY OF AS-PRESSED CP-TI ARMSTRONG POWDER (NO MILLING) AT 50 KSI, SHOWING DENSE POROSITY AREA NEAR TOP AND AN INCLUSION NEAR BOTTOM.

FIGURE 44. CROSS-SECTIONAL VIEW OF THE ARMSTRONG CP-TI PRESSED AT $100 \mathrm{KSI}$; (A) OM MACROSCOPIC VIEW (SAME AS FIG. 8A), (B) SEM IMAGE AND EDS MAP ANALYSIS RESULTS, AND (C) OM MICROSTRUCTURE OF LARGE POROSITY AGGLOMERATES. ............37

FIGURE 45. IMAGE OF THE AS-ROLL COMPACTED HDH (TOP) AND ARMSTRONG (BOTTOM) POWDERS (LEFT), AND PRESSED/SINTERED FORMED SHEET WITH THE HERRINGBONE STRUCTURE FROM THE RESPECTIVE POWDERS (RIGHT)

FIGURE 46. PICTURES OF (A) DIRECT PIF SAMPLES AND (B) DIRECT HIP SAMPLES WITHOUT CANNING. URE 47. MICROGRAPH OF CP-TI SAMPLE AFTER HIPING ROLL-COMPACTED ARMSTRONG

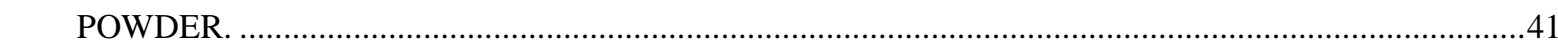

FIGURE 48. DIE PRESSED PLATES OF TI-6AL-4V (LEFT) AND CP-TI (RIGHT) ..................................41

FIGURE 49. TRUE DENSITY OF THE DIE PRESSED PLATES IN EACH STEP......................................42

FIGURE 50. A FATIGUE CRACK GROWTH SPECIMENS MACHINED FROM THE HIPED TI-6AL-4V PLATE

FIGURE 51. (A) A DRAWING OF FATIGUE SPECIMEN WHICH WILL BE SECTIONED FROM THE RECTANGLE SPECIMEN, AND (B) A PICTURE OF THE MACHINED SPECIMEN ........................43

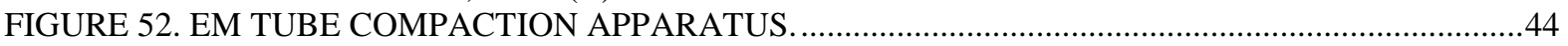

FIGURE 53. EM TUBE COMPACTION EXPERIMENTAL SETUP ……......................................................4

FIGURE 54. SCHEMATIC OF OFFSET TUBE COMPACTION FOR A GENERIC METAL POWDER (RADIAL FLYER COMPACTION).

FIGURE 55. MEASURED CURRENT (IN KA) AND VELOCITY (IN M/S) FOR DIRECT COMPACTION (A) AND OFFSET COMPACTION (B) USING ARMSTRONG POWDER AND A FIXED ELECTROMAGNETIC ACTUATOR WITH 8KJ AND 12KJ DISCHARGES, RESPECTIVELY. THE INSET PHOTO SHOWS THE INITIAL CONFINEMENT TUBE AND THAT AFTER COMPACTION. THE LATTER METHOD GIVES MUCH HIGHER VELOCITIES AT INITIAL COMPACTION.........45

FIGURE 56. TERMINAL DENSITY AS A FUNCTION OF DISCHARGE ENERGY FOR HDH AND ARMSTRONG POWDERS IN DIRECT COMPACTION. $\ldots 46$

FIGURE 57. CROSS-SECTIONAL VIEW OF THE EM COMPACTED CP-TI SAMPLES. ..........................46

FIGURE 58. THEORETICAL DENSITIES OF THE EM COMPACTED CP-TI SAMPLES PLOTTED AS A FUNCTION OF (A) EM ENERGY, AND (B) UNI-AXIAL PRESSURE. ...............................................48

FIGURE 59. CROSS-SECTIONAL VIEW OF THE EM COMPACTED TUBES AND THE AVERAGED DENSITY OF DIFFERENT PORTIONS MEASURED FROM THE MICROSTRUCTURE. .................48

FIGURE 60. AN EM COMPACTED TUBE SPECIMEN (LG20); (A) AS EM COMPACTED (WITH CU TUBE), (B) AFTER CU TUBE REMOVAL, AND (B) AFTER SINTERING AT $1300^{\circ} \mathrm{C}$ FOR $1 \mathrm{H}$ IN A VACUUM

FIGURE 61. AN EM COMPACTED TI-6AL-4V TUBE SPECIMEN (LG20); (A) AFTER SINTERING AT $1300^{\circ} \mathrm{C}$ FOR $1 \mathrm{H}$ IN A VACUUM, AND (B) OPTICAL MICROGRAPH OF THE CROSS-SECTIONAL VIEW

FIGURE 62. (A) ELECTROMAGNETIC PLATE LAUNCHING ACTUATOR WITH ROLL-COMPACTED CP-TI ARMSTRONG POWDER SPECIMEN, AND (B) THE SPECIMEN SURFACE AFTER

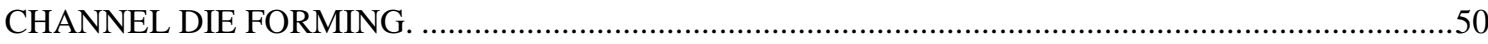

FIGURE 63. RELATIONSHIP BETWEEN THE STAGE VELOCITY AND DENSITY …..........................51

FIGURE 64. PICTURES OF HIGH STRAIN RATE FORMING DIE (A), ROLL COMPACTED TITANIUM SHEET AFTER PRESS DEFORMATION (B) AND CROSS-SECTIONAL OPTICAL MICROGRAPH OF THE BENDED PORTION (C). 
FIGURE 65. OPTICAL MICROGRAPHS OF (LEFT) PRE-SINTERED CP-TI ROLLED SHEET AND (RIGHT) PRE-SINTERED TI-64 SHEET THAT HAVE BEEN FURTHER COMPACTED USING AND ELECTROMAGNETIC UNIFORM PRESSURE ACTUATOR …..........................................................53

FIGURE 66. IMAGES OF (LEFT) PRE-SINTERED M9 CP-TI ROLLED SHEET AND (RIGHT) PRESINTERED TI-64 SHEET THAT HAVE BEEN FORMED OVER A CHANNEL DIE WITH AN ELECTROMAGNETIC UNIFORM PRESSURE ACTUATOR... .53

FIGURE 67. AN IMPACT PRESS ILLUSTRATED. A FORCE IS APPLIED TO A MOVING RAM OVER A GIVEN DISTANCE ACQUIRING A SUBSTANTIAL AMOUNT OF KINETIC ENERGY. THE ENERGY IS THEN DISCHARGED UPON IMPACT WITH THE WORKPIECE. THE EFFECTIVE TONNAGE DEPENDS UPON THE DISTANCE OVER WHICH THE ENERGY IS DISSIPATED INTO THE WORKPIECE. IN THIS SORT OF PRESS ARRANGEMENT, THE TOOLING CAN BE VERY LIGHTWEIGHT AS THE ENERGY RESULTS PRIMARILY FROM THE VELOCITY OF THE MOVING RAM AND NOT IT'S MASS.

FIGURE 68. A CHART ILLUSTRATING THE EFFECT OF REPEATED STRIKES OF AN ELECTROMAGNETIC PRESS ON 1" SQUARE ROLL-COMPACTED TITANIUM SHEET SAMPLES.

FIGURE 69. FATIGUE CRACK GROWTH RATE (DA/DN) AS A FUNCTION OF STRESS INTENSITY (DK) OF (A) CP-TI SAMPLES, AND (B) TI-6AL-4V.

FIGURE 70. A FRACTURE SURFACE OF THE TESTED SAMPLE (CP-TI, PIF, MILLED).......................56

FIGURE 71. OPTICAL MICROGRAPHS OF FULLY CONSOLIDATED CP-TI MADE FROM ARMSTRONG POWDER (AS-RECEIVED AND MILLED), HDH POWDER, AND COMMERCIAL WROUGHT PRODUCT.

FIGURE 72. OPTICAL MICROGRAPHS OF FULLY CONSOLIDATED TI-6AL-4V MADE FROM ARMSTRONG POWDER (AS-RECEIVED AND MILLED), HDH POWDER, AND COMMERCIAL WROUGHT PRODUCT. 58

FIGURE 73. OM MICROSTRUCTURE OF FULLY CONSOLIDATED ARMSTRONG CP-TI SINTERED WITH VARIOUS CONDITIONS AND THEN HIPED AT $950^{\circ} \mathrm{C} / 15 \mathrm{KSI} / 4 \mathrm{H}$; (A) SINTERED AT $1100^{\circ} \mathrm{C} / 24 \mathrm{H}$, (B) BAKED AT $300^{\circ} \mathrm{C} / 4 \mathrm{H}$ AND SINTERED AT $1100^{\circ} \mathrm{C} / 24 \mathrm{H},(\mathrm{C})$ BAKED AT $300^{\circ} \mathrm{C} / 4 \mathrm{H}$ AND SINTERED AT $1200^{\circ} \mathrm{C} / 4 \mathrm{H}$, AND (D) SINTERED AT $1300^{\circ} \mathrm{C} / 1 \mathrm{H}$

FIGURE 74. OM MICROSTRUCTURE OF SINTERED ARMSTRONG CP-TI SINTERED WITH VARIOUS CONDITIONS (BEFORE HIPING); SINTERED AT (A) $1100^{\circ} \mathrm{C} / 1 \mathrm{H}$, (B) $1100^{\circ} \mathrm{C} / 24 \mathrm{H}$, (C) $1200^{\circ} \mathrm{C} / 1 \mathrm{H}$, AND (D) $1200^{\circ} \mathrm{C} / 4 \mathrm{H}$.......

FIGURE 75. DRAWING AND A PICTURE OF MINIATURE TENSILE SPECIMEN ……...........................6

FIGURE 76. DRAWING OF FRACTURE TOUGHNESS TEST SPECIMEN ..................................................65

FIGURE 77. DRAWING OF FATIGUE CRACK GROWTH TEST SPECIMEN. .........................................66

FIGURE 78. FATIGUE CRACK GROWTH TEST RESULTS; (A) CP-TI, AND (B) TI-6AL-4V..................66 FIGURE 79. S-N PLOT OF FULLY CONSOLIDATED ARMSTRONG CP-TI POWDER MADE BY PRESSAND-SINTER TECHNOLOGY: (A) DATA OBTAINED, AND (B) REFERENCE FROM A

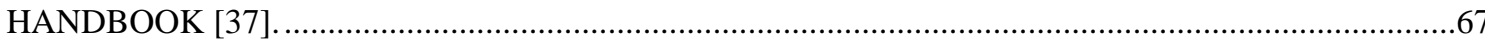

FIGURE 80. INSIDE OF ANEBM BUILD CHAMBER (LEFT) AND CLOSE UP OF RAKE AND HOPPER (RIGHT).

URE 81. OPTICAL IMAGES OF HDH POWDER USED IN THE EBM PROCESS.

FIGURE 82. BUILD LAYOUT AND PARAMETER MATRIX FOR PROCESS EVALUATION. EACH SETTING WAS USED TO MELT 3 SAMPLES 10MM X 30MM X 10MM IN THE X=0, Y=0, AND X$Y=45$ ORIENTATIONS. COMPLETED BUILD IS SHOWN AT THE FAR RIGHT. URE 83. MICROSTRUCTURE OF CP TI EBM SAMPLES SHOWING THE INCREASE IN CHEMICAL COMPOSITION NEAR THE START PLATE (RIGHT). RESULTS INDICATE THERE IS SOME DIFFUSION BETWEEN THE START PLATE AND THE EBM MATERIAL LASTING FOR 0.7MM. THE CONCENTRATION OF IMPURITY ELEMENTS DECREASE AS A FUNCTION OF Z HEIGHT AS INDICATED BY THE PEAK INTENSITY IN EDS.

FIGURE 84. COMPLEX GEOMETRY COMPONENT DESIGNED BY LOCKHEED MARTIN ...................73

FIGURE 85. CROSS SECTIONAL MICROSTRUCTURE OF TI-6AL-4V COMPONENT FABRICATED USING SPHERICAL GAS ATOMIZED POWDER. THE DEPOSITION DIRECTION IS PARALLEL TO THE VERTICAL AXIS.

FIGURE 86. PRELIMINARILY FABRICATED PRODUCTS OF (A) AN IMPELLER, AND (B) A TBRACKET FOR AIRCRAFT COMPONENTS FABRICATED BY ADDITIVE MANUFACTURING. 75 
FIGURE 87. CROSS SECTION OF IMPELLER FABRICATED THROUGH CASTING (LEFT) AND NEWLY DESIGNED IMPELLER USING ELECTRON BEAM MELTING. A 55\% WEIGHT SAVINGS WAS OBSERVED WHILE MAINTAINING SIMILAR FUNCTION.

FIGURE 88. MEASUREMENT OF AN ADEQUATE FLUID PASSAGE AND FOR THE FLUID PASSAGE THAT FAILED TO MEET THE GEOMETRIC ACCURACY REQUIRED FOR MACHINING. ONLY 1 OF THE 6 FLUID PASSAGES FAILED TO MEET THE REQUIRED GEOMETRIC ACCURACY..76

FIGURE 89. LOCKHEED MARTIN DESIGNED SPECIMEN LAYOUT CONTAINING BOTH BLOCKS OF SAMPLES AND INDIVIDUAL SAMPLES ALONG WITH WITNESS COUPONS.

FIGURE 90. LAYOUT OF LM BRACKET TO TEST MECHANICAL STRENGTH AS A FUNCTION OF LOCATION AND ORIENTATION WITHIN THE BUILD CHAMBER; (A) DRAWING OF THE COMPONENT LAYOUT, AND (B) THE AS-BUILD COMPONENTS. .78

FIGURE 91. EACH PROCESS OF DIRECT TUBE FABRICATION FROM TI-6AL-4V POWDER; (A) ARMSTRONG PROCESSED TI-6AL-4V POWDER IN A STEEL CAN (OD:3”), (B) AFTER HOT EXTRUSION (SECTIONED), AND (C) AFTER CAN REMOVAL

FIGURE 92. (A) THE H-SHAPE DIE MADE BY ADDITIVE MANUFACTURING AND A WROUGHT TI6AL-4V BILLET BEFORE HOT EXTRUSION, AND (B) A SECTION OF THE EXTRUDED BAR SHOWING THE H-SHAPE.

FIGURE 93. PICTURE OF THE H-SHAPE EXTRUDED COMMERCIAL TI-6AL-4V BAR, TOGETHER WITH CROSS-SECTIONAL MICROSTRUCTURE OBTAINED FROM TWO DIFFERENT PORTIONS. THE ELONGATED GRAIN MORPHOLOGY IN THE MICROSTRUCTURE INDICATED ANISOTROPIC STRESS APPLIED TO THE MATERIAL DURING EXTRUSION. .......79

FIGURE 94. A PROCESS FLOW DIAGRAM DEPICTING KROLL PROCESSED TITANIUM INTO VARIOUS METALLIC FORMS (KOBELCO [41]).

FIGURE 95. DEPICTION OF THE KROLL HDH PROCESS WITH A SCANNING ELECTRON MICROSCOPE IMAGE OF THE PRODUCED POWDER.

FIGURE 96. SCHEMATIC DEPICTION OF THE ARMSTRONG PROCESS® FROM INTERNATIONAL TITANIUM POWDER WITH A SCANNING ELECTRON MICROSCOPY IMAGE OF THE POWDER MORPHOLOGY.

FIGURE 97. COMPARING ENERGY REQUIREMENTS TO PRODUCE TI-6AL-4V COMPONENT BY POWDER METALLURGY USING 10:1, 5:1, AND 2:1 BUY TO FLY RATIO VERSUS A 10:1 BUY TO FLY RATIO FOR WROUGHT PRODUCT.

FIGURE 98. THE COST BREAKOUT OF TITANIUM PARTS MACHINED FROM PLATE (LEFT) AND FORGED STOCK (RIGHT) AS A FUNCTION OF BUY WEIGHT (TOP) AND FLY WEIGHT (BOTTOM). 


\section{LIST OF TABLES}

TABLE 1. LIST OF POWDER MATERIALS, PROCESSES CONDUCTED, AND OPTIMUM PROCESS

FOR FULL CONSOLIDATION IN SECTION 3.1.

TABLE 2. THEORETICAL DENSITY OF AS-PRESSED ARMSTRONG CP-TI POWDER AT VARIOUS HOLDING TIME AT 100KSI.

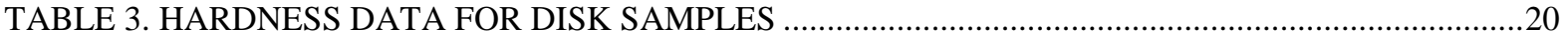

TABLE 4. SAMPLE DIMENSIONS AND DENSITY MEASUREMENTS DURING THE POWDER

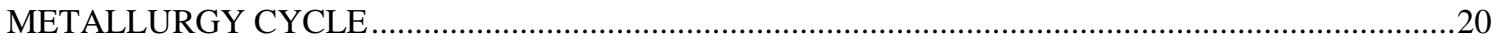

TABLE 5. THEORETICAL DENSITY OF BALL-MILLED ARMSTRONG CP-TI PRESSED AT 100KSI

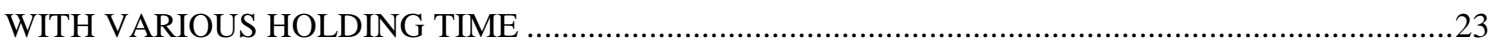

TABLE 6. CHANGES IN OXYGEN CONTENTS DURING CONSOLIDATION PROCESS OF THE BALL-

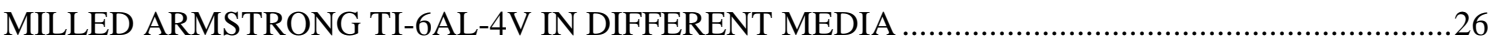

TABLE 7. CHANGES IN OXYGEN CONTENTS DURING CONSOLIDATION PROCESS OF THE BALL-

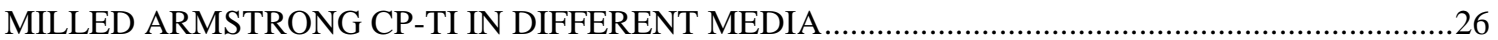

TABLE 8. TENSILE PROPERTIES AND OXYGEN CONTENTS OF FULLY CONSOLIDATED ARMSTRONG (TI-64) MILLED IN DIFFERENT TYPES OF MEDIA (TESTED AT ROOM TEMPERATURE, ASTM-E8, AVERAGED $>3$ TESTS)

TABLE 9. TENSILE PROPERTIES AND OXYGEN CONTENTS OF FULLY CONSOLIDATED ARMSTRONG CP-TI MILLED IN DIFFERENT TYPES OF MEDIA (TESTED AT ROOM TEMPERATURE, ASTM-E8, AVERAGED >3 TESTS)

TABLE 10. ANALYZED OXYGEN AND NITROGEN CONTENTS OF ARMSTRONG CP-TI POWDER BEFORE AND AFTER VIBRATORY MILLING IN DEIONIZED WATER (THE POWDERS AFTER

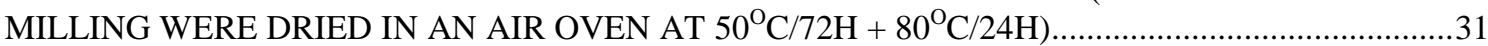

TABLE 11. GREEN DENSITY DATA AND LINEAR REGRESSION PARAMETERS FOR ARMSTRONG TI-64 SAMPLES

TABLE 12. RELATIVE DENSITIES OF ARMSTRONG CP-TI LOT 0508-1 SAMPLES PROCESSED FOR

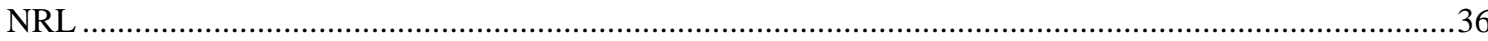

TABLE 13. LIST OF POWDER MATERIALS, PROCESSES CONDUCTED, AND OPTIMUM PROCESS FOR FULL CONSOLIDATION IN SECTION 3.2 ..............................................................................

TABLE 14. RESULTS OF CAN-LESS PIFING OF ARMSTRONG-PROCESS TITANIUM POWDERS THAT WERE PRESSED AND SINTERED TO ACHIEVE CLOSED POROSITY …….........................39

TABLE 15. RESULTS OF HIP CONSOLIDATION OF TITANIUM POWDER COMPACTS. ......................40

TABLE 16. DENSITY OF EM COMPACTED TUBES BEFORE AND AFTER SINTERING AT $1300^{\circ} \mathrm{C}$ FOR $1 \mathrm{H}$

TABLE 17. TEST CONDITIONS AND DENSITIES BEFORE AND AFTER PROCESSING OF THIN WALL EM TUBE COMPACTION USING MILLED ARMSTRONG TI-6AL-4V POWDER.....

TABLE 18. CHARGE ENERGY, VELOCITY, KINETIC ENERGY AND DENSITY OF FLYER DRIVEN ARMSTRONG CP-TI SAMPLES

TABLE 19. CHARGE ENERGY, VELOCITY, KINETIC ENERGY AND DENSITY OF FLYER DRIVEN ARMSTRONG TI-64 SAMPLES

TABLE 20. SUMMARY OF TENSILE TEST DATA FOR PIFED AND HIPED P/M TITANIUM SAMPLES

TABLE 21. FCP DATA FOR A STRESS-INTENSITY (DK) OF 20KSI $\sqrt{ }$ IN, COMPARED WITH A REFERENCE DATA*

TABLE 22. CONSOLIDATION PROCESS OF THE CP-TI SPECIMENS FOR PROPERTY SCREENING..57

TABLE 23. CONSOLIDATION PROCESS OF THE TI-6AL-4V SPECIMENS FOR PROPERTY SCREENING

TABLE 24. DENSITY AND OPEN POROSITY OF ARMSTRONG CP-TI DURING CONSOLIDATION PROCESS

TABLE 25. DENSITY AND OPEN POROSITY OF ARMSTRONG CP-TI DURING CONSOLIDATION PROCESS

TABLE 26. LIST OF POWDER MATERIALS, PROCESSES CONDUCTED, AND OPTIMUM PROCESS FOR FULL CONSOLIDATION IN SECTION 3.3. 
TABLE 27. SUMMARY OF MECHANICAL PROPERTY ASSESSMENTS COMPARED TO COMMERCIAL GRADE CP-TI AND TI-6AL-4V.

TABLE 28. AVERAGE MECHANICAL PROPERTIES FOR THE COMMERCIALLY PROCESSED TITANIUM BARS

TABLE 29. TENSILE PROPERTIES AND CHEMISTRY OF FULLY CONSOLIDATED PM TITANIUM POWDERS AND COMMERCIAL WROUGHT TITANIUM PRODUCT. ASTM/ASM MINIMUM REQUIREMENT PROPERTIES ARE ALSO LISTED. YS: YIELD STRENGTH, UTS: ULTIMATE TENSILE STRENGTH, AND EL: PLASTIC DEFORMATION TO FRACTURE

TABLE 30. TENSILE PROPERTIES OF FULLY CONSOLIDATED ARMSTRONG CP-TI POWDER WITH VARIOUS CONSOLIDATION PROCESSES AND ASTM MINIMUM REQUIREMENT

TABLE 31. FRACTURE TOUGHNESS AND CHEMISTRY OF FULLY CONSOLIDATED PM TITANIUM POWDERS AND COMMERCIAL WROUGHT TITANIUM PRODUCT. REPORTED PROPERTIES IN TI HANDBOOK ARE ALSO LISTED.

TABLE 32. DISTRIBUTION OF POWDER PARTICLES FOR LOTS OF HDH POWDER USED IN THE EBM PROCESS

TABLE 33. CHEMICAL COMPOSITION OF HDH POWDER, FUSED MATERIAL IN THE EBM, AND ASTM SPECIFICATIONS FOR CP TI

TABLE 34. ASTM PROPERTY DATA AND RESULTING MECHANICAL PROPERTY INFORMATION FOR SAMPLES FABRICATED FROM HDH CP TI MATERIAL USING THE EBM PROCESS ..........72

TABLE 35. AVERAGE MECHANICAL PROPERTIES FOR VARIOUS ORIENTATIONS OF A COMPONENT FABRICATED USING THE ELECTRON BEAM MELTING TECHNOLOGY .............74

TABLE 36. THERMODYNAMIC DATA ON THE TITANIUM HYDRIDE REACTION [38]....

TABLE 37. POTENTIAL COST SAVINGS FOR FABRICATING BRACKETS VIA POWDER METALLURGY OR ADDITIVE MANUFACTURING AS COMPARED TO CONVENTIONAL MACHINING OF PLATE. 


\section{LIST OF ACRONYMS}

AM: Additive Manufacturing

AMO: Advanced Manufacturing Office

AMS: $\quad$ Aerospace Materials Standards

ASTM: American Society Testing and Materials

BCC: $\quad$ Body Centered Cubic

BSE: Back-Scattered Electron

CAD: Computer Aided Drafting

CIP: $\quad$ Cold Isostatic Press

CP-Ti: $\quad$ Commercially Pure Titanium

DARPA: the Defense Advanced Research Projects Agency

DOD: Department of Defense

EMB: Electron Beam Melting

EDS: Energy Dispersive X-ray Spectroscopy or Spectroscope

EIP: $\quad$ Energy Intensive Processes

EM: Electromagnetic

FCGR: Fatigue Crack Growth Rate

GA: Gas Atomized

HCP: Hexagonal Close Packed

HDH: Hydride-Dehydride

HIP: $\quad$ Hot Isostatic Press

ITP: International Titanium Powder / Industrial Technologies Program

kmt: $\quad$ thousand metric tons

ksi: thousand pounds per square inch

nm: nanometer

LNG; Liquid Natural Gas

OEM: Original Equipment Manufacturer

OM: Optical Microscopy or Microscope

NC: $\quad$ Numerical Control

NRE: Non-Recurring Engineering

OD: Outer Diameter

PDV: $\quad$ Photon Doppler Velocimeter

PIF: $\quad$ Pneumatic Isostatic Forge

PM: $\quad$ Powder Metallurgy

PREP: $\quad$ Plasma Rotating Electron Process

RD: $\quad$ Relative Density

SAE: $\quad$ Society of Automotive Engineers

SE: Secondary Electron

SEM: Scanning Electron Microscopy or Microscope

TD: $\quad$ Theoretical Density

Ti-6Al-4V and Ti-64: Titanium Alloy with 6wt. \% aluminum- and 4wt \% vanadium

TINS: $\quad$ Titanium Net Shape

TPD-MS: $\quad$ Temperature Programmed Desorption Mass Spectrometry

TRL: Technology Readiness Level

US or U.S.: $\quad$ United States

UTS: $\quad$ Ultimate Tensile Strength

VHP: Vacuum Hot Press

YS: $\quad$ Yield Strength 


\section{EXECUTIVE SUMMARY}

Titanium and titanium alloys offer many attractive characteristics for industrial and commercial applications $[1,2,3,4,5,6]$. However, these properties have not been realized in many industrial applications due to the high cost and current fabrication inefficiencies of titanium with conventional reduction technology $[7,8,9]$. The aircraft industry consumes over half of the titanium milled product in the U.S., and the average yields are less than $15 \%$. The production of low cost titanium products from alternative titanium powders/sponge has the potential to enable a paradigm shift in the production and application of titanium, similar to the transformational effect of the Hall-Héroult process which enabled widespread industrial use of aluminum [10]. New low cost titanium and Ti alloy production methods have recently been developed that require less energy than conventional reduction technologies while providing pure titanium and titanium alloy powders that are suitable for powder metallurgy consolidation [11]. The implementation of powder metallurgy technologies for the new low cost titanium powders are required to take these new powders and produce economical titanium components that will benefit energy conservation both in titanium production and downstream industrial applications.

The objective of this study was to develop new near net shape manufacturing processes for potentially low cost titanium components for industry. The project was to initiate the development of industrial process routes for titanium powder metallurgy consolidation and allow near net shape manufacturing. Developing sustainable practices to manufacture high yield components directly contributes to reducing industrial energy intensity both in manufacturing practices and in downstream application. Furthermore, near net shape Ti components have the potential for the reduction of greenhouse gas emissions by expanding the potential industrial market of low-cost, corrosion resistant, and lightweight structural components.

The milestones of this project were to first establish a press and sinter technology that could allow consolidation of the powder to at least $92 \%$ of theoretical density. This milestone was successful, and the project then looked at hot isostatic pressing, pneumatic isostatic forging, and adiabatic compaction to establish full compaction. Full compaction was achieved without canning of the material, and most ASTM standard minimum parameters for wrought material were exceeded satisfying our second milestone for the project. The last milestone was to prove the feasibility that a net shape component could be fabricated using powder metallurgy, and the Armstrong powders. A net shape, aircraft component (bracket) was then manufactured using press and sinter technology with the option of hot isostatically pressing the component to ensure full consolidation. In addition to powder metallurgy, titanium powders were evaluated using additive manufacturing, specifically electron beam deposition, to make net shape components. The following paragraphs break-down the results achieved.

Comprehensive powder consolidation studies of the $\mathrm{CP}-\mathrm{Ti}$ and $\mathrm{Ti}-6 \mathrm{Al}-4 \mathrm{~V}$ powders made by the Armstrong process and the hydride-dehydride (HDH) process have been conducted. Consolidation modeling predicted pressure and density distributions of pressed Armstrong titanium powders in a cylindrical die, as well as shape changes during sintering process, as a function of aspect ratio of the pressed samples. The calculated density distribution and shape changes were consistent with those of the actual die-pressed and sintered samples.

Milling improved the tap density drastically of Armstrong titanium powders from 6-8\% (as-received) to nearly $30 \%$ (ball-milled in ethanol for $90 \mathrm{~min}$ ). The milling showed little effect on the pressed densities, but improved the sintered density of Ti-6Al-4V significantly to achieve full consolidation. However, the milling process with extended period of time or in improper atmosphere resulted in 
powder contamination (e.g. high oxygen) which caused degradation of ductility of fully consolidated samples.

Optimized press-and-sinter technology practices achieved nearly full consolidation of the Armstrong processed titanium powders. CP-Ti powder was consolidated up to $96.4 \%$ theoretical density by uniaxial die pressing at $100 \mathrm{ksi}$ and vacuum sintering at $1300{ }^{\circ} \mathrm{C}$ for $1 \mathrm{~h}$. Ti-6Al-4V powder, after milling process, achieved more than $99.8 \%$ theoretical density after die-pressing at $50 \mathrm{ksi}$ followed by vacuum sintering at $1300{ }^{\circ} \mathrm{C}$ for $1 \mathrm{~h}$. The Armstrong powder press and sinter densities were very high compared to those of the HDH CP-Ti and Ti-6Al-4V powders which pressed and sintered at the same process consolidations ( $93.3 \%$ and $71.3 \%$, respectively). Blending two different powders (Armstrong and $\mathrm{HDH}$ ) was attempted, but did not result in increasing the as-pressed and sintered densities.

Full consolidation of press and sintered plates by a variety of candidate industrial processes was examined. Fabrication of near net shape components made from the Armstrong titanium powders was successfully conducted by using press-and-sinter technology with optimized process conditions. A T-shape bracket, tubes, net shape discs, and sheets were die-pressed in the shapes and some of them were cold-isostatically pressed without any significant difficulty.

Pneumatic isostatic forging (PIF) and hot isostatic pressing (HIP) of the press-and-sintered samples successfully achieved full consolidation without a canning process for Armstrong powder, and with canning for HDH powders. The elimination of canning with the Armstrong powders at moderate densities ( $~ 80 \%$ dense) is a result of the lack of open porosity as well as inter-connected pores found with the new powder morphologies after the press-and-sinter process described above. In contrast, conventional HDH powders at these densities still contain interconnected porosity. The HIP process combined with the press-and-sinter was mainly used for preparing the fully consolidated titanium specimens of the mechanical property screening.

High strain rate powder compaction was systematically investigated under collaboration with the Ohio State University. Tube shape components were successfully pressed by utilizing electromagnetic compaction methods, which achieved full consolidation after sintering process (milled Armstrong Ti-6Al-4V). The relationship between the green density and actuator velocity, controlled by the stored energy prior to the compaction, on plate-shape compaction of Armstrong powders was also established. The optimized compaction methods achieved nearly full consolidation of CP-Ti in as-pressed condition.

Mechanical properties of fully consolidated titanium powders at room temperature, including tensile, fracture toughness, fatigue crack growth, and high cycle fatigue, were evaluated. Armstrong CP-Ti and Ti-6Al-4V samples exhibited lower tensile ductility and less fracture toughness than the minimum requirements of commercial grade 2 (CP-Ti) and grade 5 (Ti-6Al-4V) titanium products, although these results were likely due to their high oxygen contents as well as non-optimized microstructure at fully consolidated state, not from the nature of the Armstrong powders. Once Armstrong powders with the required chemistries are commercially available, future efforts should re-evaluate the ductility and fracture toughness. The Armstrong powder samples showed improved fatigue crack growth resistance (CP-Ti and Ti-6Al-4V) and extended high cycle fatigue limit (CP-Ti) compared to wrought titanium products. Fully consolidated HDH powders showed results comparable to commercial wrought products in most of the properties, except for fracture toughness of CP-Ti. These properties would meet most industrial applications, but a new anneal treatment for the HDH powders would need to be developed for aircraft components or other fracture toughness critical components. 
A press and sinter of Armstrong powders was successful in fabricating fully dense aircraft brackets. The optimum manufacturing approach for this component would be to press and sinter Armstrong Ti$6 \mathrm{Al}-4 \mathrm{~V}$ powder into a t-shape. The preform would then be hot isostatically pressed and mill annealed to ensure elimination of any localized porosity, and appropriate microstructure. For less critical components, press and sinter would be sufficient for Armstrong Ti-6Al-4V powder. The bracket was viewed as a good commercial entry point by the team due to the low yield ( $\sim 3 \%$ of incoming plate), the low service loads, and less critical nature of the component. Although the powder metallurgy approach and resulting mechanical behavior was determined to be satisfactory for this aircraft component, the low annual production rate of the component, the lack of low cost powder availability, the die amortization considerations, and the required qualification for the given part discouraged powder metallurgy as the best manufacturing practice at this time. Other components are being considered by the team, but will not move forward until powders meeting cost and chemistry criteria are commercially available.

Additive manufacturing (electron beam melting and deposition system) was also utilized to build near net shape titanium components from gas-atomized titanium powders. An impeller for a pump manufacturer and a T-bracket for aircraft (Lockheed Martin) were selected for the demonstration, which were successfully built without any technical issues. In the case for the bracket, elimination of the die and the availability of gas atomized powder provided the incentive for the fabrication and viability testing of this component (see below paragraph). The HDH CP-Ti and Ti-6Al-4V powders were also utilized in the e-beam melting system, which resulted in adequate flow properties to be utilized in an electron beam melting (EBM) machine without alteration to the current powder raking method. Anisotropic tensile properties were observed in as-deposited materials, which would need to be eliminated by optimizing deposition conditions and/or subsequent heat treatments.

The aircraft brackets fabricated via electron-beam deposition appear to have the highest technology readiness level. Lockheed Martin is interested in pursuing commercialization of this series of components. Aircraft brackets were evaluated for commercialization and proprietary cost estimates were developed and evaluated for both powder metallurgy and additive manufacturing. Additive manufacturing was down selected due to the economic, yield, and versatility benefits. The selected component fabricated by additive manufacturing could decrease the cost by 100 to $200 \%$ based on commercial estimates. Components and mechanical specimens for a wide range of testing and validation were fabricated. Lockheed Martin performed the tests, and looked at a wide range of variables. The results were favorable for commercial implementation. The next step towards commercialization is qualification, and development of a specification. The project industrial partner is evaluating the class of qualification that will provide the best return on investment (limited use allowables or extensive allowables). 


\section{INTRODUCTION}

Titanium and titanium alloys offer many attractive characteristics for industrial and commercial applications. However, these properties have not been realized in many industrial applications due to the high cost and current fabrication inefficiencies of titanium with conventional reduction technology. The aircraft industry consumes over half of the titanium milled product in the U.S., and the average yields are less than $15 \%$. Titanium has long been recognized by industry as a superior material for many applications due to such characteristics as high strength, low density (the highest strength to weight ratio of any metal), excellent corrosion resistance, good elevated temperature performance, and allowance for damage tolerant design [12, 13, 14, 15]. However, titanium has historically been viewed as a specialty material due to high cost and limited availability. The high cost and extremely long production lead times have caused many industrial designers and engineers to overlook titanium, even though titanium would yield significant energy savings, long term cost savings, and enhanced performance. Within the last seven years $(2006-2012)$, titanium plate has seen prices of $\$ 35$ to $\$ 50$ per pound [16] and lead times between 12 and 18 months. Titanium product pricing is largely cyclic and dependent on aircraft demand. Furthermore, the high cost of titanium is a result of the elaborate, multi-step process of producing titanium components. Most titanium is first produced through the Kroll process (primary sponge), then cut and acid leached, vacuum arc remelted two to three times, milled into product form, and finally machined $[17,18]$.

The aerospace industry consumes over half of the U.S. titanium production, and scrap generation is high for this industry $[19,20]$. Currently, the aerospace industry has average buy to fly ratios of 8 to 1 [20, 21, 22], the ratio of weight of material purchased versus the weight of material that remains in the final component (difference in material is machined and is designated as scrap). In complex forged components, it is common to have a final component that is less than $10 \%$ of the initial weight [23]. Furthermore, new platforms such as the F-22 fighter jet require approximately 110,000 pounds of titanium alloy be purchased, but only have a yield of approximately 10,000 pounds [24].

Considerable waste is generated and energy consumed in the production of titanium components with material efficiencies being this low.

The production of low cost titanium products from titanium powders, produced by newly developed processes, has the potential to enable a paradigm shift in the production and application of titanium,. In the last few years, low cost titanium and titanium alloy powders have become available that could enable a paradigm shift in the U.S. titanium market. New low cost titanium and Ti alloy production methods have recently been developed that require less energy than conventional reduction technologies while providing pure titanium and titanium alloy powders that are suitable for powder metallurgy consolidation as solid state manufacturing process. New low cost titanium powders produced by Armstrong process developed in the DARPA Titanium Initiative [25] could directly go into powder metallurgy processes where direct consolidation of near net shapes is economically feasible. The implementation of powder metallurgy technologies for the new low cost titanium powders are required to take these new powders and produce economical titanium components that will benefit energy conservation both in titanium production and downstream in many industrial applications.

Potential applications include, but are not limited to, automotive, heat exchangers, chemical processing, nuclear industry, condenser tubes, desalination, offshore petroleum, paper and pulp processing, department of defense applications, naval applications, liquid natural gas processing, biomedical supplies, sporting equipment, construction, and many others, which will benefit from the low cost titanium parts and lower energy consumption. 


\section{BACKGROUND}

This project examined industrial process routes for the near net shape manufacturing of titanium components from new, low cost titanium powders, for industrial applications. The effort involved the optimization of press and sinter processing of new titanium powders with low initial tap densities to improve as-sinter densities above $90 \%$ of theoretical density. Densities above $90 \%$ are required to eliminate interconnected porosity. Full consolidation of near net shape components from three separate consolidation technologies was investigated: pneumatic isostatic forging, hot isostatic pressing, and adiabatic compaction. By eliminating the interconnected porosity, titanium and titanium alloy components do not have to be canned in order to impart the pressure differential required to consolidate the components via the proposed innovative processes.

\subsection{PLATFORMS AND FOCUS AREAS}

This Energy Intensive Processes (EIP) Project "Near Net Shape Manufacturing of New, Low Cost Titanium Powders for Industry" was selected from a competitive solicitation - Industrial Technology Program, Office of Energy Efficiency and Renewable Energy's "Energy Intensive Processes 2008 Lab Call (DE-PS36-08GO98014)".

\subsection{SUPERIORITY/BENEFITS OF PROPOSED TECHNOLOGY OVER CURRENT PRACTICES}

Converting new low cost powder to fully consolidated near net shape components via press and sinter technologies followed by pneumatic isostatic forging (PIF), hot isostatic pressing (HIP), or adiabatic compaction can decrease titanium scrap generation rates from 50-95\% using Kroll melt processing down to only $5-10 \%$ using powder metallurgy. The cost of titanium before machining can decrease by over $50 \%$ while the cost of aerospace titanium components after machining could decrease by over $90 \%$. Solid state consolidation of low cost titanium powders was estimated at the beginning of the project to yield a potential energy savings of over 12 TBtus per year in the processing of titanium by year 2015. In addition, over 40 TBtus per year was estimated to be saved downstream in the commercial aerospace industry based on the commercial aircraft energy numbers and the implementation of low cost titanium and carbon fiber composites with similar energy savings estimated in the Boeing 787 across the fleet of commercial aircraft vehicles. During the project, energy estimates were made using a full cycle approach as detailed in Section 4.

The project evaluated conventional powders [i.e., hydride-dehydride and gas atomized (additive manufacturing)] with more recent irregular morphology powders (i.e., Armstrong process). Hydridedehydride powders are used today in master alloy production. Specialty components are also fabricated using these powders, but overall production is limited to high value components and only a few powder consolidation firms exist today (e.g., Dynamet, ADMA, etc.). Gas atomized (GA) powders and plasma rotated electrode powders (PREP) are also fabricated in limited production. These powders are spherical. They have good flow characteristics, but are observed as "incompressible" or hard to consolidate in room temperature consolidation. Due to their improved flowability and the ability to purchase the powders prealloyed, they are used in limited quantities for metal injection molding and more recently in additive manufacturing as described in this report. GA and PREP powders can be used to fill HIP cans and then consolidated at elevated temperatures.

However, overall utilization of titanium and titanium alloy powders have historically been limited due to cost compared to high volume applications. Development of lower cost hydride-dehydride powders directly made from Kroll sponge, and new reduction technologies provide an opportunity to realize low cost components made from these powders and powder metallurgy or additive manufacturing. 
The U.S. titanium supply will improve from two mechanisms as a result of this effort, 1) the introduction of new U.S. titanium producers/suppliers, and 2) the aerospace industry, a market that uses over $50 \%$ of the titanium in the U.S., will be able to decrease the buy to fly ratios from over 10 to 1 [26] to less than 1.5 to 1 in some of their lower yield parts, resulting in a significantly more efficient use of titanium and energy. The buy to fly ratio provides the utilization efficiency for aerospace materials; the amount of material that is purchased by the original equipment manufacturer (OEM) versus amount of material that ends up in the component. Improvements in the energy efficiency and use of titanium in the U.S. are timely when the titanium market will need to double to meet demand in less than ten years $[27,28]$.

\subsection{POTENTIAL MARKETS FOR NEAR NET SHAPE MANUFACTURING OF LOW COST TITANIUM}

The Industrial Technologies Program (currently Advanced Manufacturing Office or AMO) of the Department of Energy's Office of Energy Efficiency and Renewable Energy funded a study in 2007 to assess the current status of the titanium market, to determine the titanium alloy that is most commonly used in industrial application, to determine the most common Ti product forms used in industry, to forecast the growth of the titanium industry without a low cost titanium product, and to determine the growth of the titanium market if the cost of titanium were reduced [27]. Several of the key highlights of the report are as follows.

Even during periods of large increases in the price of titanium and the inefficiencies in the conventional Ti processing method, global and U.S. titanium consumption increased due to requirements in the industrial and aerospace markets [27, 28]. The world markets for titanium mill products totaled about 93 thousand metric tons (kmt) in 2006, and are expected to have grown by approximately 10\% in 2007 [27]. This total is composed of $27 \mathrm{kmt}$ in aerospace, $47 \mathrm{kmt}$ in industrial applications, $8.5 \mathrm{kmt}$ in emerging applications and $10.4 \mathrm{kmt}$ in defense [27]. The global demand for titanium was expected to double between 2007 and 2015 with forecasts of $175 \mathrm{kmt}$ or greater required in milled product [27]. On a global basis, the industrial markets are significantly more important. The largest volume product grade for these industrial markets is commercially pure $\mathrm{Ti}$ (CP-Ti), with the most common product form being sheet / strip / thin plate. Often these thin gauge sections are stamped or drawn into net shape components to be used in application. Thin gauge sections and tubing is used in the production of heat exchangers, desalination, power generation, condensers used in the nuclear industry, offshore petroleum refinement, deep hole drilling, and liquid natural gas (LNG) liquefaction plants [27]. Much of the growth in industrial markets such as chemical processing and power generation by conventional means is likely to take place in China and other developing countries. However, geographic market shift does not necessarily preclude expansion of the US titanium industry to supply titanium for industrial application. If current or new US producers maintain a technological and therefore economically competitive position, there is no reason why they cannot continue to be major suppliers to these foreign markets.

Currently, the US is the largest consumer of titanium, $32 \%$ of the global market [27]. Aerospace is the largest segment, with 2006 consumption of $15 \mathrm{kmt}$ of Ti mill product [27]. Other segment consumptions are $6 \mathrm{kmt}$ for industrial applications, $6.5 \mathrm{kmt}$ for energy production and only $1 \mathrm{kmt}$ for emerging applications [27]. In comparing titanium ingot and titanium powder production, very little powder is consumed in the U.S. The titanium powder industry is estimated at 200 to 300 metric tons based on discussion with industrial partners (these values are consistent in scale with powder imports being around 24 metric tons in 2009 and 119 metric tons in 2010 [29]). Most titanium powder production is used in the development of master alloys. Many U.S. industrial applications could benefit from titanium's excellent properties, but are currently using components fabricated from another material due to titanium's high cost. New trends in commercial airplane designs are to 
decrease weight through the increased use of carbon composites and titanium. An example of a recent success is the Boeing 787 where the aircraft is $50 \%$ composites and $15 \%$ titanium resulting in a $20 \%$ decrease in the aircraft weight when compared to similarly sized commercial airliners [30]. In addition, titanium is increasingly used in engine components to improve efficiencies. The Boeing 787 has shown a $20 \%$ improvement in fuel efficiencies due to engine improvements, weight reduction, and many other modifications that are dependent on the application of titanium [30]. Titanium is required due to its excellent corrosion resistance, high specific strength, and galvanic compatibility when coupled with carbon. The current aerospace demands for titanium based on conventional titanium production have been forecasted to double the overall US production of titanium within a ten year time period, and will be over three times the commercial aerospace consumption of the previous decade[27]. Current U.S. production of milled product is $28.7 \mathrm{kmt}$, and overall U.S. titanium ingot production is $53 \mathrm{kmt}$. Therefore, the U.S. is expected to require close to $50 \mathrm{kmt}$ of milled product and if US titanium ingot production follows the same trend $106 \mathrm{kmt}$ of titanium ingot by 2015 [27].

On average, titanium aerospace components require 8:1 buy to fly ratios for engine components and older jets/aerospace platforms, and 11:1 buy to fly ratios for new jets such as the Boeing 787, Lockheed Martin's F35 and Lockheed Martin's F22 [26]. Buy to fly ratios are used in the aerospace industry to estimate the amount of material that will be purchased compared to how much of that material will remain when the final component is finished; the remaining material having been removed and scrapped. Therefore, a minimum of $7 \mathrm{lbs}$ of titanium is removed and considered scrap for every eight pounds of material that is purchased for U.S. aerospace application. Some of the scrap is recycled. However, considerable energy is expended to remelt scrap into new ingot where it goes through the process all over again [31]. Scrap consumption in the U.S. was 25kmt in 2006; half of all titanium ingot produced in the U.S. for the same year. The $25 \mathrm{kmt}$ value only takes into account scrap consumption or titanium machinings that are of high enough quality to be reused, and does not take into account the gross scrap produced from machining.

In a conservative estimate ignoring the high demand of titanium in the nuclear industry, titanium is still expected to go from approximately $48 \mathrm{kmt}$ to $90 \mathrm{kmt}$ of industrial consumption by 2015 in the U.S. alone. New titanium production facilities are required to meet the highly expanding titanium demand.

Substantial growth is possible in the titanium market if the cost of titanium is greatly reduced. A recent DAPRA report stated that titanium is only produced and used at " $1 / 20^{\text {th }}$ of its current potential world volume" [32]. A low cost titanium that is at $50 \%$ of the conventional cost of titanium would create a paradigm shift in the production and consumption of titanium in the U.S. In the ITP study performed in 2007, several new potential demands were highlighted. The most significant potential is replacement of duplex stainless steels [27]. If titanium's cost were reduced by at least $50 \%$, titanium could penetrate markets where duplex stainless steels are currently used resulting from its superior properties including corrosion and high temperature resistance. It is anticipated that a $50 \%$ reduction in cost will occur as a result of developments in this project. Titanium has superior corrosion resistance to stainless for many applications. If low cost titanium components are realized, $140 \mathrm{kmt}$ of titanium could be required by 2015, over 23 times the current U.S. industrial Ti mill product market [27]. Another potential application for titanium is on DOD land combat systems. One recent DOD application was originally intended for titanium. However, the current costs of titanium are too high for the application. If thick gauge section titanium could be reduced to $\$ 15 / \mathrm{lb}$, there would be an additional requirement of 40 million pounds per year. New requirements for nuclear powder forecast an increase of $6 \mathrm{kmt}$ for titanium in the U.S., and $40 \mathrm{kmt}$ globally by 2015[27]. Liquid natural gas applications could require $2.2 \mathrm{kmt}$ in the U.S. and 5.5 globally by 2015 [27]. 


\subsection{CURRENT AND TARGET STAGES OF TECHNICAL AND COMMERCIAL DEVELOPMENT}

Based on the current U.S. Department of Energy Technology Readiness Assessment Guide (DOE G 413.3-4A, 9-15-2011), the project in general initiated in Technology Readiness Level (TRL) 3 (Research to Prove Feasibility) and ended in TRL 5 (Technology Development). The full consolidation of near net shape production of new low cost titanium powders had not previously been investigated or performed prior to this project. Previously, hydride-dehydride powders had been consolidated and made into commercial components, but other low-cost powders, such as Armstrong Powders, had not been previously consolidated in laboratory-scale studies for a prescribed press and sinter manufacturing process route. Background information and preliminary work [33] had been performed prior to the project initiating in a Defense Advanced Research Projects Agency (DARPA) funded project as part of the DARPA Ti Initiative, and in a DOE Vehicle Technologies Program funded project entitled Alloy Design and Thermomechanical Processing of a Beta Titanium Alloy for a Heavy Vehicle Application. The best manufacturing practices to achieve near net shape components with properties optimized for the specific application of intent was defined as part of this project (e.g., press, sinter, and hot isostatic pressing of Armstrong powder or additive manufacturing and hot isostatic pressing of gas atomized powder for the aircraft bracket). By taking four separate technologies, pneumatic isostatic forging, hot isostatic pressing, adiabatic compaction, and additive manufacturing, the project was able to define and develop the best concepts and/or approaches. Task one (performed in 2009-2010) was to define the optimum press and sinter parameters to increase the density and eliminate interconnected porosity in press and sintered parts. Task 2 (2009-2011) used pressed and sintered plates processed with the optimum parameters and fully consolidated the plates using the three proposed innovative technologies. In addition additive manufacturing was evaluated to develop net shape components using electron beams with a powder bed. In Task 3 (2011-2012), industrial components (complex aerospace brackets and an impeller for pump applications) were evaluated and validated for industrial application, and near net shape samples were provided to industry. 


\section{RESULTS AND DISCUSSION}

\subsection{TASK 1: PRESS AND SINTER OF LOW COST TI AND TI ALLOY POWDERS FOR NEAR NET SHAPE COMPONENTS}

The research performed in this project was the first comprehensive look at Armstrong powders and understanding how these very irregular powder morphologies behaved compared to more conventional powder morphologies. Throughout the procedure and results section, the pressing, sintering, and subsequent processing of the Armstrong powders will be compared to hydridedehydride powders. With this comparative approach, a broad range of powder characteristics and behavior will be evaluated, and provide expectations or potential behavior profiling for future powder morphologies developed from reduction technologies not currently mature. Powder handling, attrition, pressing, and sintering are parameters that can greatly affect the resulting density, microstructure, and mechanical behavior of powder metallurgy components. A table is introduced at the beginning of each task to reference the procedures, and optimum process(es) established. Table 1 illustrates the processes used in Task 1 and the optimum process determined. The goal in task 1 was to evaluate if press and sintered components could achieve densities that eliminated interconnected porosity; this is important in establishing pressure differentials in secondary isostatic pressing techniques covered in task 2 . In addition, the team was interested in observing if full densities could be achieved with only pressing and sintering.

Table 1. List of powder materials, processes conducted, and optimum process for full consolidation in Section 3.1.

\begin{tabular}{|c|c|c|c|}
\hline Task & Materials & Process & Optimum process \\
\hline \multirow{5}{*}{$\begin{array}{l}\text { Task 1: } \\
\text { Press and } \\
\text { sinter }\end{array}$} & CP-Ti Armstrong & 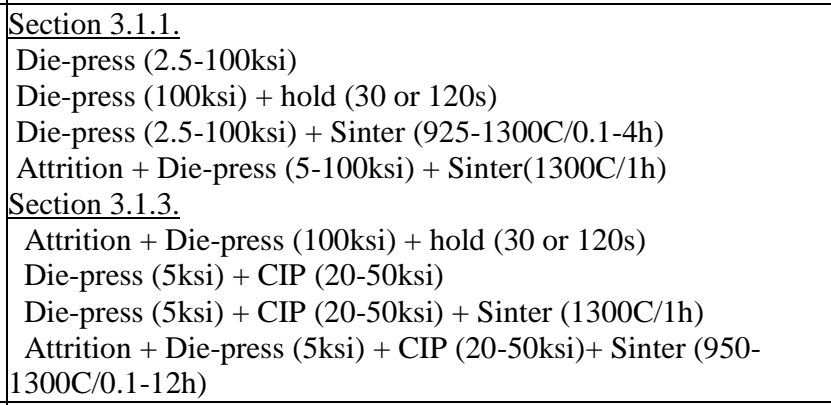 & $\begin{array}{l}\text { Die-press at } 100 \mathrm{ksi}+\text { Sinter } \\
\text { at } 1100 \mathrm{C} / 2 \mathrm{~h} \text { resulted in } \\
\text { 93.2\% } \mathbf{T D} \text {, still required } \\
\text { following full consolidation } \\
\text { described in Task } 2 \text {. } \\
\text { Attrition or CIP did not } \\
\text { increase the density after } \\
\text { the press-and-sinter process. }\end{array}$ \\
\hline & CP-Ti HDH & $\begin{array}{l}\text { Section 3.1.1. } \\
\text { Die-press }(25-100 \mathrm{ksi}) \\
\text { Die-press }(25-100 \mathrm{ksi})+\text { Sinter }(1300 \mathrm{C} / 1 \mathrm{~h})\end{array}$ & $\begin{array}{l}\text { Need canned HIP/PIFing to } \\
\text { achieve full consolidation. }\end{array}$ \\
\hline & $\begin{array}{l}\text { Ti-6Al-4V } \\
\text { Armstrong }\end{array}$ & $\begin{array}{l}\text { Section 3.1.1. } \\
\text { Die-press (2.5-100ksi) } \\
\text { Die-press (2.5-100ksi) + Sinter }(925-1300 \mathrm{C} / 0.1-4 \mathrm{~h}) \\
\text { Attrition + Die-press }(5-100 \mathrm{ksi})+\operatorname{Sinter}(1300 \mathrm{C} / 1 \mathrm{~h}) \\
\text { Section 3.1.3. } \\
\text { Die-press (5-20ksi) + CIP (5-50ksi) } \\
\text { Die-press (5ksi) + CIP (2.5-50ksi) + Sinter }(1300 \mathrm{C} / 1 \mathrm{~h}) \\
\text { Attrition + Die-press }(5 \mathrm{ksi})+\text { CIP }(5-50 \mathrm{ksi})+\text { Sinter }(1300 \mathrm{C} / 1 \mathrm{~h})\end{array}$ & $\begin{array}{l}\text { Attrition }+ \text { Die-press at } 7 \mathrm{ksi} \\
+ \text { CIP at } 50 \mathrm{ksi}+\text { sinter at } \\
1300 \mathrm{C} / 1 \mathrm{~h} \text { resulted in almost } \\
\text { fully dense with } \mathbf{9 9 . 3 \%} \text { TD. }\end{array}$ \\
\hline & Ti-6Al-4V HDH & $\begin{array}{l}\text { Sections 3.1.1. and 3.1.3. } \\
\text { Die-press }(25-100 \mathrm{ksi}) \\
\text { Die-press }(25-100 \mathrm{ksi})+\text { Sinter }(1200-1400 \mathrm{C} / 1-18 \mathrm{~h})\end{array}$ & $\begin{array}{l}\text { Need canned HIP/PIFing to } \\
\text { achieve full consolidation. }\end{array}$ \\
\hline & $\begin{array}{l}\text { CP-Ti Armstrong + } \\
\text { HDH (blended) }\end{array}$ & $\frac{\text { Section } 3.1 .3 .}{\text { Blended }(10: 90,25: 75,50: 50)+\text { Die-press }(100 \mathrm{ksi})}$ & $\begin{array}{l}\text { No advantage was observed } \\
\text { by blending two different } \\
\text { powders. }\end{array}$ \\
\hline
\end{tabular}

\subsubsection{Optimization of Pressure, Time, and Temperature}

Understanding the effect of pressure, time at pressure, temperature, and time at temperature involved in both pressing and sintering operations is required to better understand the optimal process 
methodology for a given application and resulting mechanical properties. The following subtask evaluates process parameters that effect densities and properties achieved in pressing and sintering.

\subsubsection{Powder characterization}

In this study, commercially pure titanium (CP-Ti) and Ti-6Al-4V alloy powders were selected for the investigation. The Armstrong processed powders were provided by International Titanium Powder, and the hydride-dehydride (HDH) processed powders were provided by Ametek. Figure 1 shows SEM secondary electron (SE) images of the titanium powders studied. Armstrong processed powders (Figure 1a and Figure 1c) have agglomerates of an irregular coral-like, dendritic morphology, with a dendrite (primary particle) size of approximately 2-5 $\mu \mathrm{m}$. Armstrong Ti-6Al-4V powder seems smaller dendrite size than Armstrong CP-Ti powder. The specific surface area for the as-received Armstrong CP-Ti and Ti-6Al-4V powders is $0.18 \mathrm{~m}^{2} / \mathrm{g}$ and $0.36 \mathrm{~m}^{2} / \mathrm{g}$, respectively, indicating that particle size of Ti-6Al-4V is smaller than CP-Ti. Because of the irregular, agglomerated structure of the powders, the tap density of the as-received Armstrong powder is only 6-8\% of theoretical density. On the other hands, the hydride-dehydride (HDH) processed powders (Figure 1b and Figure 1d) exhibit blocky-shape with 20-100 $\mu \mathrm{m}$ size which is larger than that of the Armstrong powders. No significant differences between HDH CP-Ti and Ti-6Al-4V can be observed.
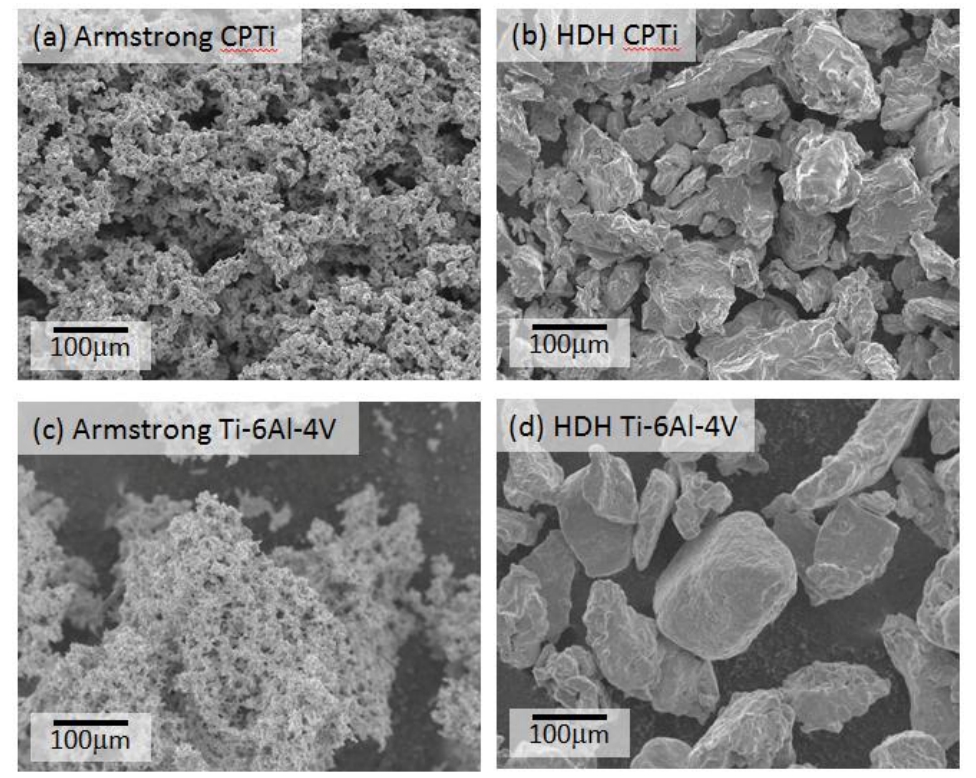

Figure 1. SEM-SE images of titanium powders studied; (a) Armstrong processed CP-Ti, (b) HDH processed CP-Ti, (c) Armstrong processed Ti-6Al-4V, (d) HDH processed Ti-6Al-4V

Cross-sectional SEM backscattered electron (BSE) images of the Armstrong Ti-6Al-4V and HDH Ti$6 \mathrm{Al}-4 \mathrm{~V}$ powders are shown in Figure 2. Both show two-phase microstructure of equi-axed alpha-Ti grains (gray contrast, HCP structure) and beta-Ti (grain boundary precipitates with bright contrast, BCC structure) which is a typical microstructure of annealed Ti-6Al-4V. However, the grain size of Armstrong Ti-6Al-4V is nearly one order of magnitude smaller than that of $\mathrm{HDH}$ Ti-6Al-4V $(1-5 \mu \mathrm{m}$ vs. 10-20 $\mu \mathrm{m}$ ). The room temperature strength strongly depends on the grain size (the smaller the better), and the final grain size of PM material relies on the initial grain size of the powders, so that the Armstrong processed powders have an advantage for microstructure control viewpoint compared to the HDH powders. 

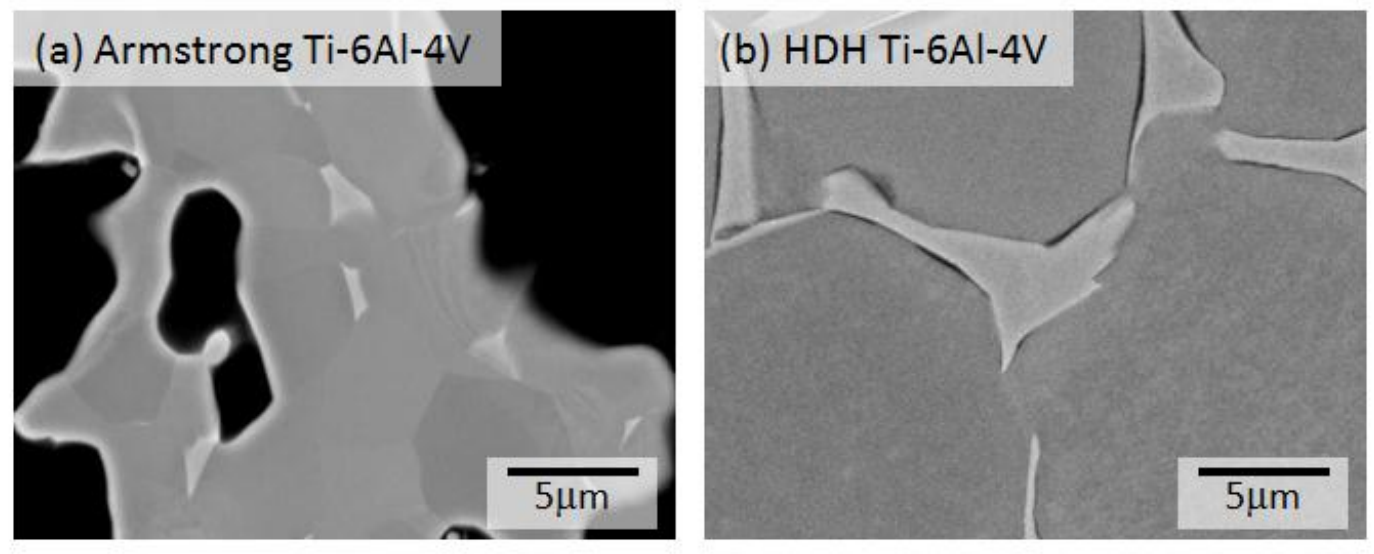

Figure 2. Cross sectional SEM-BSE images of the Ti-6Al-4V powders studied; (a) Armstrong powder, and (b) HDH powder.

\subsubsection{Press and sinter process}

The powders were uni-axially compacted by using a steel die with 0.5 inch inner diameter, as shown in Figure 3. Some of the compactions were conducted by using a single action die (Figure 3a) in which one end of the die was fixed without any movement when the pushing rod in the other side was pushed by using hydraulic press for up to 20,000 pound force. The single action causes inhomogeneous pressure distribution during powder compaction. Most of the compactions were made by using a double action die (Figure 3b) which was designed to minimize the effect of die wall friction, and therefore, the inhomogeneous pressure distribution.
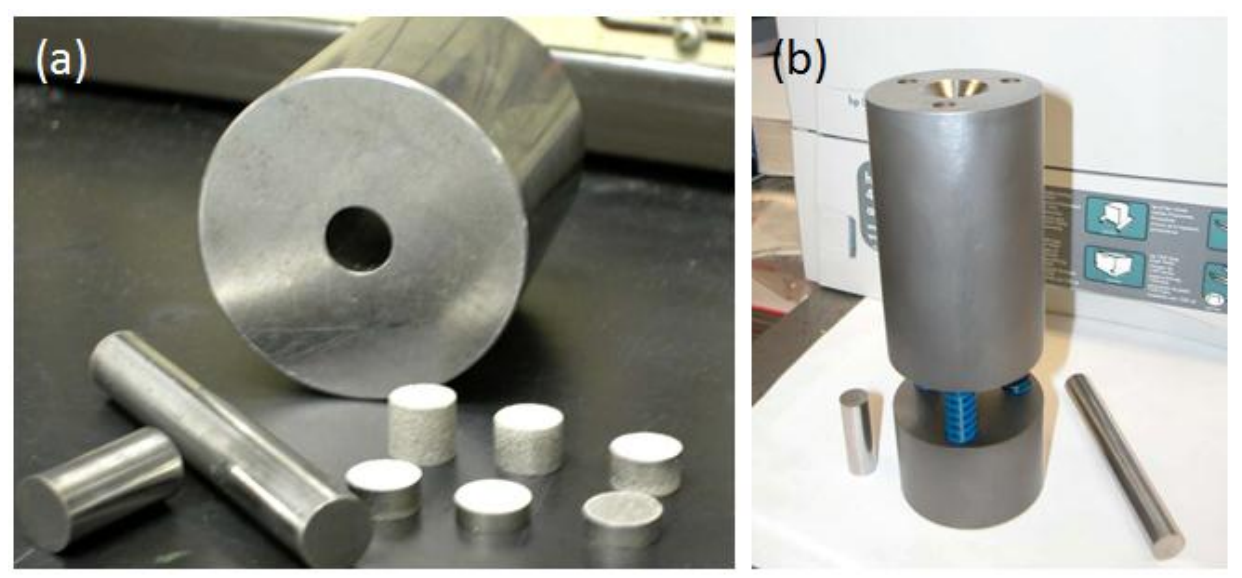

Figure 3. Titanium discs pressed using a steel die and carver press for the study (1/2" diameter); (a) single action die, and (b) double action die.

The uni-axial compaction (press) tests were conducted at room temperature and in a laboratory air (under a hood). The powders were pressed in the range from 5 to $100 \mathrm{ksi}$ for the Armstrong powders, and 25 to $100 \mathrm{ksi}$ for the $\mathrm{HDH}$ powders. After the pressing process, the compacted samples were then sintered at 925,1100 , or $1300^{\circ} \mathrm{C}$ in a vacuum furnace for several different periods of time from 6 min to $18 \mathrm{~h}$, with a constant heating and cooling rate of $10^{\circ} \mathrm{C} / \mathrm{min}$. Before and after the sintering process, the weight and dimensions of the samples were measured to calculate the dry density. The densities of the sintered samples were also measured by using Archimedes principle with ethanol at room temperature, which is designated as the wet density. There was no significant difference between the dry density and the wet density, so that most of the data in the report used the dry density unless otherwise specified. Note that all the measured density were converted to theoretical density (divided 
by $4.50 \mathrm{~g} / \mathrm{cm}^{3}$ for CP-Ti and $4.42 \mathrm{~g} / \mathrm{cm}^{3}$ for Ti-6Al-4V), in order to make a direct comparison of densification characteristics between the different materials.

Figure 4 shows the comparison of die-press pressure dependence on the density in green (as-pressed) condition and after sintering at $1300^{\circ} \mathrm{C}$ for $1 \mathrm{~h}$. For the CP-Ti powders, the theoretical densities increase monotonically with increasing pressure. Sintering process resulted in increasing the density by $8-20 \%$ compared to as-pressed condition, as shown in Figure $4 \mathrm{a}$ and Figure $4 \mathrm{~b}$. Armstrong powder tends to show higher densities for a given pressure than that of HDH powder for both before and after sintering, although the differences are not significant. For Ti-6Al-4V, as-pressed density of Armstrong powder was slightly lower than the HDH powders (Figure 4c and Figure 4d). However, after sintering, the densities of the Armstrong Ti-6Al-4V increased drastically which achieved more than $90 \%$ above 50ksi die-pressure, whereas those of the HDH increased only a few percent and achieved only around $80 \%$. This result indicates a greater sinterability of the Armstrong Ti-6Al-4V powder, which could be due to several characteristics of the powder, such as potentially higher diffusivity of the alloying elements than CP-Ti, smaller dendrite size, etc. Note that the lower aspressed density of Ti-6Al-4V than that of CP-Ti could be due to the higher strength of the alloy than the pure metal, resulting in the higher deformation resistance in Ti-6Al-4V.
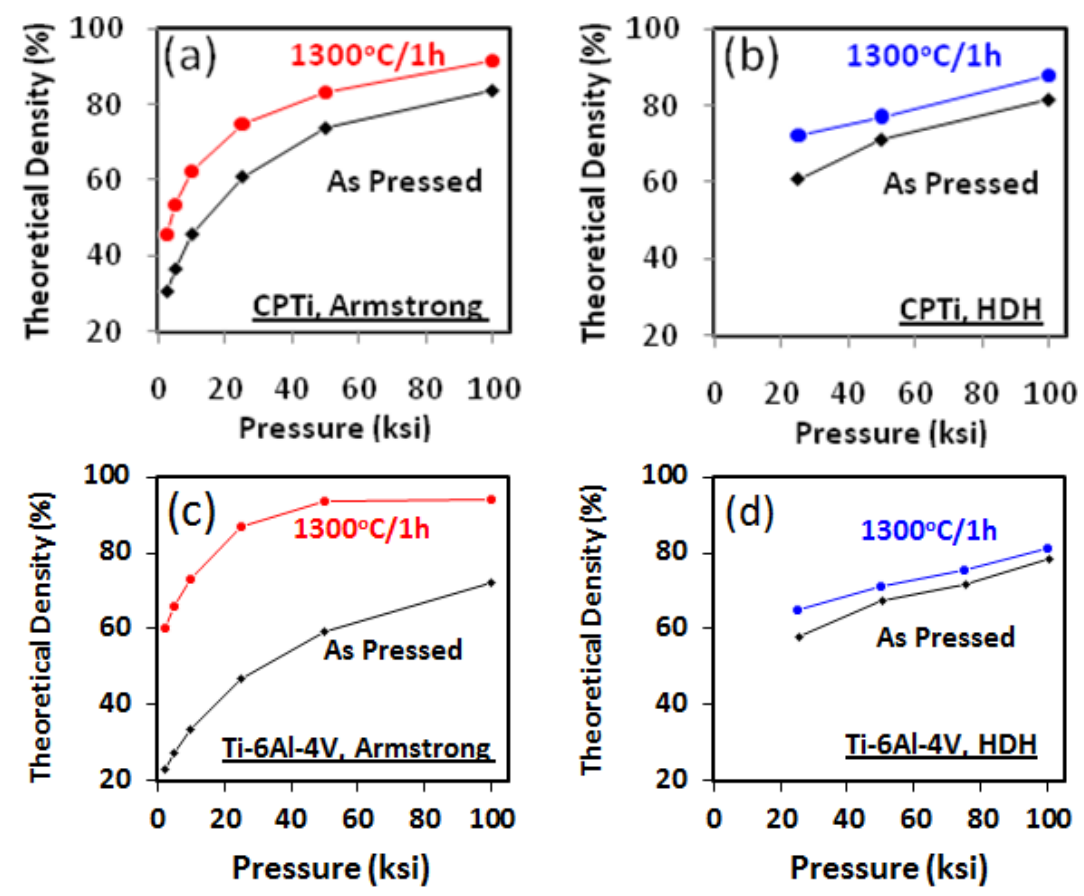

Figure 4. Theoretical densities of $\mathrm{C}-\mathrm{Ti}$ and Ti-6Al-4V before and after sintering at $1300^{\circ} \mathrm{C} / 1 \mathrm{~h}$, plotted as a function of pressure at room temperature; (a) CP-Ti-Armstrong, (b) CP Ti-HDH, (c) Ti-6Al4V-Armstrong, and (d) Ti-6Al-4V-HDH powders.

\subsubsection{Compaction and consolidation of Armstrong processed powders}

Figure 5 shows the densities of pressed and sintered Armstrong titanium powders plotted as a function of die-pressure. As-pressed densities showed some variation at a given die-pressure, but they were small enough to be ignored compared to the die-pressure dependence. For CP-Ti, the densities after sintering for $1 \mathrm{~h}$ increased slightly with raising the sintering temperature, although the effect was small and almost negligible, especially at the highest die-pressure (100 ksi). This indicates that almost no accelerated sintering kinetics could be expected by raising temperatures. In addition, the density increments after sintering were insensitive to the as-pressed density. These results could be 
interpreted such that the sintered density would strongly depend on the initial (as-pressed) density. On the other hand, Ti-6Al-4V showed strong sintering temperature dependence in the die-pressure range studied, namely, the higher sintering temperature resulting in the higher theoretical density.
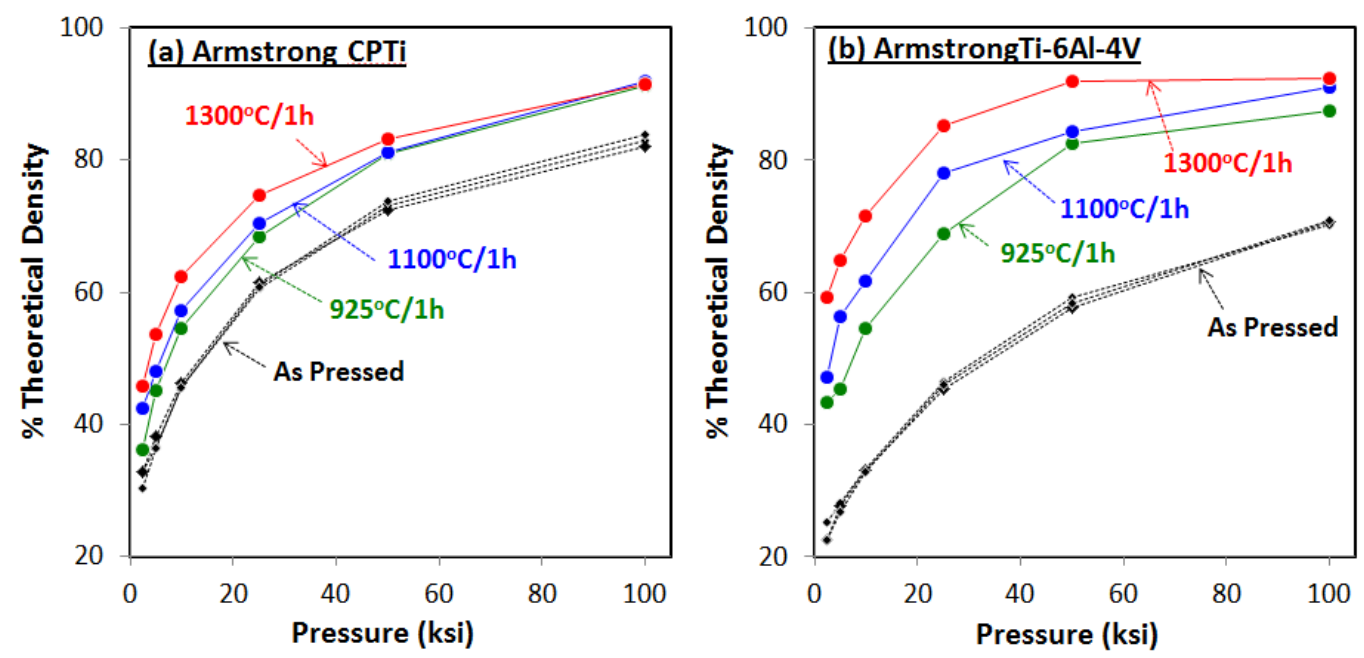

Figure 5. Sintering temperature dependence of the density of Armstrong powders: (a) CP-Ti, and (b) Ti6Al-4V.

Cross-sectional microstructures of the $100 \mathrm{ksi}$-pressed and $1 \mathrm{~h}$-sintered samples also suggest the different sintering characteristics between CP-Ti and Ti-6Al-4V, as shown in Figure 6. The CP-Ti samples exhibited dense and uniformly distributed pores with a round shape, which showed similar volume fraction to each other. This indicates that in CP-Ti the closed pores form quickly in the early stage of sintering, but the shrinkage process of the pores could be very slow during sintering. On the other hand, Ti-6Al-4V samples showed irregular shape pores with various sizes, although the numbers of relatively small pores decreased by raising sintering temperatures. This indicates that in Ti-6Al-4V the shrinkage process of the pores is dominant during sintering, which is consistent with the strong dependence of sintering temperature on the density in Figure 5. From these results, it could be summarized that the pressed density is important in the Armstrong CP-Ti powder whereas the sintering process is important in the Armstrong Ti-6Al-4V powder, in order to increase the final (sintered) densities. 
(a) $\mathrm{CP}-\mathrm{Ti}, 925^{\circ} \mathrm{C} / 1 \mathrm{~h}$

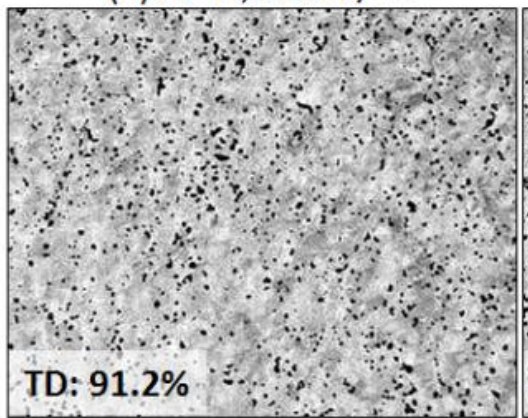

(d) $\mathrm{Ti}-6 \mathrm{Al}-4 \mathrm{~V}, 925^{\circ} \mathrm{C} / 1 \mathrm{~h}$

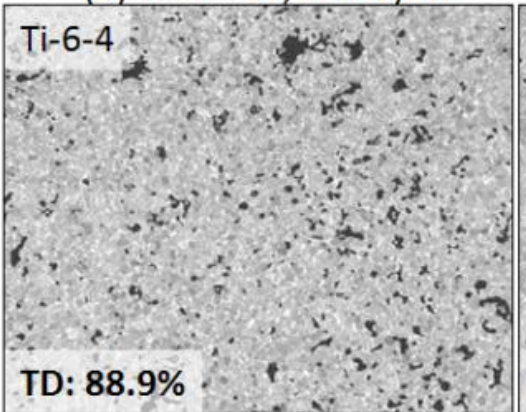

(b) $\mathrm{CP}-\mathrm{Ti}, 1100^{\circ} \mathrm{C} / 1 \mathrm{~h}$

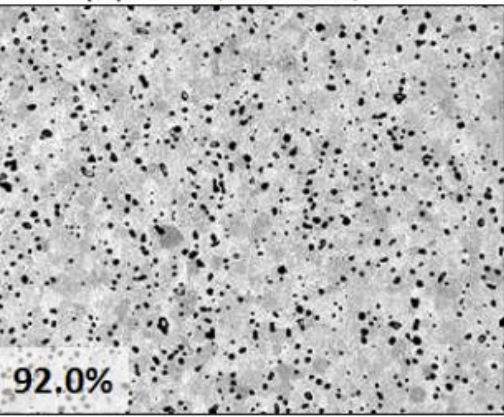

(e) Ti-6Al-4V, $1100^{\circ} \mathrm{C} / 1 \mathrm{~h}$ (c) $\mathrm{CP}-\mathrm{Ti}, 1300^{\circ} \mathrm{C} / 1 \mathrm{~h}$

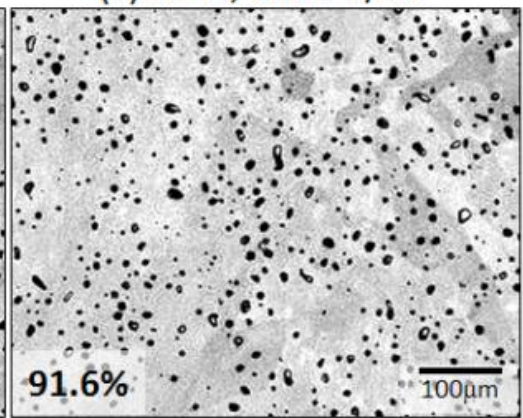

(f) $\mathrm{Ti}-6 \mathrm{Al}-4 \mathrm{~V}, 1300^{\circ} \mathrm{C} / 1 \mathrm{~h}$

Figure 6. SEM BSE images of Armstrong powders after consolidation process (pressed at 100ksi, and then sintered for $1 \mathrm{~h}$ ); (a, b, and c) CP-Ti, sintered at 925, 1100, and 1300oC, respectively, and (d, e, and f) Ti-6Al-4V, sintered at 925,1100 , and $13000 \mathrm{C}$, respectively. The numbers in the pictures correspond to the measured dry densities (converted to the theoretical densities).

(a) Volume fraction of Pores

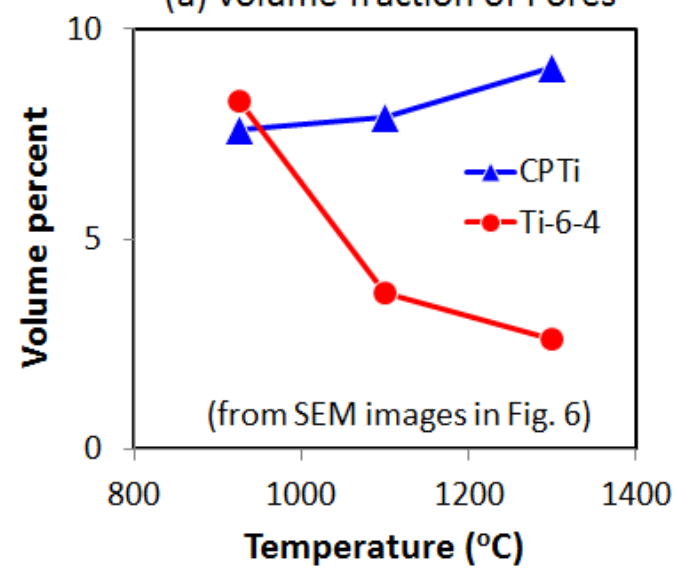

(b) Theoretical Density

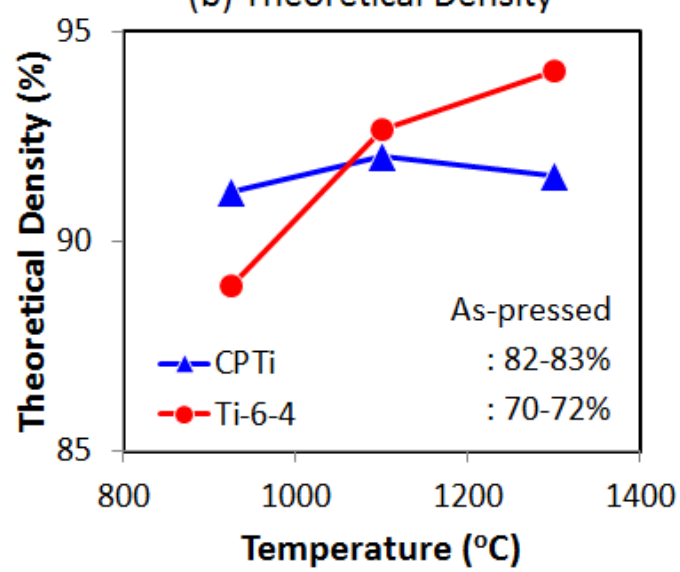

Figure 7. Temperature dependences of (a) volume fraction of pores measured from crosssectional images and $(b)$ theoretical densities.

It was found that the longer hold time could be one of the effective techniques to increase the aspressed density of the Armstrong CP-Ti powder. The test was made by simply holding the pressure at $100 \mathrm{ksi}$ for 0,30 , or $120 \mathrm{sec}$, and then releasing the pressure. Table 2 summarizes the effect of holding time on the average density (at least three of the pressed samples), which demonstrates that the density increases with increasing holding time. Note that the density did not increase after holding for more than $2 \mathrm{~min}$, indicating that $92.2 \%$ density would be the maximum density of the as-received Armstrong CP-Ti powder at the designated die-pressure. 
Table 2. Theoretical density of as-pressed Armstrong CP-Ti powder at various holding time at 100ksi.

\begin{tabular}{cccc}
\hline \multirow{2}{*}{ Armstrong CP-Ti } & \multicolumn{3}{c}{$\mathbf{1 0 0}$ ksi, holding time } \\
\cline { 2 - 4 } & no hold & $30 \mathrm{sec}$ & $2 \mathrm{~min}$ \\
\hline Average TD $(\%)$ & 88.4 & 91.8 & 92.2 \\
\hline
\end{tabular}

Figure 8 shows a part of cross-sectional OM pictures (montage) of as-pressed Armstrong CP-Ti powder at $100 \mathrm{ksi}$, representing the effect of holding time on the pore distribution. The majority of the matrix in both specimens contains very small and uniform pore distribution in this magnification, although no-hold specimen shows larger numbers of agglomerates of large pores with irregular shape (as shown in white circles) than the 2 min-hold specimen. The irregular pore agglomerates formed due to the coral-like Armstrong powder morphology which could cause non-uniform and insufficient load propagation. The formation of pore agglomerates was also observed at in-situ SEM observation of the Armstrong powder compression study [34]. However, the 2 min-holding gave enough time for these powders to deform the powders, resulting in eliminating most of such defects.

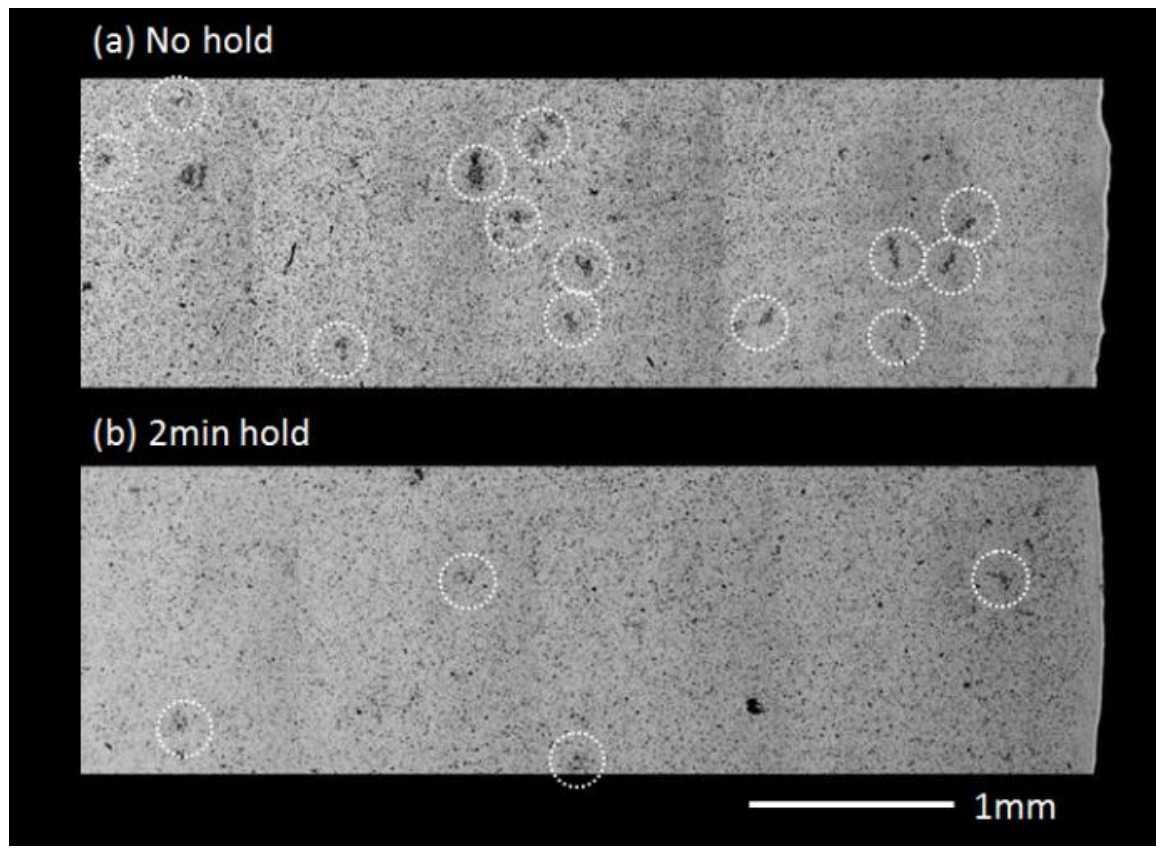

Figure 8. OM microstructure of Armstrong CP-Ti pressed at 100ksi; (a) no hold at $100 \mathrm{ksi}$ pressing, and (b) 2 min hold during pressing at $100 \mathrm{ksi}$. Circles in the pictures correspond to agglomerates of large pores.

The large pore agglomerates could also result in the residual pores after sintering process. Figure 9 shows a part of cross-sectional OM pictures (montage) of the Armstrong CP-Ti pressed at $100 \mathrm{ksi}$ with no or $2 \mathrm{~min}$ holding, followed by sintering at $1100{ }^{\circ} \mathrm{C}$ for $2 \mathrm{~h}$. This sintering process reduced the numbers small pores in the matrix compared to the microstructure in Figure $6 \mathrm{~b}$ after $1 \mathrm{~h}$ sintering at $1100{ }^{\circ} \mathrm{C}$, although the large pores still remained and distributed similar to the as-pressed samples. These results also emphasize that for Armstrong CP-Ti powder, the pore elimination during pressing process is important to obtain high density after sintering process. 


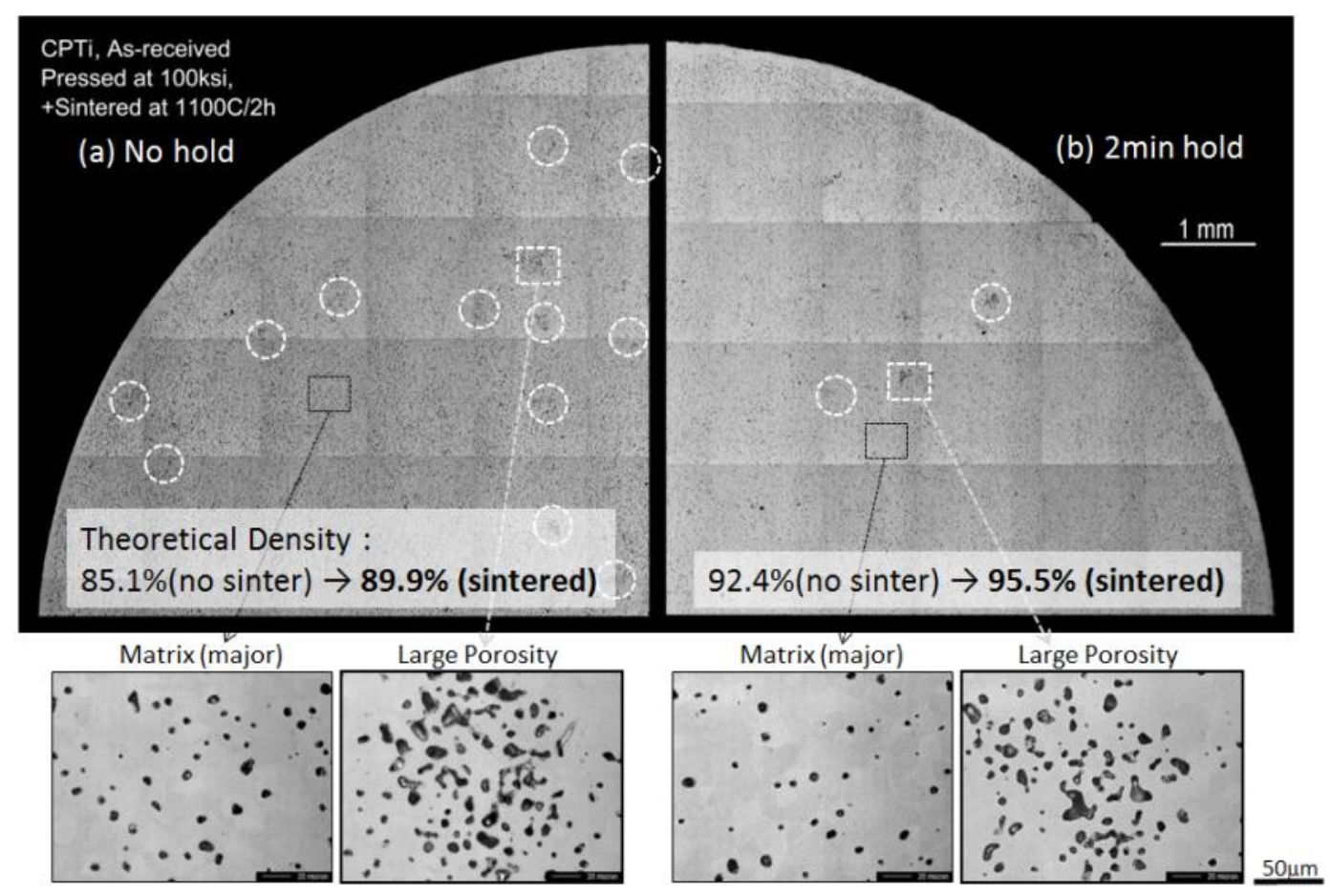

Figure 9. OM microstructure of Armstrong CP-Ti pressed at 100ksi with different hold times, followed by sintering at $1100^{\circ} \mathrm{C}$ for $2 \mathrm{~h}$; (a) no hold at $100 \mathrm{ksi}$ pressing, and (b) 2 min hold during pressing at $100 \mathrm{ksi}$.

It was also found that the longer sintering time did not increase the density, at least in the temperature and time ranges studied. Figure 10 illustrates the effect of sintering time and temperature on the density of Armstrong CP-Ti pressed at $100 \mathrm{ksi}$. It clearly showed that the density increased immediately after starting the sintering at 925 and $1100{ }^{\circ} \mathrm{C}$, and then almost no changes in the density were seen after more than $1 \mathrm{~h}$ sintering (the density at $925^{\circ} \mathrm{C}$ for $4 \mathrm{~h}$ was lower than that for $1 \mathrm{~h}$, which may be due to the lower as-pressed density of the sample used for this test condition).

Although no additional sintering data is available for $1300{ }^{\circ} \mathrm{C}$, no drastic improvement would be expected based on other temperature results.

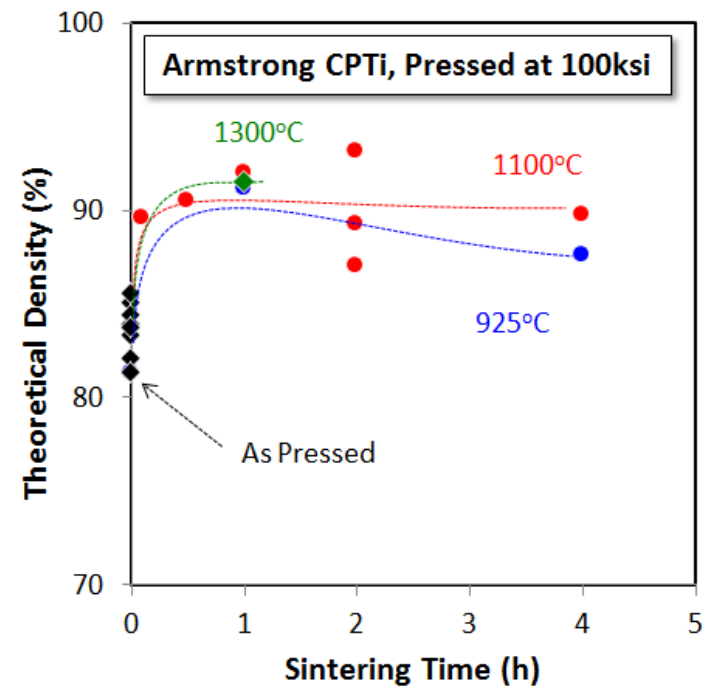

Figure 10. Effect of sintering time and temperature on the density of Armstrong CP-Ti pressed at $100 \mathrm{ksi}$. 


\subsubsection{Compaction and consolidation of $\mathrm{HDH}$ powders}

Figure 11 shows the pressed and sintered density of the HDH Ti-6Al-4V powders plotted as a function of die-pressure. Note that the HDH powders were not compacted well below $25 \mathrm{ksi}$, so that no data below $25 \mathrm{ksi}$ was obtained. No drastic improvements of density were observed compared to the Armstrong powder after sintering at $1300{ }^{\circ} \mathrm{C}$ for $1 \mathrm{~h}$, as seen in Figure 4. However, higher sintering temperatures or longer sintering time were effective to increase the density of the $\mathrm{HDH} \mathrm{Ti}-$ $6 \mathrm{Al}-4 \mathrm{~V}$. The improvement effects on density seem not sensitive to the as-pressed density, indicating that thermal reaction is more dominant to increase the sintered density. The effect of sintering time on the density can be easily discussed by using Figure 12 which is plotted as a function of sintering time. The time dependence of the density showed parabolic curves, indicating that the diffusion-controlled process was dominant in the consolidation of the $\mathrm{HDH}$ Ti-6Al-4V powder. It should be emphasized that the highest achieved density the HDH Ti-6Al-4Vwas $90.5 \%$ after sintering at $1300{ }^{\circ} \mathrm{C}$ for $18 \mathrm{~h}$, which was still lower than the density of Armstrong Ti-6Al-4V (92.3\%) after sintering at $1300{ }^{\circ} \mathrm{C}$ for $1 \mathrm{~h}$.
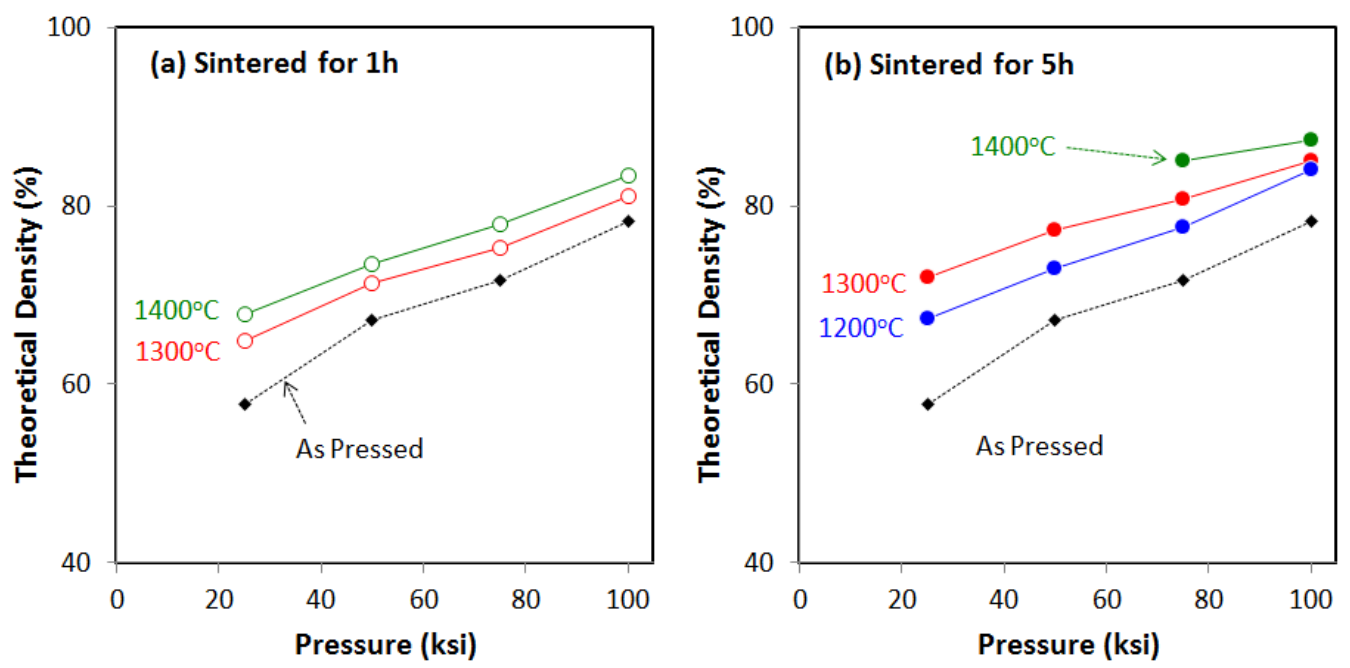

Figure 11. Theoretical density of pressed and sintered HDH Ti-6Al-4V powders plotted as a function of pressure: (a) sintered for $1 \mathrm{~h}$, and (b) for $5 \mathrm{~h}$.
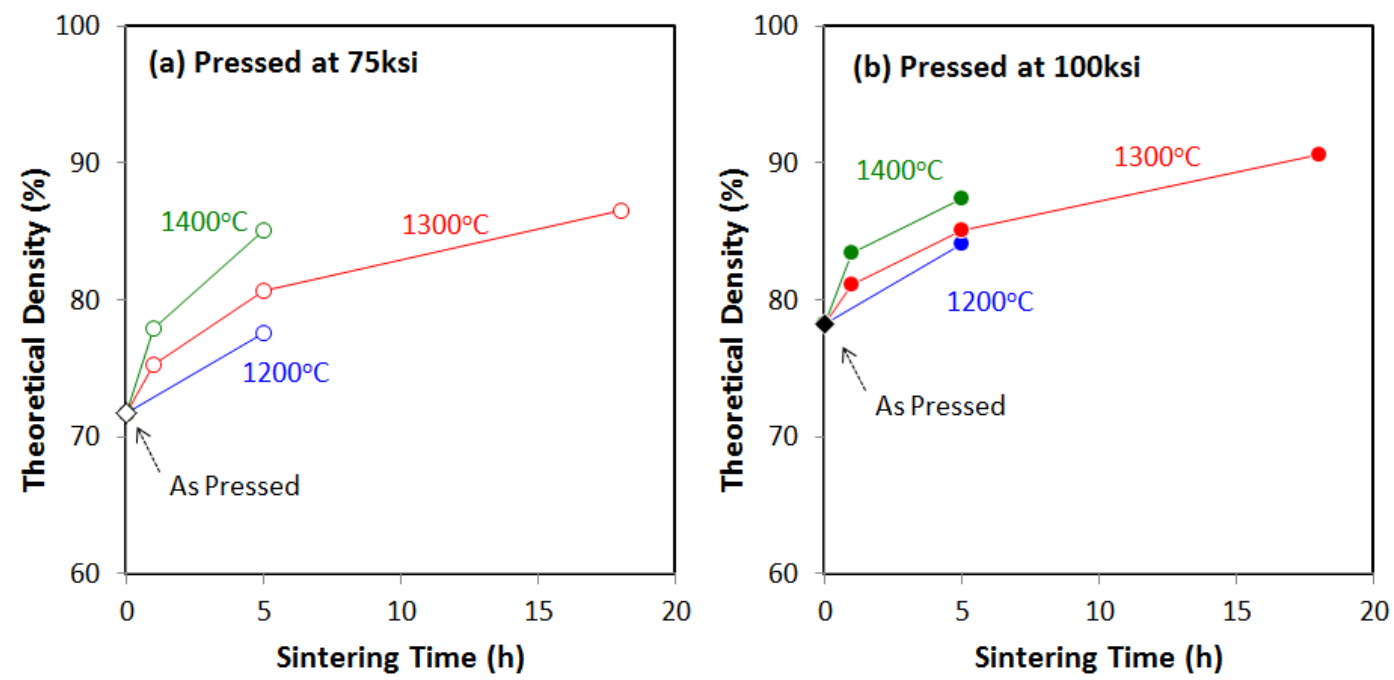

Figure 12. Theoretical density of pressed and sintered HDH Ti-6Al-4V powders plotted as a function of sintering time: (a) pressed at $75 \mathrm{ksi}$, and (b) at $100 \mathrm{ksi}$. 
The cross-sectional microstructure of the as-pressed HDH Ti-6Al-4V at100 ksi is shown in Figure 13. The powder morphology is obvious with relatively large gaps between powders, although the theoretical density is not much lower than the as-pressed Armstrong powders since the HDH powders themselves are dense. The inset shows high magnification pictures of contact interface of the HDH, indicating that the powder deformation at as-pressed condition is small, so that the elimination of the gaps (or pores) can be expected at the designated die-pressure. Note that the $100 \mathrm{ksi}$ of die-pressure is a relatively high pressure to establish in large geometry components or dies, but could be used in smaller components or high load presses.

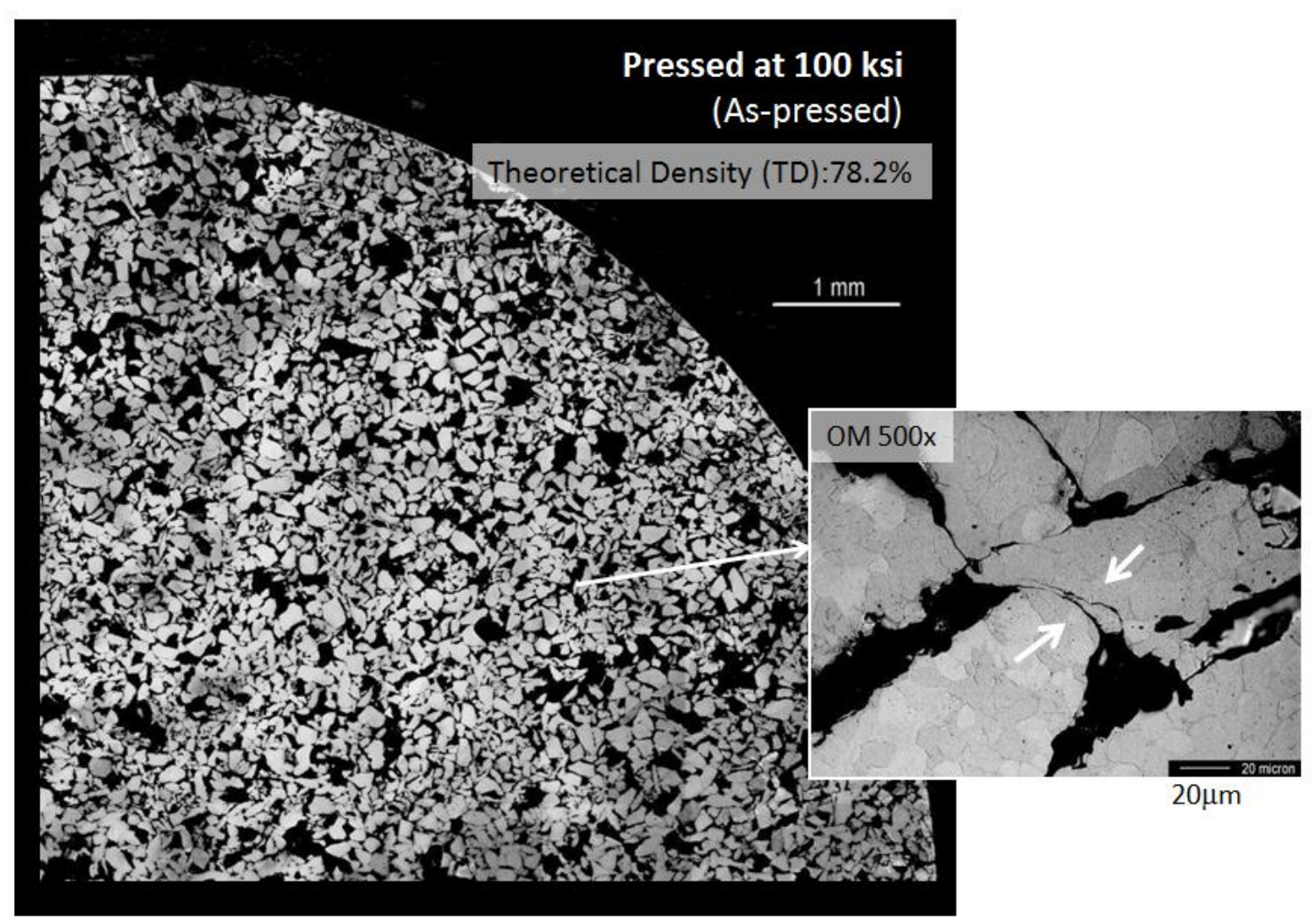

Figure 13. OM microstructure of $\mathrm{HDH}$ Ti-6Al-4V pressed at $100 \mathrm{ksi}$, together with a high magnification OM picture showing the local powder deformation indicated by arrows.

Figure 14 shows the cross-sectional microstructure the HDH Ti-6Al-4V pressed at $100 \mathrm{ksi}$ after sintering at $1300{ }^{\circ} \mathrm{C}$ for $1 \mathrm{~h}$ or $5 \mathrm{~h}$ (Figure 14a and Figure 14b, respectively). The pore shapes were blocky and the powder morphology was still visible after $1 \mathrm{~h}$ sintering. From the inset microstructure, it is observed that the pores could be inter-connected to each other. After $5 \mathrm{~h}$ sintering, the pores became round-shape and isolated to each other. The total volume of the pores seemed decreased, which was consistent with the changes in the density during sintering. Since the sintering process was conducted in a vacuum condition, the driving force of the pore shrinkage relies mainly on the surface tension of the pores. However, the driving force of pore shrinkage in the HDH Ti-6Al-4V could be much smaller than the Armstrong Ti-6Al-4V because of the smaller pore curvature. This would explain the slower kinetics of sintering process (consolidation) of the HDH samples compared to the Armstrong powder samples. 

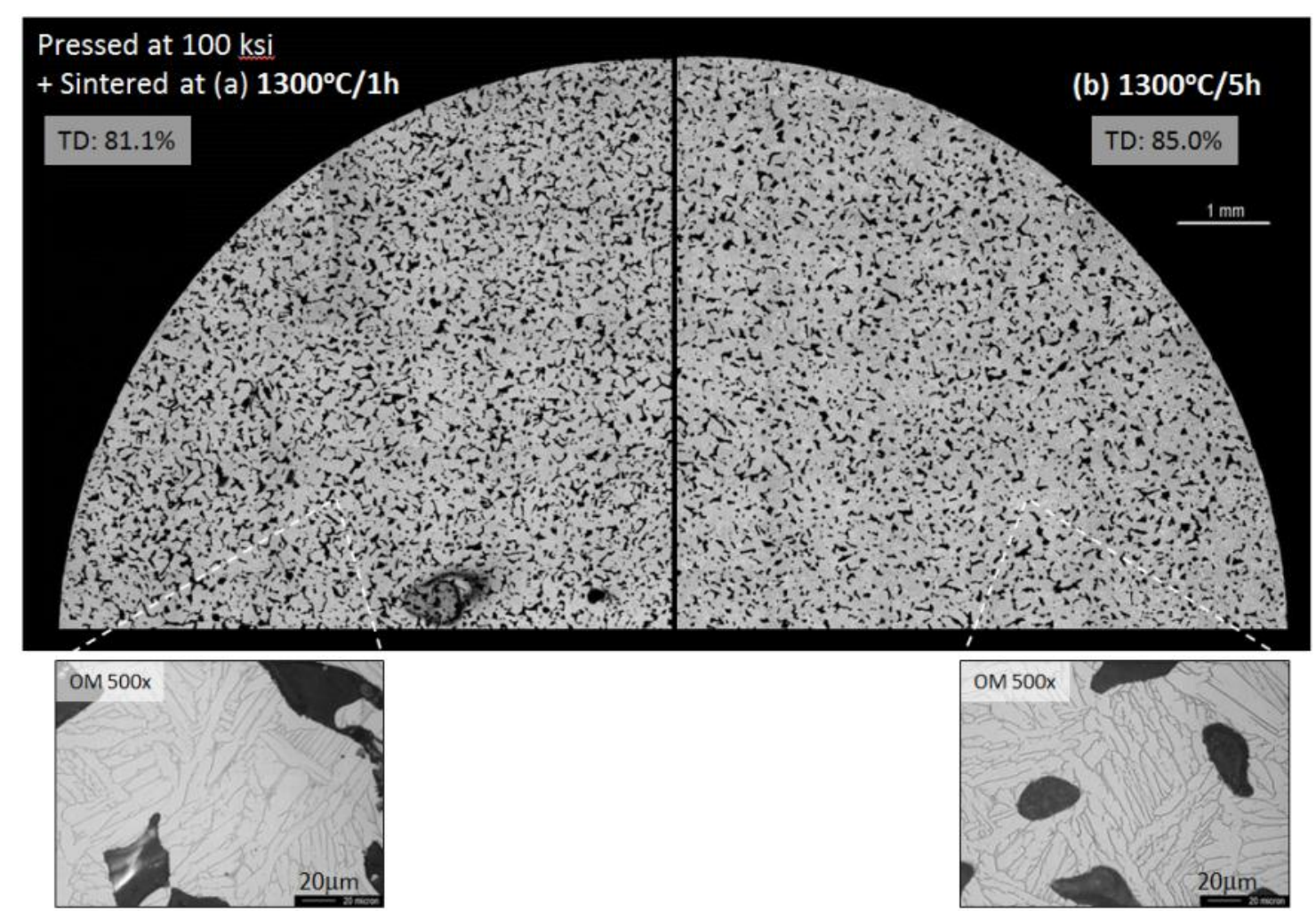

Figure 14. OM microstructure of $\mathrm{HDH}$ Ti-6Al-4V pressed at $100 \mathrm{ksi}$, followed by sintering at $1300^{\circ} \mathrm{C}$; (a) sintered for $1 \mathrm{~h}$, and (b) for $5 \mathrm{~h}$.

\subsubsection{Consolidation Modeling}

Modeling was performed to predict the effect of die wall friction on the stress and density distribution after pressing and sintering. Although the results demonstrated only a cylindrical die-pressing, the established simulation can be expanded to complicated shapes where compaction in press and sintering can predict potential low density areas in the consolidated powder. The model was then experimentally verified; results are included.

\subsubsection{Obtaining fundamental material properties}

The elastic properties of the as-pressed Armstrong CP-Ti powder compacts were obtained from experimental tests. It was found that Young's modulus exhibited an almost linear variation with the relative density (RD) of the compact for relative densities between 50 and $75 \%$ of theoretical density. The bulk modulus values exhibit a wider scatter than those of Young's modulus. The cyclic uniaxial loading and unloading experiments (Figure 15 and Figure 16) indicate that at low compact densities, the powder compacts exhibit a high degree of inelastic behavior; this makes it difficult to obtain data on Young's modulus. It was found that employing a linear component and a power law for the nonlinear component, with a fixed stress exponent of 2/3, was inappropriate for the CP-Ti material. Concerning the plasticity of the powder compacts, two compression tests were used to describe the failure line. The data sets from the diametral compression tests and simple uniaxial compression tests were successfully used to obtain the cohesion and angle of the failure line (Figure 17); these material parameters describe the evolution of the failure line as a function of the density of the compact. 

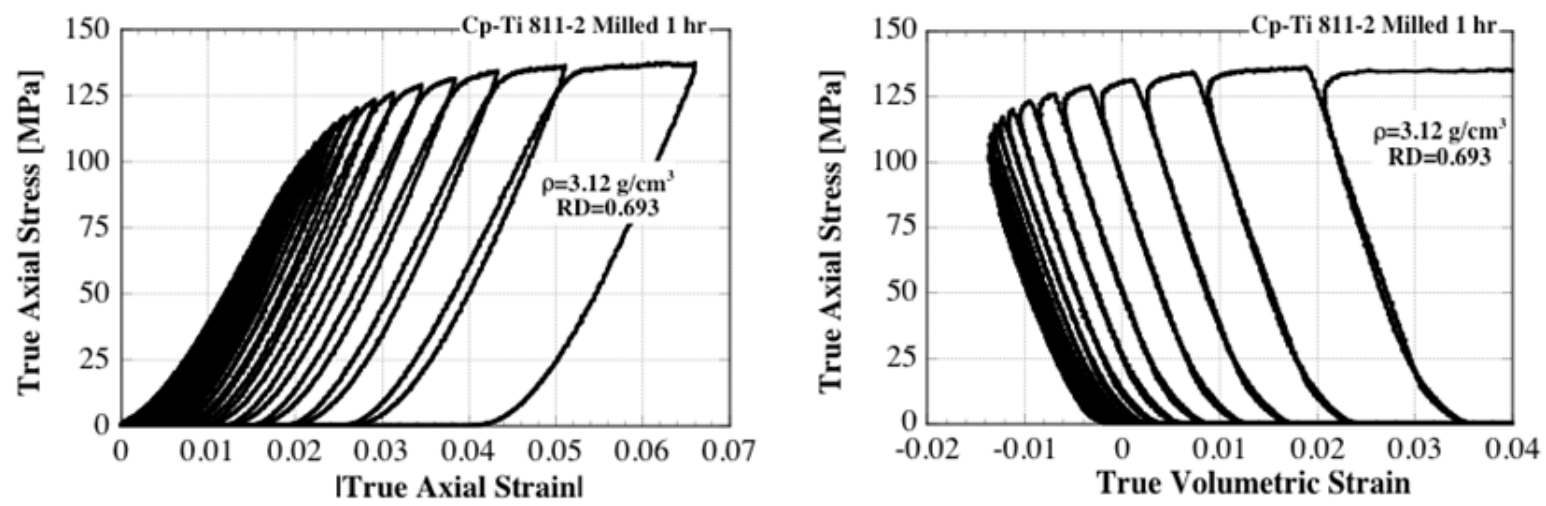

Figure 15. Uniaxial compression tests loading and unloading for $\mathrm{RD}=3.12 \mathrm{~g} / \mathrm{cm}^{3}$, sample E2a: (a) $\sigma_{x}=\sigma_{x}\left(\varepsilon_{x}\right)$, and $(\mathbf{b}) p=p\left(\varepsilon_{v}\right)$

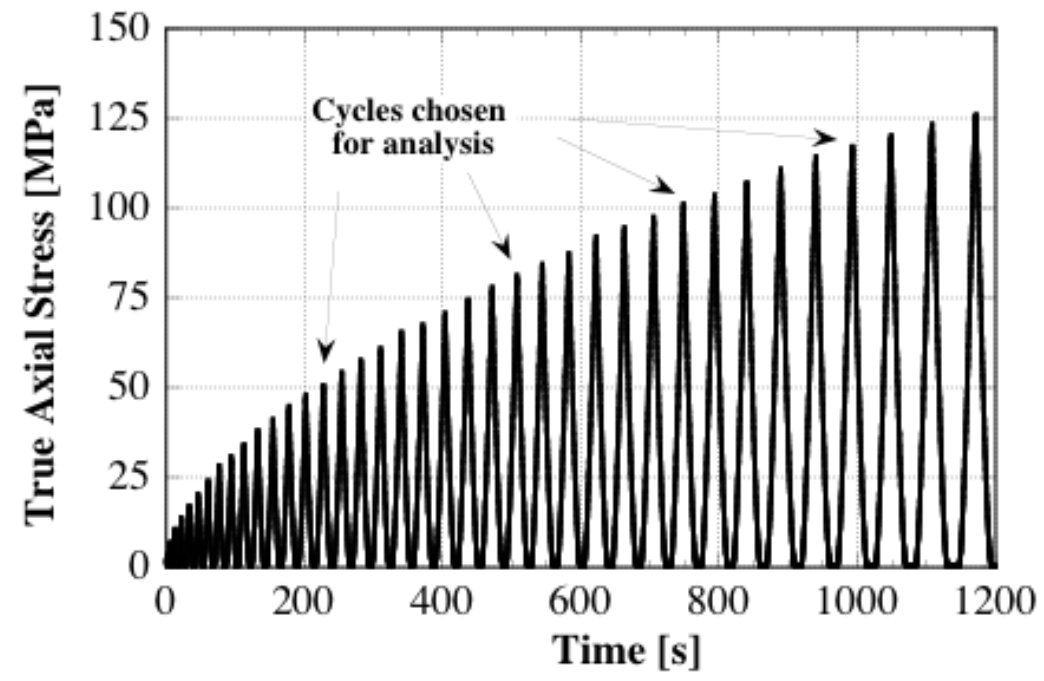

Figure 16. Cycles chosen for linear regression analysis to obtain $E$ and $K$ for $R D=3.12 \mathrm{~g} / \mathrm{cm}^{3}$.

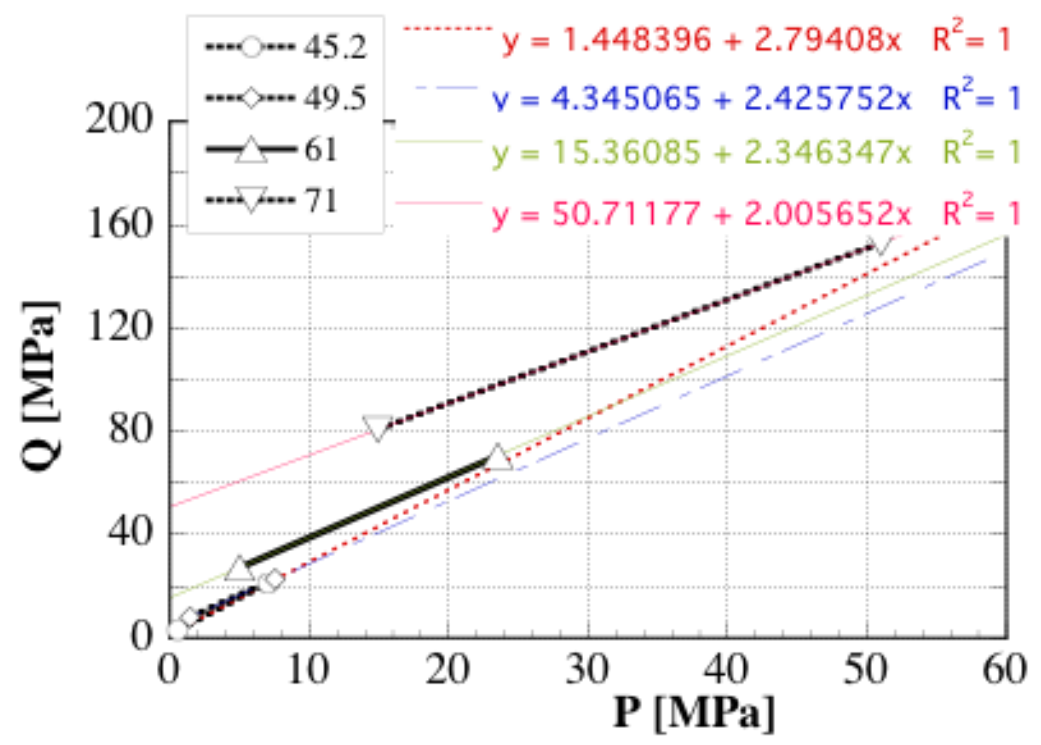

Figure 17. Failure line obtained from the two compression tests. 


\subsubsection{Pressure and density distributions of as-pressed Armstrong CP-Ti}

A computational methodology was developed for the process simulation of cold pressing of Armstrong CP-Ti Powders, where experimentally obtained mechanical properties of the as-pressed powders were used. The computational model was implemented in the commercial finite element program ABAQUS ${ }^{\mathrm{TM}}$. Since the powder deformation and consolidation is governed by specific pressure-dependent constitutive equations, several solution algorithms were developed for the ABAQUS user material subroutine, UMAT. The solution algorithms were developed for computing the plastic strain increments based on an implicit integration of the nonlinear yield function, flow rule, and hardening equations that describe the evolution of the state variables. Since ABAQUS requires the use of a full Newton-Raphson algorithm for the stress-strain equations, an algorithm for obtaining the tangent/linearization moduli, which is consistent with the return-mapping algorithm, also was developed. Several numerical simulations were conducted for cylindrical samples (Figure 18) with different aspect ratios. The numerical simulation results showed that for the disk samples, the minimum von Mises stress was approximately half than its maximum value. The hydrostatic stress distribution exhibits a variation smaller than that of the von Mises stress (Figure 19). It was found that for the disk and cylinder samples the minimum hydrostatic stresses were approximately 23 and $50 \%$ less than its maximum value, respectively (Figure 20). It was also found that the minimum density was noticeably affected by the sample height.

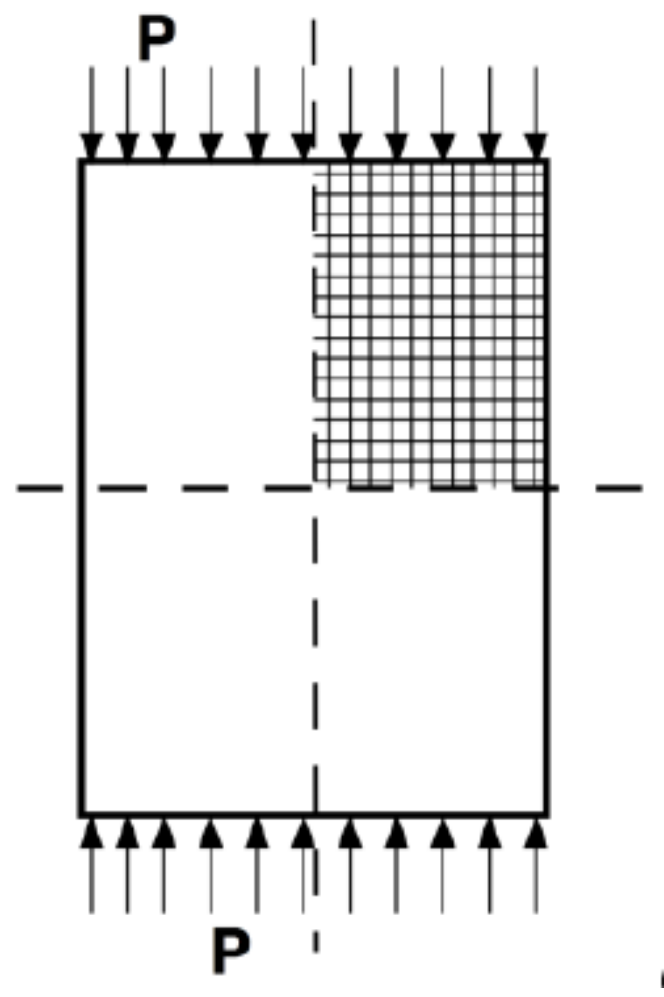

Figure 18. Schematic of vertical cross section through the cylindrical part that is subject to dual-action pressing showing the cylinder vertical axis and horizontal centerline. 


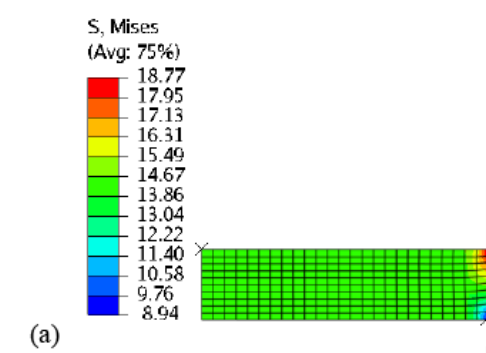

(b)

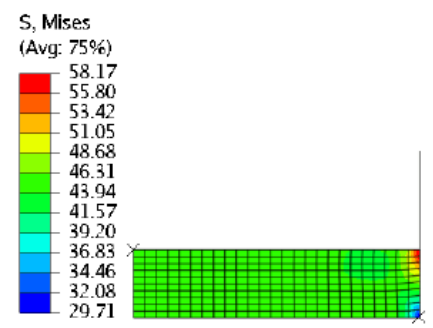

(c)
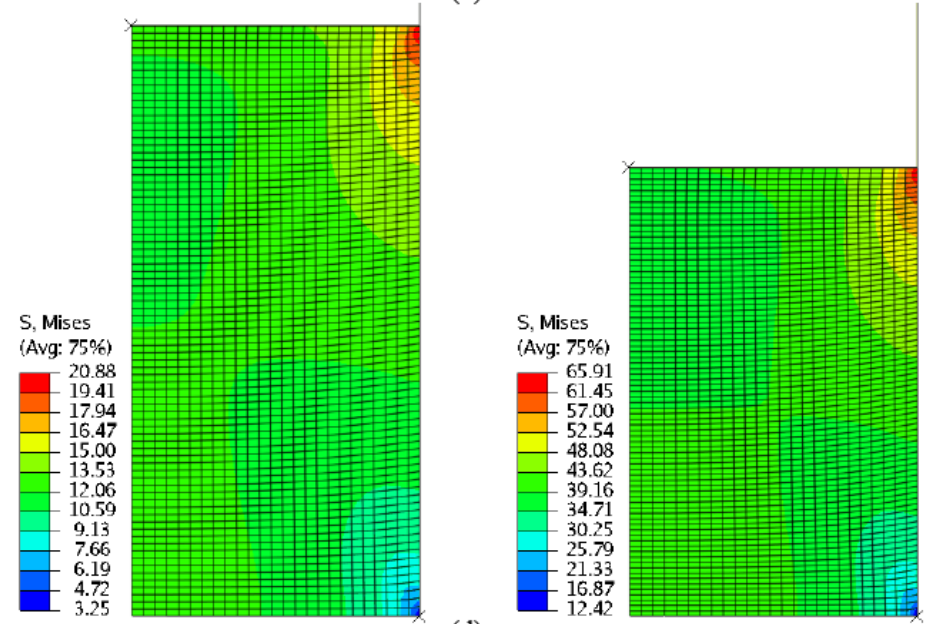

Figure 19. The effective stress [ksi] for disk samples with compaction pressures of (a) 25 ksi (172.4 MPa) and (b) $75 \mathrm{ksi}(517.1 \mathrm{MPa})$ and for cylinder samples with compaction pressures of (c) $25 \mathrm{ksi}$ (172.4 MPa) and (d) $75 \mathrm{ksi}(517.1 \mathrm{MPa})$. Deformed meshes are shown.

(a)
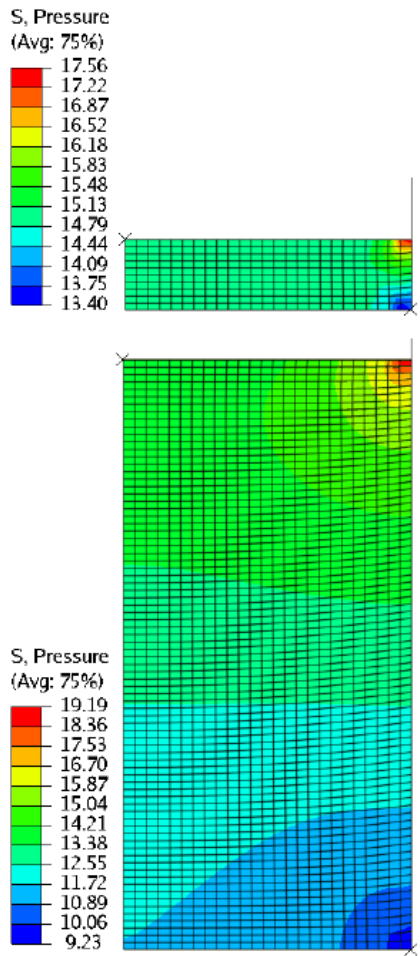

(b)
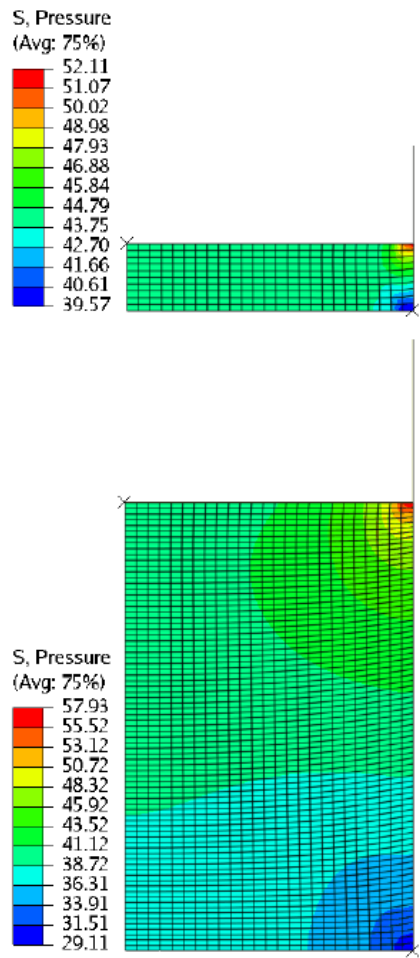

(d)

Figure 20. The distribution of hydrostatic stress [ksi] for disk samples with compaction pressures of (a) $25 \mathrm{ksi}(172.4 \mathrm{MPa})$ and (b) $75 \mathrm{ksi}(517.1 \mathrm{MPa})$ and for cylinder samples with compaction pressures of (c) $25 \mathrm{ksi}(172.4 \mathrm{MPa})$ and (d) $75 \mathrm{ksi}(517.1 \mathrm{MPa})$. Deformed meshes are shown. 


\subsubsection{Prediction of sintering characteristics}

A model for sintering was developed in order to be able to simulate the final powder compact density after the sintering step. The sintering model has been developed a user subroutine to the CREEP module in ABAQUS. A review of the literature was conducted in order to obtain constitutive equations and material property data that can be used for the sintering model. The value for the activation energy was obtained from the experimental work of Robertson and Schaffer [35]. The grain size was obtained from metallographic pictures of samples. The grain size was found to have an average of approximately $5 \mu \mathrm{m}$.

Table 3. Hardness data for disk samples

\begin{tabular}{cccccc}
\hline $\begin{array}{c}\text { Compacting pressure of } \\
\text { Sample (ksi) }\end{array}$ & 5 & 10 & 25 & 50 & 75 \\
\hline Hardness (HV) & $8.4 \pm 2.6$ & $16.9 \pm 2.6$ & $32.5 \pm 5.7$ & $57.4 \pm 15.2$ & $75.6 \pm 14.9$ \\
\hline
\end{tabular}

The hardness measurements have been conducted on the vertical cross-section of CP-Ti samples with various heights and radii. Table 3 summarized the averaged hardness as a function of compaction pressure. Using the already developed correlation between the hardness and density, distribution of the density in the vertical cross-section will be obtained for the CP-Ti specimen. Numerical simulation results between the computed and measured density will be compared in order to validate the computational model. Once validated, the computational model can be used to investigate the other process conditions and the compaction of more complex 3D shapes than rods and disks.

The numerical simulations have been extended to include the process simulation of cold pressing and sintering of Armstrong CP-Ti powders. Sintering was simulated using a model based on diffusional creep using the user subroutine CREEP. The initial mesh, stress, and density for the simulation of sintering were obtained from the results of the cold pressing simulation, minimizing the errors from decoupling the cold pressing and sintering simulations. Numerical simulation results are presented for the cold compaction followed by a sintering step of the Ti powders. The numerical simulation results for the relative density were compared to those measured from experiments before and after sintering (Table 4), showing that the relative density can be accurately predicted.

Table 4. Sample dimensions and density measurements during the powder metallurgy cycle

\begin{tabular}{|c|c|c|c|c|c|c|}
\hline Sample ID & Processing & Weight (g) & $\begin{array}{c}\text { Diameter } \\
(\mathbf{c m})\end{array}$ & $\begin{array}{c}\text { Thickness } \\
\text { (cm) }\end{array}$ & $\begin{array}{l}\text { Density } \\
(\mathrm{g} / \mathrm{cm} 3) \\
\end{array}$ & $\begin{array}{l}\text { RD } \\
{[\%]}\end{array}$ \\
\hline $\mathrm{S} 1$ & as-pressed & 1.99 & 1.273 & 0.497 & 3.15 & 70.02 \\
\hline $\begin{array}{l}\text { S1 after } \\
\text { sintering }\end{array}$ & Sinter $1200{ }^{\circ} \mathrm{C} / 1 \mathrm{~h}$ & 2.02 & 1.209 & 0.472 & 3.72 & 82.76 \\
\hline $\mathrm{S} 2$ & as-pressed & 2.01 & 1.273 & 0.484 & 3.27 & 72.58 \\
\hline $\begin{array}{l}\text { S2 after } \\
\text { sintering }\end{array}$ & Sinter $1300 \mathrm{C} / 1 \mathrm{~h}$ & 2.02 & 1.206 & 0.461 & 3.83 & 85.17 \\
\hline
\end{tabular}

The numerical simulation results for the density were compared to those measured from experiments before and after sintering. The simulations of sintering and cold pressing were closely coupled. Examples of the simulation results are shown in Figure 21 and Figure 22. The initial mesh, stress, and density for the simulation of sintering were obtained from the results of the cold pressing simulation. A diffusion parameter for the sintering model was identified by trial-and-error procedures such that good agreement was obtained between the computed and experimentally measured density for one sample. The computational results for a second sample, which was sintered at a different temperature than the first sample, were obtained using the same model parameters as those for the 
first sample. Numerical simulation results show that the relative density for the second sample was predicted with an error of $8 \%$, validating the proposed computational model. It was found that the non-uniform density after cold pressing leads to a larger reduction in the diameter at the bottom than that at the top of the sample during sintering.

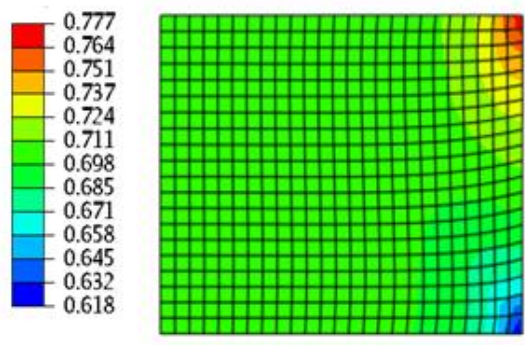

(a)

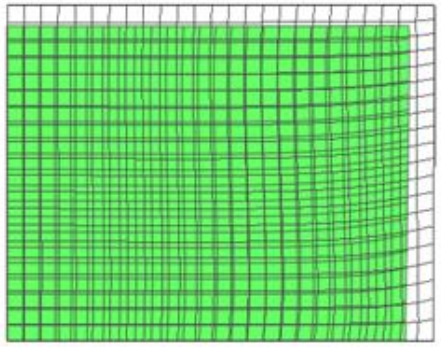

(b)

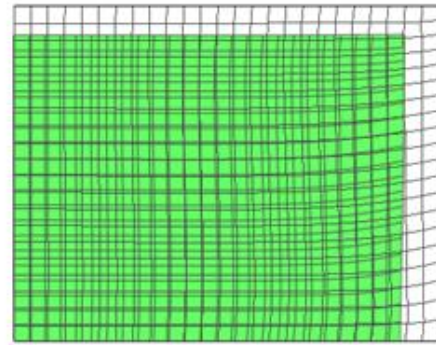

(c)

Figure 21. Examples of the simulation results: (a) Deformed mesh showing the distribution of relative density for simulation of CIP of the sample S2. Initial (white) and deformed (green) meshes showing the densification during sintering: (b) at the end of the hold time and (c) after cooling to room temperature.

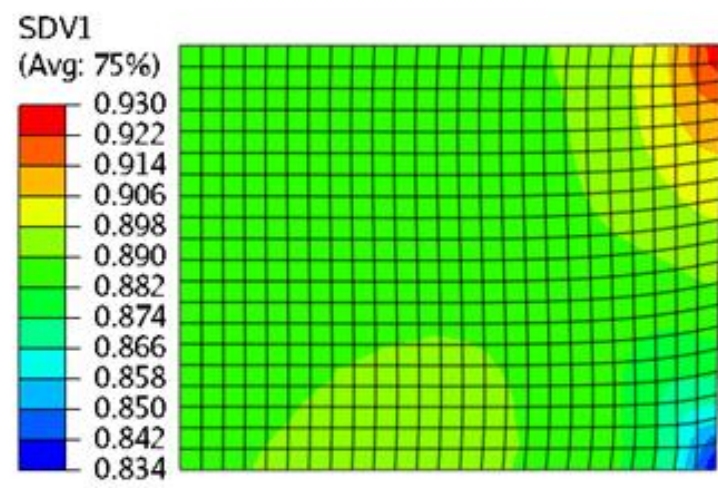

(a)

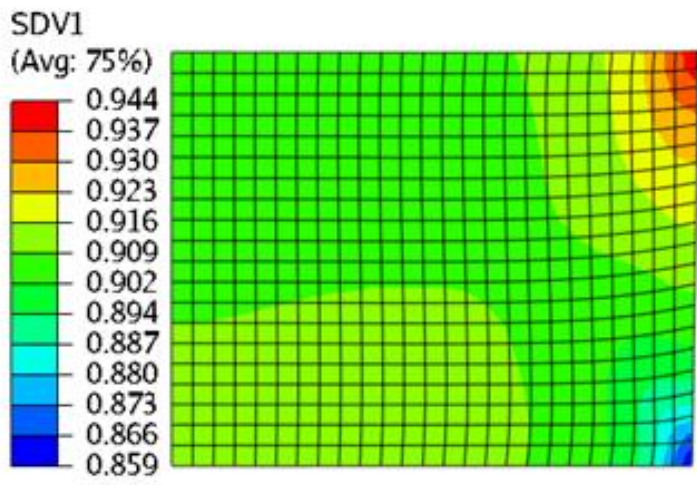

(b)

Figure 22. Distribution of relative density during sintering for the sample in Figure 21, (a) at the end of the hold time and (b) after cooling to room temperature.

\subsubsection{Innovative Approaches to Maximizing Tap Densities}

This section covers alternative approaches to improving tap density and subsequent compaction and sintering densities. Handling, attrition, and understanding the compaction of the powder is critical to developing optimized consolidation approaches. For components that are only press and sintered with no subsequent processes to further consolidate, this area of research can be critical to whether one can achieve full density after sintering, and maximizing mechanical properties; this was found to be especially true of the Armstrong powders where irregular morphologies had not been fully explored and closely interfaced powder particles can make the difference between full density or localized porosity and spatial density irregularities.

\subsubsection{Tap density}

Systematic ball-milling studies were performed by using high-density zirconium-oxide media with dry argon gas, isopropyl alcohol, or ethanol. Powder size distribution, tap densities, and the amount of oxygen and nitrogen were measured as a function of milling time for up to $150 \mathrm{~min}$. 
Figure 23 shows powder size distribution (Figure 23a) and the tap density (Figure 23b) of Armstrong CP-Ti power before and after milling in ethanol. The results revealed that the milling process considerably refined the powder size compared to the as-received condition. Tap densities were doubled to triple in the first 30 minutes of milling, which could be due to breaking the initial irregular powder morphologies of the Armstrong powders, resulting in reducing the gaps between each powder. Extended milling times resulted in further reductions in size distribution, but at much slower rates. Preliminary studies of the Ti-6Al-4V Armstrong powder exhibited similar results. However, tap density did not increase by much with milling times greater than 60 minutes.
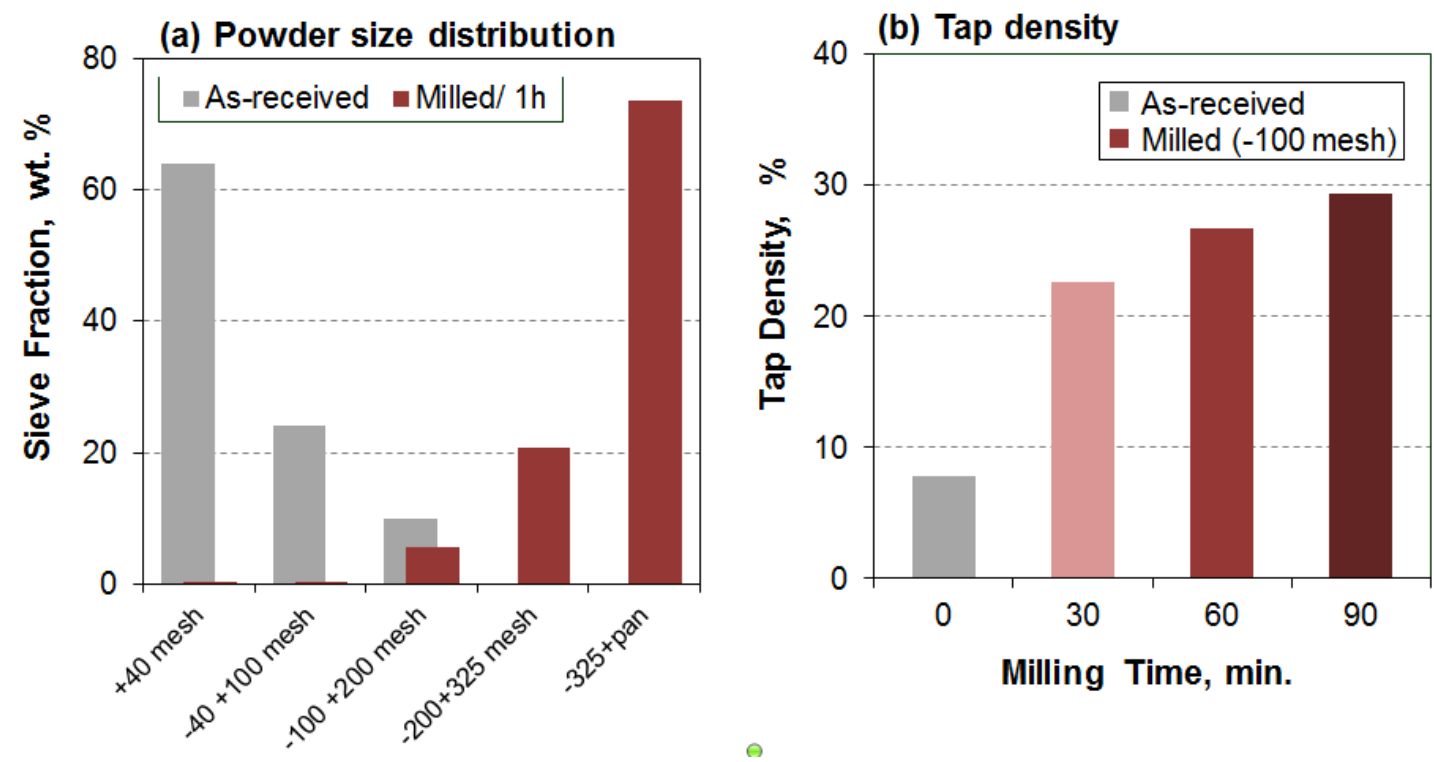

Figure 23. (a) Powder size distribution and (b) tap density of Armstrong CP-Ti powder before and after ball-milling in ethanol.

The SEM-SE images of the Armstrong powders after milling for $1 \mathrm{~h}$ are shown in Figure 24 . The powders become much smaller than the as-received ones shown in Figure 1a and Figure 1c, although each small piece still consists of the agglomerates of coral-like dendrite. Lots of flattened powders as indicated by white arrows have also been observed for both powders, which formed due to the direct compaction by balls.
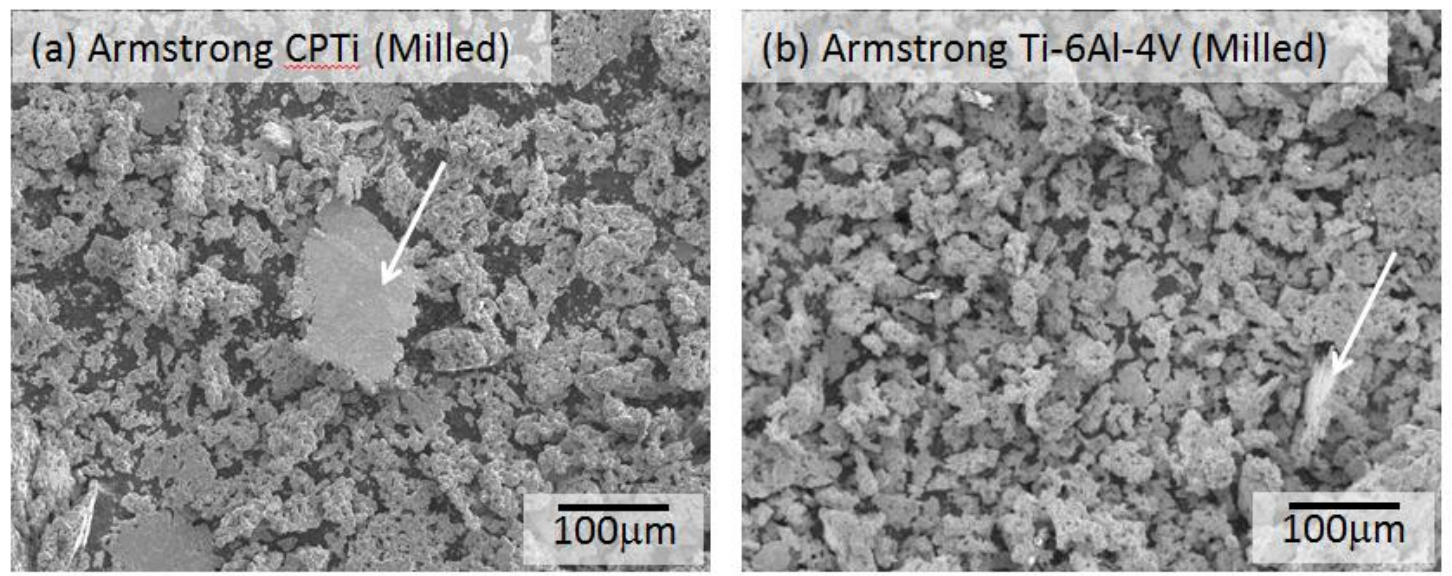

Figure 24. SEM images of (a) Armstrong CP-Ti powder and (b) Armstrong Ti-6Al-4V powder after ball-milling in ethanol for $1 \mathrm{~h}$. Arrows indicate flattened particles formed by direct compaction of balls. 


\subsubsection{Effect of milling on density}

No significant advantage of the milling process has been observed in the as-pressed density. Table 5 summarizes the density of the ball-milled Armstrong CP-Ti powders pressed at $100 \mathrm{ksi}$, together with the results from the no-milled powders. Surprisingly, the densities of the milled powders did not exceed those of no-milled powders. From the cross-sectional microstructure observation shown in Figure 25, it is obvious that the milling process did not successfully eliminate any large pore agglomerates such as those observed in Figure 8. Instead, a different type of irregular-shaped pores was observed attached to the large compressed particles with flattened shape shown in Figure 24. It seems the flattened particle does not have enough deformability to fit with the shape of the other powders, which may cause to leave large pore agglomerates between them. It should be emphasized that the milling powders still have the advantage of much larger tap density compared to as-received ones, so that the balance of the effects needs to be considered.

Table 5. Theoretical density of ball-milled Armstrong CP-Ti pressed at 100ksi with various holding time

\begin{tabular}{cccc}
\hline \multirow{2}{*}{ CP-Ti, Armstrong } & \multicolumn{3}{c}{ 100ksi, holding time } \\
\cline { 2 - 4 } & no hold & $30 \mathrm{sec}$ & $2 \mathrm{~min}$ \\
\hline No milling & 88.4 & 91.8 & 92.2 \\
\hline Milled & - & 89.2 & 90.5 \\
\hline
\end{tabular}

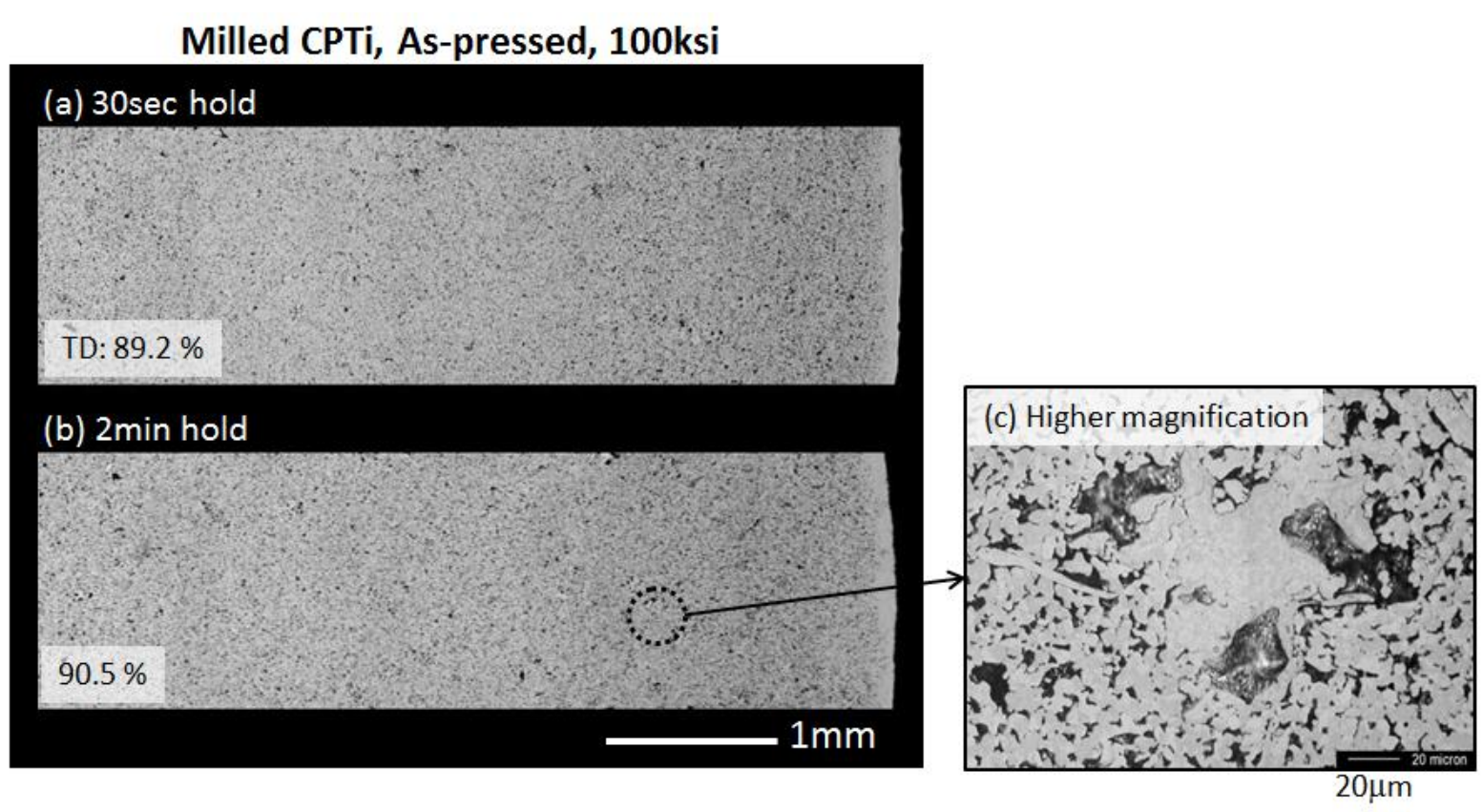

Figure 25. OM pictures of ball-milled Armstrong CP-Ti pressed at 100ksi; (a) hold for $30 \mathrm{sec}$ at $100 \mathrm{ksi}$, and (b) hold for $2 \mathrm{~min}$ at 100ksi, together with (c) a high magnification picture.

\subsubsection{Effect of blending the Armstrong and the HDH powders on density}

Blending the Armstrong and the HDH powders did not increase the as-pressed density because the HDH powders with blocky shape caused increasing porosities surrounding the powders, as shown in Figure 26. This result was similar to the effect on the milling powders described above. The volume of the large pores attached to the HDH powder increased with increasing the volume ratio of the HDH powder. Figure 27 shows the as-pressed density of blended powders as a function of blending ratio (fraction of the $\mathrm{HDH}$ powder), which exhibits monotonic, negative relationship. 

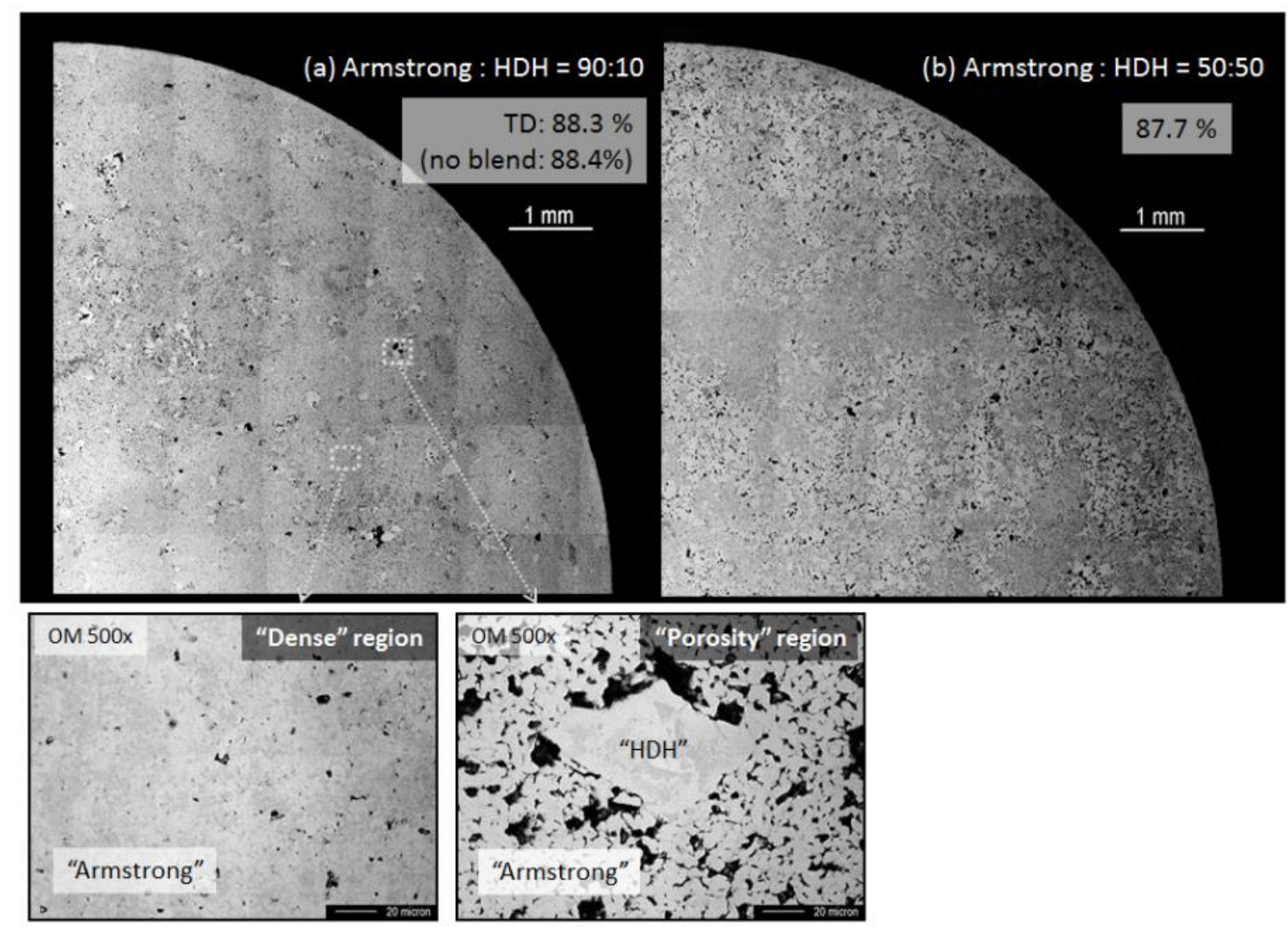

Figure 26. OM pictures of as-pressed the Armstrong and the HDH CP-Ti powders blended with different ratio (a) Armstrong: $\mathrm{HDH}=90: 10$, and (b) 50:50.

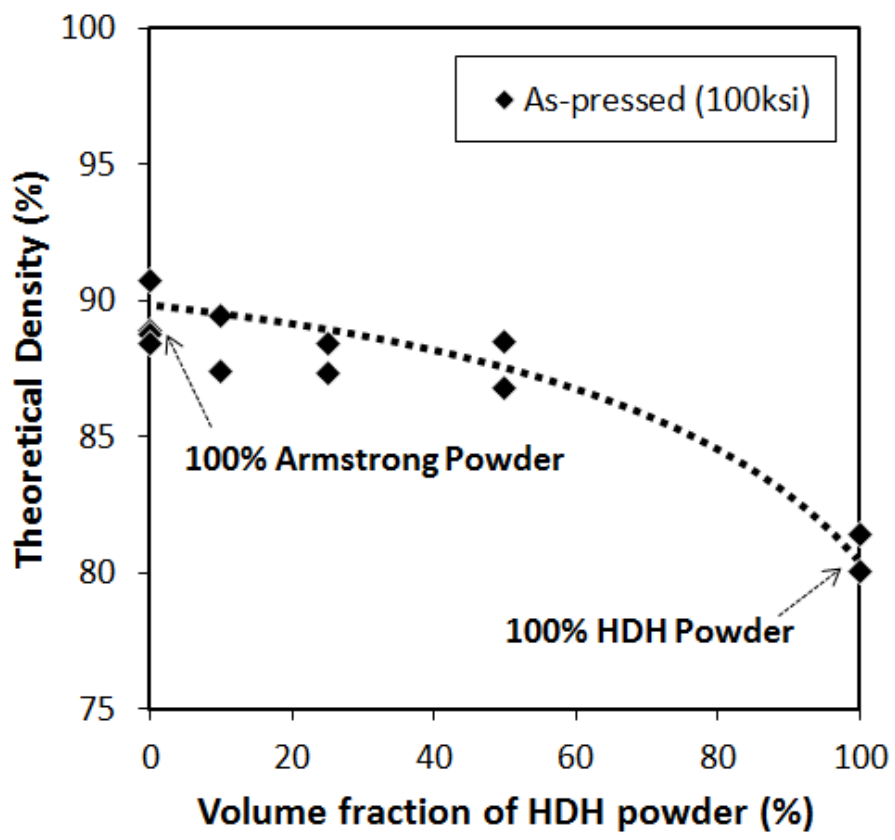

Figure 27. Density of blended CP-Ti powder pressed at 100ksi, plotted as a function of volume fraction of HDH powder. 


\subsubsection{Effect of milling and cold isostatic pressing on Armstrong Ti-6Al-4V}

In addition to the efforts of systematic ball-milling studies to improve tap densities and to minimize contamination problems, the effects of the milling treatment and the processing method on the density after the consolidation process were investigated. Figure 28 shows the effect of the ball-milling on the density of Armstrong Ti-6Al-4V powder before and after sintering at $1300{ }^{\circ} \mathrm{C}$ for $1 \mathrm{~h}$, for both uniaxial die pressing (Figure 28a) and cold-isostatic pressing (CIPing) (Figure 28b). The ball-milling showed a little effect on increasing the as-pressed densities in both die pressed and CIPed conditions, although the densities were quite far from full-consolidation state. However, after sintering at $1300{ }^{\circ} \mathrm{C}$ for $1 \mathrm{~h}$, the samples achieved more than $99 \%$ density, by a combination of the milling and the die pressing with more than $25 \mathrm{ksi}$. The CIPed samples after sintering also demonstrated the advantage of the milling to increase the densities. Note that the CIPing was also effective to increase the densities of the Ti-6Al-4V powder after sintering, even without milling.

(a) Die-Press and Sinter

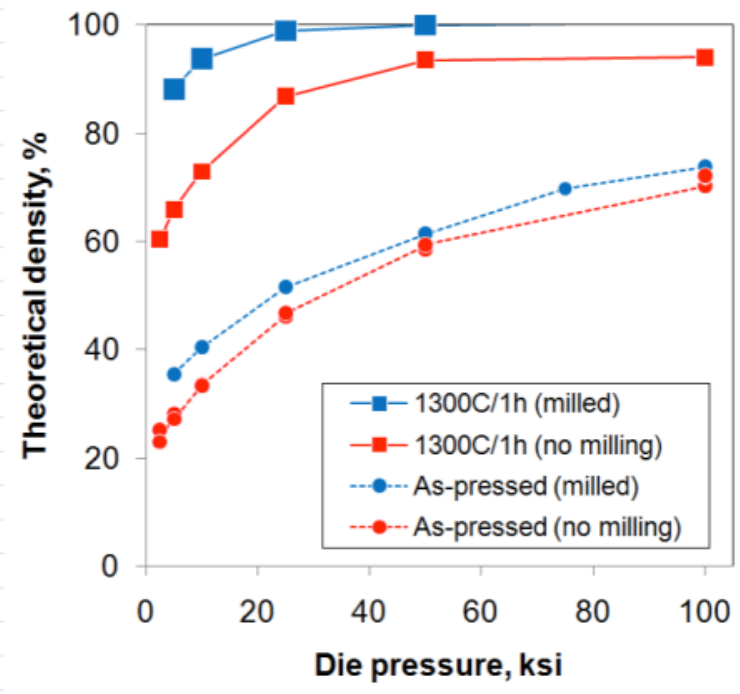

(b) Isostatic Press and Sinter

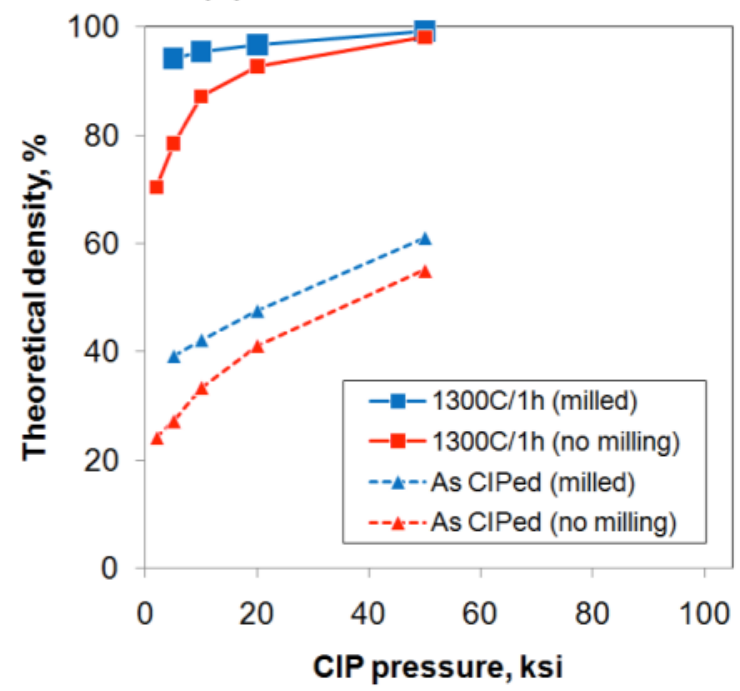

Figure 28. Theoretical densities of Armstrong Process Ti-6Al-4V powder before and after sintering at ${ }^{1300}{ }^{\circ} \mathrm{C}$ for $1 \mathrm{~h}$ plotted as a function of (a) die pressure and (b) cold-isostatic pressure.

\subsubsection{Effect of milling on powder chemistry, processibility, and properties of fully dense parts}

Several different milling processes of the as-received Armstrong Ti powders were conducted, in order to find the effect of milling of contamination, processing, density after process, and mechanical properties. The analyzed chemistry of as-received, milled, and hot-pressed or HIPed samples (process details are described in the tables) of Ti-6Al-4V and CP-Ti powders are summarized in Table 6 and Table 7, respectively. Note should be taken that oxygen levels listed for as-received powder are an estimate since results have varied within 300 parts per million from measurement to measurement. Milling the Armstrong powders with zirconia ball media in air, deionized water, ethanol, and Ar gas, resulted in various amounts of oxygen pick up as a contamination. In both powders, the milling in air and argon caused the highest oxygen levels. On the other hand, the milling in ethanol or water resulted in relatively lower oxygen pickup (or even smaller numbers than as-received in case of CPTi), indicating that these media would be preferred in the viewpoint of less contamination during milling. The results from the powder provided by ITP (proprietary milling process, in Ar gas) are also shown in the tables. They achieved minimum oxygen pickup during the milling process demonstrating the effect milling time, methodology, and media can have on final oxygen content. 
The oxygen levels increased a lot in the CP-Ti after HIPing process, although this was due to residual open porosity after sintering process (which resulted in not being fully consolidated after HIPing process), and it would be difficult to explain the nature of contamination mechanism from this data. On the other hand, the Ti-6Al-4V showed nearly $0.1 \mathrm{wt} \%$ oxygen pickup after HIPing, and they were fully consolidated by the process, so that it was obvious that the HIPing process was the source of the oxygen pickup. Vacuum hot-pressing resulted in much less oxygen pickup with around $0.04 \mathrm{wt} \%$ increments. There was no simple dependence on the type of milling media on the amount of oxygen pickup. Figure 29 shows the bar graphs of the data summarized in Table 6 and Table 7, for comparison purpose.

Table 6. Changes in oxygen contents during consolidation process of the ball-milled Armstrong Ti-6Al$4 \mathrm{~V}$ in different media

\begin{tabular}{rcccc}
\hline Milling media & As received & Milled & Hot pressed* & HIPed** \\
\hline Air, ball milled for 1h & 0.238 & 0.292 & 0.333 & 0.394 \\
Ar gas, ball milled for 1h & 0.238 & 0.293 & & 0.381 \\
Ethanol, ball milled for 1h & 0.238 & 0.281 & & 0.349 \\
Water, ball milled for 1h & 0.238 & 0.267 & & 0.331 \\
\hline \hline Ar (ITP milling, proprietary) & 0.238 & 0.235 & 0.277 & 0.293 \\
\hline
\end{tabular}

*HIPed: die pressed at $32.3 \mathrm{ksi}+$ sintered at $1300 \mathrm{C} / 1 \mathrm{~h}$ in a vacuum + HIPed at $950 \mathrm{C} / 15 \mathrm{ksi} / 4 \mathrm{~h}$ with $\mathrm{Ar}+$ mill annealed at $750 \mathrm{C} / 90 \mathrm{~min} / \mathrm{FC}$ in a vacuum.

$* *$ Hot pressed: hot pressed at $950 \mathrm{C} / 3.5 \mathrm{ksi} / 1 \mathrm{~h}+$ beta annealed at $1300 \mathrm{C} / 1 \mathrm{~h}+$ mill annealed at $750 \mathrm{C} / 90 \mathrm{~min} / \mathrm{FC}$ (whole process were in a vacuum).

Table 7. Changes in oxygen contents during consolidation process of the ball-milled Armstrong CP-Ti in different media

\begin{tabular}{rcccc}
\hline Milling media & As received & Milled & Hot pressed* & HIPed $^{* *}$ \\
\hline Air, ball milled for 1h & 0.278 & 0.320 & 0.360 & 0.529 \\
Ar gas, ball milled for 1h & 0.278 & 0.334 & & 0.513 \\
Ethanol, ball milled for 1h & 0.278 & 0.229 & & 0.446 \\
Water, ball milled for 1h & 0.278 & 0.258 & & 0.390 \\
\hline Ar (ITP milling, proprietary) & 0.261 & 0.265 & 0.325 & 0.380 \\
\hline
\end{tabular}

*HIPed: die pressed at $32.3 \mathrm{ksi}+$ sintered at $1300 \mathrm{C} / 1 \mathrm{~h}$ in a vacuum + HIPed at $950 \mathrm{C} / 15 \mathrm{ksi} / 4 \mathrm{~h}$ with $\mathrm{Ar}+$ mill annealed at $750 \mathrm{C} / 90 \mathrm{~min} / \mathrm{FC}$ in a vacuum.

$* *$ Hot pressed: hot pressed at $950 \mathrm{C} / 3.5 \mathrm{ksi} / 1 \mathrm{~h}+$ beta annealed at $1300 \mathrm{C} / 1 \mathrm{~h}+$ mill annealed at $750 \mathrm{C} / 90 \mathrm{~min} / \mathrm{FC}$ (whole process were in a vacuum).
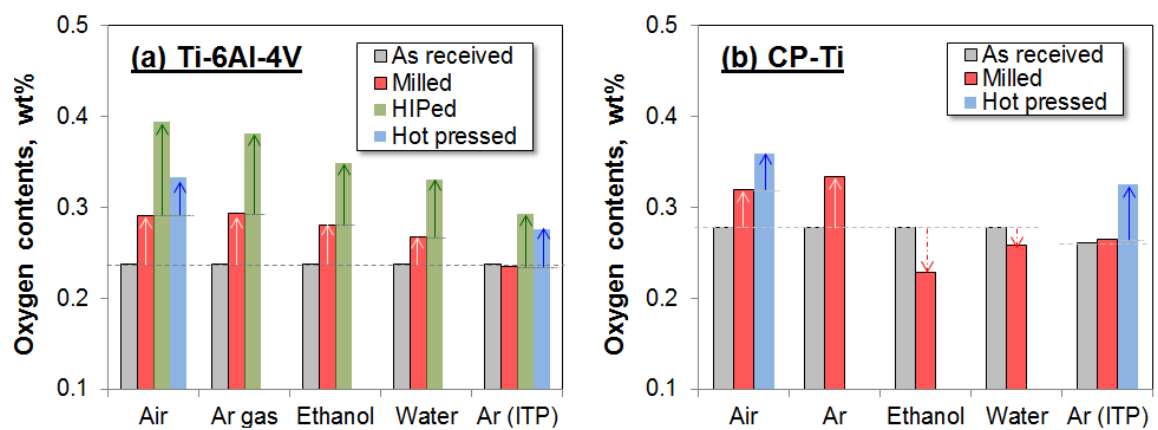

Figure 29. Changes in oxygen contents during consolidation process of Armstrong titanium powders milled in different types of media; (a) Ti-6Al-4V, and (b) CP-Ti.

Tensile properties of the fully consolidated Armstrong Ti-6Al-4V and CP-Ti powders are summarized in Table 8 and Table 9, respectively. All Ti-6Al-4V samples resulted in higher oxygen pickup than the ASTM Grade $5(<0.20 \mathrm{wt} \%)$, with the range from 0.277 to $0.394 \mathrm{wt} \%$. The tensile 
strength of all samples exceeded the minimum requirement of the ASTM standard. In general, strength increased and elongation decreased with increasing oxygen content as would be expected from the literature [1]. It was interesting that the samples milled in ethanol and water (and ITP powder) after HIPing met with the standard requirement of the elongation even with higher oxygen contents. There was no CP-Ti which was fully consolidated by HIPing, and only two samples were obtained by hot-pressing. The milled CP-Ti powder in air resulted in much lower elongation even meeting the oxygen levels of Grade 4. On the other hand, the ITP powder met the requirement of Grade 3.

Table 8. Tensile Properties and oxygen contents of fully consolidated Armstrong (Ti-64) milled in different types of media (tested at room temperature, ASTM-E8, averaged >3 tests)

\begin{tabular}{lrrrrrr}
\hline \multicolumn{1}{c}{ Samples } & Milling conditions & & YS, MPa & UTS, MPa & EL, \% & O, wt.\% \\
\hline & Air & 1051 & 1094 & 9.7 & 0.394 \\
Ar & 1013 & 1057 & 9.9 & 0.381 \\
Ti-64, HIPed* & Ethanol & 1037 & 1081 & 13.5 & 0.349 \\
& Deionized Water & 1036 & 1081 & 10.4 & 0.331 \\
\cline { 2 - 6 } & Ar (ITP milling) & 970 & 1017 & 14.3 & 0.293 \\
\hline Ti-64, Hot pressed** & Air & 1070 & 1117 & 8.0 & 0.333 \\
\cline { 2 - 6 } & Ar (ITP milling) & 996 & 1043 & 9.0 & 0.277 \\
\hline Ti-64, Standard & (ASTM Grade 5) & 828 & 895 & 10.0 & $<0.20$ \\
\hline
\end{tabular}

${ }^{* * * *}$ theoretical density: $\left.99.6-100 \%\right)$

Table 9. Tensile Properties and oxygen contents of fully consolidated Armstrong CP-Ti milled in different types of media (tested at room temperature, ASTM-E8, averaged $>3$ tests)

\begin{tabular}{lrrrrr}
\hline \multicolumn{1}{c}{ Samples } & \multicolumn{1}{c}{ Milling conditions } & YS, MPa & \multicolumn{1}{c}{ UTS, MPa } & EL, \% & \multicolumn{1}{c}{ O, wt \% } \\
\cline { 2 - 6 } CP-Ti, Hot pressed** & Air & 654 & 677 & 2.0 & 0.360 \\
\cline { 2 - 6 } & Ar (ITP milling) & 619 & 713 & 16.0 & 0.325 \\
\hline \multirow{2}{*}{ CP-Ti, Standard } & (ASTM Grade 2) & 275 & 345 & 20.0 & $<0.25$ \\
\cline { 2 - 6 } & (ASTM Grade 3) & 380 & 450 & 18.0 & $<0.35$ \\
\cline { 2 - 6 } & (ASTM Grade 4) & 483 & 550 & 15.0 & $<0.40$ \\
\hline
\end{tabular}

${ }^{* * * *}$ theoretical density: 99.6-100\%)

Surfaces of the as-received and milled Armstrong CP-Ti powder were analyzed using a Physical Electronic Scanning Auger Nanoprobe (model Phi 680). The spot analysis was made at several different locations, and obtained the chemistry profile of the points as a function of the surface depth by removing the constant thickness of surface layers using Ar-ion beam. A primary electron beam of $20 \mathrm{kV}$ and $10 \mathrm{nA}$ was focused to a $15 \mathrm{~nm}$ diameter spot at points of interest or rastered over larger areas to generate secondary electron images. Survey scans were made over a kinetic energy range from $30 \mathrm{eV}$ to $1900 \mathrm{eV}$ to determine what elements were present on the surface. Trace amounts of Si were detected $(<0.5$ at.\%) and very small amounts of $\mathrm{Na}(\sim 1-2$ at.\%) were detected on both the as received and ball milled samples. It is possible that trace amounts of $\mathrm{Fe}$ and $\mathrm{Zr}(<0.5$ at.\%) were also present, but the results were not conclusive. Sputter profiles were performed using a $3.5 \mathrm{kV}$ Ar-ion beam rastered over the sample in a $0.5 \times 0.5 \mathrm{~mm}$ pattern. The sputter rate used was $20 \mathrm{~nm} / \mathrm{min}$ and 15 second sputter cycles were used. After each sputter cycle, Auger signals of $\mathrm{C}, \mathrm{O}, \mathrm{Ti}, \mathrm{Si}$, and Na were monitored. Only the results for $\mathrm{O}$ and $\mathrm{C}$ are plotted in Figure 30 since the $\mathrm{Na}$ and Si signals were too low using reasonable data collection times. The obtained data clearly showed the oxygen was enriched near the surface after milling process. The oxygen profile of as-received powder in Figure 30a indicated the existence of the titanium oxide layer which forms on any titanium surface exposed to ambient environment. After milling, however, the oxygen profile near the surface in Figure 30b shifted slightly higher than that in the as-received powder. There was no difference in the oxygen levels below $60 \mathrm{~nm}$ depth, indicating that only the surface contamination could be the source of 
oxygen pickup during milling. Note that there was a spike of carbon level on the surface of milled powder. This could be due to the enriched ethanol on the surface, and it made the relative amount of oxygen much lower only at the surface.
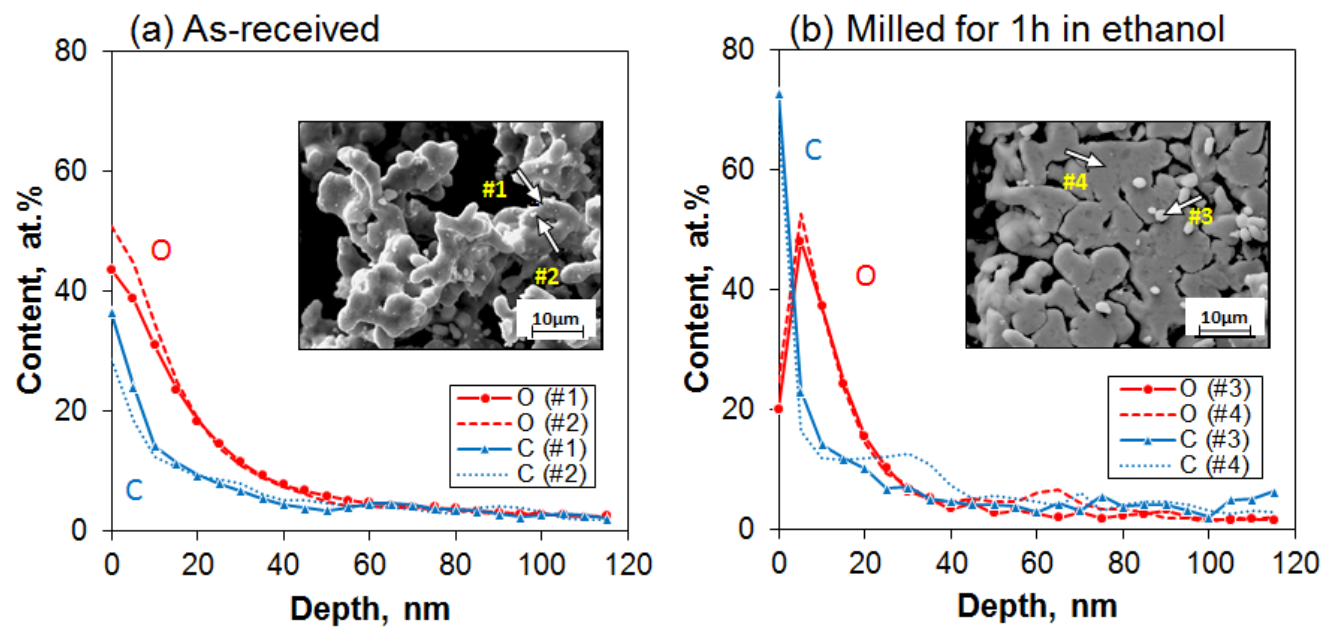

Figure 30. Composition profiles of $\mathrm{C}$ and $\mathrm{O}$ near the surface of Armstrong CP-Ti powder before and after ball-milling, measured by physical electronic scanning auger nanoprobe

Effect of long-term air exposure (simulating powder storage in air) on the contamination was evaluated by using ball-milled Armstrong CP-Ti powders in nitrogen, argon, and air. All ball-milling process for this experiment was made at ORNL. The milled powders were stored in a plastic bottle without any backfilled gas (filled by laboratory air) for up to 3 months. The chemical analysis results are plotted as a function of time, as shown in Figure 31, indicating that the oxygen contents increased in all powders in the early stage of exposure. However, the ball-milling in nitrogen gas resulted in almost no further oxygen pickup during long time exposure (between 2 weeks and 3 months). This could be due to the formation of protective nitride layer on the powder surface to prevent further oxidation at room temperature. On the other hand, milling in Ar or air resulted in the further oxygen pickup after 3 months. These results indicate that the milling process in nitrogen would be better than the others to store the powder for a long time after milling. The nitrogen pickup was also observed, especially in the powders milled in nitrogen and Ar, although the increment ranges were almost negligible since they were one order of magnitude smaller than the oxygen pickup.
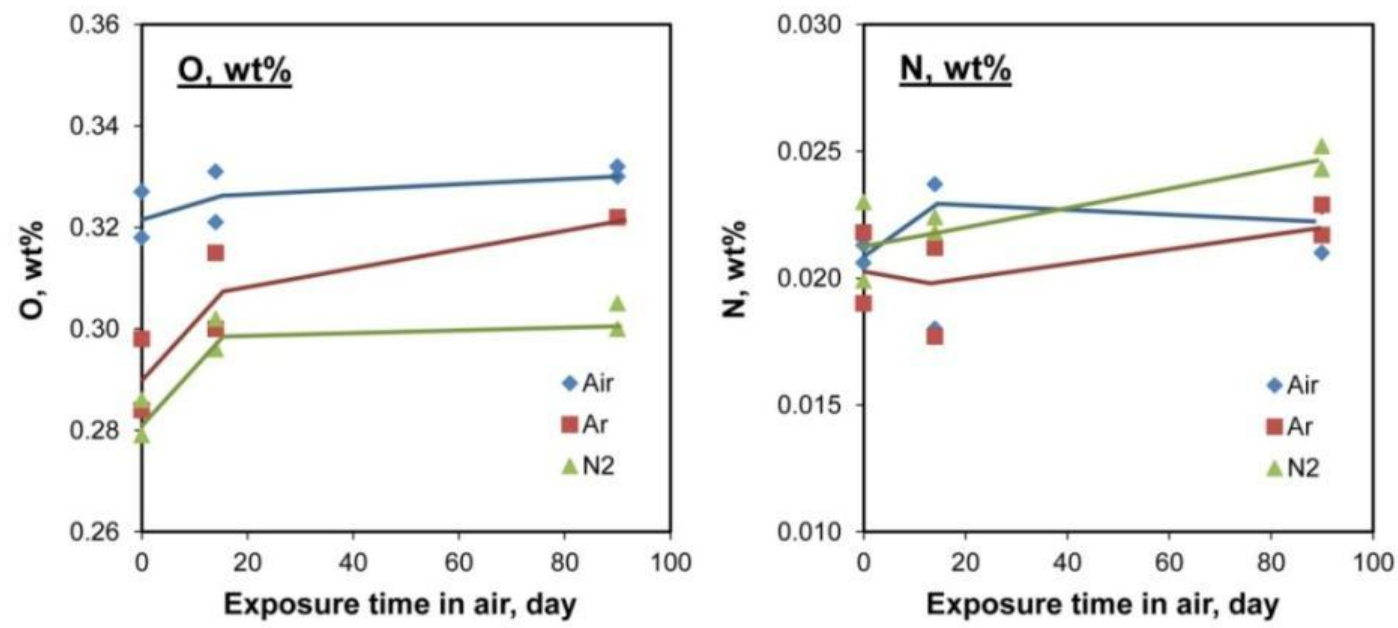

Figure 31. Effect of ball-milling atmosphere (air, Ar, and $\mathrm{N}_{2}$ ) of Armstrong CP-Ti powder on the chemistry after long time exposure in air; (a) oxygen and (b) nitrogen. 


\subsubsection{Vibratory mill}

A powder milling study by using a vibratory grinding mill (Figure 32) was conducted. The Armstrong Ti-6Al-4V powders were milled for several periods of time up to $60 \mathrm{~min}$ in argon cover gas with tungsten carbide media (from 1 to $30 \mathrm{~min}$ ) or steel media $(60 \mathrm{~min}$ ). The size distribution, tap density, and chemical composition as a function of milling time are summarized in Figure 33 and Figure 34 below.

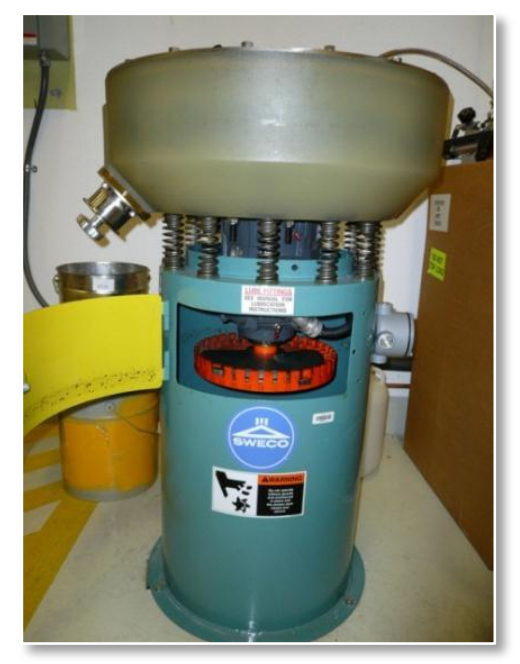

Figure 32. SWECO vibratory milling apparatus

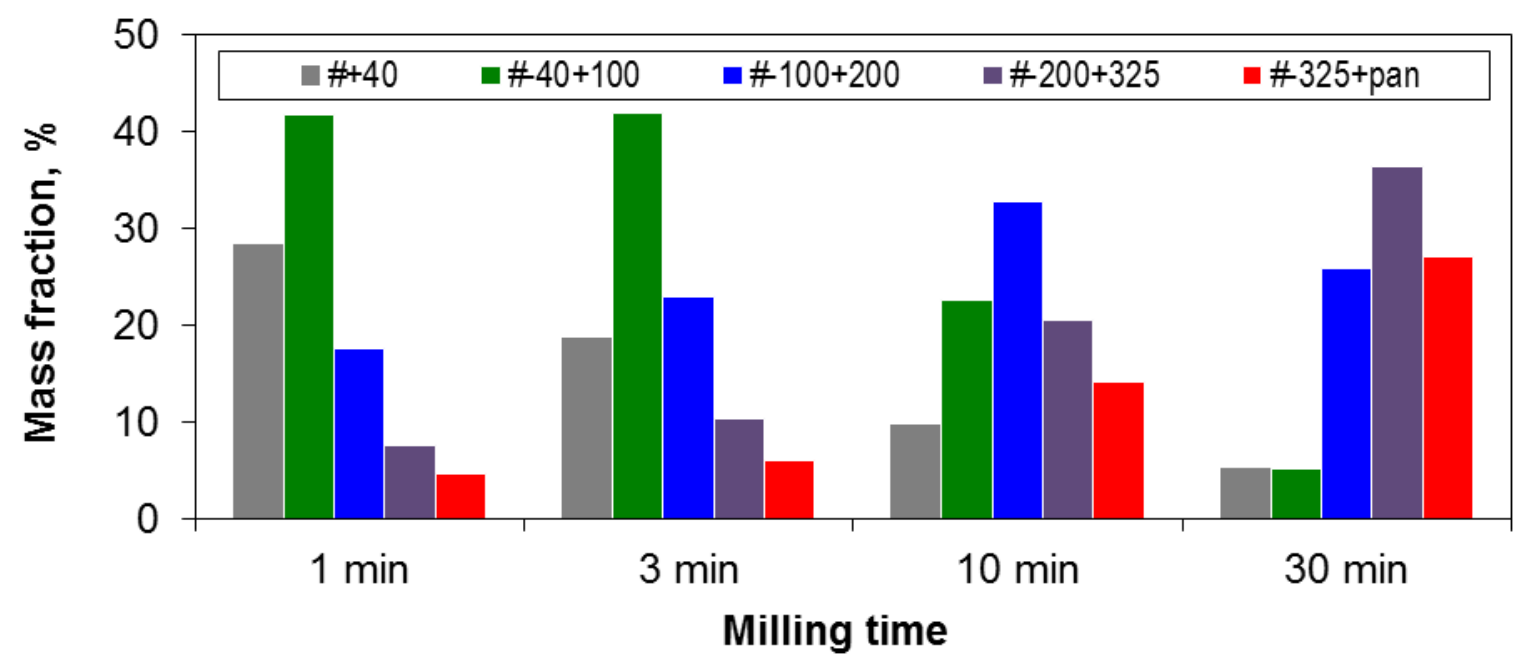

Figure 33. Size distribution of the vibratory milled ITP Ti-6Al-4V powders $(100 \mathrm{~g})$ with tungsten carbide media $(19 \mathrm{~kg})$ in Ar gas. Note that the sieve size of each mesh is as follows; $\# 40=442 \mu \mathrm{m}, \# 100=$ $152 \mu \mathrm{m}, \# 200=77 \mu \mathrm{m}$, and $\# 325=44 \mu \mathrm{m}$. 
(a) Tap density

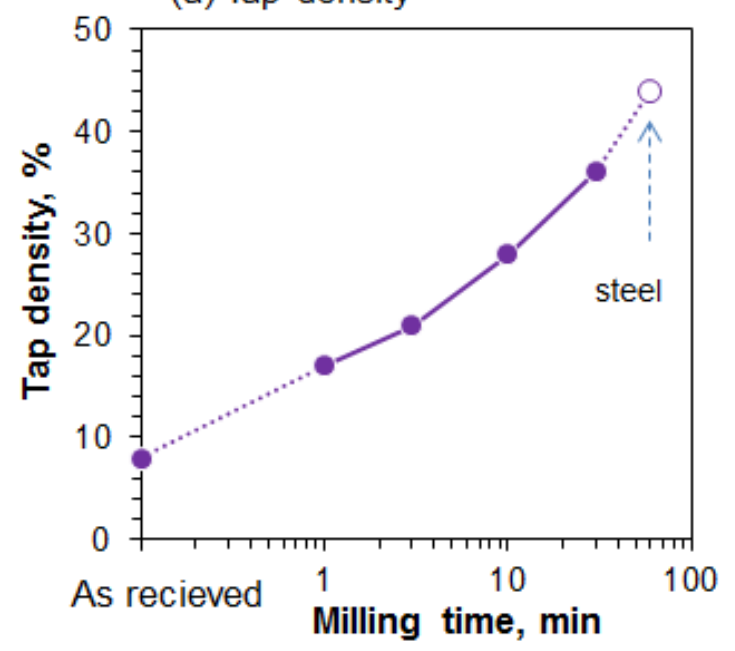

(b) Chemistory

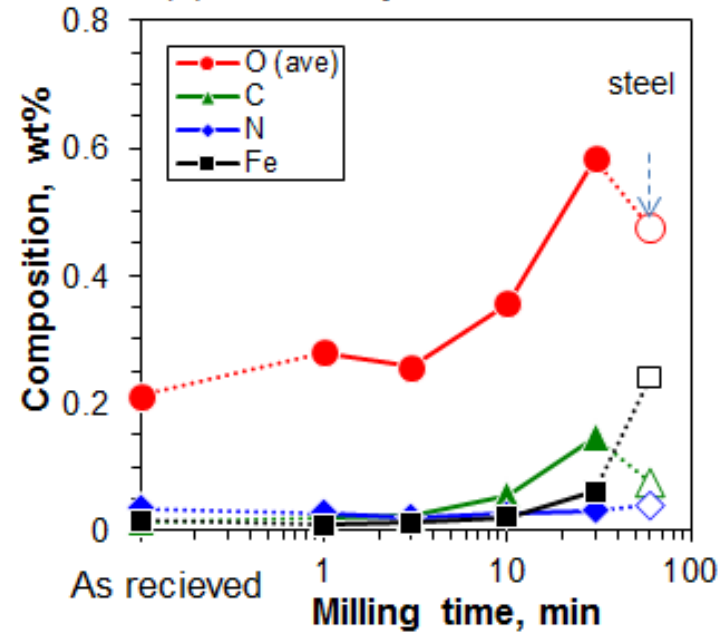

Figure 34. (a) Tap density of the vibratory milled ITP Ti-6AI-4V powders, and (b) chemical analysis results of the vibratory milled ITP Ti-6Al-4V powders plotted as a function of milling time.

As shown in the figures, increasing milling time resulted in increasing finer size powders and tap density, together with the levels of contamination elements such as oxygen, carbon, and iron. These are same trends as those found in conventional ball-milling with zirconia media as previously discussed, although the milling process becomes much faster than the ball-milling. This could be due to much higher ratio of media vs. powder than that of ball-milling, 190:1 vs. 22:1. It should be noted that milling with steel media resulted in high amount of Fe contamination.

Vibratory-milling of the Armstrong CP-Ti powder in deionized water with tungsten carbide media was also attempted (Figure 35). The 10min milling in water resulted in successfully refining the powder with almost negligible amount of oxygen pickup, as shown in Table 10. Although this process required long time drying process (nearly four days), this is one of the preferable milling processes with less amount of contamination.

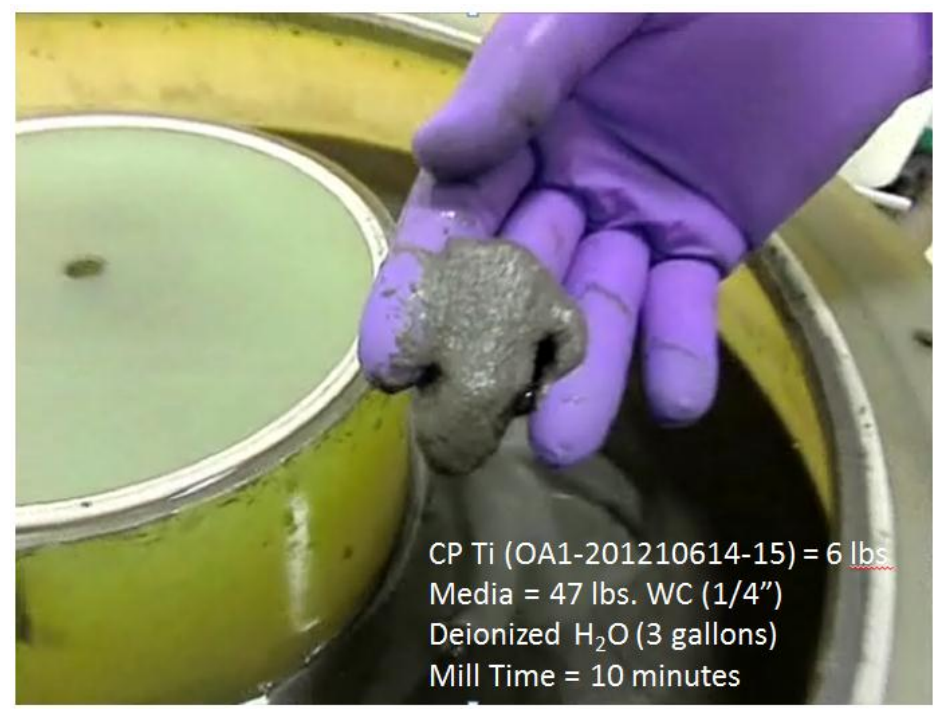

Figure 35. Slurry of vibratory-milled Armstrong CP-Ti powder with deionized water. 
Table 10. Analyzed oxygen and nitrogen contents of Armstrong CP-Ti powder before and after vibratory milling in deionized water (the powders after milling were dried in an air oven at $50^{\circ} \mathrm{C} / 72 \mathrm{~h}+$ $\left.80^{\circ} \mathrm{C} / 24 \mathrm{~h}\right)$

\begin{tabular}{ccc}
\hline & $\mathbf{O , w t} \mathbf{w}$ & $\mathbf{N}, \mathbf{w t} \%$ \\
\hline As received & $0.235 \pm 0.009$ & $0.025 \pm 0.002$ \\
\hline After milling & $0.239 \pm 0.007$ & $0.020 \pm 0.002$ \\
\hline
\end{tabular}

\subsubsection{Fabrication of Low Cost Ti and Ti Alloy Net Shape Press and Sintered Parts}

ORNL fabricated several net shape or near net shape components using the press and sinter technology. Both HDH and Armstrong powders were successfully pressed into shapes.

Figure 36 shows an example of the as-pressed coins by using two different powders. The Armstrong powder provided clearer detail in the as-pressed condition. The HDH powder holds shape, but will begin to crumble and wear if handled for extended periods of time, whereas the Armstrong powder does not degrade with handling. Significant shrinkage is observed in the Armstrong Ti-6Al-4V samples as compared to the HDH samples; this is partially related to the low as-pressed density, but also indicative of the improved sinterability of the Armstrong Powder as pointed out in section 3.11. A die was constructed for a near net shape Lockheed Martin component (Figure 37). Multiple samples were successfully pressed into green bodies. The powder metallurgy approach indicates the potential to reduce the buy to fly ratio from 33:1 down to 4:1. Further refinement of the die would result in further material savings, and increase the potential to reduce the buy to fly ratio. The full consolidation of the samples has successfully been achieved after sintering.

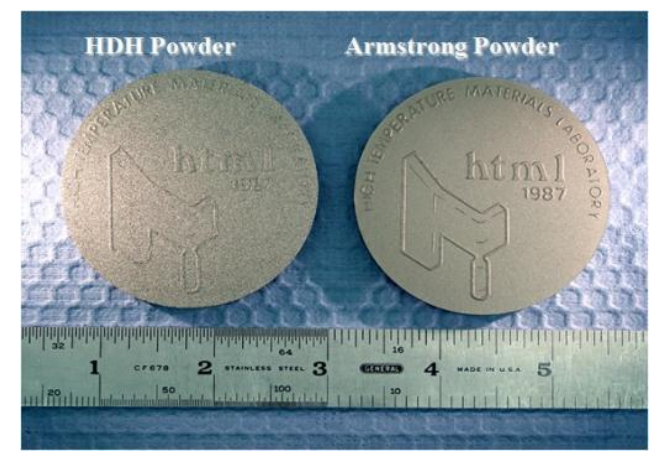

Figure 36. As-pressed net shape discs of $\mathrm{HDH}$ powder (left) and Armstrong Powder (right).

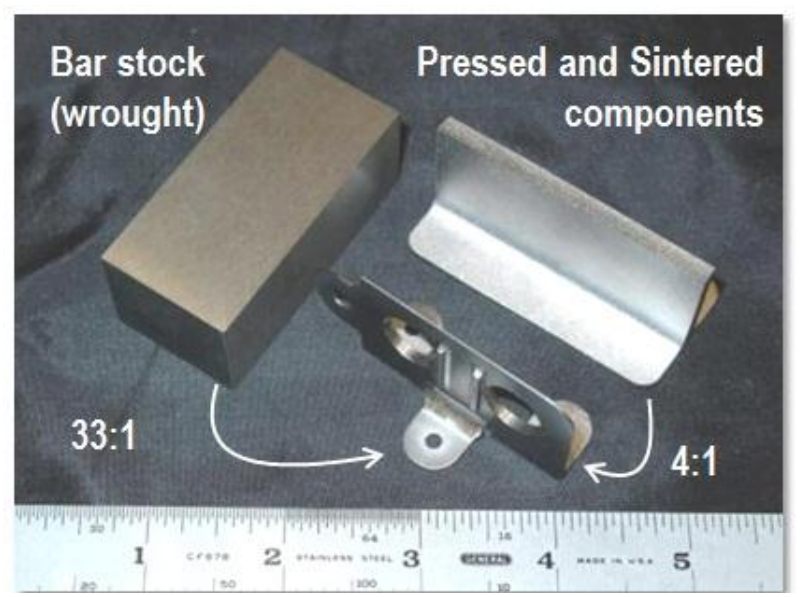

Figure 37. Examples of pressed and sintered Armstrong powderTi-6Al-4V components. A component blank is shown at top right and two components machined from blanks are pictured. 
Figure 38 shows an example of Ti-6Al-4V cylinders which was isopressed on a mandrel, followed by sintering at $1300{ }^{\circ} \mathrm{C}$ in a high vacuum. The top of the sintered cylinder remained perfectly circular; however the bottom showed distortion due to mechanical drag as the cylinder shrank during the sintering process. Modifications to the cylinder supports in the furnace and possibly to the sintering cycle will be needed to eliminate the distortion.

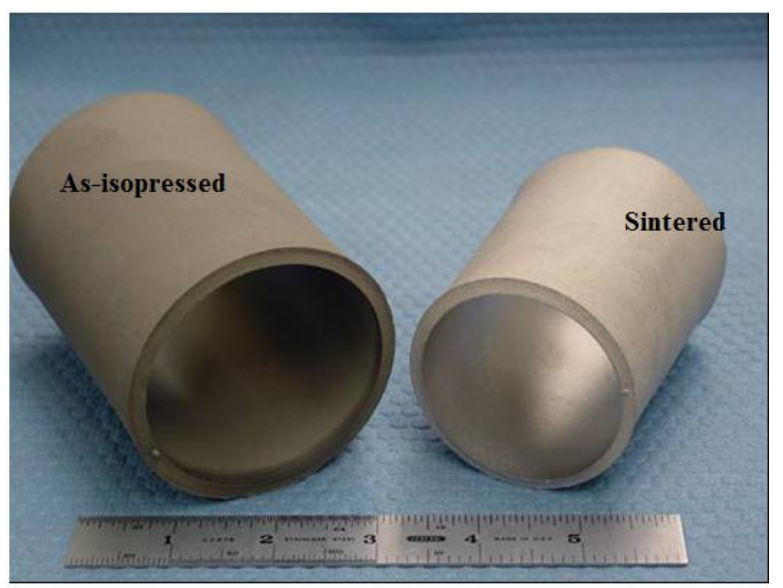

Figure 38. Examples of pressed and sintered Armstrong Ti-6Al-4V components. Cylindrical isopressing on a mandril and sintering at ${ }^{1300}{ }^{\circ} \mathrm{C}$ have been successfully performed.

Electromagnetic (EM) tube compaction was successfully conducted at the Ohio State University to make direct tube-shape fabrication of both Armstrong and HDH CP-Ti powders. This method realizes high speed deformation (= high strain rate compaction) of powder samples by releasing a large stored electric energy into electromagnetic actuators. The theoretical density of as-received tubes was measured after removing the outer $\mathrm{Cu}$ tubes, as shown in Figure 39. The density of Armstrong CP-Ti tube achieved 82.5\% TD after sintering, and the Armstrong Ti-6Al-4V tube successfully achieved full consolidation (more than 99.8\% TD). The details are discussed in section 3.2.3.

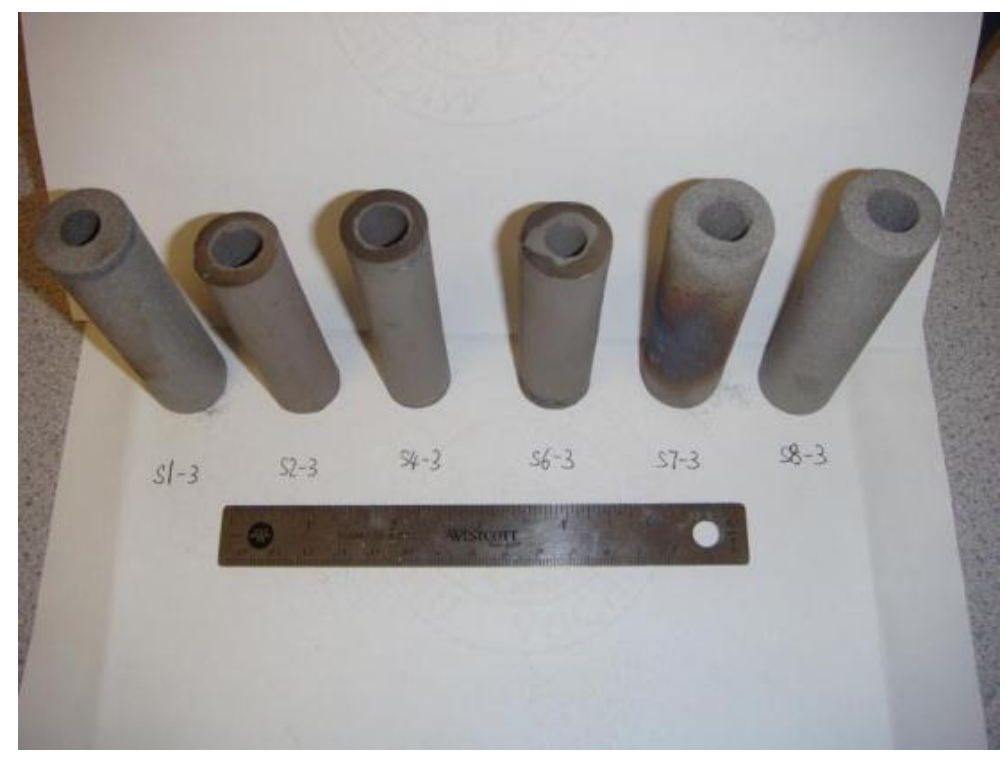

Figure 39. As-received tubes after removing the outer $\mathrm{Cu}$ tubes.

\subsubsection{Characterization and Evaluation of Press and Sintered Low Cost Ti and Ti Alloy}


Understanding the shape, distribution, and reason for porosity in consolidated powder is important in order to develop techniques to minimize porosity and its detrimental effects on mechanical properties. Like a chain's strength being determined by its weakest link, most bulk properties are determined by its local defects; this is very true for consolidated powder. By optimizing the density and reducing the amount of large pores, subsequent sintering and elevated temperature consolidation practices are more effective in consolidating the material through diffusion. In this section, the density distributions of Ti-6Al-4V specimens are examined by both destructive means as well as nondestructive methods.

\subsubsection{Density distribution of as-pressed Ti-6Al-4V}

The green density distribution of uni-axially die-pressed Ti-6Al-4V powder was evaluated experimentally. The overall green density was $57.5 \%$ and $63.3 \%$ for the Armstrong Ti-6Al-4V powders pressed at $345 \mathrm{MPa}(50 \mathrm{ksi})$ and $517 \mathrm{MPa}(75 \mathrm{ksi})$ with aspect ratio 2, respectively. The samples were then sliced into 4 pieces and the density of each piece was measured, as shown in Figure 40. It is obvious that the density of the middle two pieces is lower than the top or bottom ones, and the higher pressure led to the larger density distribution. For the sample pressed at 345 $\mathrm{MPa}$, the average density difference between the middle two pieces and the top+bottom pieces is $5.5 \%$; while for the sample pressed at $517 \mathrm{MPa}$, the value is $6.3 \%$. For a certain aspect ratio, the overall, maximum and minimum densities in each sample increases with the applied die-pressure. The axial density distribution is consistent with the Finite Element result shown in section 3.1.2. In addition, two samples were cut into concentric rings for evaluating the radial density difference (Figure 40b). The density in the radial direction is the same. This result is expected since the reduction of the powder bed height during the pressing process is uniform along the radial direction.

(a)

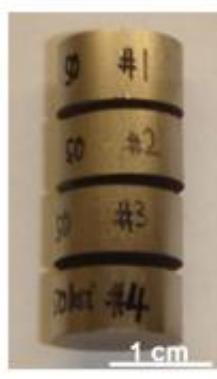

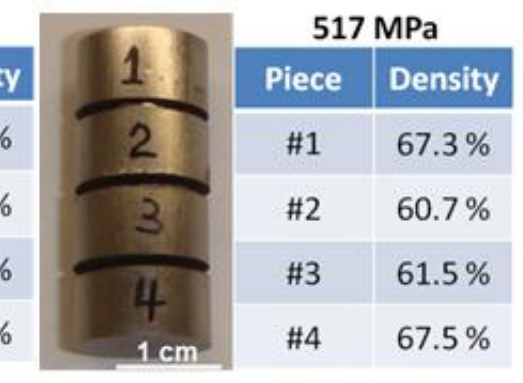

(b)

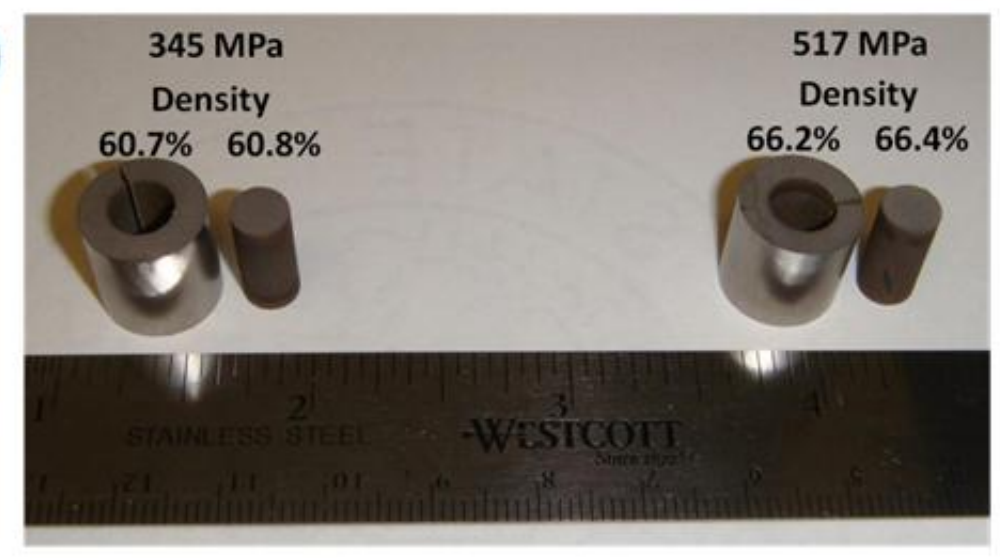

Figure 40. Green density distribution in Armstrong Ti-6Al-4V samples pressed at $345 \mathrm{MPa}$ and $517 \mathrm{MPa}$. (a) axial density of samples with aspect ratio 2, and (b) radial density of samples with aspect ratio 1. 


\subsubsection{Characterization of powder compressibility}

The relationship between the green density and aspect ratio of the die-pressed samples has been discussed in terms of the die-wall friction. Figure 41 illustrates the effect of aspect ratio on green density at six different applied die pressures and the detailed density data are included in Table 11. In the table, $|\mathrm{a}|$ value, is the slope of the linear curve which corresponds to an indication of the extent of die-wall friction. If there is no friction, |a| should be zero. The Y-intercept (b value) is the relative density when the aspect ratio equals zero and can be used to estimate the green density when there is no friction. Figure 41 can also be used to estimate the green density of samples with different aspect ratios as a function of compaction pressures. Die-wall friction is related to the radial wall stress transmitted by powders through axial stress, so it is a material-dependent value and difficult to measure experimentally.

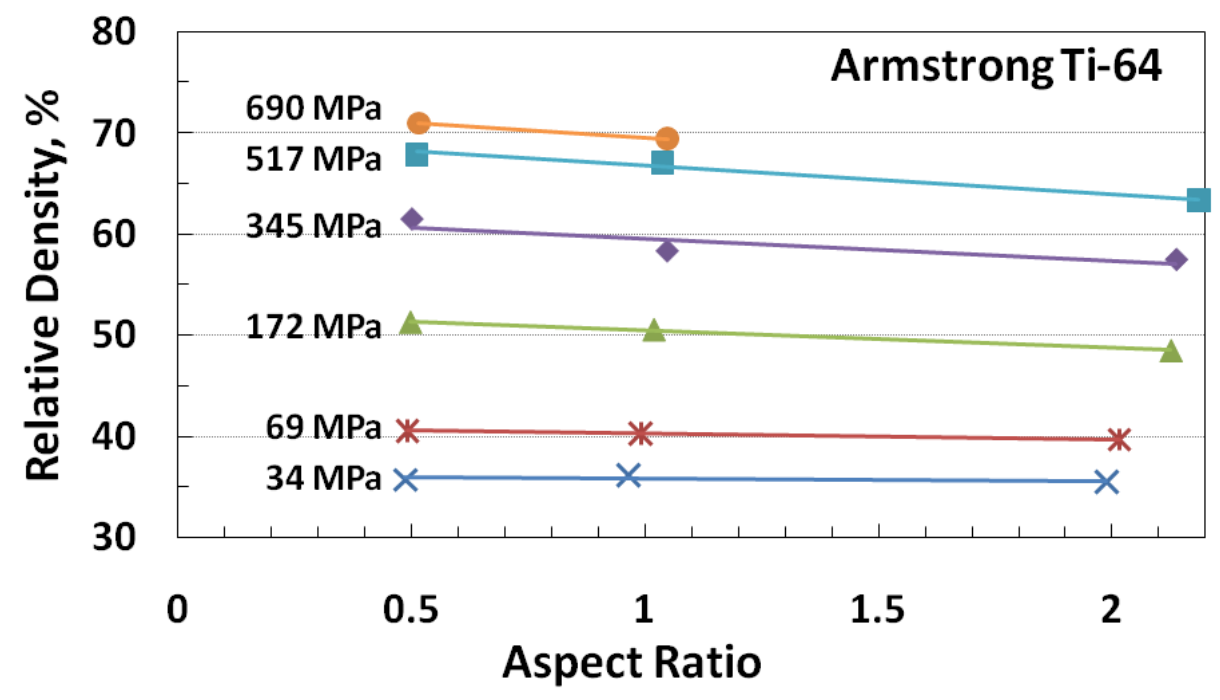

Figure 41. Green density versus aspect ratio plot for the Armstrong Ti-6Al-4V samples pressed at 6 different pressures.

Table 11. Green density data and linear regression parameters for Armstrong Ti-64 samples

\begin{tabular}{|c|c|c|c|c|c|}
\hline \multirow{3}{*}{ Pressure, $\mathrm{MPa}$} & \multicolumn{3}{|c|}{ Relative Density, \% } & \multirow{2}{*}{\multicolumn{2}{|c|}{ 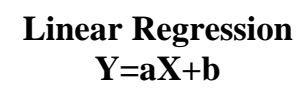 }} \\
\hline & \multicolumn{3}{|c|}{ Nominal Sample Aspect Ratio } & & \\
\hline & 0.5 & 1 & 2 & $|\mathrm{a}|$ & $\mathrm{b}$ \\
\hline 34 & 35.7 & 36.2 & 35.5 & 0.2 & 36.1 \\
\hline 69 & 40.6 & 40.3 & 39.7 & 0.6 & 40.9 \\
\hline 172 & 51.3 & 50.6 & 48.5 & 1.8 & 52.3 \\
\hline 345 & 61.5 & 58.3 & 57.5 & 2.2 & 61.8 \\
\hline 517 & 67.9 & 67.1 & 63.3 & 2.8 & 69.6 \\
\hline 690 & 71.0 & 69.4 & N/A & 2.9 & 72.5 \\
\hline
\end{tabular}


The density-pressure data for the Armstrong Ti-64 powders were analyzed using the Panelli equation [36];

$$
\ln \left(\frac{1}{1-D}\right)=A \sqrt{P}+B
$$

in which $D$ is the relative density of the compacted material and $\mathrm{P}$ is the applied die pressure. $A$ is a constant which represents the compressibility (powder's ability to densify by plastic deformation).

$$
B=\ln \left(\frac{1}{1-D_{0}}\right)
$$

B is the Y-intercept, where D0 represents the loose powder density (tap density). Figure 42 shows the curve fitting for the milled powder pressed to 3 different aspect ratios. The linear correlation coefficient was greater than 0.99 in all cases, indicating a good agreement between Equation (1) and the experimental data. The increased die-wall friction due to the higher aspect ratio reduced the pressure transferred to the powder bed and caused the decrease of apparent compressibility of the Armstrong Ti-64 powder. The three curves converged at the lower pressure end, indicating the decrease of friction at a lower pressure. The predicted tap density (D0) was 5.3\% for the as-received powder and 17.9 20.6\% for the milled powder, which were all lower than the experimentally measured tap density (6 8\% for as-received powder and 30 32\% for the milled powder). The discrepancy indicates the limitation of the Panelli equation at low pressures (Stages I and II) so extrapolation into this area is not accurate due to the different densification mechanisms. However, the density prediction within the studied pressure range (Stage III) shows good agreement. The A value of the as-received powder is larger than the milled powder, indicating its less compressibility. This could be due to the complicated morphology of the as-received powder, which increased the deformation resistance.

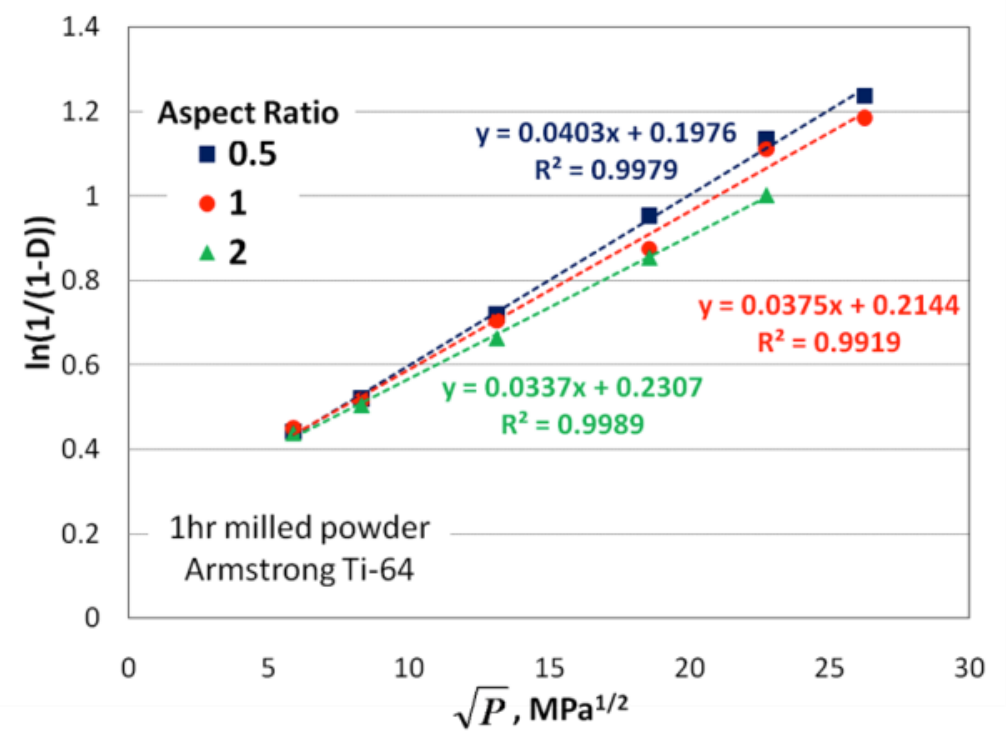

Figure 42. Green density versus die-pressure fitted to the Panelli equation for the Armstrong Ti6Al-4V powder (milled for $1 \mathrm{~h})$. 


\subsubsection{X-ray high-resolution tomography}

Characterization of the defects in compressed and consolidated powders by using X-ray tomography technique was conducted with a support from Dr. Richard Everett and Dr. Ashraf Imam of the Naval Research Laboratory (NRL). The high-resolution tomography at NRL is unique to their lab. In addition, some materials such as powders and sliced sample portions were examined with SEM for a better understanding of the images received using the tomography analysis.

The CP-Ti powder used for the study is Armstrong CP-Ti lot 0508-1. Samples listed in Table 12 were sent to NRL. Note that samples were either pressed or were pressed and then isostatically pressed at room temperature. Some of the samples were then sintered in a tungsten element furnace at either 1200 or $1300{ }^{\circ} \mathrm{C}$ for $1 \mathrm{~h}$ in a $10-5$ torr vacuum. The relative densities of the samples were measured using the Archimedes principle with 200 proof ethanol as the fluid medium. The measurements show that under certain conditions, which includes a sintering step, the porosity of the samples can changed from open to closed. This is a property that can be useful for later processing, such as for can-less HIPing (hot isostatic pressing).

Table 12. Relative densities of Armstrong CP-Ti Lot 0508-1 samples processed for NRL

\begin{tabular}{|c|c|c|c|}
\hline Sample Description & $\begin{array}{c}\text { Density, } \\
\text { g/cc }\end{array}$ & $\begin{array}{l}\text { Theoretical } \\
\text { Density, \% }\end{array}$ & $\begin{array}{c}\text { Open } \\
\text { Porosity }\end{array}$ \\
\hline \multicolumn{4}{|l|}{ As-received Powder } \\
\hline $50 \mathrm{ksi}$ uni axial press & 3.43 & 76.16 & 23.36 \\
\hline 50 ksi uni-axial press and sintered @ 1200 c 1 hr. & 3.86 & 85.73 & 1.68 \\
\hline 50 ksi uni-axial press and sintered @ 1300 c 1 hr. & 3.92 & 87.02 & 2.73 \\
\hline 10 ksi uni-axial and CIP @ 50 ksi & 3.41 & 75.79 & 23.41 \\
\hline $10 \mathrm{ksi}$ uni-axial press CIP $50 \mathrm{ksi}, 1200 \mathrm{c} 1 \mathrm{hr}$. & 3.84 & 85.25 & 0.24 \\
\hline 10 ksi uni-axial CIP 50 ksi Sintered @ 1300c 1 hr. & 3.89 & 86.54 & 0.00 \\
\hline \multicolumn{4}{|l|}{ Milled Powder } \\
\hline 50 ksi uni-axial press & 3.34 & 74.29 & 24.68 \\
\hline 50 ksi uni-axial press, sintered @ 1200c 1 hr. & 3.82 & 84.93 & 1.92 \\
\hline 50 ksi uni-axial press sintered @ 1300 c 1 hr. & 3.94 & 87.58 & 0.25 \\
\hline $10 \mathrm{ksi}$ uni-axial press and CIP $50 \mathrm{ksi}$ & 3.30 & 73.39 & 26.30 \\
\hline 10 ksi uni-axial CIP 50 ksi Sintered @ 1200 c 1 hr. & 3.90 & 86.71 & 0.24 \\
\hline 10 ksi uni-axial CIP 50 ksi Sintered @ 1300 c 1 hr. & 4.02 & 89.41 & 0.00 \\
\hline
\end{tabular}

Characterization of as-pressed CP-Ti Armstrong powder (no milling) was evaluated by using an Xray tomography which allows non-destructive observation of the internal defects. Obtained results indicated that localized low density/high porosity areas $(\sim 0.5 \mathrm{~mm} \times 2.8 \mathrm{~mm})$ and spherical inclusions ( 3 or 4 per volume at $\sim 50$ microns) were observed (Figure 43 ). The former is consistent with previous cross-sectional microscopy observations in press and sintered parts from as-received Armstrong powder shown in Figure 8; extended pressing and/or milling minimize the low density areas. The latter could be as a result of contamination during handling or pressing of the titanium sample. The particle has not yet been identified, although it could be a steel particle contained into the original powder mistakenly. 


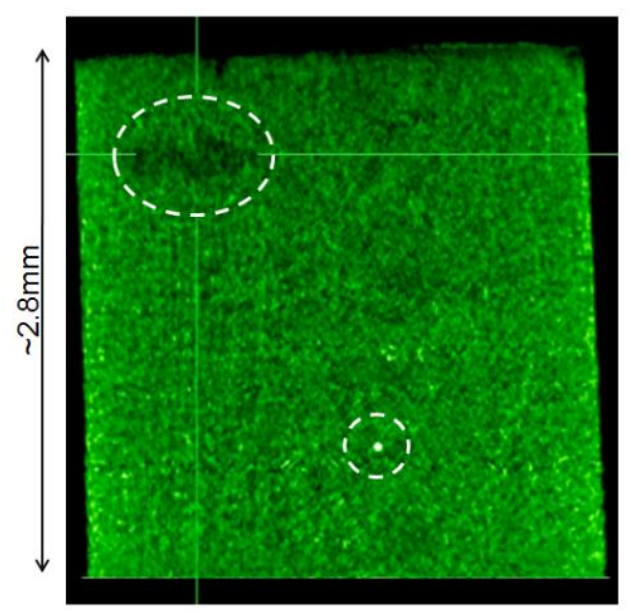

Figure 43. An image of X-ray tomography of as-pressed CP-Ti Armstrong powder (no milling) at $50 \mathrm{ksi}$, showing dense porosity area near top and an inclusion near bottom.

SEM-EDS analysis of cross-sectional as-pressed Armstrong CP-Ti sample, operated at ORNL, (Figure 44) revealed that there was a similar size of large porosity agglomerates to that observed in the X-ray tomography in Figure 43. The analysis also revealed that there was sodium and oxygen enriched particle which was also similar size to the low density area. Since the reduced process of Armstrong powder used sodium, the residual sodium could be observed in the powder. This is one of the important contaminants which need to be eliminated.
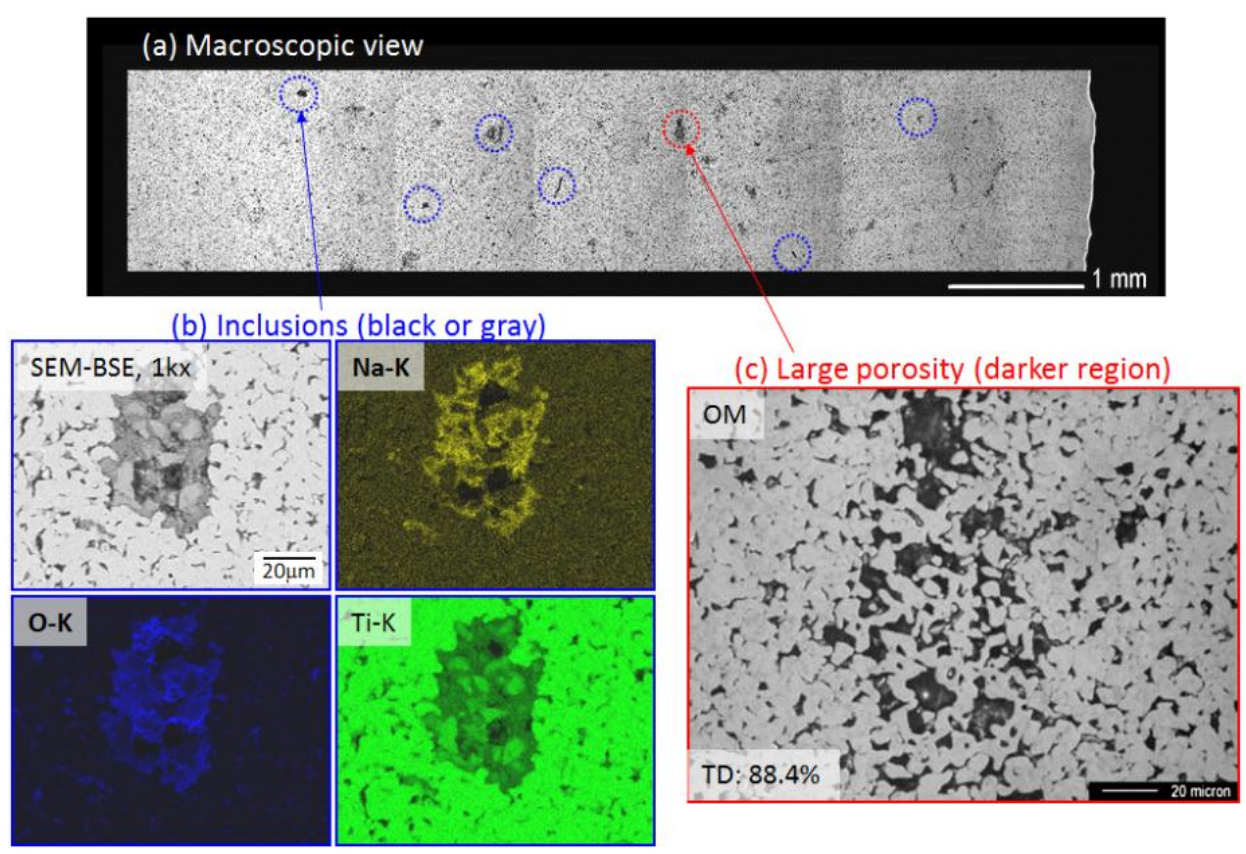

Figure 44. Cross-sectional view of the Armstrong CP-Ti pressed at $100 \mathrm{ksi}$; (a) OM macroscopic view (same as Fig. 8a), (b) SEM image and EDS map analysis results, and (c) OM microstructure of large porosity agglomerates.

\subsubsection{Stamping of Thin Gauge Titanium for Heat Exchangers}

Commercially-pure titanium powder was roll compacted into thin gauge sections by AMETEK. A special die was constructed at ORNL to press the herringbone structure of the heat exchanger into the powder derived sheet during the sinter process. This process would eliminate cold pressing of the 
sheet in a separate process step, and retain the high ductility of extremely low oxygen CP-Ti sheet required for forming. Several attempts were made to directly press the part into shape before sintering, and during sintering. Roll compacted sheet as thin as 0.007 ' has been pressed into the herringbone structure, as shown in Figure 45. Early attempts resulted in cracking within areas of deep drawing. A couple samples had minimal cracking after adjusting pressing parameters. A similar attempt was made at OSU by using electro-magnetic actuator with high strain rate. The details are summarized in section 3.2.3.

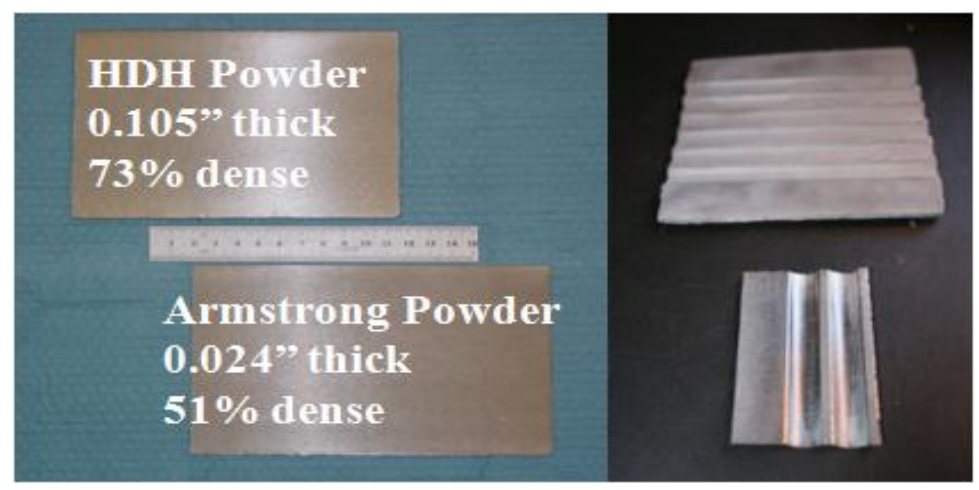

Figure 45. Image of the as-roll compacted HDH (top) and Armstrong (bottom) powders (left), and pressed/sintered formed sheet with the herringbone structure from the respective powders (right).

\subsection{TASK 2: FULL CONSOLIDATION OF PRESS AND SINTERED PLATES}

In this task, the research team explored multiple methods to achieve full consolidation of the powders. This included using technologies such as pneumatic isostatic forging (PIF) or hot isostatic pressing (HIP) where components are held at elevated temperature and pressure over a given time. The pressures are higher for PIF, but the time is much lower. The pressure is lower for hot isostatic pressing, but is performed over hours. Table 13 contains the processes evaluated in task 2 , and the optimum scenario achieved. By evaluating multiple technologies, industry has options as to the best method to obtain fully dense components with the desired microstructures and properties while weighing process costs. The preliminary goal was to evaluate if full consolidation would be met using these technologies. The second goal is to establish if properties are sufficient or comparable to wrought material. In addition, both canned and press and sintered materials without cans were evaluated. Canning can be expensive for small components and can limit the complexity of the finished part. In contrast, large, simple-geometry components may be able to forgo press and sintering, and minimally processed powder may be placed directly in the can, reducing process steps. The final manufacturing practice is determined by the size, the complexity, and the required properties of the component. In addition to the two isostatic technologies, high strain rate, or adiabatic, compaction was evaluated to determine if nontraditional strain rates could increase pressed and sintered densities sufficiently to eliminate secondary processes of elevated temperature and pressure. 
Table 13. List of powder materials, processes conducted, and optimum process for full consolidation in Section 3.2.

\begin{tabular}{|c|c|c|c|}
\hline Task & Materials & Process & Optimum process \\
\hline \multirow{5}{*}{$\begin{array}{l}\text { Task 2: } \\
\text { Full } \\
\text { consolidation }\end{array}$} & $\begin{array}{l}\text { CP-Ti Armstrong, } \\
\text { 2nd consolidation }\end{array}$ & $\begin{array}{l}\text { Sections 3.2.1. } \\
\text { Press + Sinter + PIF (condition: proprietary) } \\
\text { Press + Sinter + HIP }(960 \mathrm{C} / 15 \mathrm{ksi} / 4 \mathrm{~h})\end{array}$ & $\begin{array}{l}\text { Almost full consolidation } \\
(\mathbf{9 9 . 6 - 9 9 . 8 \% ~ T D )}\end{array}$ \\
\hline & $\begin{array}{l}\text { Ti-6Al-4V } \\
\text { Armstrong, } \\
\text { 2nd consolidation }\end{array}$ & $\begin{array}{l}\text { Sections 3.2.1. } \\
\text { Press + Sinter + PIF (condition: proprietary) } \\
\text { Press + Sinter + HIP (960C/15ksi } / 4 \mathrm{~h}) \\
\text { Press + Can + HIP }(960 \mathrm{C} / 15 \mathrm{ksi} / 4 \mathrm{~h}) \\
\end{array}$ & $\begin{array}{l}\text { Almost full consolidation } \\
(\mathbf{9 9 . 8 - 1 0 0 \%} \text { TD) }\end{array}$ \\
\hline & $\begin{array}{l}\text { Ti- } 6 \text { Al- } 4 \mathrm{~V} \mathrm{HDH} \text {, } \\
\text { 2nd consolidation }\end{array}$ & $\begin{array}{l}\text { Sections 3.2.1. } \\
\text { Press + Sinter + Can + HIP (960C/15ksi/4h) } \\
\text { Press + Can + HIP (960C/15ksi/4h) }\end{array}$ & $\begin{array}{l}\text { Full consolidation }(\mathbf{1 0 0 \%} \\
\text { TD) }\end{array}$ \\
\hline & $\begin{array}{l}\text { CP-Ti Armstrong, } \\
\text { High strain rate } \\
\text { compaction }\end{array}$ & $\begin{array}{l}\text { Sections 3.2.3. } \\
\text { EM Direct tube compaction }(6-12 \mathrm{~kJ}) \\
\text { EM Direct tube compaction }(6-12 \mathrm{~kJ})+\text { Sinter }(1300 \mathrm{C} / 1 \mathrm{~h}) \\
\text { Roll compaction + Uni-axial EM compaction }(2.6-5.7 \mathrm{~kJ}) \\
\end{array}$ & $\begin{array}{l}\text { Roll-compaction + Uni- } \\
\text { axial EM compaction } \\
\text { achieved almost full } \\
\text { consolidation }(\mathbf{9 9 . 7 \%} \text { TD })\end{array}$ \\
\hline & $\begin{array}{l}\text { Ti-6Al-4V } \\
\text { Armstrong, } \\
\text { High strain rate } \\
\text { compaction }\end{array}$ & $\begin{array}{l}\text { Section } 3.2 .3 . \\
\text { EM Direct tube compaction }(6-12 \mathrm{~kJ}) \\
\text { EM Direct tube compaction }(6-12 \mathrm{~kJ})+\text { Sinter }(1300 \mathrm{C} / 1 \mathrm{~h}) \\
\text { Roll compaction + Uni-axial EM compaction }(2.6-5.7 \mathrm{~kJ})\end{array}$ & $\begin{array}{l}\text { Direct tube compaction }+ \\
\text { Sinter achieved full } \\
\text { consolidation }(\mathbf{1 0 0 \%} \mathbf{T D})\end{array}$ \\
\hline
\end{tabular}

\subsubsection{Pneumatic Isostatic Forging / Hot Isostatic Pressing of Press and Sintered Plates}

Consolidation of press and sinter samples by pneumatic isostatic forging (PIFing) was performed on commercially-pure titanium Armstrong powder samples. The powder was produced in International Titanium Powder's small R\&D loop, and had higher than specification interstitial oxygen levels. ORNL used the powder to develop the consolidation processing methodology while waiting for onspecification powder. Cylindrical samples were made from isopressing the powder at 50ksi, room temperature. The samples were then sintered at $1300^{\circ} \mathrm{C}$ for one hour. Press and sintered densities were as low as $83.1 \%$ of theoretical density. Since the pre-press and sinter process closed the open porosity of the samples, they were PIFed without canning (canless PIFing). The measured density before and after PIFing are shown in Table 14. All samples achieved full density (above 99\% dense). It is interesting to note that Armstrong samples having relatively low starting densities, such as CP$\mathrm{Ti}$, could be PIFed to nearly full dense (more than 99\%) without canning, as long as no open (pores not connected) porosity was present prior to the PIFing process; this is contrary to conventional wisdom. Historically, components press and sintered using conventional powders had to be at least 93\% of theoretical density in order to eliminate interconnected porosity, and allow full consolidation.

Table 14. Results of can-less PIFing of Armstrong-process titanium powders that were pressed and sintered to achieve closed porosity

\begin{tabular}{ccc}
\hline \multirow{2}{*}{ Material } & \multicolumn{2}{c}{ Theoretical Density, \% } \\
\cline { 2 - 3 } & $\begin{array}{c}\text { Pressed \& } \\
\text { Sintered }\end{array}$ & PIFed \\
\hline CP-Ti & 79.7 & 99.8 \\
\hline CP-Ti & 85.1 & 99.9 \\
\hline Ti-6Al-4V & 92.7 & 100 \\
\hline Ti-6Al-4V & 95.2 & 100 \\
\hline Ti-6Al-4V & 97.8 & 100 \\
\hline
\end{tabular}

Samples of both Armstrong-process and hydride/dehydride-process titanium powders were pressed into compacts for hot isostatic pressing (HIP) in a similar fashion to the samples that were PIFed. Some of the samples were pressureless sintered prior to HIPing. Table 15 shows the results of density measurements. Both canned and canless samples were successfully HIPed to full density, $>99 \%$ of theoretical density. 
Table 15. Results of HIP consolidation of titanium powder compacts

\begin{tabular}{|c|c|c|c|c|}
\hline \multirow[b]{2}{*}{ Material } & \multirow[b]{2}{*}{ Canned } & \multicolumn{3}{|c|}{ Theoretical Density, \% } \\
\hline & & Pressed & $\begin{array}{c}\text { Pressed and } \\
\text { Sintered }\end{array}$ & HIPed \\
\hline \multirow{3}{*}{ Armstrong Ti-6Al-4V } & yes & 62.0 & & 100 \\
\hline & no & & 95.2 & 99.8 \\
\hline & no & & 96.8 & 99.8 \\
\hline \multirow{2}{*}{ HDH Ti-6Al-4V } & yes & 65.3 & & 100 \\
\hline & yes & & 71.5 & 100 \\
\hline \multirow{2}{*}{ Armstrong CP-Ti } & no & & 83.1 & 99.6 \\
\hline & no & & 84.9 & 99.6 \\
\hline
\end{tabular}

In addition, powders that had been roll-compacted into green strips were used for the canned HIP/PIF study. By studying this methodology, manufacturing processes for simple shapes may be able to skip press and sinter steps, with powders or partially consolidated shapes being placed directly in the can. In order to prevent can rupture during HIP or PIF activities, the material must be over $50 \%$ dense going into the can. Roll compaction is an inexpensive, continuous method to increasing the density of powder; this method is similar to the traditional methods of "pucking" or "pilling" used to improve handling, increase density, and/or fill dies and cans. The roll-compacted sheets can easily be stacked and vacuum sealed in the steel cans, since the sheet type samples can simplify the filling process in the steel cans that are used for subsequent pressure consolidation by HIPing or PIFing for large components. The Armstrong-process and hydride/dehydride-process Ti-6Al-4V powders that had been roll compacted to $51 \%$ and $73 \%$ theoretical density, respectively. Samples were sent to a commercial heat treater for HIPing, and to AMETEK for PIFing. The HIPing was performed at $960^{\circ} \mathrm{C}$ and $\sim 15 \mathrm{ksi}$ for 245 minutes. The PIFing condition is proprietary. All HIPed/PIFed sheet samples achieved full consolidation state. Note that there was no difference between the powder samples and stacked sheet samples in the density after PIF/HIP process.

The densified disk samples of Ti Armstrong powder after PIFing are shown in Figure 46a. Both CP$\mathrm{Ti}$ and Ti-6Al-4V samples were fully dense $(\sim 99.8 \%)$ at this state. Figure $46 \mathrm{~b}$ shows the cylindrical samples after HIPing without a can. The as-HIPed density was $99.6 \%$ or greater for the samples. Note that these samples were mill-annealed at $750^{\circ} \mathrm{C}$ for 1.5 hours. Figure 47 is a micrograph of the CP Ti sample after HIPing which is made from the layered roll-compacted powder. No defects such as pores can be observed as expected from the density measurement.
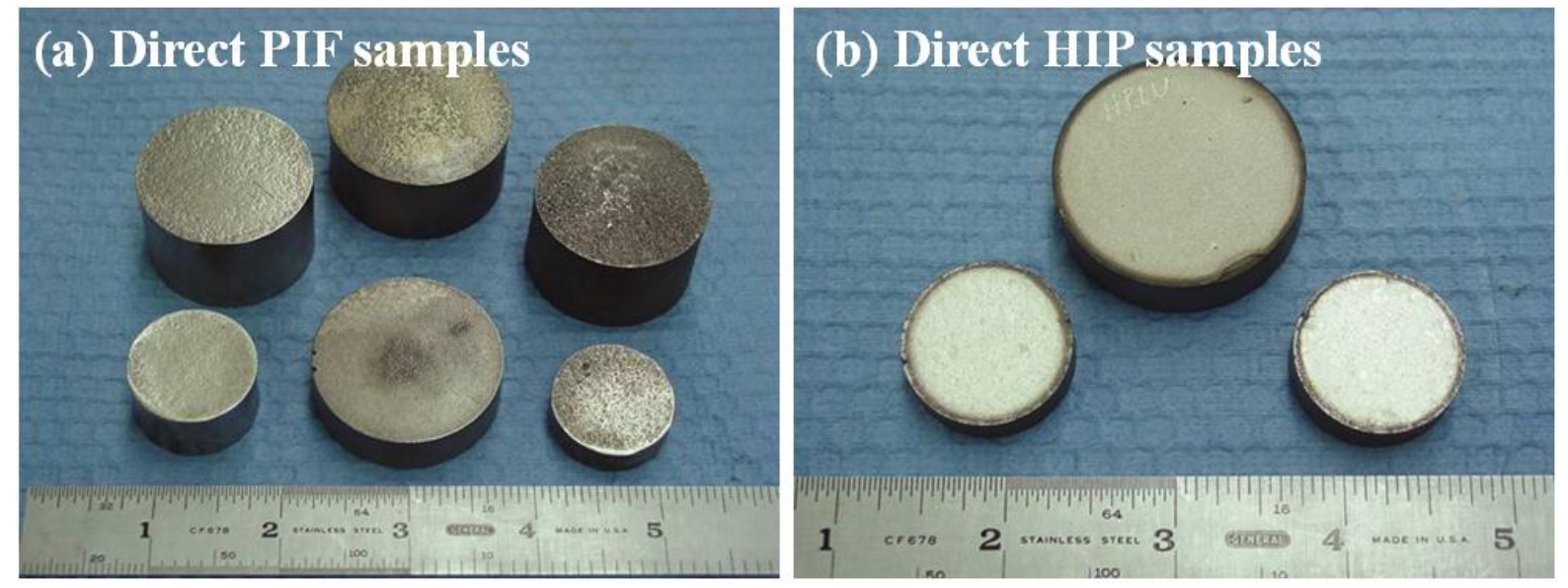

Figure 46. Pictures of (a) direct PIF samples and (b) direct HIP samples without canning. 


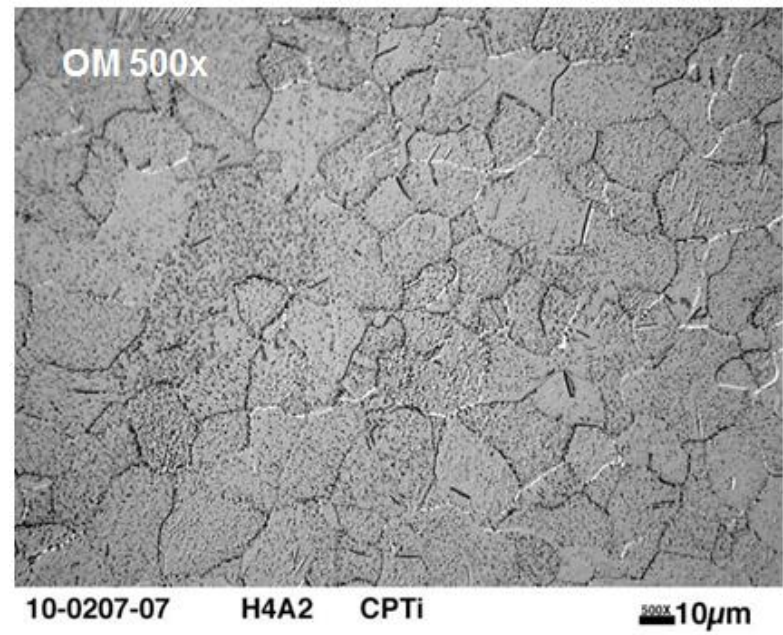

Figure 47. Micrograph of CP-Ti sample after HIPing roll-compacted Armstrong powder.

Plate samples were prepared by uni-axial die pressing the Armstrong powder in a steel die in a pressure range from 5 to $20 \mathrm{ksi}$. The resulting samples were approximately $3 \times 1.75 \times 0.6$ inches. A total of 8 plates, $4 \mathrm{Ti}-6 \mathrm{Al}-4 \mathrm{~V}$ and $4 \mathrm{CP}-\mathrm{Ti}$, were fabricated. Examples of the die pressed plates are shown in Figure 48 (left Ti-6Al-4V, right CP-Ti). The die pressed plate samples were cold isostatic pressed (CIPed) at $50 \mathrm{ksi}$, followed by sintering in a high vacuum at $1300^{\circ} \mathrm{C}$ for 1 hour. The plates showed no open porosity after sintering. This was true even for the CP-Ti samples, which had densities of 84 to $86 \%$ after sintering. The plates were subsequently HIPed or PIFed at 950C without canning, after which all of the samples measured $100 \%$ theoretical density. A comparison of the sample densities after the various processing steps is shown in Figure 49. The HIPed or PIFed plates were mill annealed at $750^{\circ} \mathrm{C}$ for 1.5 hours prior to being machined into test specimens. An example of a fatigue crack growth specimen machined from one of the HIPed Ti-6Al-4V plates is shown in Figure 50.

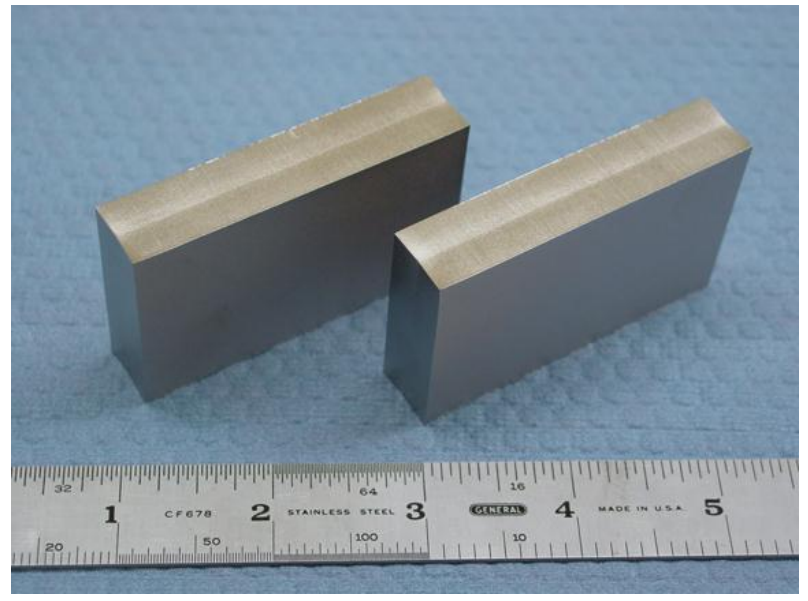

Figure 48. Die pressed plates of Ti-6Al-4V (left) and CP-Ti (right) 


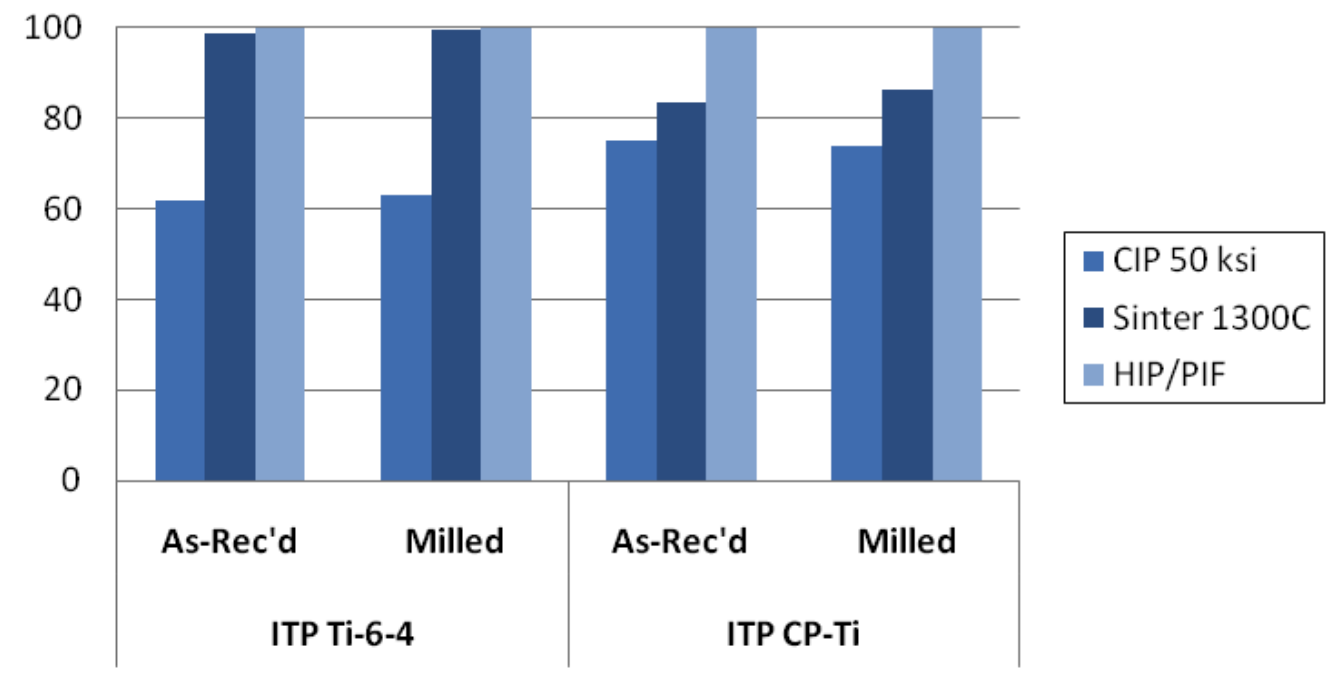

Figure 49. True Density of the die pressed plates in each step.

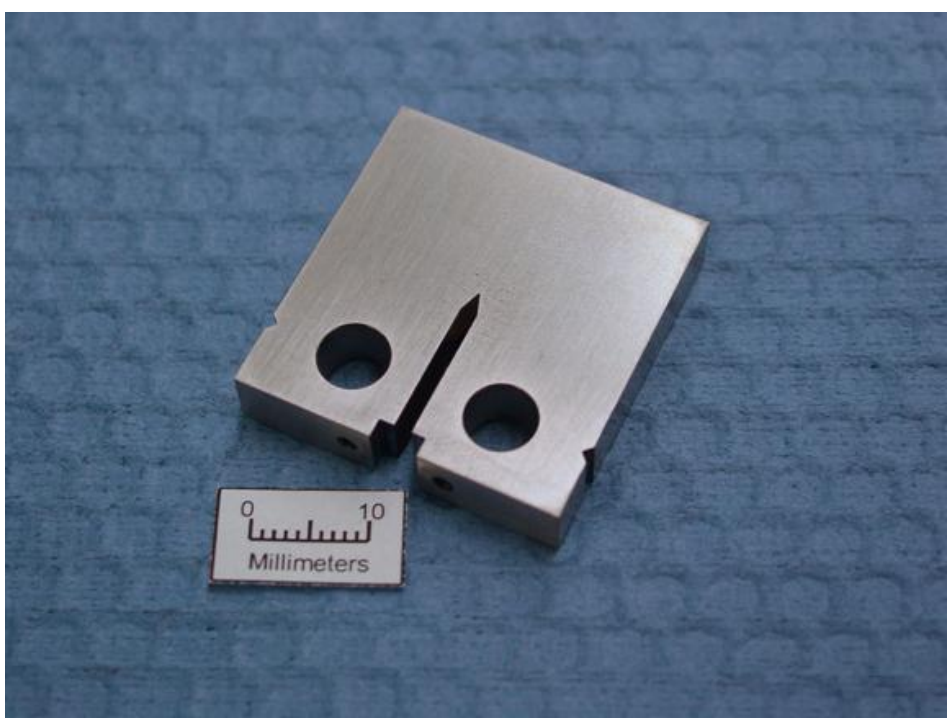

Figure 50. A fatigue crack growth specimens machined from the HIPed Ti-6Al-4V plate

Additional rectangle plate shape specimens of fully consolidated Armstrong CP-Ti powder have been made through die-pressing, cold isostatic pressing, vacuum sintering, and hot isostatic pressing with optimized condition, in order to prepare fatigue specimens (shown in Figure 51). The test details are described in section 3.3.1. The test was performed according to ASTM E466 Fatigue Test Standard. 

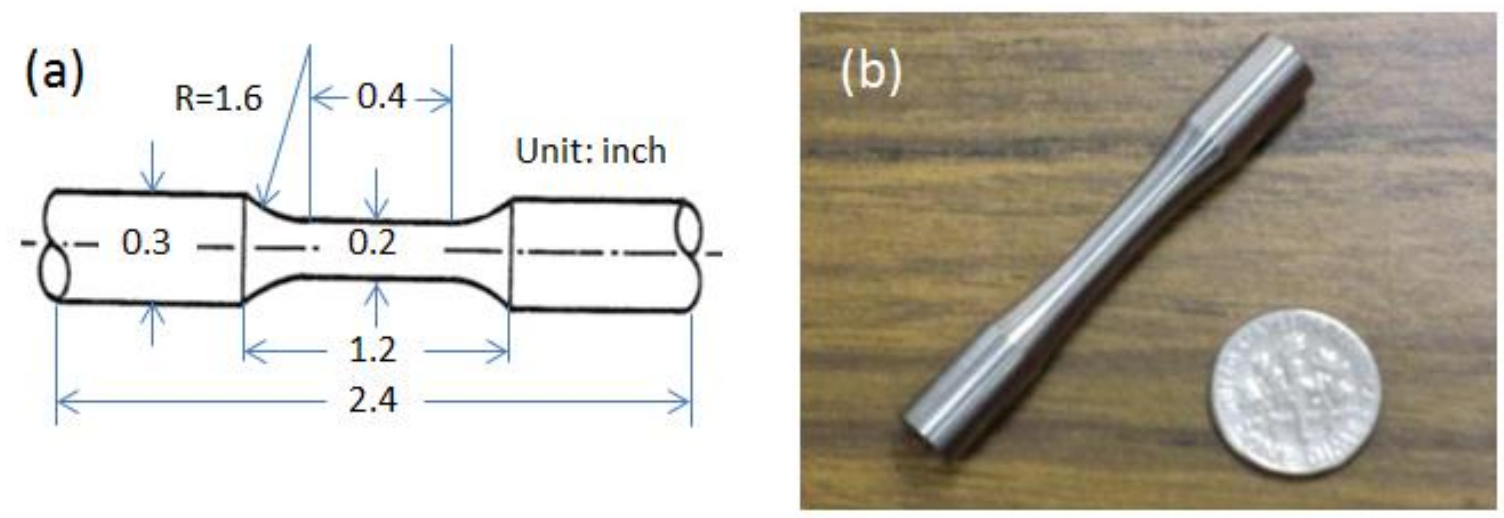

Figure 51. (a) Drawing of fatigue specimen which will be sectioned from the rectangle specimen, and (b) a picture of the machined specimen.

\subsubsection{Adiabatic Compaction of Low Cost Ti and Ti Alloys}

High strain rate powder compaction offers the possibility to reach higher densities because there is a potential to reach higher pressures than static equipment can. Also, the high strain rates can produce local collision welding and higher rates of strain hardening. These effects can produce higher material strength. The subject matter for subtasks 3.2.2 and 3.2.3 are so closely linked that the results are captured for both subtasks under 3.2.3. The Ohio State University collaborated with ORNL to perform these tasks. Mr. Bradley Kabert, under the direction of Dr. Glenn Daehn, performed his Master's thesis based on this subtask, entitled "High Strain Rate Consolidation and Forming of Armstrong and HDH Titanium Powder and Sheet Material" published in 2011. Below is an extensive briefing. However, the thesis will provide a comprehensive description of the procedures and results performed for these two subtasks.

\subsubsection{Establishing Pressure Density Relationships at High Strain Rates for a Fundamental Understanding}

Work in this task considers both examining flat planar compaction for creating components as well as axisymmetric compaction to develop both terminal pressure-density relationships and using the data to produce pressure-density relationships along the compaction path.

\subsubsection{Tube compaction}

The groundwork has been laid to establish high strain rate pressure-density of both the HDH and Armstrong titanium powder morphologies. Procedures for compaction by both direct and offset electromagnetically driven tubes have been established, as well as a procedure for compaction by disposable coil. Figure 52 and Figure 53 show schematic illustrations of the EM tube compaction apparatus, and Figure 54 illustrates the mechanism of radial flyer compaction. 

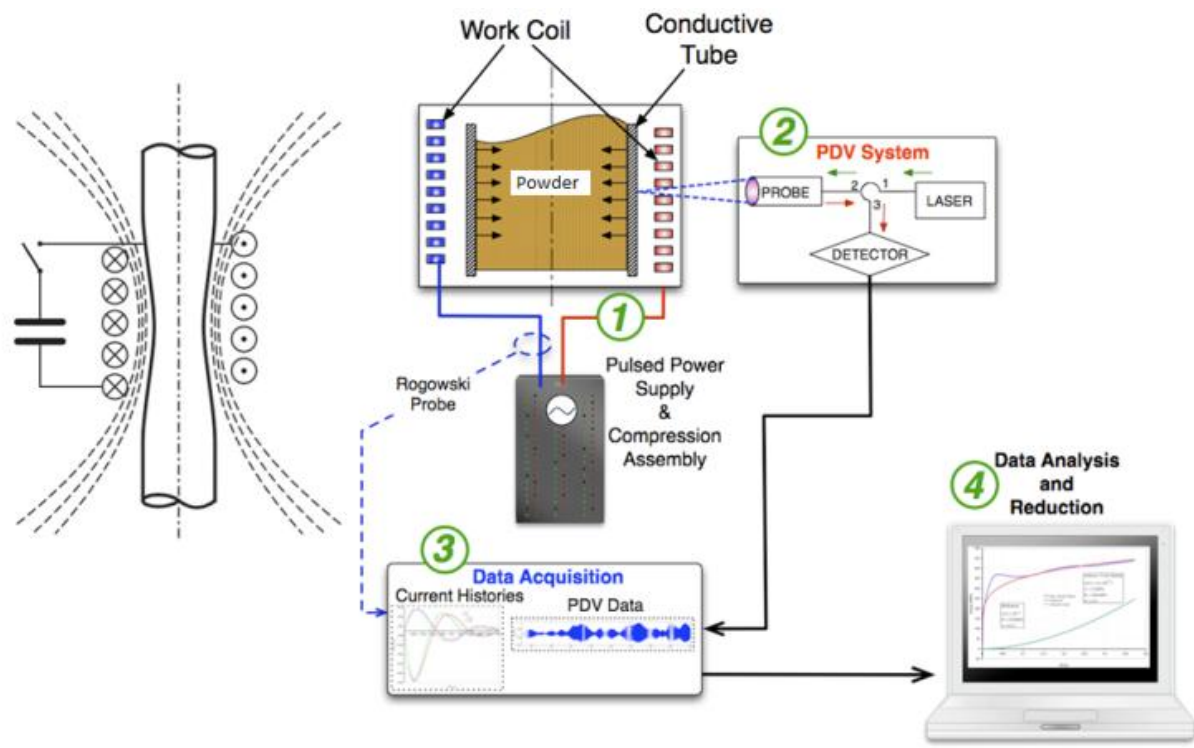

Figure 52. EM tube compaction apparatus.

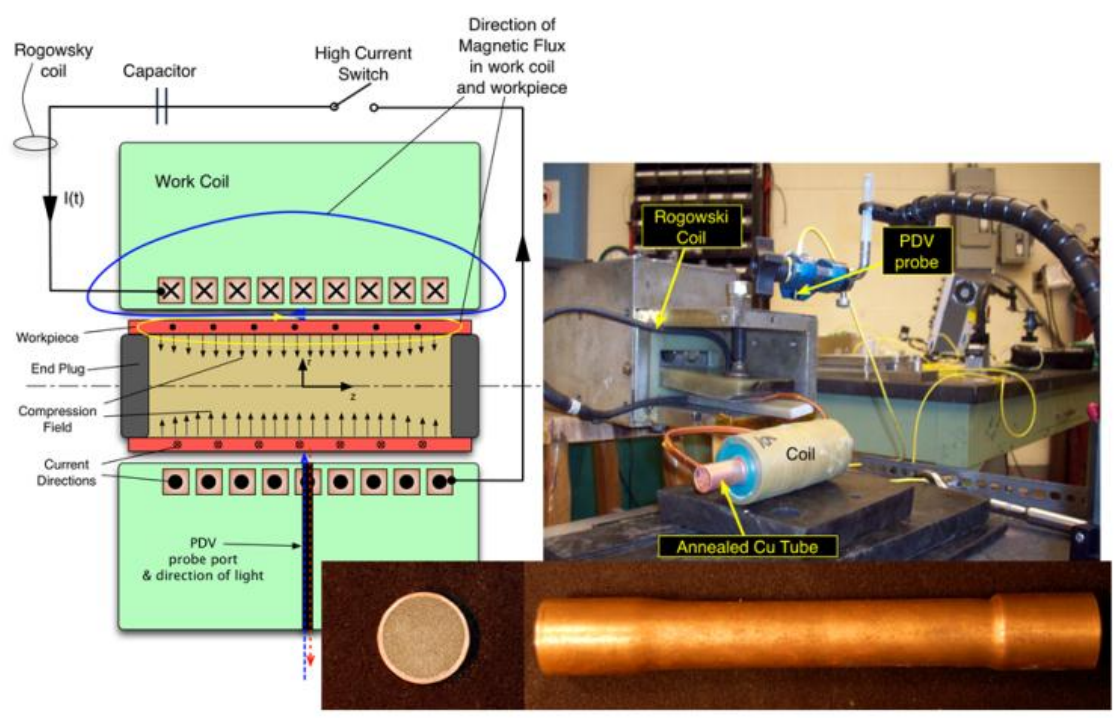

Figure 53. EM tube compaction experimental setup 


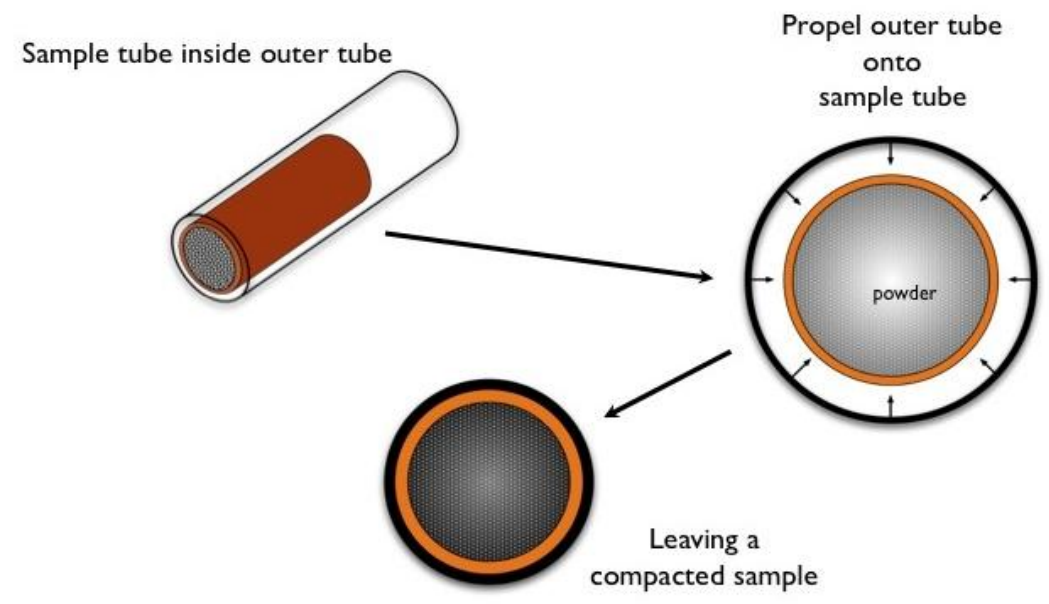

Figure 54. Schematic of offset tube compaction for a generic metal powder (radial flyer compaction).

Powder samples were compacted by two methods, the first of which being direct tube compaction. In direct tube compaction, a copper tube with a mandrel inside is filled with titanium powder and compacted radically by an EM Actuator. A Rogowski coil was used to measure the current in the actuator while a Photon Doppler Velocimeter (PDV) precisely measures the radial velocity. These data was processed to develop in-situ pressure-density relationships. The second method of testing was the offset tube compaction. A thin walled polymer tube containing a mandrel is filled with titanium powder. A copper tube is placed over the polymer tube leaving a small offset, allowing the tube to accelerate prior to impacting the polymer tube and titanium powder. This can produce much higher initial compaction strain rates and has been shown to enhance fragmentation in brittle powders. Figure 55 shows examples of obtained profiles of the EM current and measured tube velocities from two different compactions.

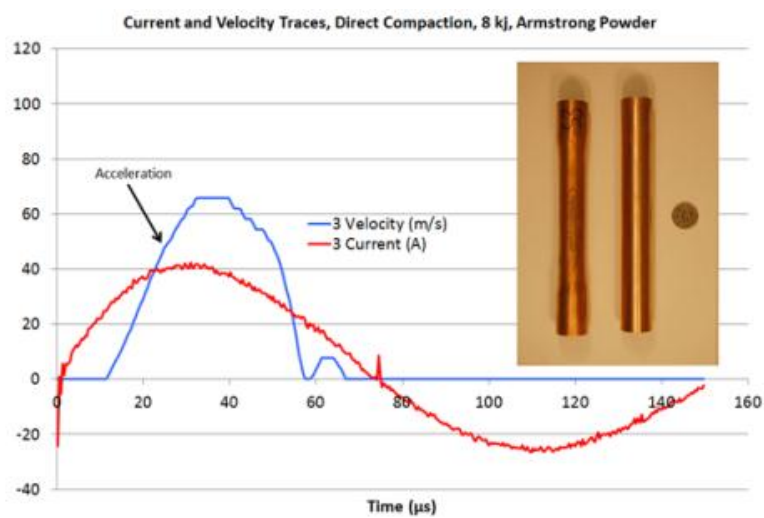

(a)

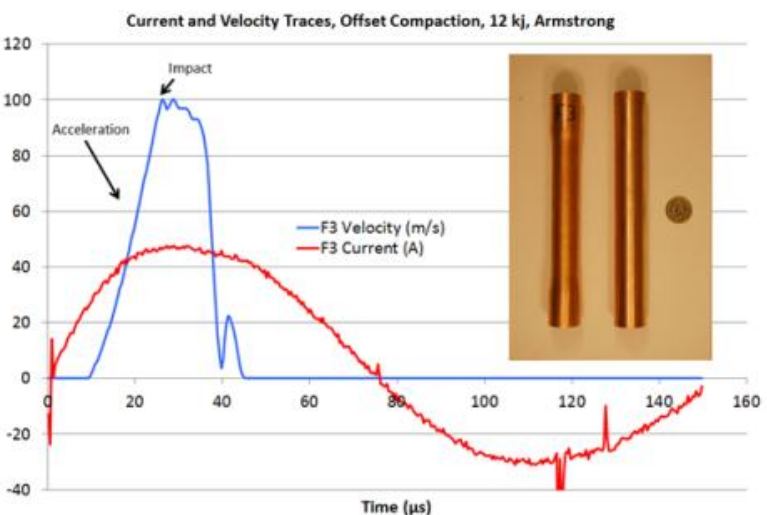

(b)

Figure 55. Measured current (in $\mathrm{kA}$ ) and velocity (in $\mathrm{m} / \mathrm{s}$ ) for direct compaction (a) and offset compaction (b) using Armstrong powder and a fixed electromagnetic actuator with $8 \mathrm{~kJ}$ and $12 \mathrm{~kJ}$ discharges, respectively. The inset photo shows the initial confinement tube and that after compaction. The latter method gives much higher velocities at initial compaction.

Through the acquired current and velocity information, the compaction pressure can be extracted during the process. The relationship between the stored electrical energy in the capacitor bank and terminal density of the powder in direct compaction experiments is shown in Figure 56. Note that the density was measured from the reduction of the outer $\mathrm{Cu}$ tube diameter. Direct density measurement was also conducted after $\mathrm{Cu}$ tube removal. 


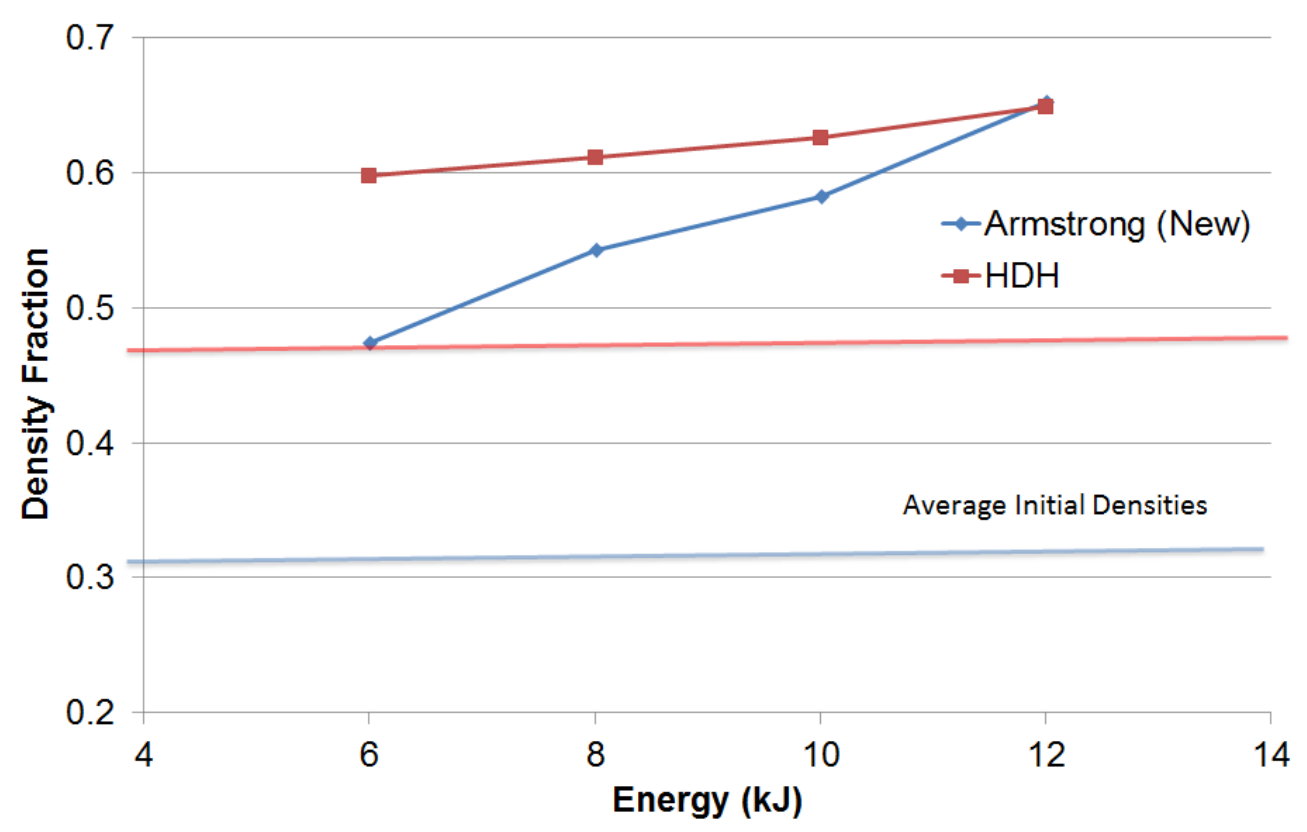

Figure 56. Terminal density as a function of discharge energy for HDH and Armstrong powders in direct compaction.

All eight samples (CP-Ti, four Armstrong and four $\mathrm{HDH}$ powder samples) were sectioned and used for metallographic characterization. Figure 57 shows their macroscopic cross-sectional views of asEM compacted state. No apparent dependence of the stored electrical energy on the macroscopic feature was observed, although the compacted HDH with lower stored energy (e.g. $8 \mathrm{~kJ}$ ) was not compacted well to keep the tube form during sectioning. Table 16 summarizes the density of tubes before and after sintering at $1300^{\circ} \mathrm{C}$ for $1 \mathrm{~h}$ in a high vacuum. The Armstrong powders tend to show lower as-compacted density than that of the HDH powder. However, the sintered densities of Armstrong powders are much higher than that of the HDH powders at a given stored energy.

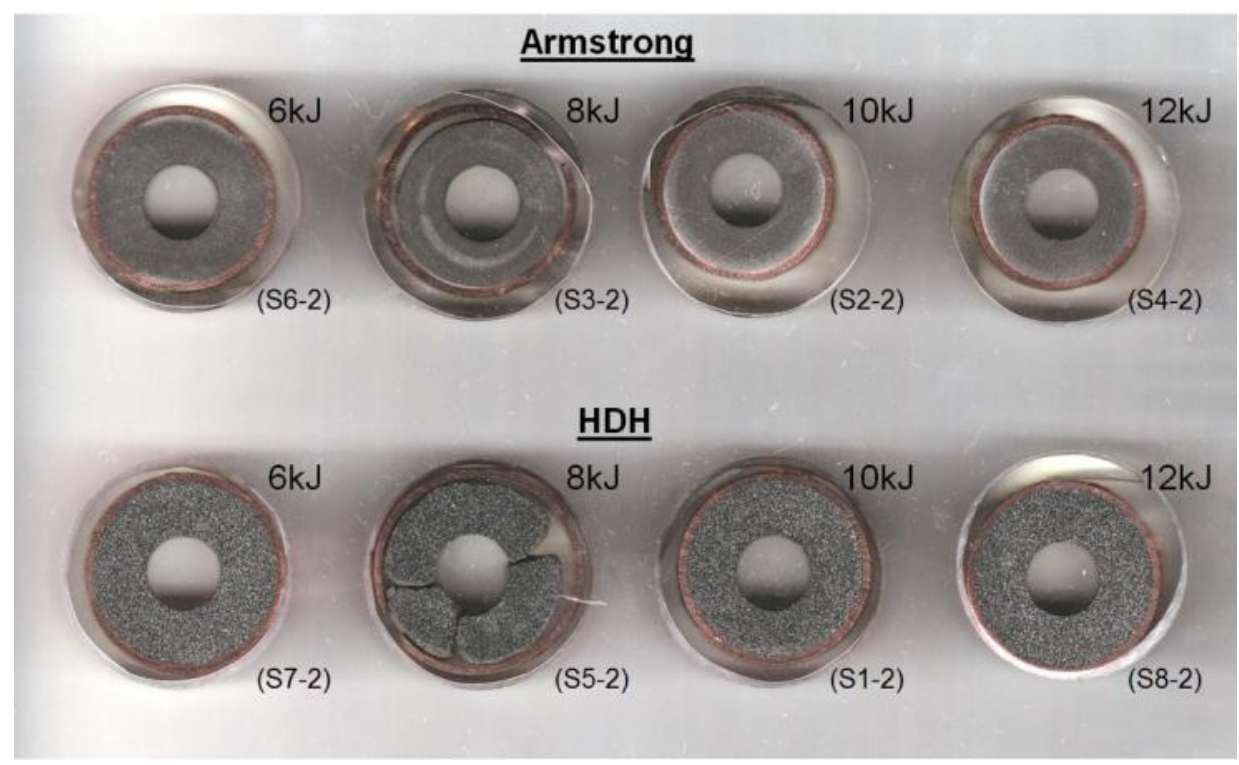

Figure 57. Cross-sectional view of the EM compacted CP-Ti samples. 
Table 16. Density of EM compacted tubes before and after sintering at $1300^{\circ} \mathrm{C}$ for $1 \mathrm{~h}$

\begin{tabular}{ccccc}
\hline \multirow{2}{*}{ Armstrong CP-Ti } & $\mathbf{6 k J}(\mathbf{S 6})$ & $\mathbf{8 k J}(\mathbf{S 3})$ & $\mathbf{1 0 k J}(\mathbf{S 2})$ & $\mathbf{1 2 k J}(\mathbf{S 4})$ \\
\cline { 2 - 5 } & $\mathrm{S6-3}$ & $\mathrm{S} 3-3$ & $\mathrm{~S} 2-3$ & $\mathrm{~S} 4-3$ \\
\hline Density after can-removal (\%) & 45.4 & 58.9 & 54.4 & 62.3 \\
\hline Density after sintering (\%) & 72.3 & $72-75$ & 76.0 & 82.5 \\
\hline \hline \multirow{2}{*}{ HDH CP-Ti } & $\mathbf{6 k J}(\mathbf{S 7})$ & $\mathbf{8 k J}(\mathbf{S 5})$ & $\mathbf{1 0 k J}(\mathbf{S 1})$ & $\mathbf{1 2 k J}(\mathbf{S 8})$ \\
\cline { 2 - 5 } & $\mathrm{S} 7-3$ & $\mathrm{~S} 5-3$ & $\mathrm{~S} 1-3$ & $\mathrm{~S} 8-3$ \\
\hline Density after can-removal (\%) & 55.5 & 62.0 & 59.5 & 61.2 \\
\hline Density after sintering (\%) & 65.1 & $67-71$ & 67.4 & 70.1 \\
\hline
\end{tabular}

Figure 58 shows the EM compacted tube density plotted as a function of the stored energy, together with the results from uni-axial die pressed samples for comparison purpose. At the as-EM compacted state, the tube density of Armstrong powder varies from 45.4 to $62.3 \%$, which corresponds to around 10 to $30 \mathrm{ksi}$ pressure of uni-axially die-pressed specimens. However, the tube density after sintering process seems much higher than the corresponding sintered density of die-pressed samples (72-82.5 $\%$ vs. $60-75 \%$, respectively). On the other hands, the as-EM compacted tube densities of the HDH powder range from 55.5 to $61.2 \%$ which correspond to the die-pressure less than $25 \mathrm{ksi}$. Therefore, the obtained tube densities were below the compaction limit of uni-axial die press to be compacted. The sintered densities of the HDH powder tubes were much lower than that of the Armstrong powder, which was due to insufficient contact surface of the HDH powder in the EM-compacted tube.

Microstructure of the EM-compacted tubes after sintering was characterized, as shown in Figure 60. A partial cross-sectional view of the Armstrong CP-Ti tube at $12 \mathrm{~kJ}$ showed that the amount of pores distributed not homogeneously but gradually increased to the outside of the tube. The average density measured from the microstructure also decreases from near center (mandrill) to the surface (the $\mathrm{Cu}$ tube). This feature has been observed in all the EM compacted tubes for both Armstrong and HDH powders, in the range of 6 to $12 \mathrm{~kJ}$ compaction, and simply indicates that the stress inside of the tubes could be higher than outside to balance the compacted force between the mandrill and the $\mathrm{Cu}$ tube. It should be emphasized that the variety of the density along the pressure axis (= radial direction) in the EM compacted tube was much lower than the uni-axial die pressed samples (shown in Figure 40), which could be due to no die-wall friction in the tube compaction. This indicates that relatively uniform density distribution (such as in the Armstrong powder tubes) could assist the better densification process. However, much higher as-EM compacted density will be required, especially for Armstrong CP-Ti, from the discussion in section 3.1.1, in order to achieve full consolidation after sintering process. Optimization of the EM compact process will be required, such as selecting thinner die-wall, etc. 
(a) EM Tube Compaction

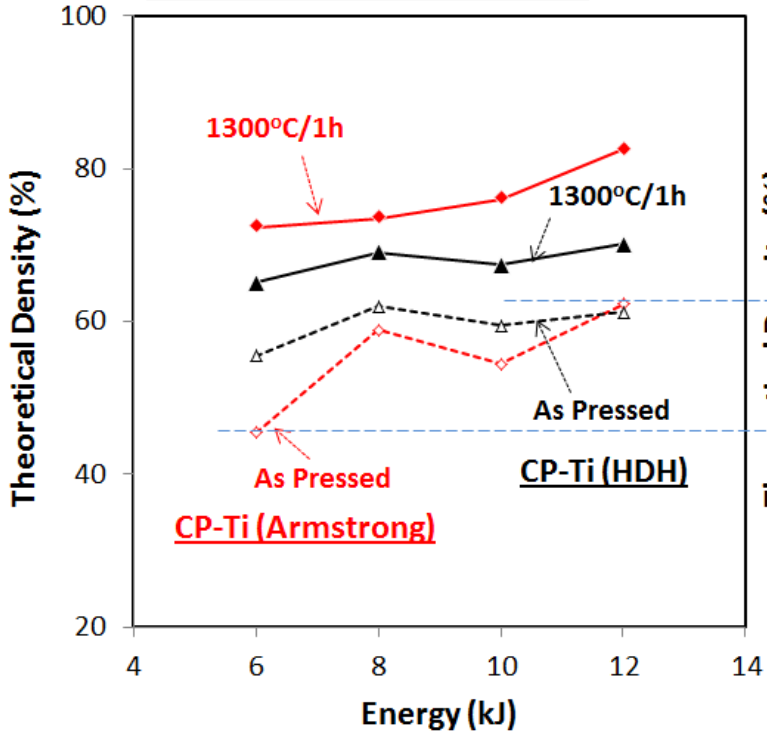

(b) Press and Sinter

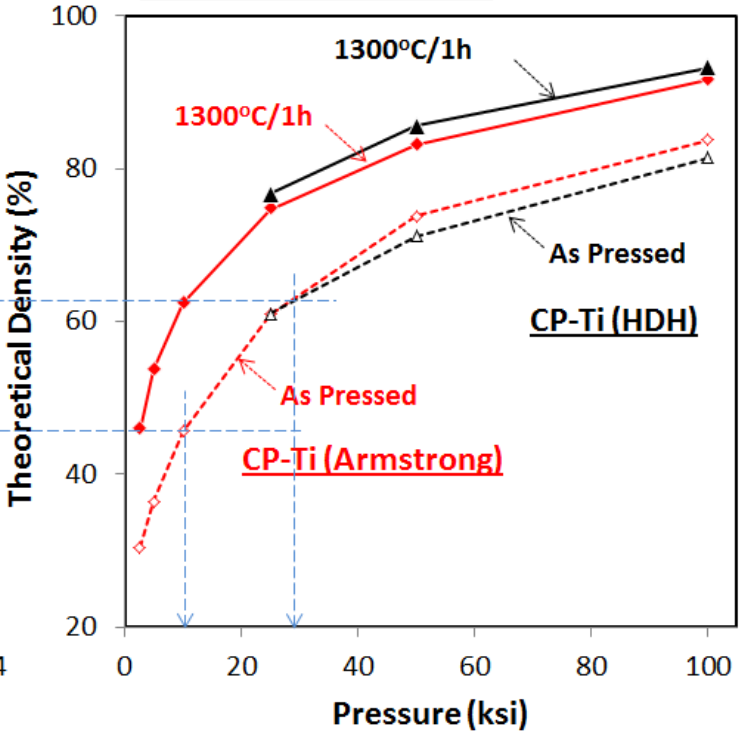

Figure 58. Theoretical densities of the EM compacted CP-Ti samples plotted as a function of (a) EM energy, and (b) uni-axial pressure.

Density of CP-TiS3-3 8kJ Armstrong $1300^{\circ} \mathrm{C} / 1 \mathrm{hr}$ sintered

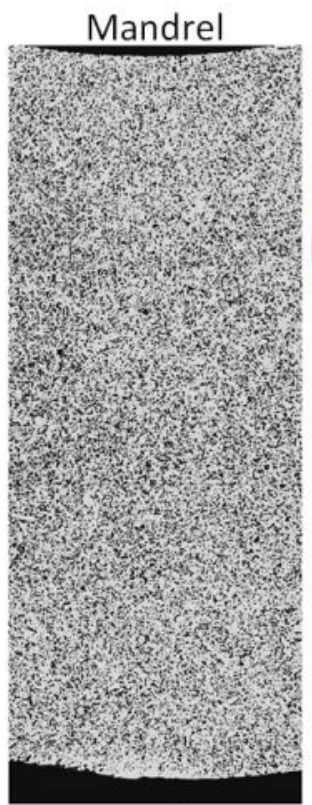

Cu tube
Density of CP-TiS5-3 8kJ HDH

$\underline{1300^{\circ} \mathrm{C} / 1 \mathrm{hr} \text { sintered }}$
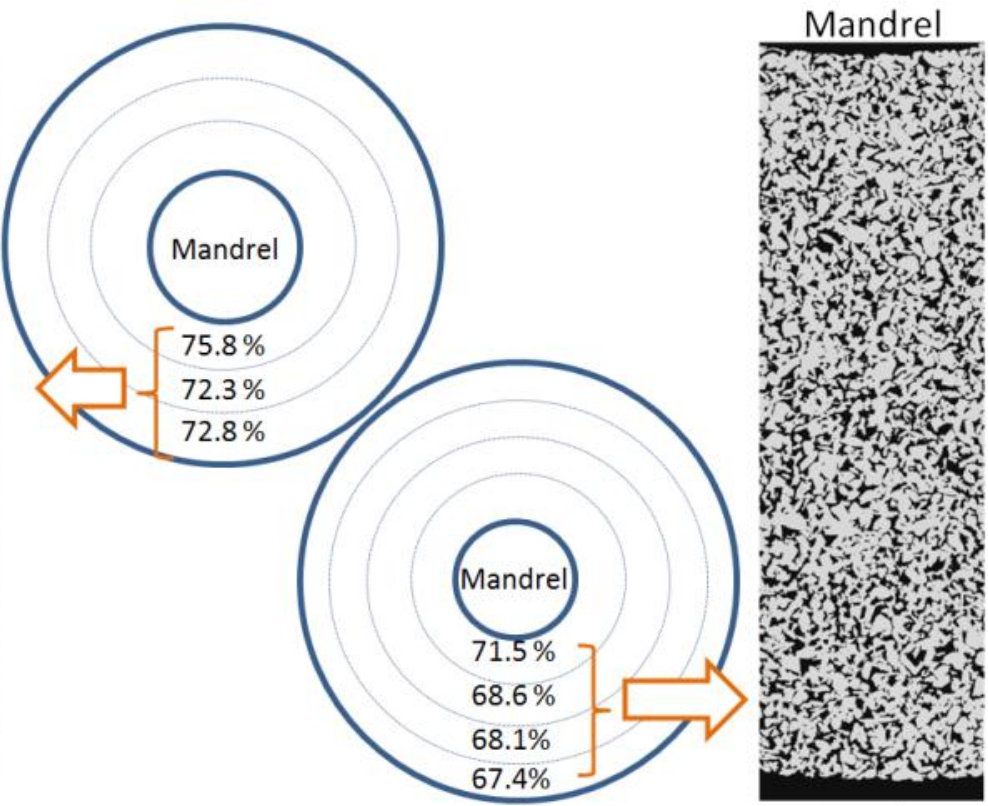

Cu tube

Figure 59. Cross-sectional view of the EM compacted tubes and the averaged density of different portions measured from the microstructure.

Another attempt of electromagnetic (EM) tube compaction at the Ohio State University was conducted by using milled Armstrong Ti-6Al-4V powder, which was successfully made into a fully consolidated Ti-6Al-4V tube after sintering, as shown in Figure 60. Thin wall EM tube compaction with two different diameters of mandrel was conducted (Lg: 0.75 " and Sm: 0.625 " in diameter) with several different stored electric energies. The test conditions and densities before and after processing are summarized in Table 17. 

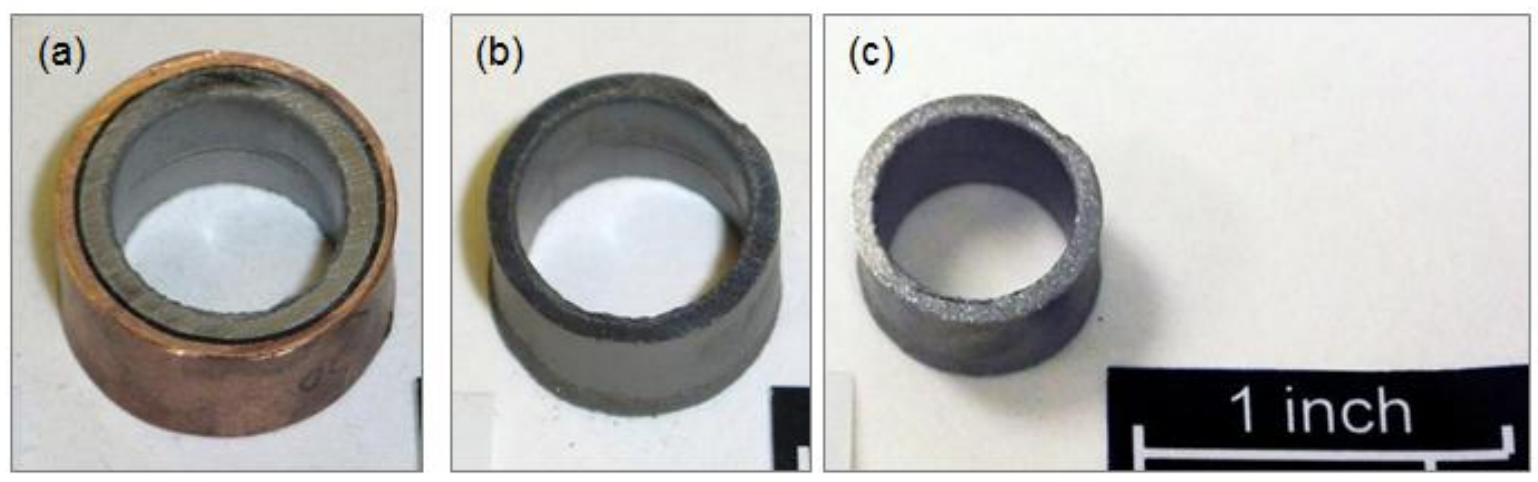

Figure 60. An EM compacted tube specimen (Lg20); (a) as EM compacted (with Cu tube), (b) after $\mathrm{Cu}$ tube removal, and (b) after sintering at $1300^{\circ} \mathrm{C}$ for $1 \mathrm{~h}$ in a vacuum.

Table 17. Test conditions and densities before and after processing of thin wall EM tube compaction using milled Armstrong Ti-6Al-4V powder

\begin{tabular}{|c|c|c|c|c|c|c|}
\hline \multirow{2}{*}{ Test ID } & \multicolumn{2}{|c|}{ Process at OSU } & \multirow{2}{*}{$\begin{array}{c}\text { Initial } \\
\text { Density } \\
(\%)\end{array}$} & \multirow{2}{*}{$\begin{array}{l}\text { As-compacted } \\
\text { Density }(\%)\end{array}$} & \multicolumn{2}{|c|}{$\begin{array}{c}\text { After sintering at } \\
1300 \mathrm{C} / 1 \mathrm{~h} / \mathrm{vac}\end{array}$} \\
\hline & $\begin{array}{c}\text { Charge } \\
\text { Energy }(k J)\end{array}$ & $\begin{array}{c}\text { Mandrel } \\
\text { Diameter (in) }\end{array}$ & & & Density (\%) & $\begin{array}{c}\text { Open } \\
\text { porosity }(\%)\end{array}$ \\
\hline $\operatorname{Lg} 14$ & 2.24 & 0.75 & 32.0 & 57.8 & 99.1 & 0.43 \\
\hline Lg20 & 3.20 & 0.75 & 31.2 & 69.2 & 100.1 & 0.00 \\
\hline $\operatorname{Lg} 26$ & 4.16 & 0.75 & 32.0 & 72.0 & 99.5 & 0.47 \\
\hline $\operatorname{Lg} 32$ & 5.12 & 0.75 & 30.2 & 72.5 & 100.0 & 0.18 \\
\hline Lg44 & 7.04 & 0.75 & 30.4 & 72.5 & 98.7 & 1.15 \\
\hline Sm14 & 2.24 & 0.625 & 32.0 & 55.3 & 98.6 & 0.44 \\
\hline $\operatorname{Sm} 20$ & 3.20 & 0.625 & 31.5 & 58.0 & 98.9 & 0.41 \\
\hline Sm26 & 4.16 & 0.625 & 32.5 & 68.3 & 100.1 & 0.00 \\
\hline Sm32 & 5.12 & 0.625 & 29.9 & 72.4 & 99.3 & 0.54 \\
\hline $\mathrm{Sm} 44$ & 7.04 & 0.625 & 31.0 & 74.4 & 99.9 & 0.00 \\
\hline
\end{tabular}

The green density increased with increasing the stored energy, which was independent of the range of mandrel size studied. Interestingly, the vacuum sintering at $1300^{\circ} \mathrm{C}$ for $1 \mathrm{~h}$ resulted in almost fully consolidation for most of the specimens. This result strongly suggests that the EM tube compaction has a high potential to be one of the direct tube fabrication process from the Armstrong processed titanium powder.

The microstructure of electromagnetic (EM) compacted Ti-6Al-4V tube after sintering at $1300^{\circ} \mathrm{C}$ for $1 \mathrm{~h}$ was characterized, as shown in Figure 61. The cross-sectional microstructure indicated uniform lamellar microstructure with very little amount of pores. Since microstructure of Ti-6Al-4V alloy, and its mechanical properties, can be easily controlled by using controlled cooling rate, the current result promises to fabricate a fully dense PM Ti-6Al-4V tube with controlled mechanical properties. 

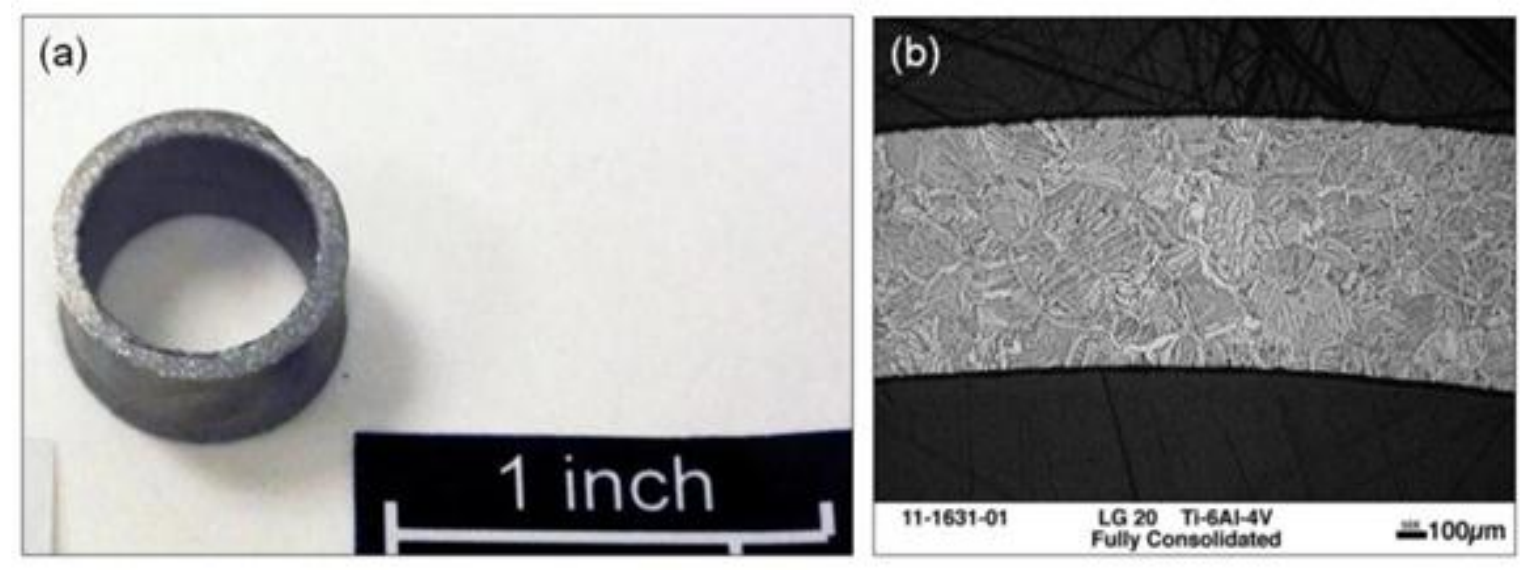

Figure 61. An EM compacted Ti-6Al-4V tube specimen (Lg20); (a) after sintering at $\mathbf{1 3 0 0}^{\circ} \mathrm{C}$ for $1 \mathrm{~h}$ in a vacuum, and (b) optical micrograph of the cross-sectional view.

\subsubsection{Uni-axial compaction}

A Uniform Pressure Actuator was used to drive a sample over a flat stage or a die with channels of varying geometry to assess the high strain rate formability of the strip. A Plate Launching Actuator was also used to impact a coupon of roll compacted tape to determine the effectiveness of using high strain rate techniques to increase tape density (Figure 62). Initial samples of Armstrong Ti powder have been compacted using an offset electromagnetically driven tube. Procedures and computer scripts for analyzing the Photon Doppler Velocimeter data determined the compaction pressure. The formed strip has similar channel geometries to the herringbone structure in heat exchanger plates, but at a smaller scale.
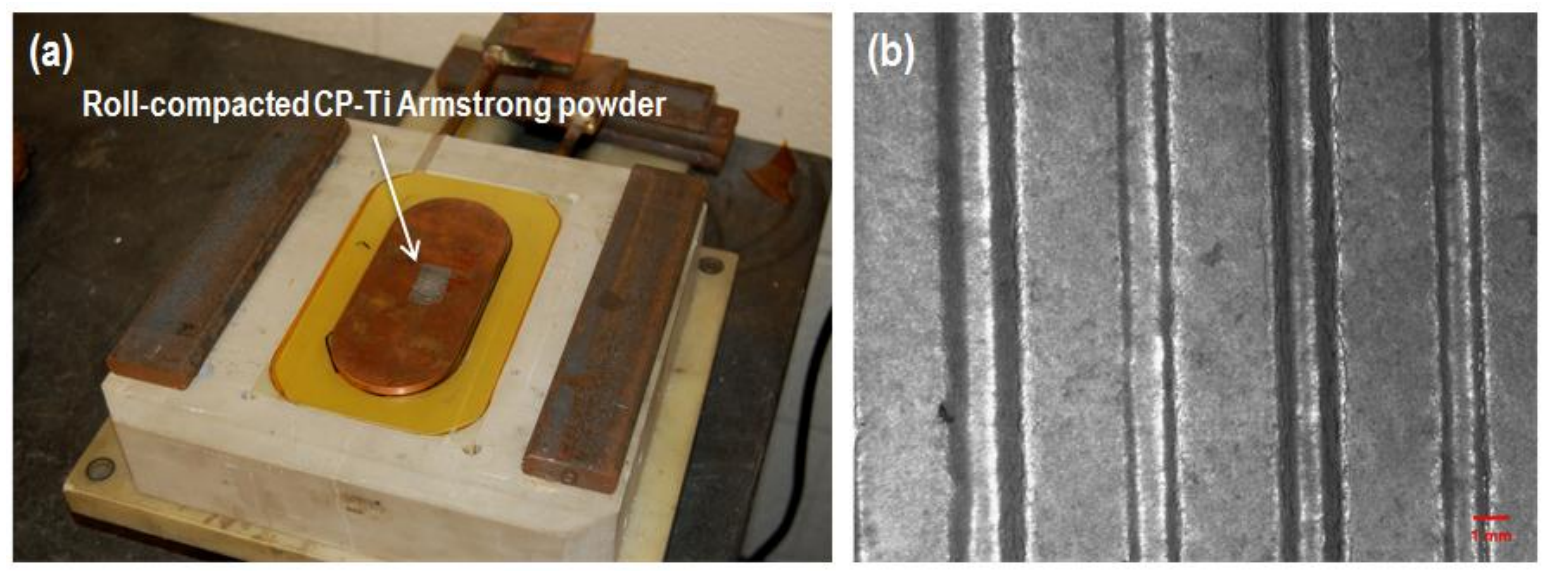

Figure 62. (a) Electromagnetic plate launching actuator with roll-compacted CP-Ti Armstrong powder specimen, and (b) the specimen surface after channel die forming.

The obtained results demonstrated the great advantage of the high strain rate compaction on the Armstrong titanium powders.

Table 19 summarizes the relationship among the charged energy, the compaction velocity, and the density of roll compacted titanium sheet after the EM compaction. Although the physical geometries, such as the stage size, titanium sheet shape, starting sheet density, and so on, could affect the absolute values of the final density, the velocity dependence of the density would be still useful to be discussed, as plotted in Figure 63. Both CP-Ti and Ti-6Al-4V showed a maximum peak of the density at around $140 \mathrm{~m} / \mathrm{s}$, and no density improvement was observed above that velocity. This indicates that 
high strain rate is not monotonically effective to increase the density, but there is a limitation. Since the initial thickness of the CP-Ti and Ti-6Al-4V were 0.0181 " and 0.0131 ", respectively, the strain rates at around $140 \mathrm{~m} / \mathrm{s}$ could be calculated as $3.0 \times 10^{5} / \mathrm{s}$ and $4.2 \times 10^{5} / \mathrm{s}$, respectively. More importantly, the achieved densities were $99.7 \%$ and $87.9 \%$ for $\mathrm{CP}-\mathrm{Ti}$ and Ti-6Al-4V, respectively, which were much higher than the maximum densities achieved by uni-axial die pressing at 100ksi.

Table 18. Charge energy, velocity, kinetic energy and density of flyer driven Armstrong CP-Ti samples Charge energy, $\mathrm{kJ}$ Velocity, $\mathbf{m} / \mathbf{s}$ Kinetic Energy, $\mathrm{J} / \mathrm{cm}^{2}$ Density, \% TD

\begin{tabular}{llll}
2.56 & 103 & 1.74 & 83.1 \\
3.20 & 127 & 2.63 & 93.7 \\
3.84 & 141 & 3.25 & 98.3 \\
4.48 & 136 & 3.03 & 99.7 \\
5.12 & 145 & 3.44 & 98.3 \\
5.70 & $176^{*}$ & 5.07 & 94.7 \\
\hline
\end{tabular}

*Insufficient velocity data replaced with similarly driven sample of other chemistry

Table 19. Charge energy, velocity, kinetic energy and density of flyer driven Armstrong Ti-64 samples Charge energy, kJ Velocity, $\mathbf{m} / \mathbf{s}$ Kinetic Energy, J/cm ${ }^{2}$ Density, \% TD

\begin{tabular}{llcl}
2.56 & 101 & 1.81 & 73.1 \\
3.20 & 118 & 2.48 & 77.7 \\
3.84 & 141 & 3.55 & 81.5 \\
4.48 & 136 & 3.3 & 87.9 \\
5.12 & 152 & 4.13 & 81.3 \\
5.70 & 176 & 5.53 & 79.8 \\
\hline
\end{tabular}

*Insufficient velocity data replaced with similarly driven sample of other chemistry

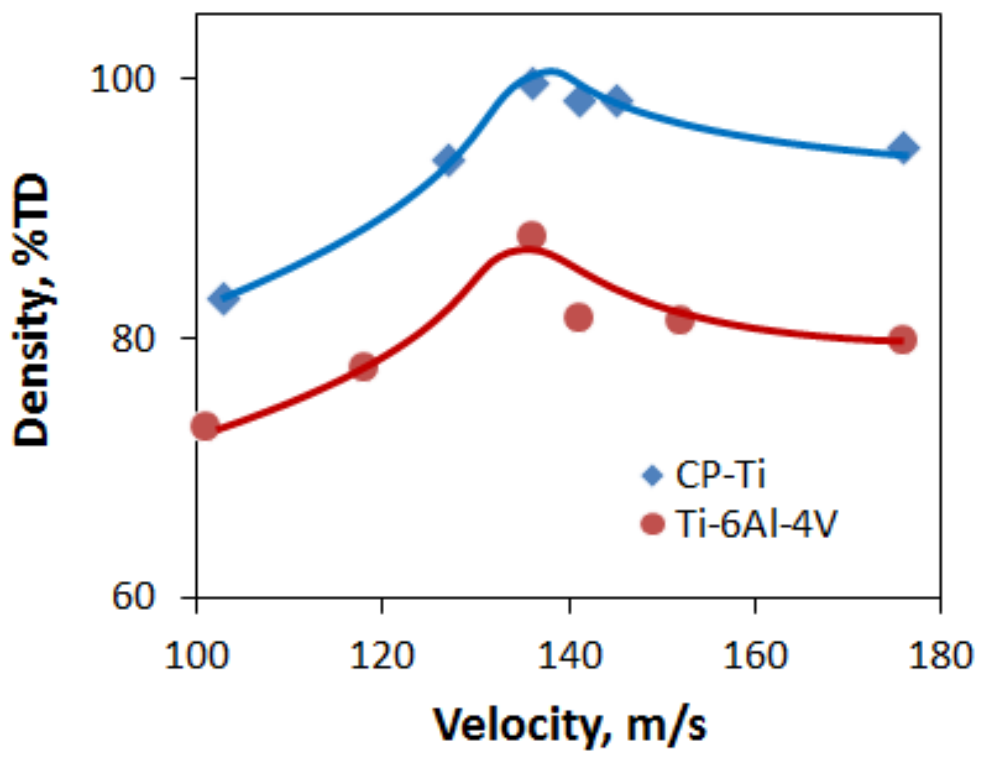

Figure 63. Relationship between the stage velocity and density 
The brittleness of the untreated roll compacted titanium sheets make it nearly impossible to form the material using conventional techniques. A particularly difficult shape to achieve without tearing or cracking of the material is a dimple. Forming material at a higher strain rate increases the amount of strain that can be produced before failure. With this in mind, a dimpled die has been created to determine the high strain rate formability limits of these new titanium sheets. As shown in Figure 64 a, the dimpled die contains various depths, wall angles, and corner radii. A copper driver sheet was used with a Uniform Pressure Actuator to propel an as-rolled titanium sheet over the die. Figure 64b shows a typical result of one of these experiments. It has been shown that with gentler corner radii and a wall angle up to $45^{\circ}$, dimples can be formed without complete failure, however some cracking on the walls of the dimples are typically observed. Densities across each dimple range from $\sim 75$ $93 \%$, with regions parallel to the driver showing the highest densities even in the dimple. A partial section in Figure 64c shows an inner corner in the bottom of a well-formed dimple, including a crack in a wall and a well-compacted zone.
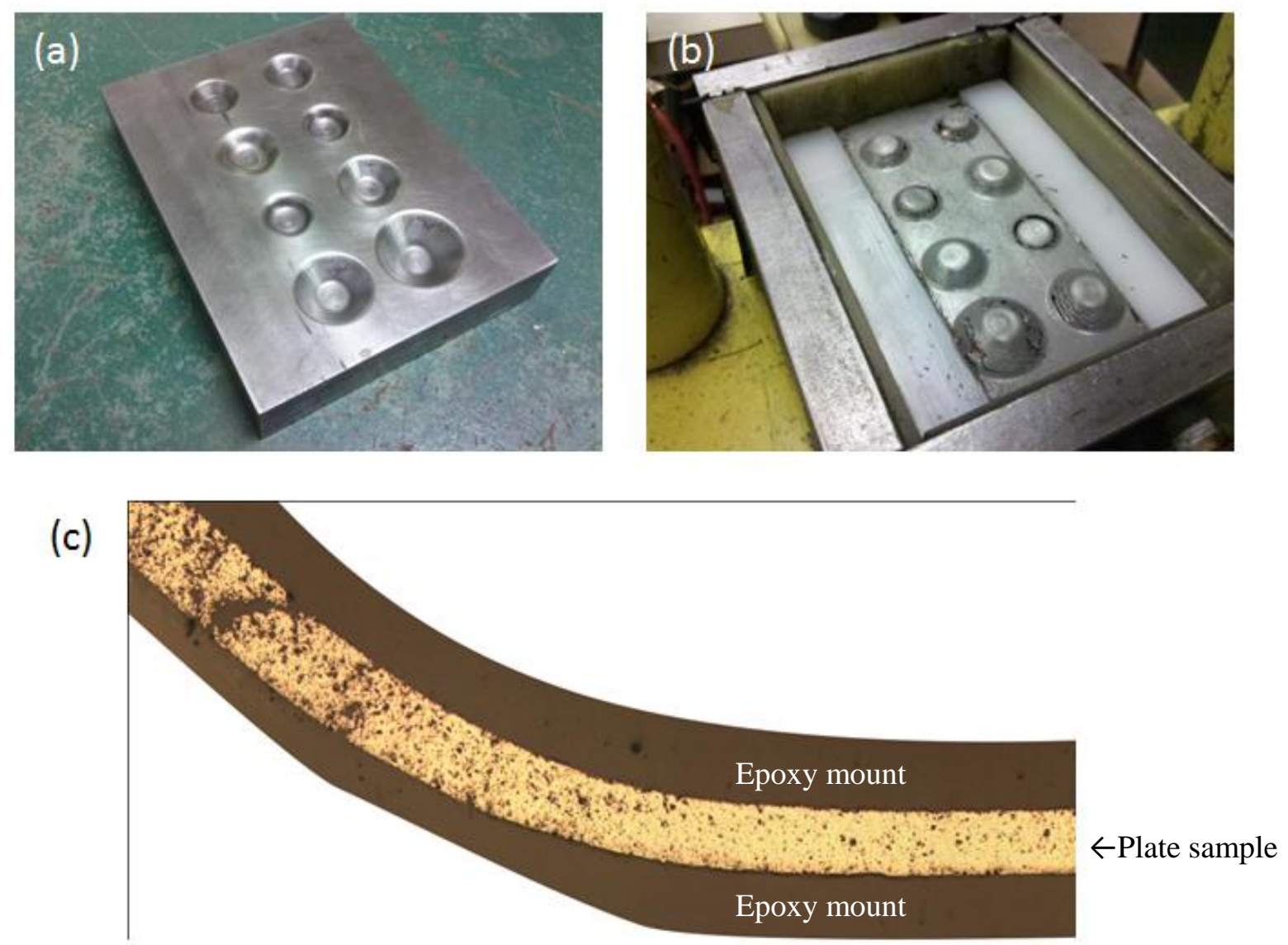

Figure 64. Pictures of high strain rate forming die (a) roll compacted titanium sheet after press deformation (b) and cross-sectional optical micrograph of the bended portion (c).

There has been much recent interest in sheet applications utilizing roll compacted Armstrong titanium powder. As such, a significant portion of the work was focused on the simultaneous compaction and forming of these sheets utilizing high strain rate techniques. The techniques used include an electromagnetic uniform pressure actuator capable of driving sheet samples, a vaporizing aluminum foil method that also drives the sample, and a newly developed electromagnetically driven kinetic energy press that strikes the material. In past work, high strain rate forming has been shown to enhance the formability of some materials. The use of these techniques with porous materials offers the added advantage of a high peak pressure to aid in consolidation, due to the material being struck or striking the die over which it is being formed. 
Using an electromagnetically driven uniform pressure actuator, 1.65" x 4" samples of as-rolled titanium sheet have been both impacted on a flat die and driven onto a flat die while velocity measurements were taken. Samples were impacted at velocities from $100 \mathrm{~m} / \mathrm{s}$ to $190 \mathrm{~m} / \mathrm{s}$. Densities greater than $97 \%$ and $88 \%$ were achieved in a single impact with the pre-sintered CP-Ti sheets and pre-sintered Ti-64, respectively. Figure 65 shows example sections of these compacted sheets.
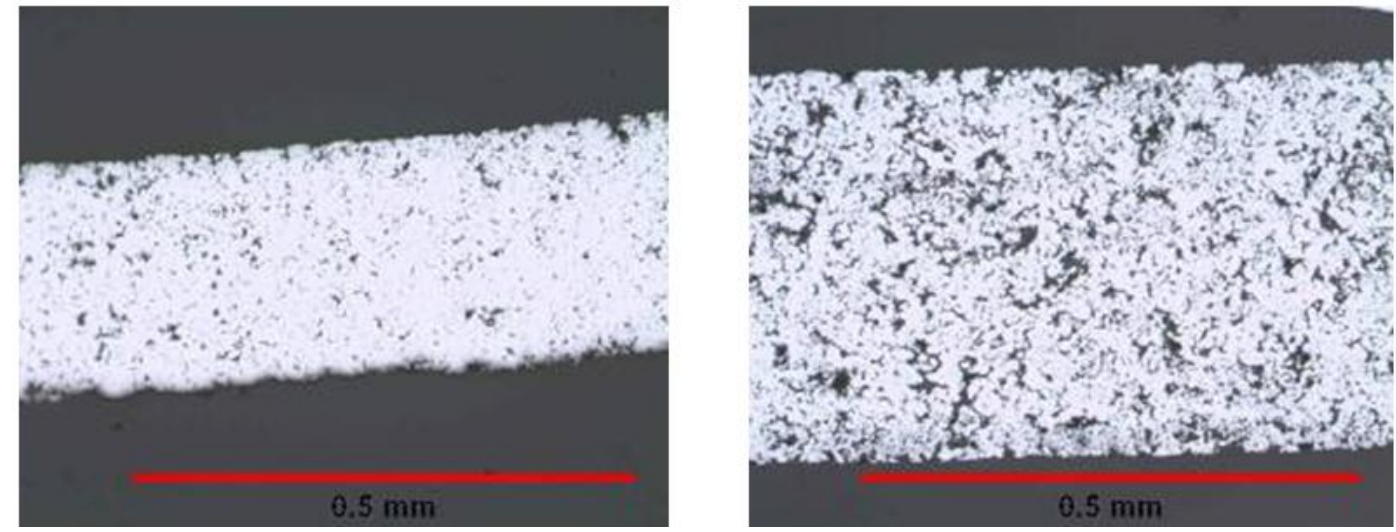

Figure 65. Optical micrographs of (left) pre-sintered CP-Ti rolled sheet and (right) pre-sintered Ti-64 sheet that have been further compacted using and electromagnetic uniform pressure actuator.

Using the same uniform pressure actuator, samples were driven over a die with channels of varying wall angles and depths. The maximum wall angle attempted was $40^{\circ}$, with a maximum depth attempted of $1 / 10$ of an inch. Using pre-sintered CP-Ti Sheets, a maximum wall angle of $34^{\circ}$ and a depth of .08 inches were attained without cracking. Due to the impact with the die, the sample was simultaneously compacted to greater $90 \%$ dense. A maximum wall angle of $37^{\circ}$ with a depth of $1 / 10^{\text {th }}$ of an inch and densities greater than $88 \%$ were achieved in the pre-sintered Ti-64 sheets. Images of these samples are show in Figure 66.
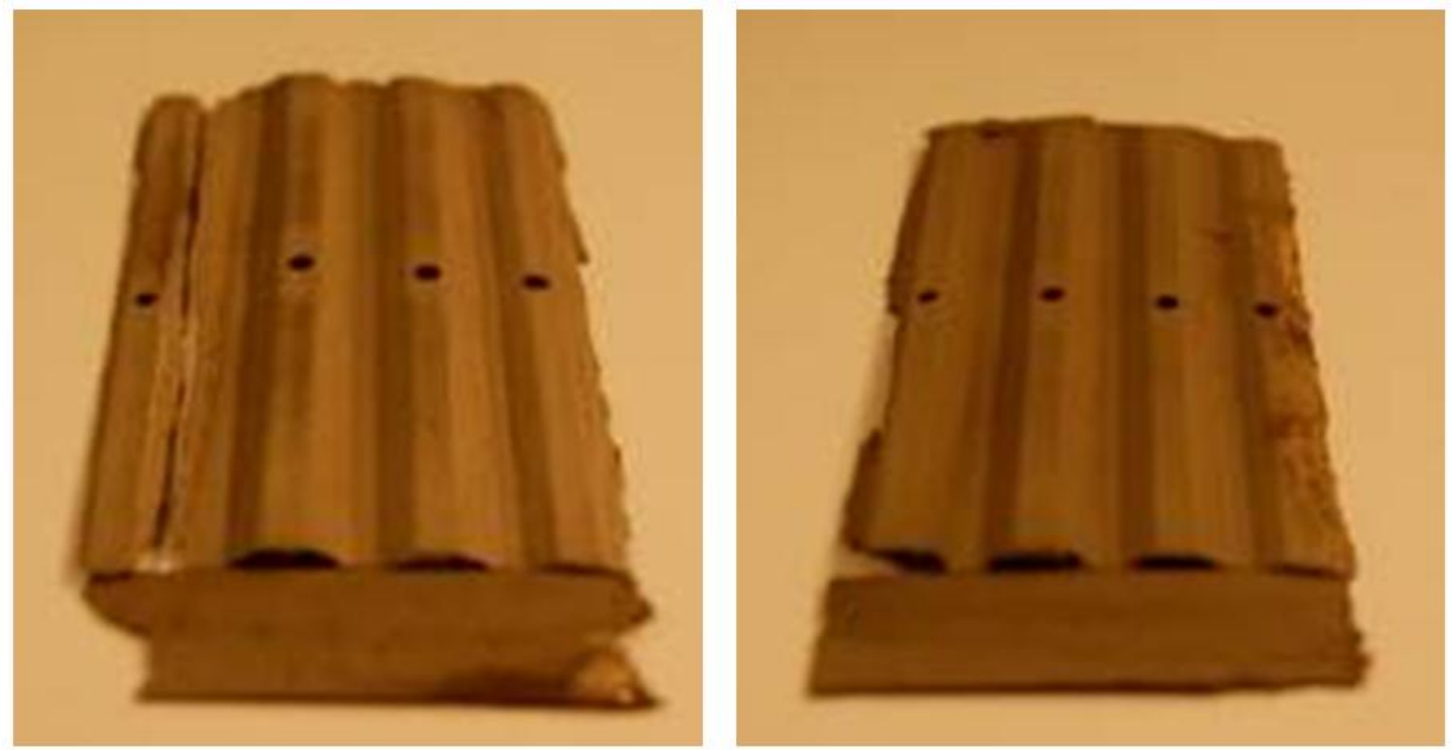

Figure 66. Images of (left) pre-sintered M9 CP-Ti rolled sheet and (right) pre-sintered Ti-64 sheet that have been formed over a channel die with an electromagnetic uniform pressure actuator. 
In addition, experiments utilizing vaporizing aluminum foils were conducted on flat samples. Using a capacitor bank, a large electric pulse is passed through a thin foil. The foil then vaporizes over 10$20 \mu$ s producing a pressure wave on the order of hundreds of Megapascals. Utilizing this method, densities of greater than $97 \%$ were produced in both the pre-sintered CP-Ti and Ti-64 roll compacted sheets.

In other related work, the effect of repeated impacts on a sample was observed using an electromagnetically driven kinetic press. Figure 67 illustrates the design of and measurement of work in a kinetic energy press. The newly developed electromagnetically driven press at OSU is capable of multiple impacts per minute with a $1 \mathrm{~kg}$ ram at $20 \mathrm{~m} / \mathrm{s}$. In this particular arrangement, a 1" coupon was placed on a flat die surface and struck by a flat ram. Each impact creates a large impulse, compacting the coupon further with each strike. After 20 cycles on an M9 CP-Ti coupon, an average density throughout the sample of $97 \%$ was achieved. At a slightly higher energy, an average density throughout the sample of $88 \%$ was achieved in the Ti-64 pre-sintered material. Figure 68 is a chart showing the change in density of these samples over a number of impacts.

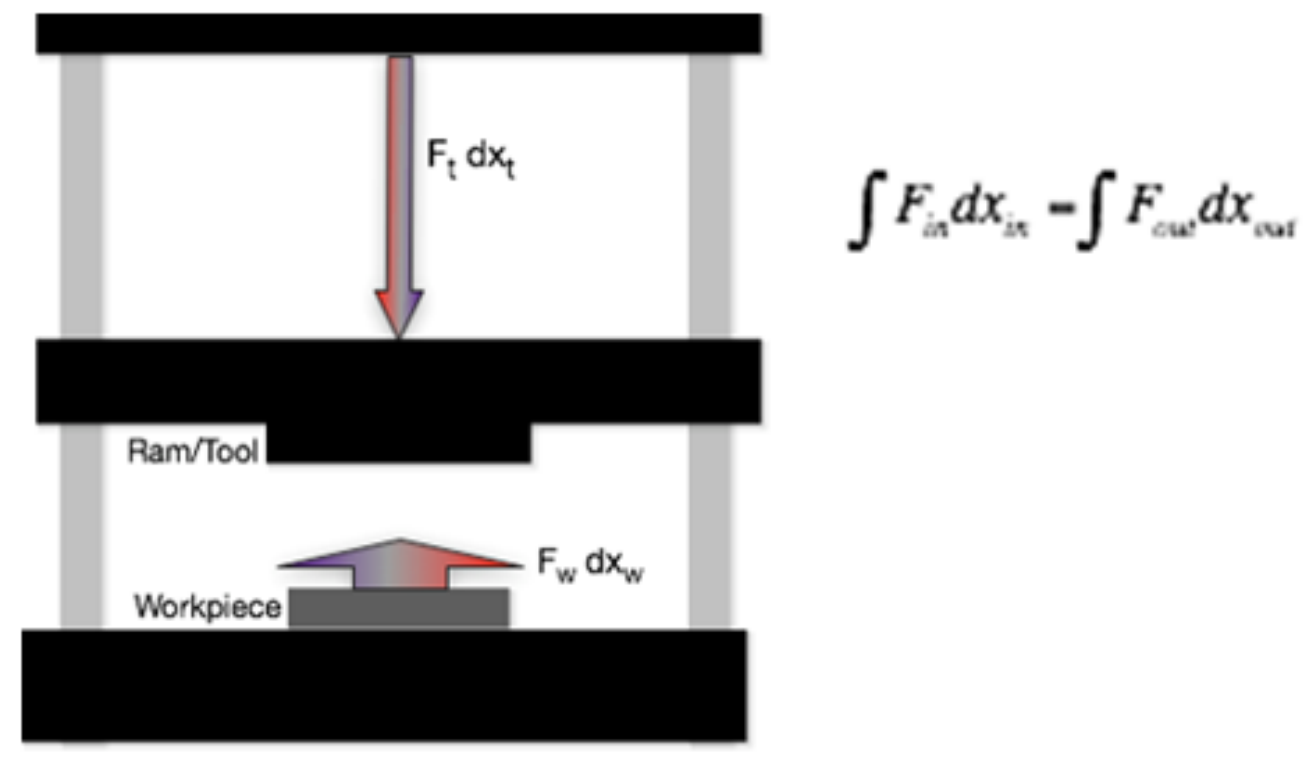

Figure 67. An impact press illustrated. A force is applied to a moving ram over a given distance acquiring a substantial amount of kinetic energy. The energy is then discharged upon impact with the work piece. The effective tonnage depends upon the distance over which the energy is dissipated into the work piece. In this sort of press arrangement, the tooling can be very lightweight as the energy results primarily from the velocity of the moving ram and not it's mass. 


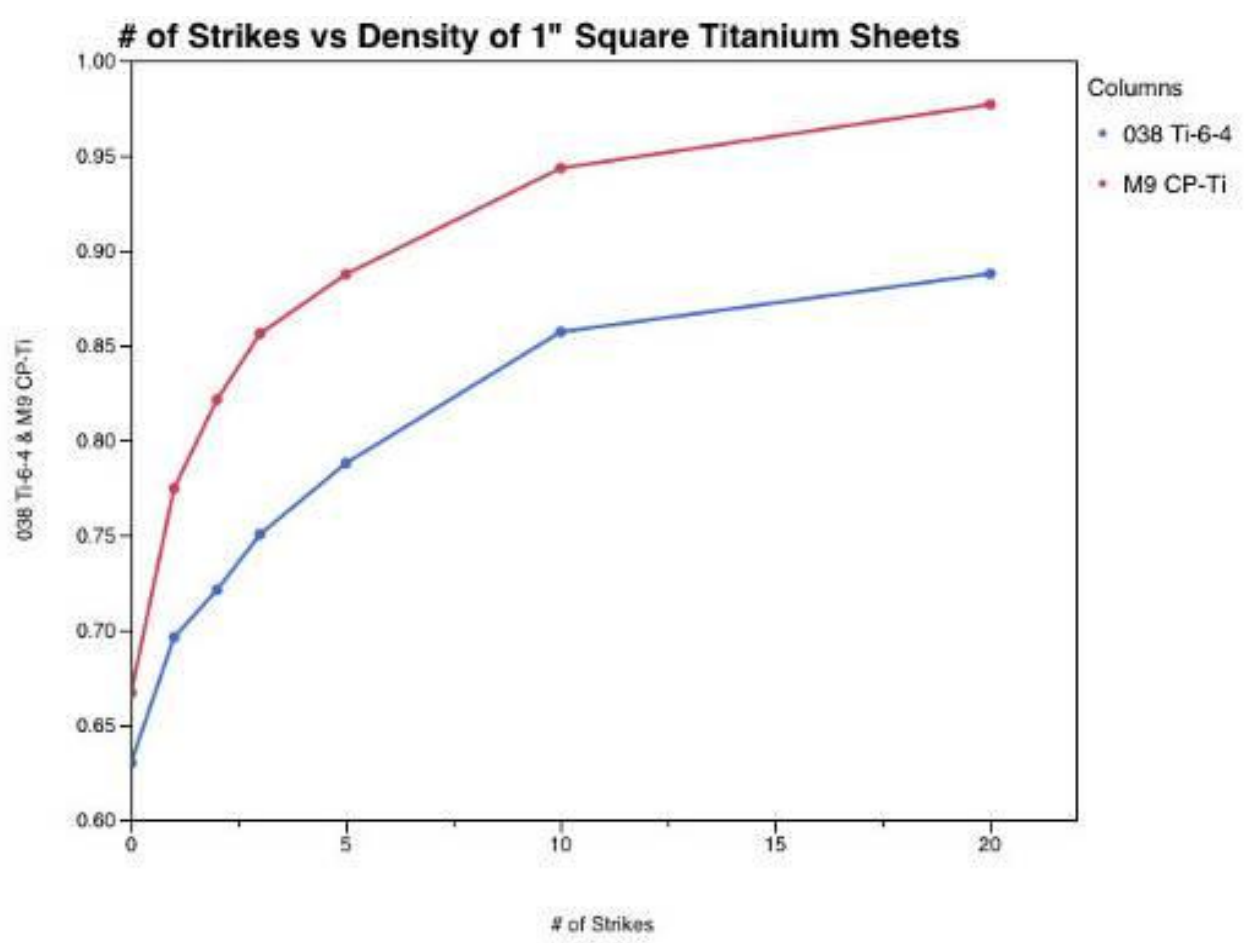

Figure 68. A chart illustrating the effect of repeated strikes of an electromagnetic press on 1" square roll-compacted titanium sheet samples.

Using these various high strain rate techniques, OSU achieved pre-sintered densities well beyond the roll compacted limits of the materials received and have simultaneously formed them in a manner which would not be possible using traditional techniques.

\subsubsection{Characterization of Fully Consolidated Plate Produced by Three Methods}

\subsubsection{Property screenings of PIFed/HIPed samples}

Monotonic tensile tests were performed on the consolidated PIFed/HIPed samples. Interstitial levels were high in the as-received powder, so ductility or elongation was anticipated to be low. Strength measurements met or were well above ASTM specifications for the HIPed samples. Increased elongation values that meet specification are anticipated for future samples that meet lower interstitial levels.

Table 20. Summary of Tensile Test Data for PIFed and HIPed P/M Titanium Samples

\begin{tabular}{cccc}
\hline \multirow{2}{*}{ Material } & \multicolumn{2}{c}{ Strength, ksi* } & Elongation, \\
\cline { 2 - 4 } & Yield & Ultimate & \%* \\
\hline CP-Ti Armstrong, PIFed (after press and sinter) & $66.4 \pm 3.2$ & $77.6 \pm 2.6$ & $9.9 \pm 2.7$ \\
\hline CP-Ti Armstrong, HIPed (after press and sinter) & $83.4 \pm 5.5$ & $101.0 \pm 3.0$ & $16.7 \pm 3.4$ \\
\hline CP-Ti Armstrong, HIPed (roll-compacted sheets) & $87.2 \pm 1.6$ & $103.3 \pm 2.0$ & $18.9 \pm 4.2$ \\
\hline ASTM B348-09 Grade 4, MIL-T-9047G CP-Ti & 70 & 80 & 15.0 \\
\hline & & $*$ & $*$ \\
\hline
\end{tabular}

Fatigue crack growth testing of fully consolidated CP-Ti and Ti-6Al-4V specimens (shown in section 3.2.1., with or without milling process, followed by press + sinter + PIF or HIP) was conducted. The results for CP-Ti samples are shown in Figure 69a, which were conducted with a frequency of $20 \mathrm{~Hz}$, and $R=0.1$. The curves of crack growth rate $(\mathrm{da} / \mathrm{dN})$ vs. stress intensity (DK) seem quite similar to each other, indicating almost no effect of the powder attritions and/or full consolidation processes on 
the properties. The fracture surface (Figure 70) and cross-sectional microstructure analyses indicated that no significant difference in the microstructure among each sample condition. The curves of Ti6Al-4V samples in Figure 69b also show almost no scattering among the different preparations, which is similar to the CP-Ti samples. The obtained crack growth rate of the Ti-6Al-4V samples, at a stress-intensity of $20 \mathrm{ksi} \sqrt{ }$ in, is in the range of a reference data of wrought titanium alloy in the ASM handbook (Table 22), indicating that the full consolidation process such as HIP/PIFing promises a good fatigue property comparable to the wrought materials.

(a) CP-Ti

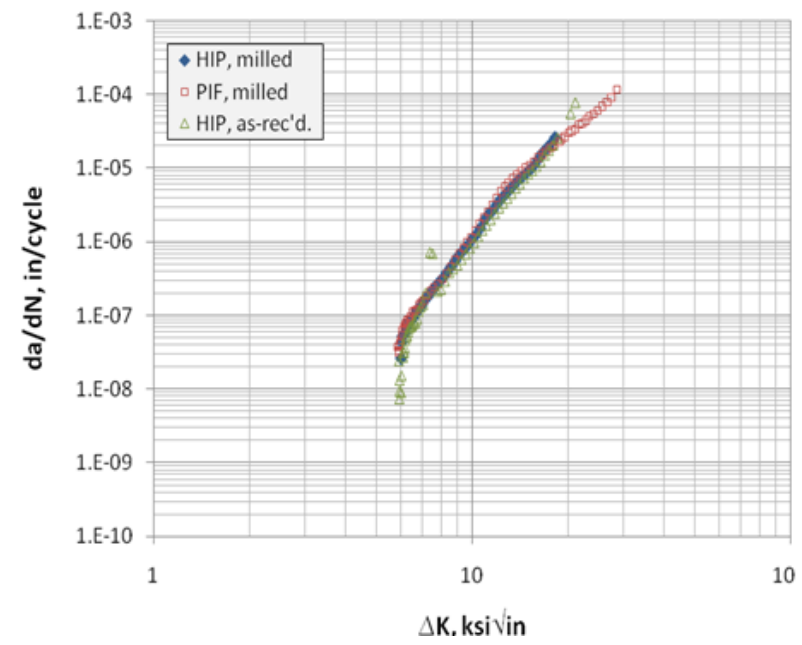

(b) Ti-6Al-4V

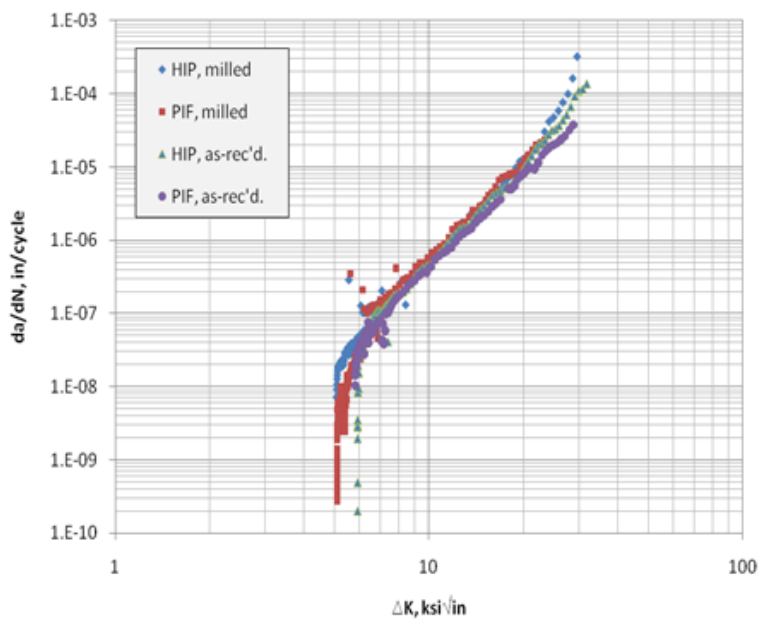

Figure 69. Fatigue crack growth rate (da/dN) as a function of stress intensity (DK) of (a) CP-Ti samples, and (b) Ti-6Al-4V.

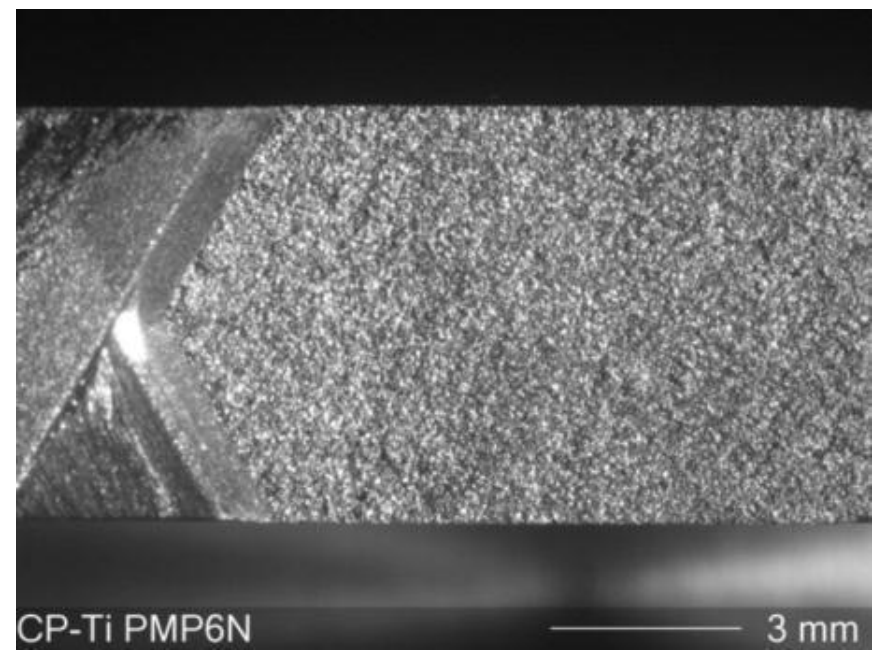

Figure 70. A fracture surface of the tested sample (CP-Ti, PIF, milled).

Table 21. FCP data for a stress-intensity (DK) of $20 \mathrm{ksi} / \mathrm{in}$, compared with a reference data*

\begin{tabular}{ll}
\multicolumn{1}{c}{ Samples } & \multicolumn{1}{c}{ da/dN, in/cycle } \\
\hline Present results (Ti-6Al-4V) & $7 \times 10^{-6} \sim 1.2 \times 10^{-5}$ \\
\hline Ti-6Al-4V, mill annealed* & $2 \times 10^{-5}$ \\
\hline
\end{tabular}

* Source: Fracture Mechanics Evaluation of B-1 Materials AFML-TR-76-137, Oct. 1976. 


\subsubsection{Sample preparation of comprehensive mechanical property evaluation}

Several block-shape samples of fully consolidated CP-Ti and Ti-6Al-4V powders made from both Armstrong process and HDH process were prepared by using press + sinter + HIP or vacuum hot press (VHP), in order to machine the specimens for tensile testing, fracture toughness testing, and fatigue crack growth rate measurement. Optimized conditions to obtain the fully consolidated materials as well as less oxygen pickup, as previously reported, were used for the sample preparation. The consolidation processes and corresponding microstructure of each specimen are summarized in Table 22 and Table 23 and Figure 71 and Figure 72, respectively.

Different types of consolidation processes were attempted in order to minimize oxygen pickup as well as full consolidation. The Armstrong CP-Ti samples contained $0.270-0.277 \mathrm{wt} \%$ oxygen which were slightly higher than the specification of ASTM Grade $2(<0.25 \mathrm{wt} \%)$. Oxygen levels of the Armstrong Ti-6Al-4V samples also were slightly out of specification of ASTM Grade 5 ( $<0.20 \mathrm{wt} \%)$. The HDH samples of both CP-Ti and Ti-6Al-4V meet the specification.

Table 22. Consolidation process of the CP-Ti specimens for property screening

\begin{tabular}{|c|c|c|c|c|}
\hline CP-Ti & Fatigue crack growth rate & $\begin{array}{l}\text { Fracture } \\
\text { toughness }\end{array}$ & Tensile properties & $\begin{array}{l}\text { Chemistry } \\
(\mathrm{O} / \mathrm{N}, \mathrm{wt} \%)\end{array}$ \\
\hline $\begin{array}{l}\text { Armstrong } \\
\text { powder }\end{array}$ & $\begin{array}{l}\text { As-received powder; } \\
\text { Die-pressed at } 5 \mathrm{ksi}+\mathrm{CIP} \text { at } 50 \mathrm{ksi} \\
\text { +Sintered at } 1300 \mathrm{C} / 1 \mathrm{~h} \\
\text { +Canless HIP at } 950 \mathrm{C} / 15 \mathrm{ksi} / 4 \mathrm{~h} \\
\text { +Mill-annealed at } 750 \mathrm{C} / 1.5 \mathrm{~h} / \mathrm{FC}\end{array}$ & \multicolumn{2}{|c|}{$\begin{array}{l}\text { Milled powder; } \\
\text { Die-pressed at } 20 \mathrm{ksi}+\mathrm{CIP} \text { at } 50 \mathrm{ksi} \\
\text { +Sintered at } 1300 \mathrm{C} / 1 \mathrm{~h} \\
\text { +Canless HIP at } 950 \mathrm{C} / 15 \mathrm{ksi} / 4 \mathrm{~h} \\
\text { +Mill-annealed at } 750 \mathrm{C} / 1.5 \mathrm{~h} / \mathrm{FC}\end{array}$} & $\begin{array}{l}0.270 / 0.009 \\
\text { (for FCGR) } \\
0.277 / 0.023 \\
\text { (for } \\
\text { FT/Tensile) }\end{array}$ \\
\hline $\mathrm{HDH}$ & \multicolumn{3}{|c|}{ Vacuum hot pressed at $950 \mathrm{C} / 2 \mathrm{ksi} / 90 \mathrm{~min}+$ Mill-annealed at $750 \mathrm{C} / 90 \mathrm{~min} / \mathrm{FC}$} & $0.228 / 0.003$ \\
\hline Wrought & \multicolumn{3}{|c|}{ Commercial rod (ASTM B348) + Mill-annealed at 750C/90min/FC } & $0.146 / 0.011$ \\
\hline
\end{tabular}
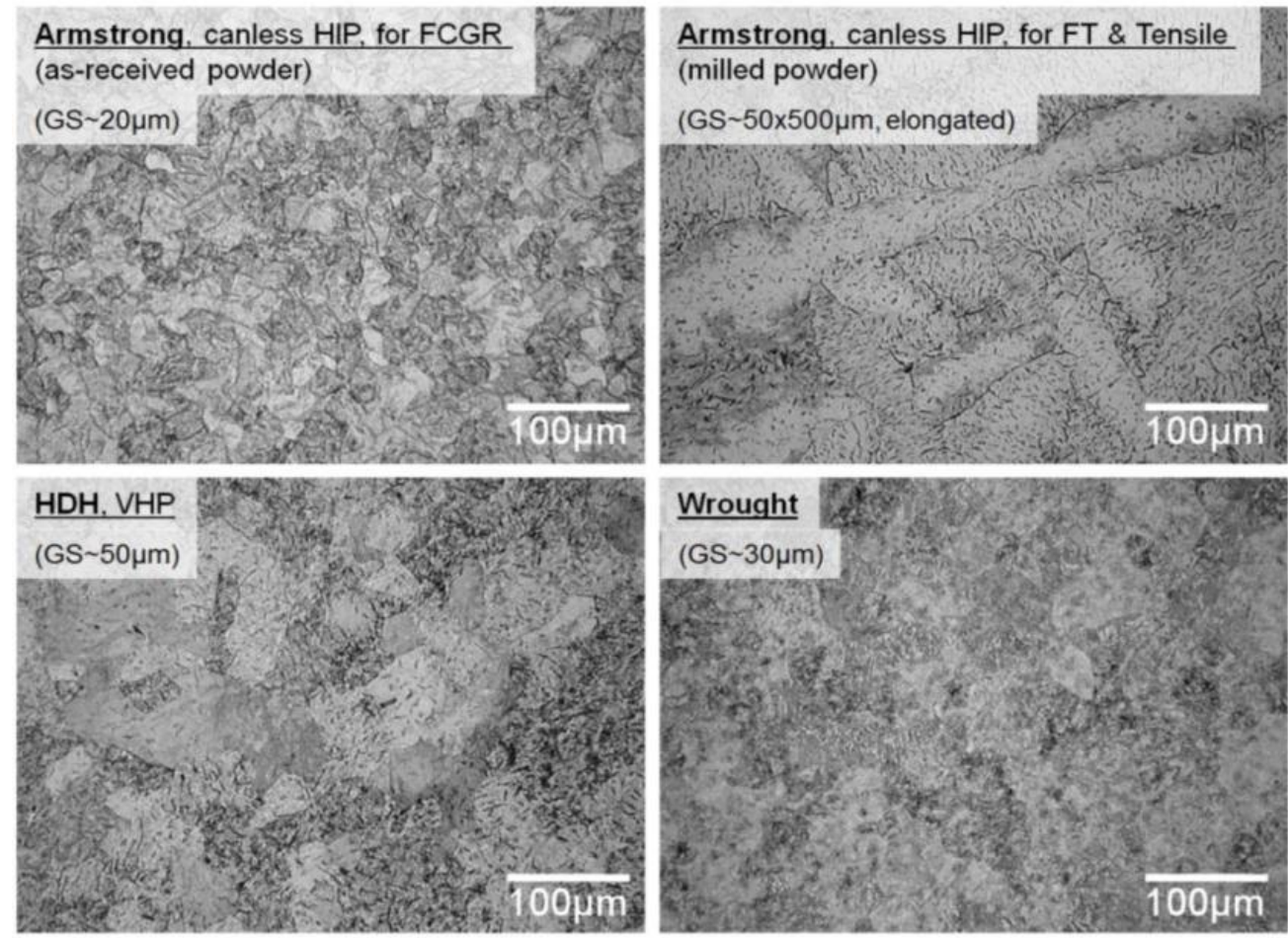

Figure 71. Optical micrographs of fully consolidated CP-Ti made from Armstrong powder (asreceived and milled), HDH powder, and commercial wrought product. 
Table 23. Consolidation process of the Ti-6Al-4V specimens for property screening

\begin{tabular}{|c|c|c|c|c|}
\hline Ti-6Al-4V & Fatigue crack growth rate & $\begin{array}{l}\text { Fracture } \\
\text { toughness }\end{array}$ & $\begin{array}{l}\text { Tensile } \\
\text { properties }\end{array}$ & $\begin{array}{l}\text { Chemistry } \\
(\mathrm{O} / \mathrm{N}, \text { wt \% })\end{array}$ \\
\hline $\begin{array}{l}\text { Armstrong } \\
\text { powder }\end{array}$ & $\begin{array}{l}\text { Milled powder; } \\
\text { Die-pressed at } 5 \mathrm{ksi}+\mathrm{CIP} \text { at } 50 \mathrm{ksi} \\
\text { +Sintered at } 1300 \mathrm{C} / 1 \mathrm{~h} \\
\text { +Canless HIP at } 950 \mathrm{C} / 15 \mathrm{ksi} / 4 \mathrm{~h} \\
\text { +Mill-annealed at } 750 \mathrm{C} / 1.5 \mathrm{~h} / \mathrm{FC}\end{array}$ & \multicolumn{2}{|c|}{$\begin{array}{l}\text { As-received powder; } \\
\text { Vacuum hot pressed at } \\
\text { 950C/2ksi/90min } \\
\text { + Mill-annealed at } \\
\text { 750C/90min/FC }\end{array}$} & $\begin{array}{l}0.275 / 0.122 \\
\text { (for FCGR) } \\
0.236 / 0.009 \\
\text { (for FT/Tensile) }\end{array}$ \\
\hline $\mathrm{HDH}$ & \multicolumn{3}{|l|}{$\begin{array}{l}\text { Canned HIP at } 950 \mathrm{C} / 15 \mathrm{ksi} / 4 \mathrm{~h} \\
\text { +Mill-annealed at } 800 \mathrm{C} / 1 \mathrm{~h} / \mathrm{AC}\end{array}$} & $0.146 / 0.023$ \\
\hline Wrought & \multicolumn{3}{|c|}{ Commercial rod (ASTM B348) + Mill-annealed at 750C/90min/FC } & $0.194 / 0.006$ \\
\hline
\end{tabular}
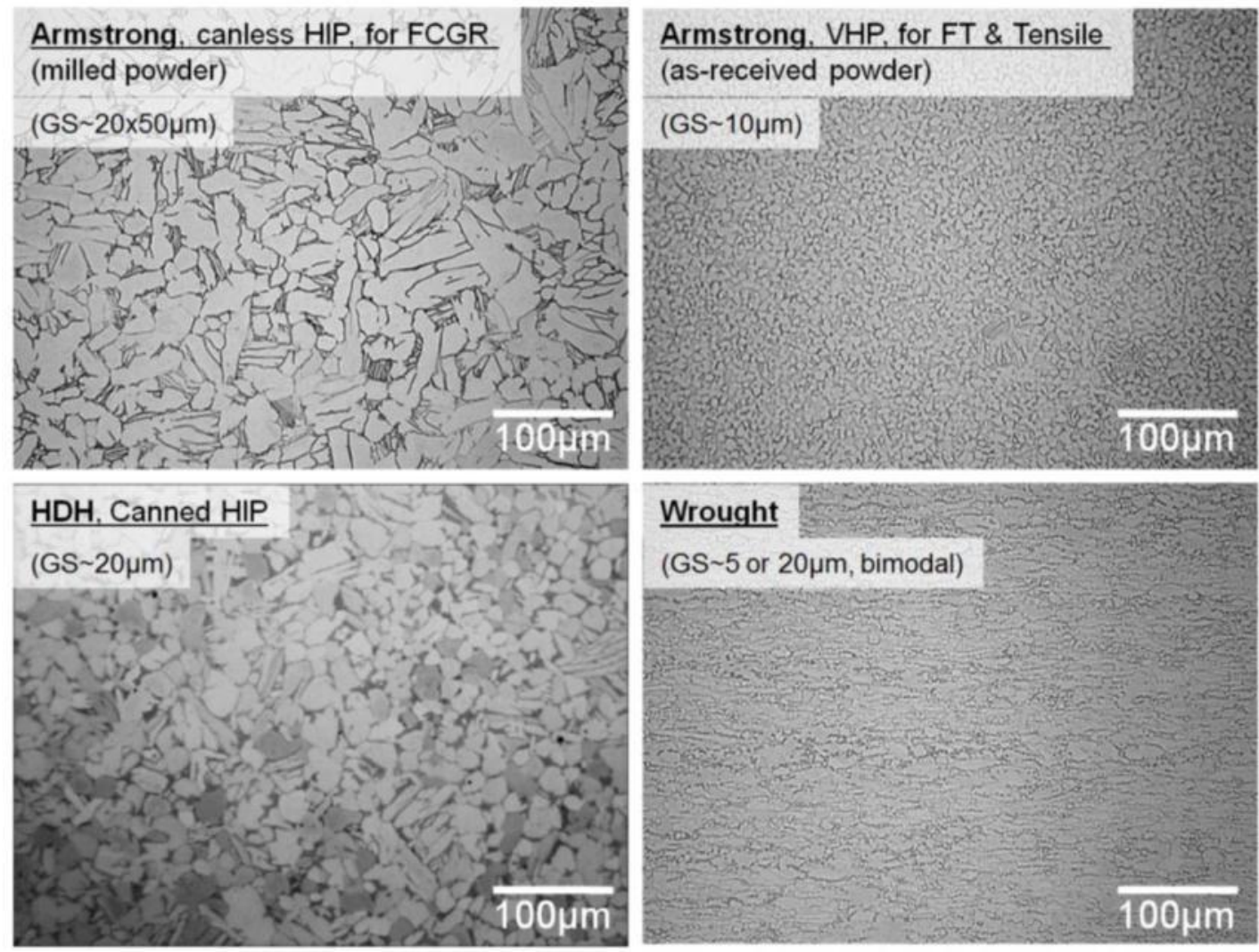

Figure 72. Optical micrographs of fully consolidated Ti-6Al-4V made from Armstrong powder (as-received and milled), HDH powder, and commercial wrought product.

Figure 71 and Figure 72, show the microstructure varies significantly to each other, which strongly depends on maximum temperature and time during consolidation process. There was some difficulty to obtain the similar microstructure by selecting different types of consolidation process. These samples were served for the mechanical property testing in section 3.3.1, so that obtained properties may depend on the microstructure and chemistry, not the nature of each process. It should be emphasized that the Armstrong CP-Ti samples consolidated from milled powder resulted in formation of elongated grains which were not ideal to expect better mechanical properties. Trial microstructure control was attempted, and the results are discussed in the latter part of this section. 


\subsubsection{Microstructure control to improve properties}

Microstructure control (grain size and morphology) of the fully consolidated Armstrong CP-Ti by using press + sinter + HIP process was attempted. The results indicate that controlled, equiaxed grain structure can be obtained by selecting relatively lower sintering temperature and proper sintering time, and subsequent HIPing process will be required to achieve full consolidation. Figure 73 shows $\mathrm{OM}$ microstructure of the fully consolidated Armstrong CP-Ti with various sintering conditions followed by HIPing. Previous consolidation study revealed that high temperature sintering, such as at $1300^{\circ} \mathrm{C}$, resulted in unexpected alpha-grain coarsening occasionally, as shown in Figure 73d, which might cause less ductility. The equi-axed grain structure would be favourable for better mechanical properties. Such microstructure with around $30 \mu \mathrm{m}$ grain size was successfully obtained as shown in Figure 73 a-Figure $73 \mathrm{c}$, by selecting lower sintering temperature such as 1100 and $1200^{\circ} \mathrm{C}$ followed by HIPing at $950^{\circ} \mathrm{C}$.

Figure 74 shows the microstructure of as-sintered CP-Ti (before HIPing) at 1100 and $1200^{\circ} \mathrm{C}$. The sintering for $1 \mathrm{~h}$ at both temperatures (Figure 74a and Figure 74c) showed no inter-connected porosity remained in the microstructure. However, the immersion density measurements indicated $13 \%$ and $2.5 \%$ of the open porosity existed in the samples sintered at 1100 and $1200^{\circ} \mathrm{C}$ (for $1 \mathrm{~h}$ ), respectively (Table 24). The open porosity needs to be eliminated for full consolidation by subsequent HIPing process without canning. Further sintering for total $24 \mathrm{~h}$ at $1100^{\circ} \mathrm{C}$ and $4 \mathrm{~h}$ at $1200^{\circ} \mathrm{C}$ (Figure $74 \mathrm{~b}$ and Figure $74 d$, respectively) did not change the microstructure as well as the density, as shown in the figures or in Table 24 . However, the open porosity decreased to less than $1 \%$, which led a successful full consolidation after HIPing process.
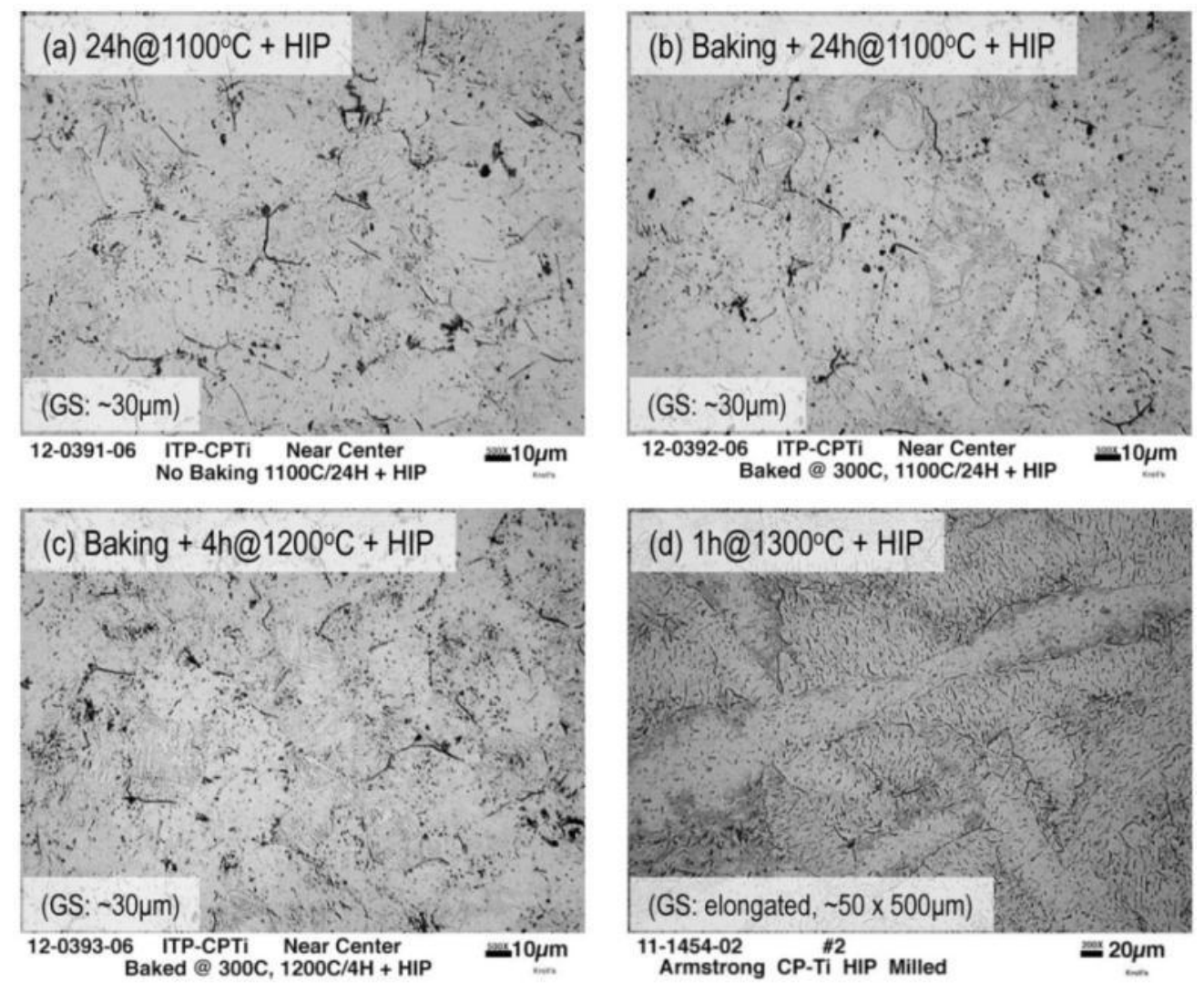

Figure 73. OM microstructure of fully consolidated Armstrong CP-Ti sintered with various conditions and then HIPed at $950^{\circ} \mathrm{C} / 15 \mathrm{ksi} / 4 \mathrm{~h}$; (a) sintered at $1100^{\circ} \mathrm{C} / 24 \mathrm{~h}$, (b) baked at $300^{\circ} \mathrm{C} / 4 \mathrm{~h}$ and sintered at $1100^{\circ} \mathrm{C} / 24 \mathrm{~h}$, (c) baked at $300^{\circ} \mathrm{C} / 4 \mathrm{~h}$ and sintered at $1200^{\circ} \mathrm{C} / 4 \mathrm{~h}$, and (d) sintered at $1300^{\circ} \mathrm{C} / 1 \mathrm{~h}$ 
Table 24. Density and open porosity of Armstrong CP-Ti during consolidation process

\begin{tabular}{|c|c|c|c|c|}
\hline \multirow{2}{*}{ Conditions } & \multicolumn{4}{|c|}{ Density $\left(\mathrm{g} / \mathrm{cm}^{3}\right) /$ Open porosity $(\%)$} \\
\hline & as pressed* & $\left(1100^{\circ} \mathrm{C} / 1 \mathrm{~h}\right)$ & $1100^{\circ} \mathrm{C} / 24 \mathrm{~h}$ & +HIP@950 ${ }^{\circ} \mathrm{C} / 15 \mathrm{ksi} / 4 \mathrm{~h}$ \\
\hline No baking & $73.6 /-$ & $81.8 / 13.3$ & $82.9 / 0.7$ & $100 / 0$ \\
\hline \multirow[t]{2}{*}{ Baked at $300^{\circ} \mathrm{C} / 4 \mathrm{~h}$} & $75.3 /-$ & $81.9 / 13.3$ & $83.0 / 0.3$ & $100 / 0$ \\
\hline & as pressed* & $\left(1200^{\circ} \mathrm{C} / 1 \mathrm{~h}\right)$ & $1200^{\circ} \mathrm{C} / 4 \mathrm{~h}$ & $+\mathrm{HIP} @ 950^{\circ} \mathrm{C} / 15 \mathrm{ksi} / 4 \mathrm{~h}$ \\
\hline Baked at $300^{\circ} \mathrm{C} / 4 \mathrm{~h}$ & $74.4 /-$ & $84.5 / 2.5$ & $85.4 / 0.1$ & $100 / 0$ \\
\hline
\end{tabular}

* die-ressed at $20 \mathrm{ksi}+$ CIPed at $50 \mathrm{ksi}$
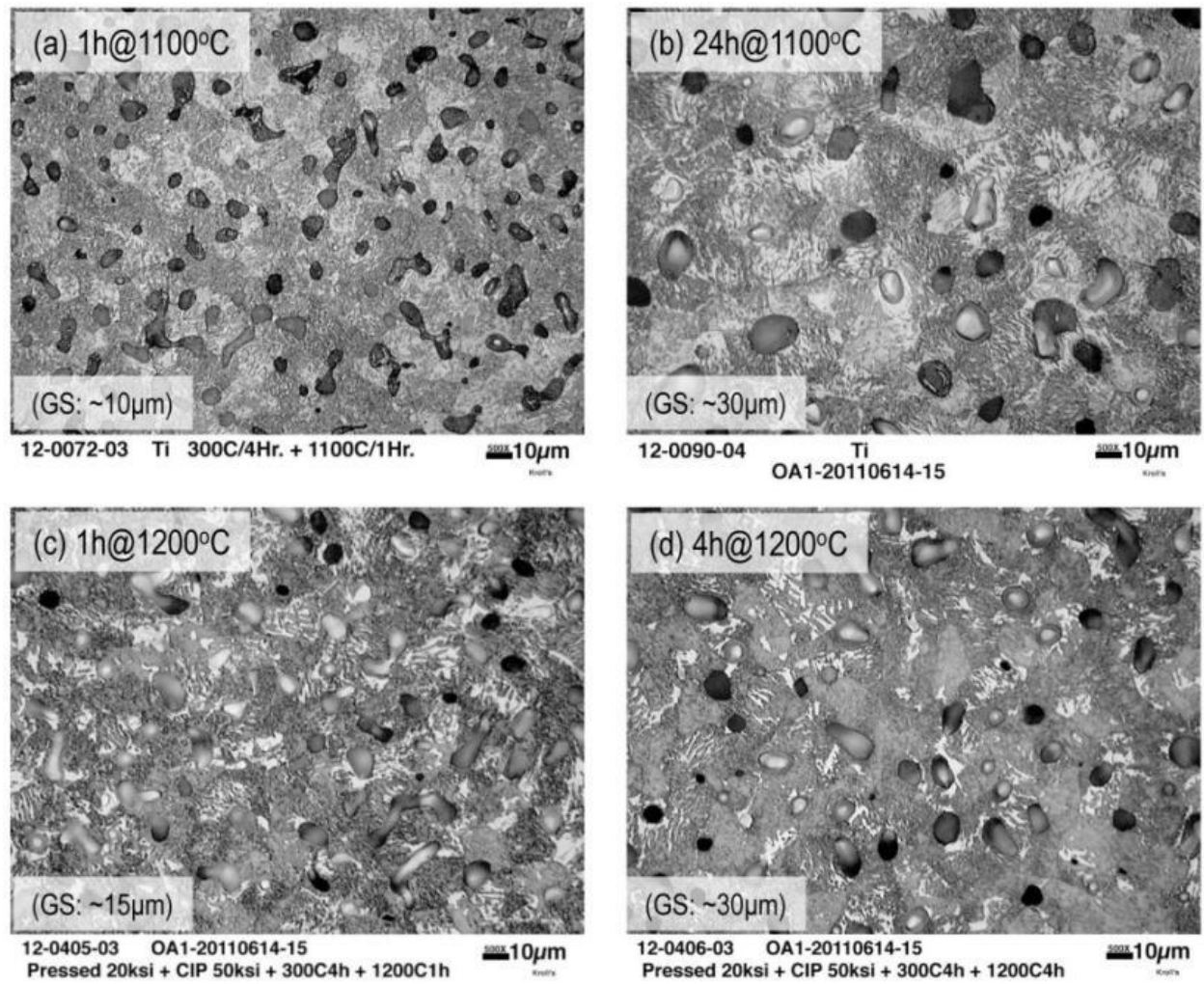

Figure 74. OM microstructure of sintered Armstrong CP-Ti sintered with various conditions (before HIPing); sintered at (a) $1100^{\circ} \mathrm{C} / 1 \mathrm{~h}$, (b) $1100^{\circ} \mathrm{C} / 24 \mathrm{~h}$, (c) $1200^{\circ} \mathrm{C} / 1 \mathrm{~h}$, and (d) $1200^{\circ} \mathrm{C} / 4 \mathrm{~h}$.

Literature reports [37] that moisture $\left(\mathrm{H}_{2} \mathrm{O}\right)$ on the titanium surface could be a source of oxygen by decomposition of $\mathrm{H}_{2} \mathrm{O}$ during heating above $\sim 350^{\circ} \mathrm{C}$. Therefore, some of the as-pressed specimens were baked at $300^{\circ} \mathrm{C} / 4 \mathrm{~h}$ in a vacuum prior to the sintering process, in order to reduce the potential oxygen pickup during heating. The chemical analysis after HIPing (in Table 25) indicated that a significant amount of oxygen pickup was observed after sintering (from 0.24 to $0.45 \mathrm{wt} \%$ ) when no baking process was applied. However, the amount of oxygen pickup was drastically reduced (to 0.36 $\mathrm{wt} \%$ ) when the sample was baked. It still needs to be figured out what is the source of the oxygen pickup even after baking, but the effect of baking seemed very positive. Note that the sintered samples showed relatively higher oxygen contents compared to the HIPed samples, which could be due to the pores on the sample surface for chemical analysis acting as a sink of contaminants. Further analysis of the degas behaviour during baking process by using TPD-MS (temperature programed desorption mass spectrometry) was also attempted, which supported the discussion presented above. 
Table 25. Density and open porosity of Armstrong CP-Ti during consolidation process

\begin{tabular}{|c|c|c|c|c|}
\hline \multirow{2}{*}{ Conditions } & \multicolumn{4}{|c|}{ Oxygen / Nitrogen (wt\%) } \\
\hline & Powder* & $\left(1100^{\circ} \mathrm{C} / 1 \mathrm{~h}\right)$ & $1100^{\circ} \mathrm{C} / 24 \mathrm{~h}$ & HIP@950 C/15ksi/4h \\
\hline No baking & $0.239 / 0.020$ & $(0.363 / 0.027)$ & - & $0.450 / 0.027$ \\
\hline \multirow[t]{2}{*}{ Baked at $300^{\circ} \mathrm{C} / 4 \mathrm{~h}$} & $0.239 / 0.020$ & $(0.358 / 0.025)$ & $(0.404 / 0.028)$ & $0.361 / 0.022$ \\
\hline & as pressed* & $\left(1200^{\circ} \mathrm{C} / 1 \mathrm{~h}\right)$ & $1200^{\circ} \mathrm{C} / 4 \mathrm{~h}$ & $\mathrm{HIP} @ 950^{\circ} \mathrm{C} / 15 \mathrm{ksi} / 4 \mathrm{~h}$ \\
\hline Baked at $300^{\circ} \mathrm{C} / 4 \mathrm{~h}$ & $0.239 / 0.020$ & $(0.361 / 0.024)$ & $(0.406 / 0.029)$ & $0.377 / 0.024$ \\
\hline
\end{tabular}

* Armstrong CP-Ti (ID: OA1-20110614-15), vibratory-milled in deionized water for 10min

\subsection{TASK 3: FABRICATION OF PROTOTYPE OF NEAR NET SHAPE COMPONENTS AND OEM VALIDATION}

Task 3 was performed to fabricate and validate with the OEMs (i.e., Lockheed Martin and a pump manufacturer) net shape components fabricated by the powder metallurgy and/or additive manufacturing process methodologies developed in the project. In general, positive feedback was received by the OEMs associated with the project. The bracket was the primary thrust of this task. Though both powder metallurgy and additive manufacturing exhibited positive results for this particular application, additive manufacturing is most attractive due to the versatility of potential components made with conventional low buy to fly ratios, and the projected costs. Table 26 provides an overview of the processes evaluated and the selected process by the industrial partner.

Table 26. List of powder materials, processes conducted, and optimum process for full consolidation in Section 3.3.

\begin{tabular}{|c|c|c|c|}
\hline Task & Materials & Process & Selected process \\
\hline \multirow{3}{*}{$\begin{array}{c}\text { Task 3: } \\
\text { Fabrication of } \\
\text { near net shape } \\
\text { components }\end{array}$} & $\begin{array}{l}\text { Ti-6Al-4V, } \\
\text { T-bracket }\end{array}$ & $\begin{array}{l}\text { Section } 3.1 .4 \\
\text { Press + Sinter (required machining with } 4: 1 \text { of } \\
\text { "buy to fly" ratio) +HIP } \\
\text { Section } 3.3 .2 \\
\text { E-beam deposition } \\
\text { E-beam deposition + HIP } \\
\end{array}$ & $\begin{array}{l}\text { E-beam deposition + HIP achieved } \\
\text { essentially } 1: 1 \text { buy to fly ratio. }\end{array}$ \\
\hline & $\begin{array}{l}\text { Ti-6Al-4V, } \\
\text { Impeller }\end{array}$ & $\frac{\text { Section } 3.3 .2}{\text { E-beam deposition }}$ & $\begin{array}{l}\text { E-beam deposition successfully reduced } \\
\text { the component weight by } 55 \% \text { with an } \\
\text { optimized designing. }\end{array}$ \\
\hline & $\begin{array}{l}\text { Ti-6Al-4V, } \\
\text { Tube }\end{array}$ & \begin{tabular}{|l|} 
Section 3.3.3. \\
Can + Hot-extrusion
\end{tabular} & Achieved more than $99.8 \%$ TD. \\
\hline
\end{tabular}

\subsubsection{Comprehensive Mechanical Properties Evaluation}

A more comprehensive range of mechanical testing was performed in task 3 to provide properties that would be of interest for most aircraft and industrial applications. Tensile properties, fracture toughness, fatigue crack growth rates, and high cycle fatigue are some of the mechanical tests that were performed. Table 27 covers the tests performed for each material and how the properties compared to wrought product and/or specification. It is important to keep in mind that this does not mean the material is good or bad, but rather identifies if the material meets the current standards. In many cases, these standards were initiated due to requirements in the aircraft industry. 


\begin{tabular}{|c|c|c|c|c|c|c|c|c|}
\hline 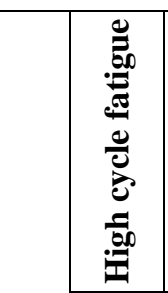 & ' & 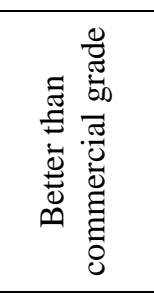 & 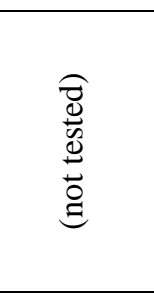 & 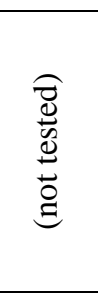 & ' & 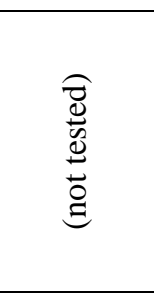 & 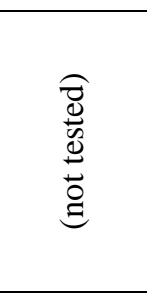 & 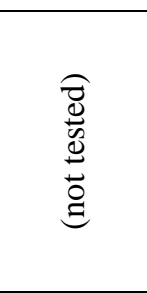 \\
\hline \multirow{3}{*}{ 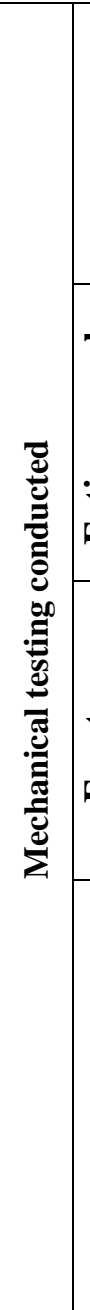 } & ' & 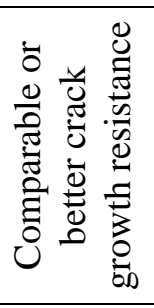 & 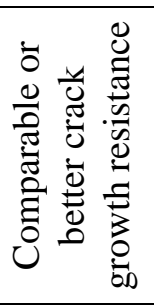 & 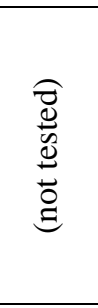 & ' & 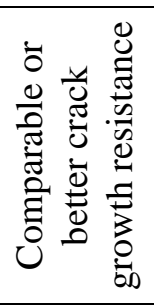 & 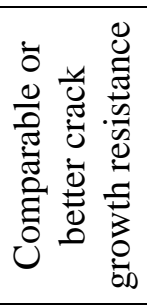 & 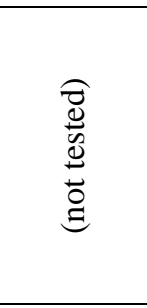 \\
\hline & 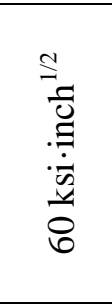 & 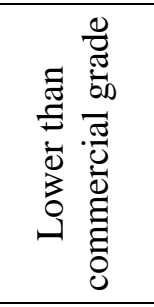 & 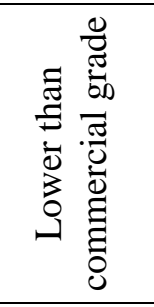 & 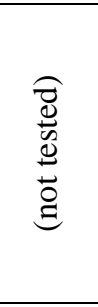 & 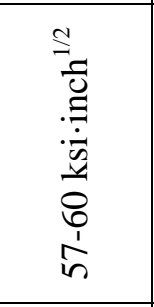 & 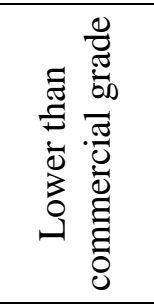 & 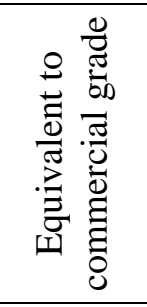 & 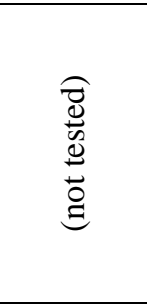 \\
\hline & 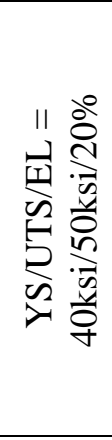 & 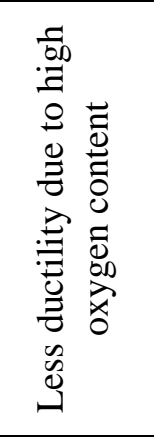 & 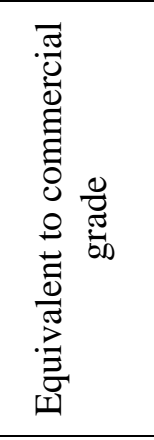 & 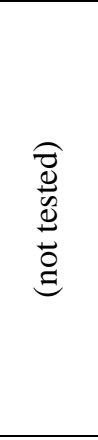 & 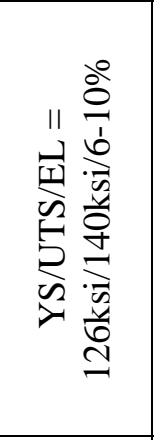 & 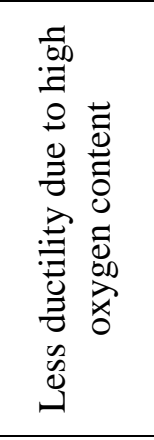 & 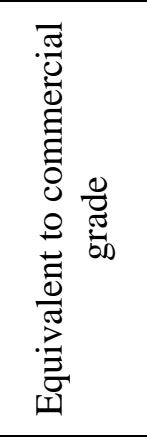 & 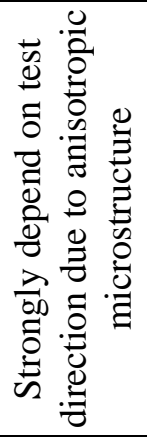 \\
\hline$\frac{d}{2}$ & 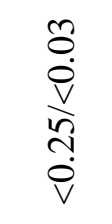 & 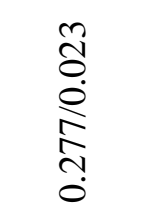 & \begin{tabular}{l}
$\infty$ \\
8 \\
$\stackrel{0}{0}$ \\
\multirow{1}{1}{} \\
0
\end{tabular} & $\frac{\nwarrow}{\mathrm{Z}}$ & 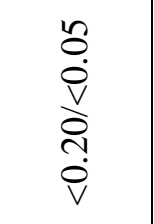 & $\begin{array}{l}8 \\
8 \\
0 \\
0 \\
0 \\
\\
0\end{array}$ & $\begin{array}{l}\stackrel{3}{0} \\
\grave{\delta} \\
\dot{0} \\
\dot{0}\end{array}$ & $\frac{\mathbb{Z}}{\mathrm{z}}$ \\
\hline 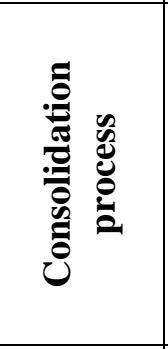 & $\sum_{\substack{\infty \\
\infty}}^{\infty}$ & 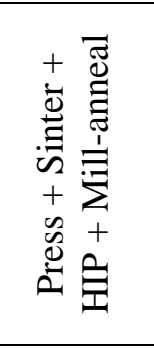 & 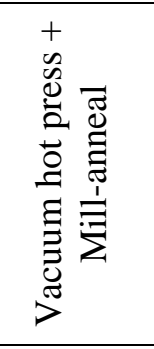 & 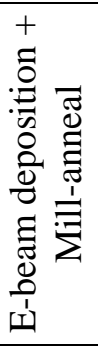 & 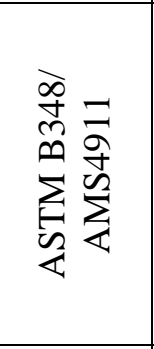 & 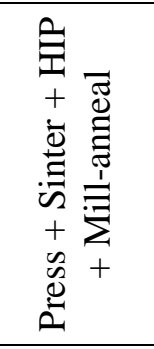 & 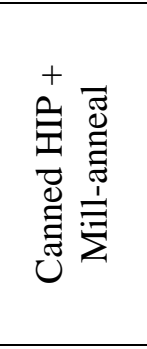 & 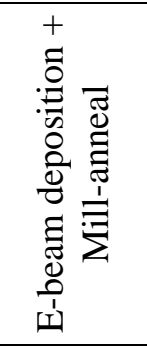 \\
\hline 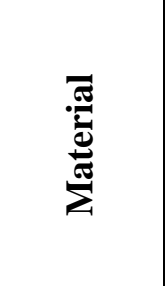 & 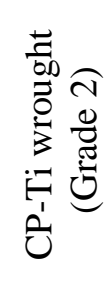 & 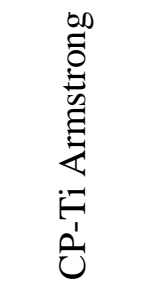 & 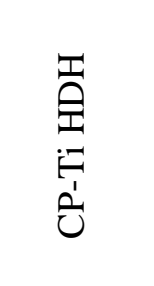 & 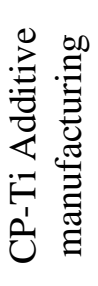 & 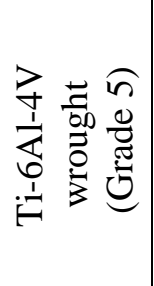 & 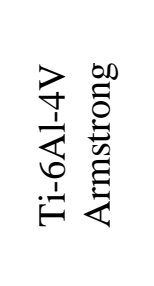 & 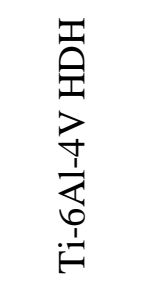 & 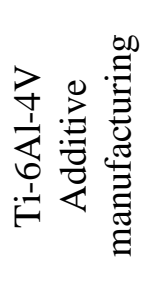 \\
\hline
\end{tabular}




\subsubsection{Tensile properties}

Monotonic tensile testing can provide such properties as yield strength, ultimate tensile strength, elasticity, and elongation to failure. These properties are important to almost all aspects of design and engineering, and are needed for both critical and non-critical applications. Mechanical property evaluation of commercial titanium products was conducted at first, in order to evaluate the standard material properties under the same test conditions as the materials processed/tested at ORNL. Several sub-sized dog-bone shape tensile specimens shown in Figure 75 were cut from commercial CP-Ti and Ti-6Al-4V bars (ASTM B348 with D 2" x L 12" size, Grade 2 and Grade 5, respectively), which were sectioned parallel and perpendicular to the bar axis. Table 28 summarizes the tensile properties at room temperature. They show a good agreement with the listed properties in the literature [38]. The difference of the properties between parallel and perpendicular to the bar axis would be due to the grain structure elongated along with the bar axis. These data was used for the direct comparison with the materials processed at ORNL.

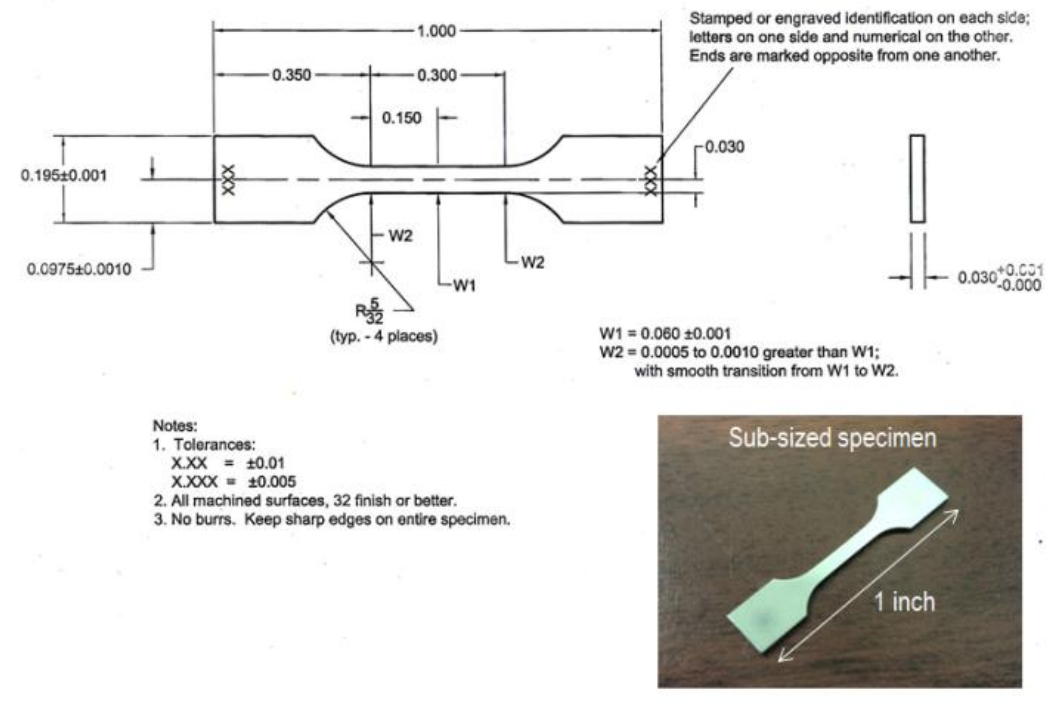

Figure 75. Drawing and a picture of miniature tensile specimen

Table 29 summarizes the room temperature tensile properties of the PM materials (as processed in tables 20 and 21) and commercial wrought product tested in the same experiment. All values were then compared to the ASTM standard values. Sub-sized tensile specimens were cut from the bulk plate samples prepared in the project (see section 3.2.4), and then tested at room temperature. More than three specimens were tested, and the average properties are shown in the table. For CP-Ti, all materials exceeded minimum requirement of the yield and the ultimate tensile strengths. However, the consolidated Armstrong powder showed less ductility than the minimum requirement, which could be due to relatively higher oxygen content at consolidated state as well as the coarse and elongated grain structure, as shown in Figure 71. Proper microstructure control can improve the ductility, but suppression of the oxygen level is also required. HDH CP Ti had very good ductility exceeding the ASTM minimum and the wrought samples; this demonstrates that PM components can exceed wrought product in strength and ductility if chemistries are within specification. Similar to $\mathrm{CP}-\mathrm{Ti}$ results, most of the Ti-6Al-4V properties exceeded the minimum requirement except for the ductility of the consolidated Armstrong powder, which could also be due to relatively higher oxygen pickup.

Table 30 summarizes the tensile properties of the consolidated Armstrong CP-Ti with optimized microstructure control (equi-axied grain formation) discussed in section 3.2.4 and shown in Figure 73. Although all three materials contained high oxygen compared to the sample shown in Table 29, 
the latter two samples had a "baking" process added $\left(300^{\circ} \mathrm{C}\right.$ for four hours $)$ after pressing and before sintering which successfully improved their ductility. This process was added after original results (covered in Task 1) were high in oxygen to drive off any residual water vapor absorbed on the surface of the powder particles that would increase the overall oxygen content.

Table 28. Average mechanical properties for the commercially processed titanium bars

\begin{tabular}{ccccc}
\hline Specimen & Direction & YS, ksi & UTS, ksi & Total Elongation, \% \\
\hline Grade 2 (CP- & // bar axis & $56.0 \pm 0.5$ & $56.0 \pm 0.5$ & $26.0 \pm 0.9$ \\
Ti) & $\perp$ bar axis & $66.9 \pm 1.5$ & $78.2 \pm 1.8$ & $18.4 \pm 0.6$ \\
\hline Grade 5 & // bar axis & $136 \pm 1.0$ & $144 \pm 1.0$ & $17.7 \pm 1.4$ \\
(Ti-6Al-4V) & $\perp$ bar axis & $130 \pm 1.0$ & $135 \pm 1.1$ & $10.4 \pm 0.6$ \\
\hline
\end{tabular}

Table 29. Tensile properties and chemistry of fully consolidated PM titanium powders and commercial wrought titanium product. ASTM/ASM minimum requirement properties are also listed. YS: yield strength, UTS: ultimate tensile strength, and EL: plastic deformation to fracture

\begin{tabular}{lllll}
\hline CP-Ti & YS, ksi & UTS, ksi & EL, \% & O/N, wt\% \\
\hline Armstrong (HIP) & $86 \pm 2$ & $96 \pm 5$ & $9 \pm 3$ & $0.277 / 0.023$ \\
\hline $\begin{array}{l}\text { HDH (Vacuum Hot Pressed, } \\
\text { VHP) }\end{array}$ & $74 \pm 2$ & $88 \pm 2$ & $25 \pm 4$ & $0.228 / 0.003$ \\
\hline Wrought (Grade 2) & $57 \pm 3$ & $70 \pm 7$ & $20 \pm 7$ & $0.146 / 0.011$ \\
\hline $\begin{array}{l}\text { ASTM B265 } \\
\text { minimum requirement }\end{array}$ & 40 & 50 & 20 & $<0.25 /<0.03$ \\
\hline & $\mathbf{Y S}, \mathbf{k s i}$ & $\mathbf{U T S}, \mathbf{k s i}$ & $\mathbf{E L}, \boldsymbol{\%}$ & $\mathbf{O} / \mathbf{N}, \mathbf{w t} \%$ \\
\hline Ti-6Al-4V & $137 \pm 4$ & $140 \pm 4$ & $9 \pm 4$ & $0.236 / 0.009$ \\
\hline Armstrong (VHP) & $144 \pm 3$ & $150 \pm 3$ & $12 \pm 1$ & $0.146 / 0.023$ \\
\hline HDH (HIP) & $139 \pm 7$ & $146 \pm 8$ & $12 \pm 4$ & $0.194 / 0.006$ \\
\hline Wrought (Grade 5) & 126 & 134 & $6-10$ & $<0.20 /<0.05$ \\
\hline $\begin{array}{l}\text { AMS-4911 } \\
\text { minimum requirement } \\
\text { (thickness, up to 0.1875") }\end{array}$ & & & & \\
\hline
\end{tabular}

Table 30. Tensile properties of fully consolidated Armstrong CP-Ti powder with various consolidation processes and ASTM minimum requirement

\begin{tabular}{llllll}
\hline \multirow{2}{*}{ Samples } & \multicolumn{2}{l}{ Properties (average) } & \multicolumn{3}{c}{ Chemistry } \\
\cline { 2 - 6 } & YS, ksi & UTS, ksi & $\mathbf{E L , ~ \% ~}$ & $\mathbf{O , ~ w t \%}$ & $\mathbf{N}, \mathbf{w t} \%$ \\
\hline No bake + 1100C/24h + HIP & $118 \pm 5$ & $123 \pm 4$ & $6.1 \pm 4.6$ & 0.450 & 0.027 \\
\hline Baked + 1100C/24h + HIP & $104 \pm 1$ & $116 \pm 1$ & $13.7 \pm 1.9$ & 0.361 & 0.022 \\
\hline Baked + 1200C/4h + HIP & $107 \pm 10$ & $116 \pm 5$ & $12.1 \pm 2.7$ & 0.377 & 0.024 \\
\hline (no bake + 1300C/1h + HIP) & $86 \pm 2$ & $96 \pm 5$ & $9 \pm 3$ & 0.277 & 0.023 \\
\hline Grade 2 (ASTM B265/B348) & 40 & 65 & 20 & 0.25 & 0.03 \\
\hline Grade 3 (ASTM B265/B348) & 55 & 80 & 18 & 0.35 & 0.05 \\
\hline Grade 4 (ASTM B265/B348) & 70 & 95 & 15 & 0.4 & 0.05 \\
\hline
\end{tabular}




\subsubsection{Fracture toughness}

Figure 76 shows the drawing of fracture toughness test specimen used in this study. Fracture toughness of the materials is listed in Table 31. In general, the PM components showed lower fracture toughness values compared to wrought plate. The attributing factors could be the finer grain structure associated with the PM materials tested, and the presence of interstitials. The PM materials with higher oxygen pickup (the Armstrong and the HDH CP-Ti, and the Armstrong Ti-6Al-4V) tend to show lower fracture toughness than others.

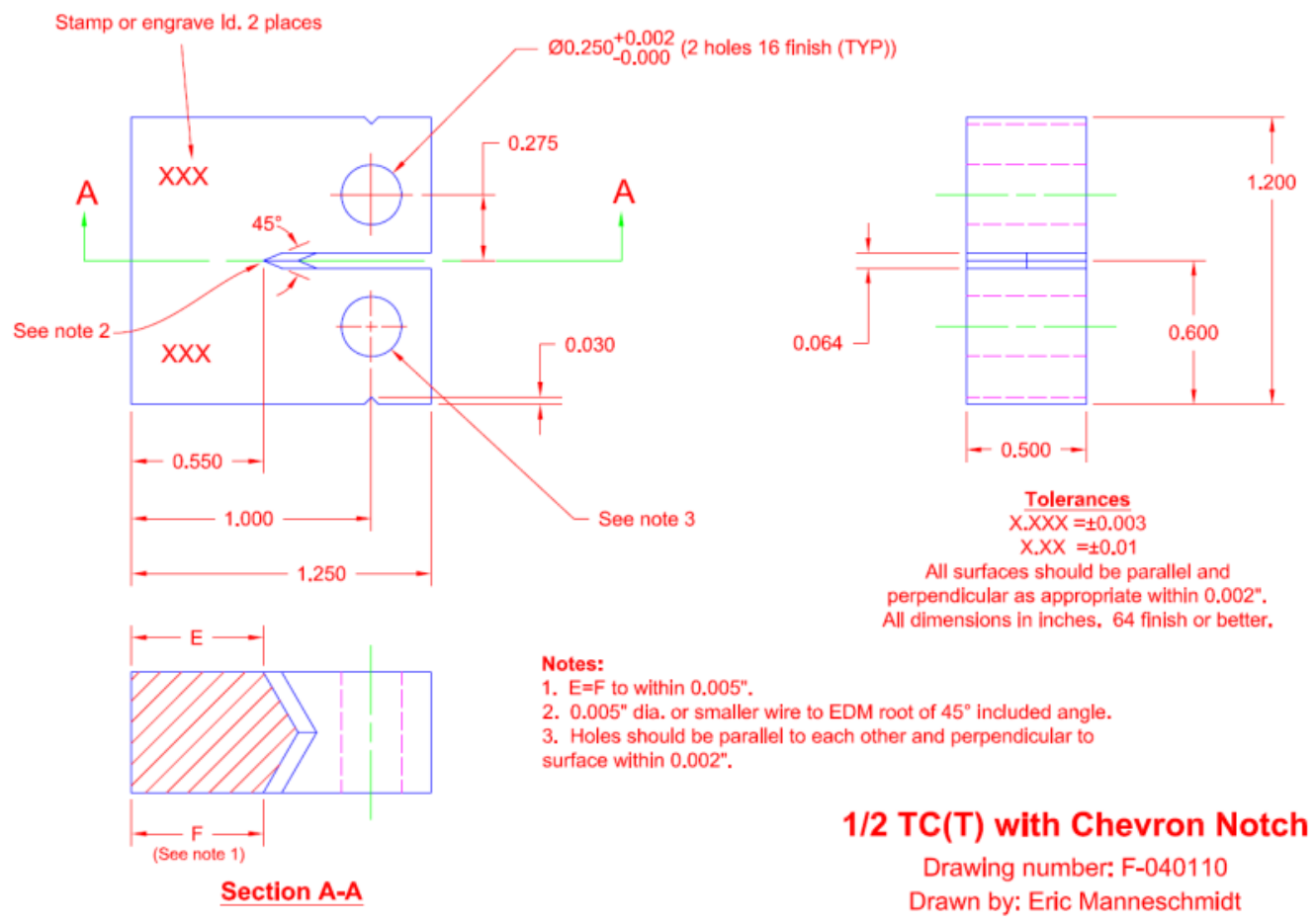

Figure 76. Drawing of fracture toughness test specimen.

Table 31. Fracture toughness and chemistry of fully consolidated PM titanium powders and commercial wrought titanium product. Reported properties in Ti Handbook are also listed

\begin{tabular}{|c|c|c|c|}
\hline CP-Ti & $\begin{array}{l}\text { Fracture toughness, } \\
\mathrm{ksi}^{1} \cdot \mathrm{inch}^{1 / 2}\left(\mathrm{MPa} \cdot \mathrm{m}^{1 / 2}\right)\end{array}$ & $\mathrm{O} / \mathrm{N}, \mathrm{wt} \%$ & Grain size, $\mu \mathrm{m}$ \\
\hline Armstrong & $37.4(41.3)$ & $0.277 / 0.023$ (HIP) & $\begin{array}{l}\sim 50 \times 500 \\
\text { (elongated) }\end{array}$ \\
\hline $\mathrm{HDH}$ & $37.4(41.3)$ & $0.228 / 0.003(\mathrm{VHP})$ & 50 (equi-axed) \\
\hline Wrought & $71.7(78.8)$ & $0.146 / 0.011$ & 20 (equi-axed) \\
\hline Ti Handbook data & 60 (Gr.2) & $<0.25 /<0.03$ & - \\
\hline Ti-6Al-4V & $\begin{array}{l}\text { Fracture toughness, } \\
\mathrm{ksi}^{1 / \mathrm{nch}^{1 / 2}}\left(\mathrm{MPa} \cdot \mathrm{m}^{1 / 2}\right)\end{array}$ & $\mathrm{O} / \mathrm{N}, \mathrm{wt} \%$ & Grain size, $\mu \mathrm{m}$ \\
\hline Armstrong & $31.6(34.8)$ & $0.236 / 0.009(\mathrm{VHP})$ & 10 (equi-axed) \\
\hline $\mathrm{HDH}$ & $54.9(61.6)$ & 0.146/0.023 (HIP) & 20 (equi-axed) \\
\hline Wrought & $60.9(66.9)$ & $0.194 / 0.006$ & $\begin{array}{c}\sim 5 \text { or } 20 \\
\text { (bimodal) }\end{array}$ \\
\hline Ti Handbook data & $57 \sim 60$ (Gr.5) & $<0.20 /<0.05$ & - \\
\hline
\end{tabular}




\subsubsection{Fatigue crack growth rate}

Fatigue crack growth rate testing is important to determine the relationship between a given flaw or crack in material undergoing repetitive loading of a given stress, and if that crack will continue to propagate or the crack will arrest; this parameter is important in aircraft components. Figure 77 shows the drawing of fatigue crack growth specimen used in this study. Fracture toughness of the materials is listed in Figure 78. The PM materials showed comparable and superior crack growth resistances in $\mathrm{CP}-\mathrm{Ti}$ and $\mathrm{Ti}-6 \mathrm{Al}-4 \mathrm{~V}$, respectively, to the commercial wrought titanium products in most of the stress intensity ranges studied. This means that once a crack initiates, its growth is at a slower rate for a given stress intensity.

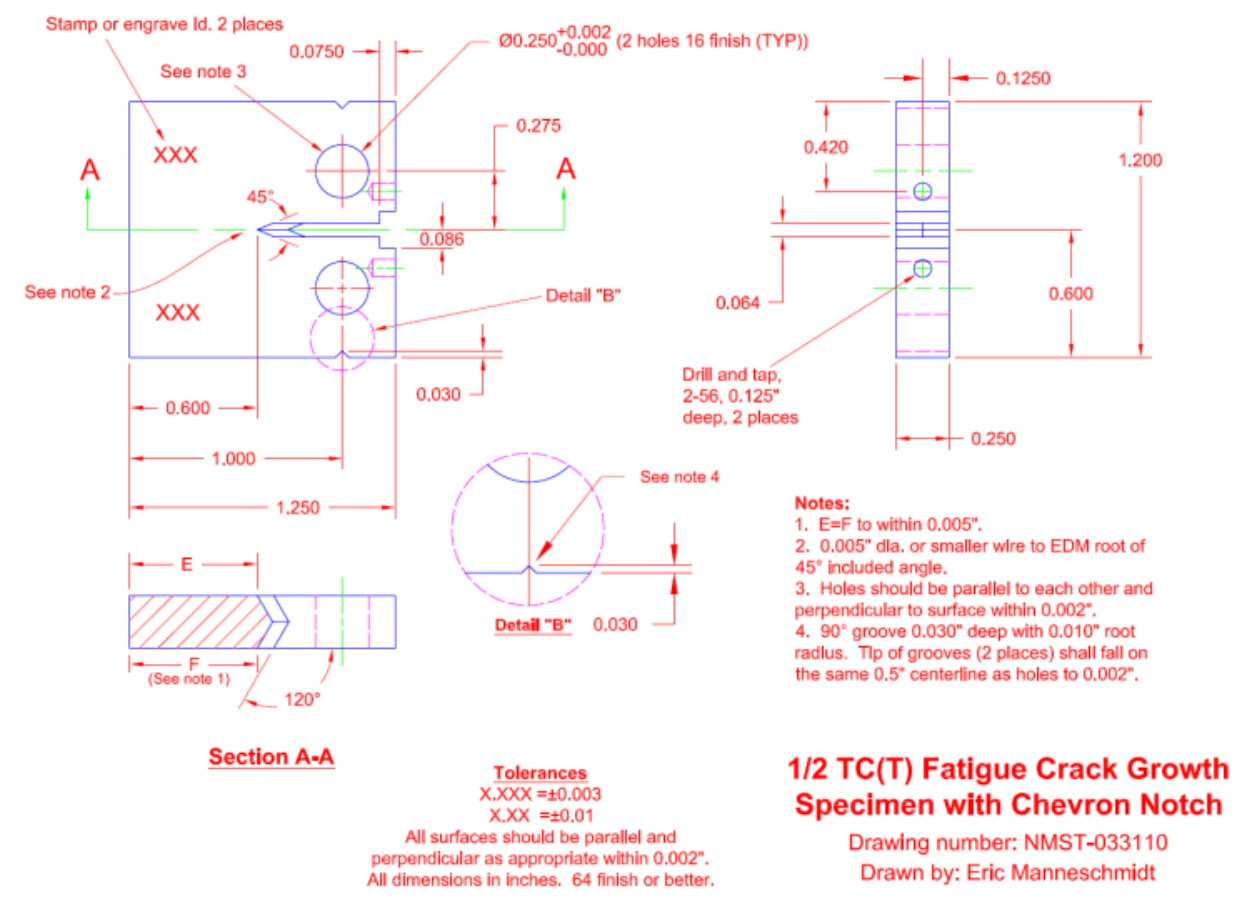

Figure 77. Drawing of fatigue crack growth test specimen.

(a) CP-Ti

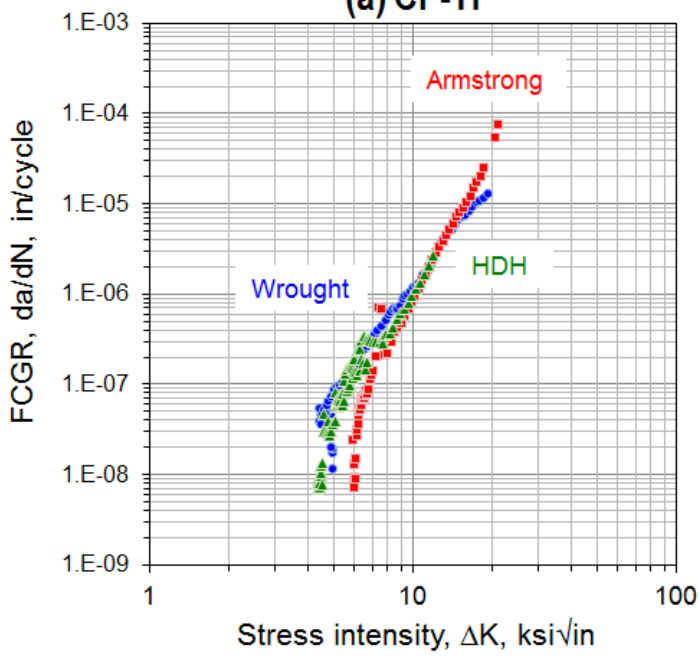

(b) Ti-6Al-4V

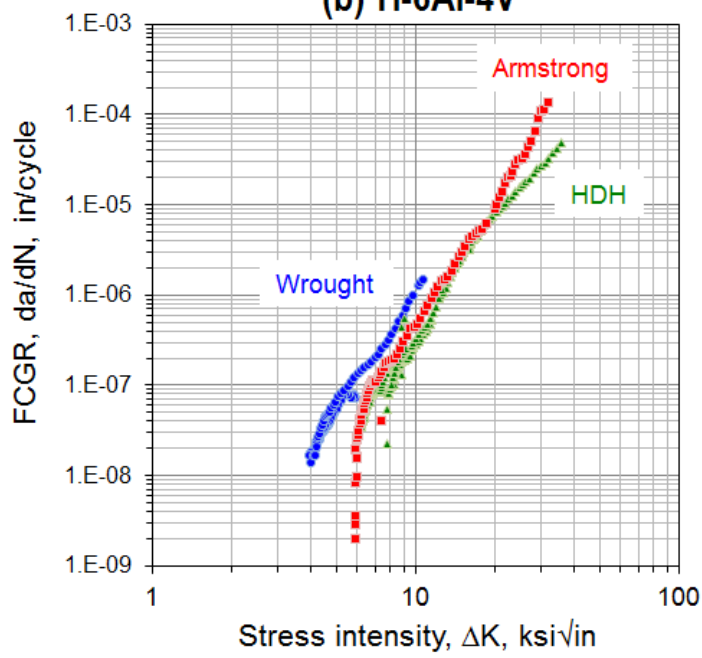

Figure 78. Fatigue crack growth test results; (a) CP-Ti, and (b) Ti-6Al-4V. 


\subsubsection{High cycle fatigue:}

Stress controlled high-cycle fatigue test of fully consolidated Armstrong CP-Ti powder was completed. Fatigue is one of the important mechanical properties for aerospace components, and high cycle test was selected to accelerate the test progress due to limited time schedule. High cycle fatigue provides material lifetime information and the number of cycles that can be expected out of a material for a given stress. The cylindrical fatigue samples with a gauge section of 0.125 inch in diameter were prepared by die-press $(20 \mathrm{ksi})+\mathrm{CIP}(50 \mathrm{ksi})+\operatorname{sinter}\left(1300^{\circ} \mathrm{C}, 1 \mathrm{~h}\right)+\mathrm{HIP}\left(950^{\circ} \mathrm{C}, 15 \mathrm{ksi}, 4 \mathrm{~h}\right)$ process, and tested after the mill-annealing process at $750^{\circ} \mathrm{C} / 1.5 \mathrm{~h} / \mathrm{FC}$. The obtained $\mathrm{S}-\mathrm{N}$ curves in Figure 79 indicate a significant improvement of fatigue life at higher stress levels compared to wrought-Ti product reported in the Ti handbook [38], as shown in Figure 79b. Although there was no detailed sample information in the handbook, the better results than the literature could be attributed to the fine grain size $(\sim 20 \mu \mathrm{m})$ and relatively higher oxygen contents $(\sim 0.31 \mathrm{wt} \%)$ in the samples tested. Both features would strongly impact to increase the tensile strength of the CP-Ti samples which would also increase the high-cycle fatigue life as well. Note that three tests were conducted at the stress level of 500-50 MPa. Two of them exceeded 10-million-cycle (tests were interrupted), whereas one sample failed as short as $\sim 75,000$ cycles. Fracture surface observation indicated that this is very likely due to some surface defects of the specimen.
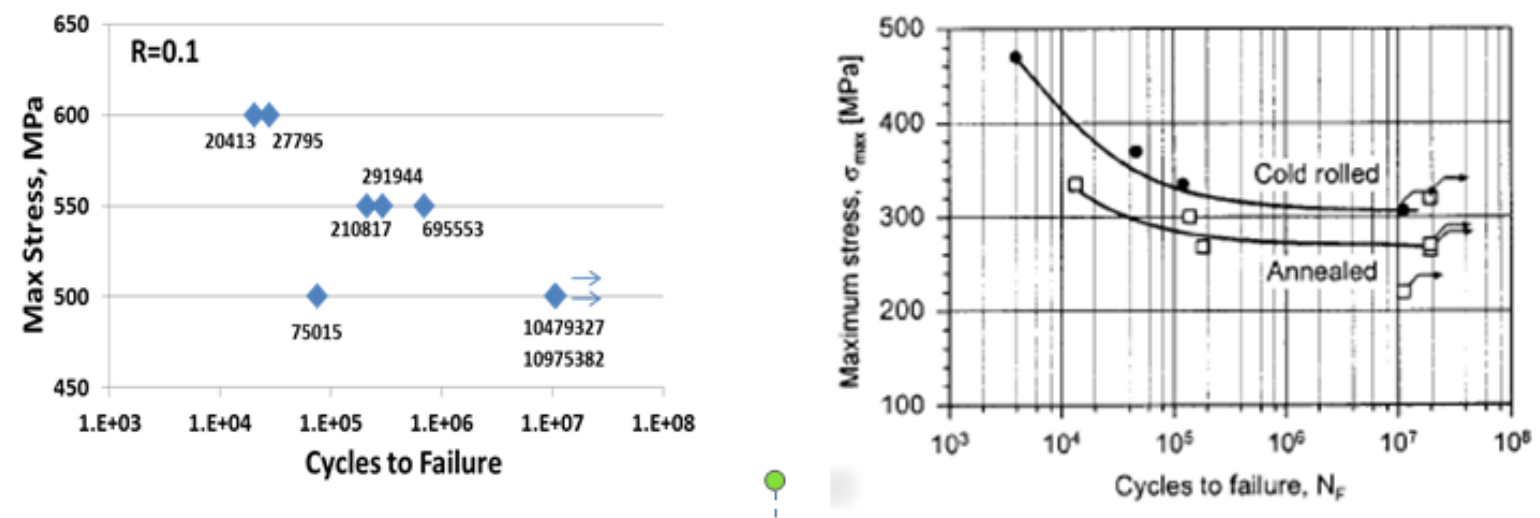

Figure 79. S-N plot of fully consolidated Armstrong CP-Ti powder made by press-and-sinter technology: (a) data obtained, and (b) reference from a handbook [38].

\subsubsection{Additive Manufacturing of Titanium Powders}

Electron Beam Melting (EBM) is a powder bed additive manufacturing (AM) technology that can fabricate complex geometric components. There are several potential benefits to the additive manufacturing process, including decreased energy consumption during the manufacturing process as well as increased downstream energy efficiency during component operation. The increased energy efficiency during the manufacturing process stems from the near net shape fabrication process and nearly full utilization of feedstock materials during process. Because components are built net shape, limited or no machining of the final component is required. This can significantly decrease energy consumption because a significant portion of the energy during the manufacturing process is consumed during the machining of the component. Titanium components can be particularly difficult and energy consuming to machine. In addition, significant amounts of cutting fluid may be eliminated based on the decrease in machining time. Downstream energy savings can be achieved by redesigning a component to optimize performance, decrease total systems part counts, and eliminate excess weight all through the design flexibility afforded by AM technologies. This project was amended to demonstrate the ability to make complex geometric components by EBM to increase 
energy efficiency with material properties similar to or better than ASTM wrought material as well as examine the feasibility of fabricating components from lower cost feedstock materials.

\subsubsection{Background on Electron Beam Melting Technology}

In powder bed additive manufacturing process, a computer aided drawing (CAD) file is sectioned into individual layers with specific thickness (thickness is machine and processing theme dependent). For an EBM process, the layer thickness is typically between $200 \mu \mathrm{m}$ and $50 \mu \mathrm{m}$. The information for each slice of the component is saved in the .abf file specific to the EBM technology. This file is input into the machine and determines processing parameters such as beam current, beam speed, power, etc. The inside of the commercial build chamber is shown in Figure 80.

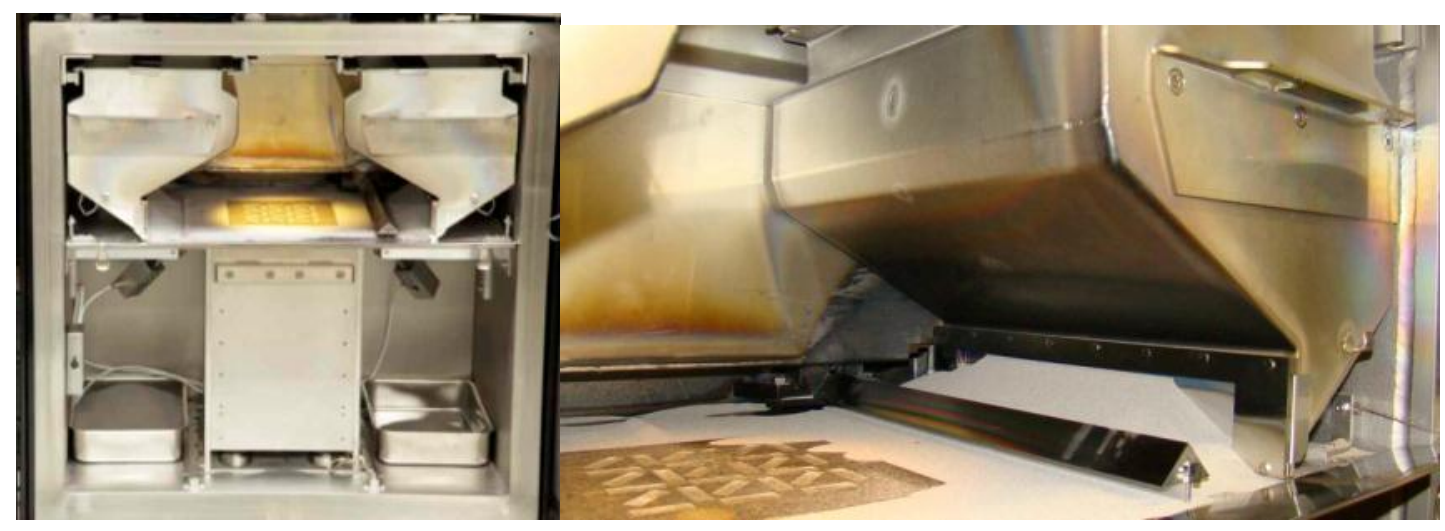

Figure 80. Inside of an EBM build chamber (left) and close up of rake and hopper (right).

The powder is loaded into the hopper located at each side of the chamber and powder is loaded into the build tank shown in the center of the image. The rake is used to level the start plate in the build tank, the start plate is cleaned of any powder, and the chamber door is closed and the inside of the chamber is pulled under vacuum. After adequate vacuum is reached $\left(10^{-5} \mathrm{mBarr}\right)$, the electron beam is turned on, the beam is centered and the beam astigmatism is corrected, and the process is started. The start plate is heated using a defocused electron beam at $50 \mathrm{~mA}$ which is rastered in a line format until the start plate reaches the specified temperature. Once the temperature is reached, the rake impinges on the powder from the hopper to catch a thin line of powder that is then raked over the start plate. The thickness of the powder is determined by the z-height travel of the start plate. The amount of powder is controlled by a powder sensor that measures the amount of powder that falls through a small hole on side of the chamber. The duration of time that the sensor is activated is determined by the amount of powder pulled across the start plate. The targeted pulse length typically for deposition is 200 to 250 milliseconds. Proprietary algorithms are used to move the rake position to constantly achieve the desired pulse length as deposition continues.

Once the layer of powder is raked over the surface of the start plate, the electron beam is used to preheat the powder surface. Preheating is done by defocusing the electron beam and rastering it over the powder surface to partially sinter the material. The preheat beam current is typically $50 \mathrm{~mA}$ with a focus offset value of 50-80. After the material is preheated, the beam is focused and used to melt at locations specifically determined through the CAD file. Once the layer is completed, the stage is lowered and the same procedure is performed subsequently. This iteration occurs until the process is completed and all build layers are finished. The build is then cooled to room temperature, removed from the EBM machine and placed into a powder recovery system. The powder recovery system (PRS) is a modified blasting cabinet where the blast material is powder recycled in the process. This allows for all of the powder to be reclaimed in the process, virtually eliminating all material waste. The powder is put through a screen to eliminate any foreign material and then placed back into the 
EBM build chamber for another build. The powder can be recycled for a significant time period although some oxygen pickup can occur in the powder during processing. The increased oxygen pickup can be detrimental to material properties, especially in $\mathrm{Ti}$ and $\mathrm{Ti}$ alloys.

\subsubsection{Lower cost powder processing using electron beam melting technology}

The current commercial EBM technology utilizes spherical powder in the size range between $45 \mu \mathrm{m}$ and $100 \mu \mathrm{m}$ because reliability increases in powder distribution and increased material properties of final components. The machine provider prefers to distribute powder for the EBM process and supplies commercially pure (CP) Ti powder, Ti-6Al-4V, Ti-6Al-4V ELI (extra low interstitial), CoCr, and TiAl. The machine provider does not identify the specific powder producer for these materials but certifies the powder and distributes the powder to ensure that the powder works with the EBM process.

The powder feedstocks in the process have specific requirements in order to work in the EBM technology. Firstly, the powder must properly flow in the hopper and must be able to be distributed by the raking mechanism. For this reason, spherical powder has a tendency to work best in the machine. However, the powder manufacturing process can have a large influence on the final quality of the EBM component. Powders now are gas atomized and plasma rotating electrode processed. The amount of satellites on the powder surface can affect the flow properties of the material and result in lower quality material. In addition, gas atomized powders can have entrapped porosity from the atomization process. This residual porosity gets transferred to the EBM component and remains in the final component. This can significantly decrease mechanical properties such as tensile strength, elongation, and fatigue life.

The packing density of the powder can also largely affect the final properties of the components because additional energy will be required to melt very dense powder and less energy is required to melt less dense powder. It is ideal in the process to have a uniform sized starting powder so the size distribution of the powder remains constant as a function of powder lifetime. The main limitation to the ideal EBM powder is the cost of the powder. Current powder costs are $\sim \$ 150 / \mathrm{lb}$. for Ti-6Al-4V and slightly less for $\mathrm{CP}$ Ti. This portion of the project examines the ability to use lower cost feedstock materials in the EBM process. Two different powders were examined, both hydridedehydride (HDH) powder from Reading Alloys Inc. and milled powder from International Titanium Powder made using the Armstrong powder process.

CP Ti powder supplied by International Titanium Powder that was discussed previously in this report was placed into the EBM hopper and build platform in both the as received and milled conditions. Milled powder was sieved to $-100+325$ mesh prior to putting it into the machine. However, the powder did not flow in the machine and could not be tested. Several changes to the EBM powder hopper system were made, but the results were unsuccessful. The packing nature of the powder resulted in detrimental movement of the rake. This resulted in termination of the raking process in order to not damage the machine. Further studies on the ITP Armstrong powder were eliminated.

Hydride-dehydride powder was ordered from Reading Alloys for both CP Ti (Lot \#32108) and Ti6Al-4V (Lot\#32238) in the size distribution of $-100+200$ mesh in hopes that a tighter size distribution would increase the flow properties of the powders. The powders were mounted and examined using optical microscopy shown in Figure 81. From the images, it can be seen that the morphology of the powder is blocky in nature and is far from spherical powder typically utilized in the commercial E Beam process. This morphology is consistent with powders produced by this methodology, resulting in a comparable morphology to crushed stone. 


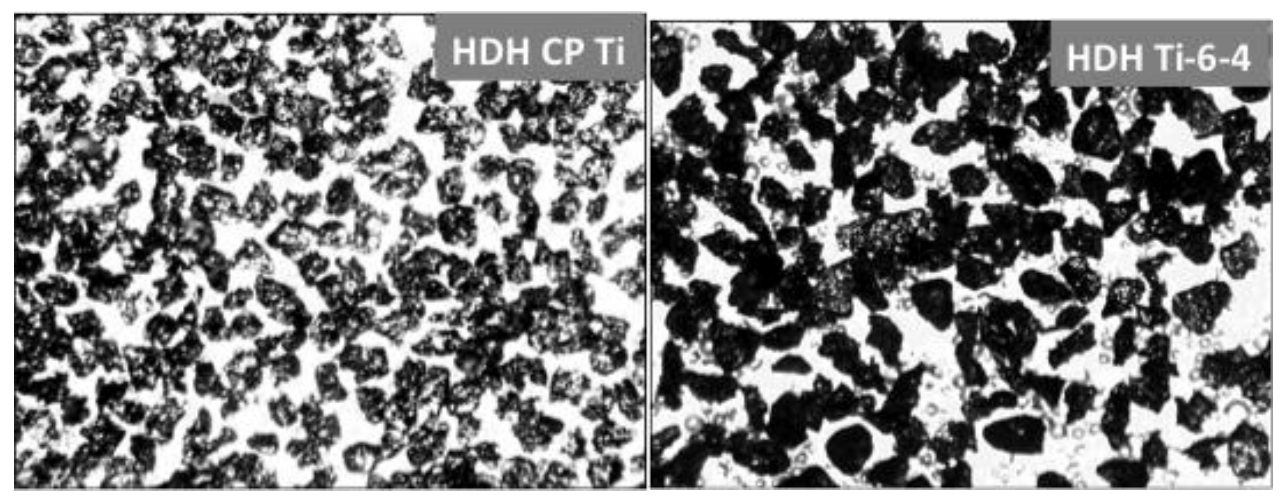

Figure 81. Optical images of HDH powder used in the EBM process.

The size distribution of the powders is shown in Table 32 for both CP Ti and Ti-6Al-4V respectively. It can be observed from Table 32 that the $\mathrm{CP}$ Ti powder contained a much tighter size distribution of powder than the Ti-6Al-4V powder. The angle of repose was measured for each of the various powder lots tested including the HDH and Armstrong powders using ASTM standard C1444-00. However, the angle of repose was similar for both HDH and Armstrong powders (39.0 to 43.1) and it was determined this was not an adequate method to classify the ability of the powder to flow in the EBM machine. Similar raking experiments were conducted on the HDH powder being placed in the machine, and both $\mathrm{CP}$ Ti and Ti-6Al-4V HDH powder flowed adequately in the EBM machine. The powder could be properly raked similarly to spherical powder, however the pulse length sensor did not appear to adequately work. During the build process, powder was visibly being distributed across the start plate and build tank, although the powder sensor reading was very low. It was determined that for HDH powder deposition, an adequate pulse length was not needed to achieve deposition.

Table 32. Distribution of powder particles for lots of HDH powder used in the EBM process HDH CP Ti (-100x200 Mesh) Reading Alloys Lot \#32108

\begin{tabular}{|c|c|c|c|c|c|c|c|c|}
\hline HDH CP Ti (-100x200 Mesh) Reading Alloys Lot \#32108 & \multicolumn{2}{l}{ HDH Ti-6-4 (-100x200 Mesh) Reading Alloys Lot \#32238 } \\
\hline Mesh Size & $\begin{array}{c}\text { Miron } \\
\text { Size }\end{array}$ & $\begin{array}{c}\text { Powder Wt. } \\
\text { grams (49.24) }\end{array}$ & $\begin{array}{c}\text { Powder } \\
\text { wt. \% }\end{array}$ & Mesh Size & $\begin{array}{c}\text { Miron } \\
\text { Size }\end{array}$ & $\begin{array}{c}\text { Powder Wt. } \\
\text { grams (49.24) }\end{array}$ & $\begin{array}{c}\text { Powder } \\
\text { wt. \% }\end{array}$ \\
\hline+100 & $>149$ & 0 & 0 & +100 & $>149$ & 0.53 & 1.2 \\
\hline$-100+120$ & 125 to 149 & 0.03 & 0.001 & $-100+120$ & 125 to 149 & 27.68 & 62.2 \\
\hline$-120+140$ & 105 to 125 & 43.41 & 88.2 & $-120+140$ & 105 to 125 & 11.15 & 25.1 \\
\hline-140 & $<105$ & 5.80 & 11.8 & -140 & $<105$ & 5.15 & 11.6 \\
\hline
\end{tabular}

The EBM process settings for the HDH CP Ti powder deposition were based on the latest commercial software version for the deposition of Ti-6Al-4V material. However, a parameter evaluation matrix was conducted using 9 different parameter settings. For the 9 different samples, parameters such as surface temperature and speed function were altered. The parameter settings for an example build and specimen layout are shown in Figure 82. The average current setting in the preheat step was changed to $12 \mathrm{~mA}$ and the maximum time was 15 seconds. The build successfully competed and the resulting surface finishes on the samples were similar to those fabricated using spherical powders. 


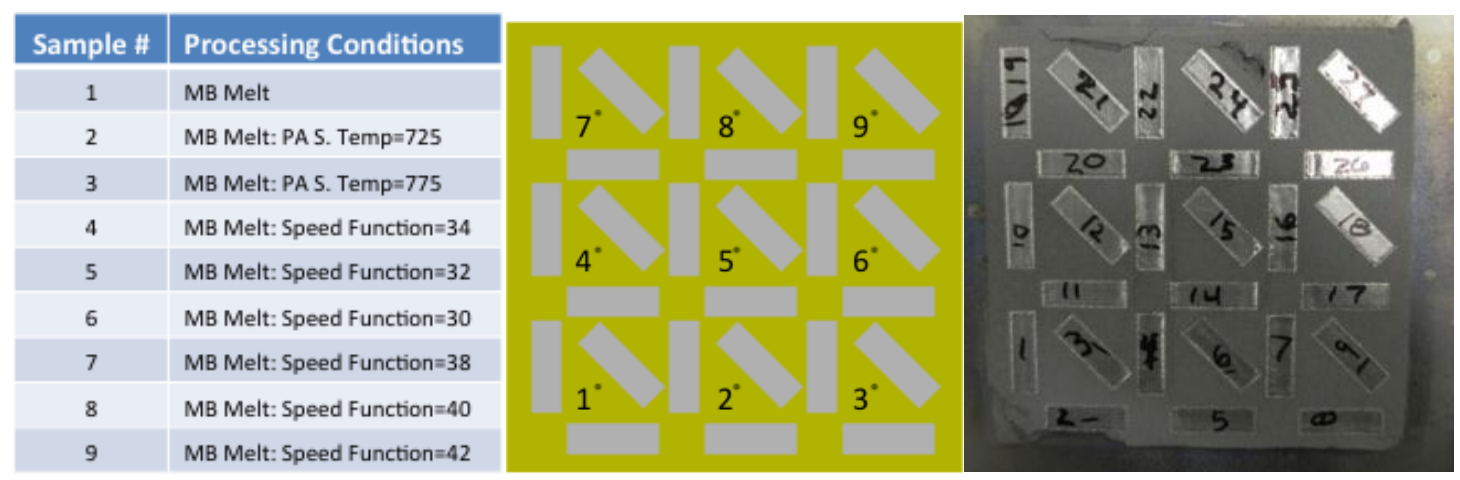

Figure 82. Build layout and parameter matrix for process evaluation. Each setting was used to melt 3 samples $10 \mathrm{~mm} \times 30 \mathrm{~mm} \times 10 \mathrm{~mm}$ in the $x=0, y=0$, and $x-y=45$ orientations. Completed build is shown at the far right.

The chemical composition of the HDH powder both before and after deposition, the composition of the fused material, and the ASTM standards for the various grades of CP Ti material are shown in Table 33Table 33. The chemical analysis results indicate no compositional changes with oxygen, nitrogen, carbon or iron content during the EBM process and a slight indication of decreased nitrogen content with use. These results are expected because the process is conducted under a vacuum. During the fusing process, there is no indication of impurity pickup of oxygen, nitrogen, or iron, but there is a slight increase in the carbon content of the material. However, the fused material falls within the ASTM chemical specifications for Grade $1 \mathrm{CP}$ Ti material.

Table 33. Chemical composition of HDH powder, fused material in the EBM, and ASTM specifications for CP Ti

\begin{tabular}{|c|c|c|c|c|c|c|c|c|c|c|c|c|}
\hline Identification & \multicolumn{3}{|c|}{ Oxygen } & \multicolumn{3}{|c|}{ Nitrogen } & \multicolumn{3}{|c|}{ Carbon } & \multicolumn{3}{|c|}{ Iron } \\
\hline Powder & \multicolumn{3}{|c|}{ \% } & \multicolumn{3}{|c|}{ \% } & \multicolumn{3}{|c|}{ \% } & \multicolumn{3}{|c|}{ \% } \\
\hline CP Ti Run 1 & 0.167 & 0.163 & 0.169 & 0.056 & 0.054 & 0.058 & 0.015 & 0.013 & 0.02 & 0.013 & 0.012 & 0.012 \\
\hline CP Ti Run 2 & 0.16 & 0.166 & 0.165 & 0.028 & 0.026 & 0.027 & 0.014 & 0.017 & 0.025 & 0.011 & 0.011 & 0.012 \\
\hline Sample Run 1 & \multicolumn{3}{|c|}{-..-- } & \multicolumn{3}{|c|}{$-\cdots$} & \multicolumn{3}{|c|}{-..- } & \multicolumn{3}{|c|}{$\cdots$} \\
\hline $\mathrm{CP} \mathrm{Ti}$ & 0.163 & 0.154 & 0.153 & 0.024 & 0.023 & 0.021 & 0.022 & 0.027 & 0.028 & 0.017 & 0.012 & 0.017 \\
\hline ASTM Standard & \multicolumn{12}{|c|}{ SB-381 Titanium and Titanium Alloy Forgings } \\
\hline $\mathrm{F}-1$ & \multicolumn{3}{|c|}{0.18} & \multicolumn{3}{|c|}{0.03} & \multicolumn{3}{|c|}{0.08} & \multicolumn{3}{|c|}{0.02} \\
\hline $\mathrm{F}-2$ & \multicolumn{3}{|c|}{0.25} & \multicolumn{3}{|c|}{0.03} & \multicolumn{3}{|c|}{0.08} & \multicolumn{3}{|c|}{0.03} \\
\hline $\mathrm{F}-3$ & \multicolumn{3}{|c|}{0.35} & \multicolumn{3}{|c|}{0.05} & \multicolumn{3}{|c|}{0.08} & \multicolumn{3}{|c|}{0.30} \\
\hline $\mathrm{F}-4$ & \multicolumn{3}{|c|}{0.4} & \multicolumn{3}{|c|}{0.05} & \multicolumn{3}{|c|}{0.08} & \multicolumn{3}{|c|}{0.50} \\
\hline
\end{tabular}

Mechanical test samples in the form of SS3 tensile samples were extracted from several of the EBM fabricated samples from the parametric study. The results of the tensile testing in terms of mechanical properties are shown in Table 34 along with the ASTM values for wrought CP Ti materials. It can be seen that the yield and ultimate strength of the material is consistent with ASTM F-3 and sometimes is consistent with ASTM F-4 material. However, the elongation values for total plastic strain nearly always meet ASTM F-1 material and always meet ASTM F-2 material. This is somewhat unique for CP Ti material because the strength and ductility of the material are usually determined by chemical impurities. A low impurity content such as the material we have fabricated using EBM should have high elongation and low strength based on the ASTM specifications. Typically, increases in strength can be achieved by increasing the oxygen or other impurity content of the material but the ductility of the material will suffer as the impurity content increases. However, the resulting microstructure from EBM material gives a combination of properties where both high 
strength and high elongation can be achieved. A more in depth study should be conducted relating the microstructure, chemistry, and material properties for EBM materials.

Table 34. ASTM property data and resulting mechanical property information for samples fabricated from HDH CP Ti material using the EBM process

\begin{tabular}{|cccccc|}
\hline $\begin{array}{c}\text { Specimen } \\
\text { Number }\end{array}$ & Yield (PSI) & Ultimate (PSI) Elongation (\%) & $\begin{array}{c}.2 \% \\
\text { Elongation (\%) }\end{array}$ & $\begin{array}{c}\text { Total Plastic } \\
\text { Strain (\%) }\end{array}$ \\
\hline ASTM F-1 & 25000 & 35000 & & & $24(\mathrm{~min})$ \\
ASTM F-2 & 40000 & 50000 & & & 20 (min) \\
ASTM F-3 & 55000 & 65000 & & & $18(\mathrm{~min})$ \\
ASTM F-4 & 70000 & 80000 & & 2.92 & $15(\mathrm{~min})$ \\
\hline 2A & 63760 & 76820 & 26.67 & 23.75 \\
2B & 69370 & 82610 & 25.67 & 3.22 & 22.45 \\
2C & 63670 & 76600 & 32.67 & 3.503 & 29.167 \\
\hline 19A & 64790 & 77910 & 32 & 3.1 & 28.9 \\
19B & 62940 & 77040 & 36.33 & 2.95 & 33.38 \\
19C & 69690 & 83710 & 28 & 3.077 & 24.923 \\
\hline 27A & 70570 & 83650 & 30 & 3.243 & 26.757 \\
27B & 70040 & 83210 & 28.67 & 3.22 & 25.45 \\
27C & 70720 & 83870 & 25.67 & 3.277 & 22.393 \\
\hline
\end{tabular}

An additional phenomenon that was discovered was the chemical diffusion of the substrate material into the samples during the EBM process. Similar behavior for Ti-6Al-4V has been reported previously in the literature [38]. EDS analysis was conducted on a sample fabricated using HDH powders to examine the chemistry as a function of $\mathrm{z}$ height. It was determined through EDS scans that the chemical diffusion into the build occurred for approximately $0.7 \mathrm{~mm}$ in the $\mathrm{z}$ direction. However, a more detailed study would need to be conducted to determine the actual chemical diffusion into the build. From the EDS analysis in Figure 83, it was determined that diffusion of Fe, $\mathrm{Cr}$ and $\mathrm{Ni}$ occurred into the Ti material. These elements are expected because the substrate material is a stainless steel. The presence of these elements results in the formation of a duplex microstructure observed in the center of the image. The material deposited on the substrate is at the right while the $\mathrm{z}$ height increases occurs moving towards the left. Chemical segregation into components is not believed to affect the bulk of the material into the component although components requiring precise chemistry control would require the bottom surface of the component adjacent to the substrate to be machined away. An alternate method would be to raise the component off of the start plate a given distance.

Similar deposition studies were conducted using HDH Ti-6Al-4V powders. A complex geometric component was fabricated from the HDH materials for Lockheed Martin. The geometry was chosen because it had several features relative to most brackets Lockheed Martin would be manufacturing with the EBM technology and included vertical surfaces, inclined surfaces, through holes, blind holes, pegs, etc. The geometry of the component is shown in Figure 84 along with a component fabricated using HDH Ti-6Al-4V powder. The resulting surface finish of the component was noticeably rougher than the same part fabricated using spherical powder. It was not apparent if the surface finish could be improved through refining of the processing parameters. 


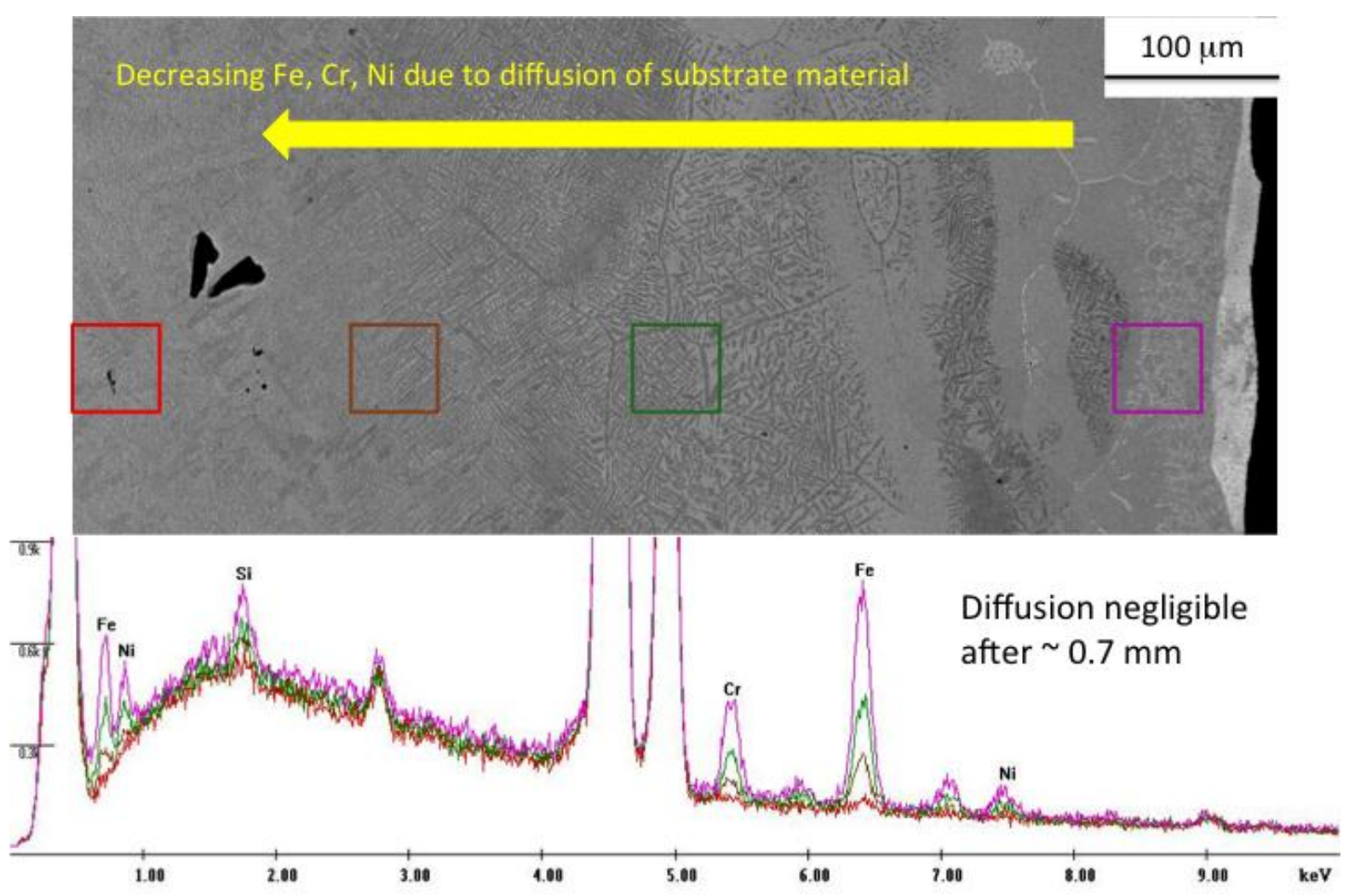

Figure 83. Microstructure of CP Ti EBM samples showing the increase in chemical composition near the start plate (right). Results indicate there is some diffusion between the start plate and the EBM material lasting for $\sim 0.7 \mathrm{~mm}$. The concentration of impurity elements decrease as a function of $\mathrm{z}$ height as indicated by the peak intensity in EDS.

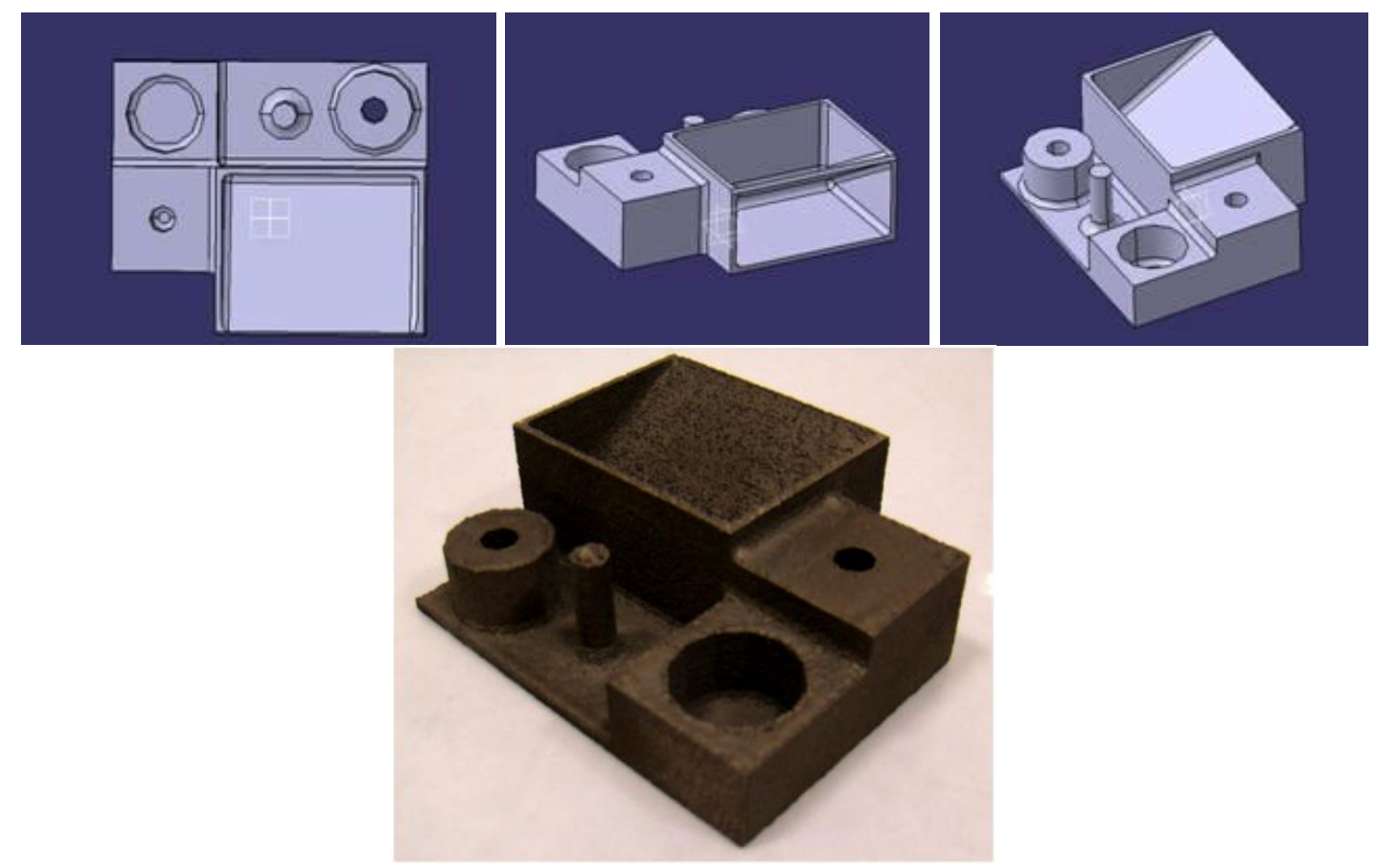

Figure 84. Complex geometry component designed by Lockheed Martin. 


\subsubsection{Production of near net shape components by additive manufacturing}

Three components/geometries were selected to evaluate additive manufacturing of net shape titanium components from powder: 1) a feature specimen with a complex geometry was selected in conjunction with a commercial partner to fabricate using electron beam melting. The component was fabricated using spherical gas atomized Ti-6Al-4V powder, sectioned and polished for microscopy purposes. The microstructure, shown in Figure 85 was typical for material sintered using electron beam melting. However, there was evidence of porosity in the sample, which indicates a larger parametric study must be performed in order to ensure full consolidation. Tensile samples were prepared at three orientations, parallel, perpendicular, and at 45 degrees to the deposition direction. The results of tensile testing are shown in Table 35.

Table 35. Average mechanical properties for various orientations of a component fabricated using the electron beam melting technology

\begin{tabular}{cccc}
\hline Specimen Orientation & $\begin{array}{c}\text { Yield Strength } \\
\text { (PSI) }\end{array}$ & $\begin{array}{c}\text { Ultimate Tensile } \\
\text { Strength (PSI) }\end{array}$ & $\begin{array}{c}\text { Total Elongation } \\
(\boldsymbol{\%})\end{array}$ \\
\hline Parallel & 145,525 & 151,450 & 11.4 \\
\hline Perpendicular & 137,525 & 146,200 & 5.5 \\
\hline 45 Degrees & 149,800 & 153,425 & 4.1 \\
\hline
\end{tabular}

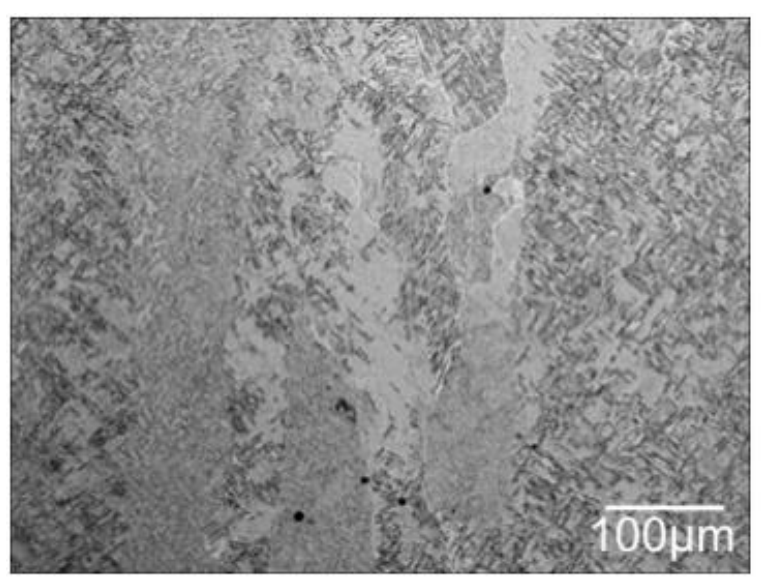

Figure 85. Cross sectional microstructure of Ti-6Al-4V component fabricated using spherical gas atomized powder. The deposition direction is parallel to the vertical axis.

An impeller for chemical pump manufacture and a T-bracket for aircraft (Lockheed Martin) were selected for the demonstration of near net shape product fabrication. Preliminarily fabricated products are shown in Figure 86. A representative image of a generic impeller fabricated using EBM is shown in place of the actual impeller because the impeller design is proprietary to the industrial partner. The actual impeller was built by using additive manufacturing process with an e-beam deposition system and spherical titanium powders, and was sent to the company and analyzed for geometrical accuracy. The component met the geometrical tolerances required and was subsequently machined to the specific tolerances required for in-situ evaluation. 

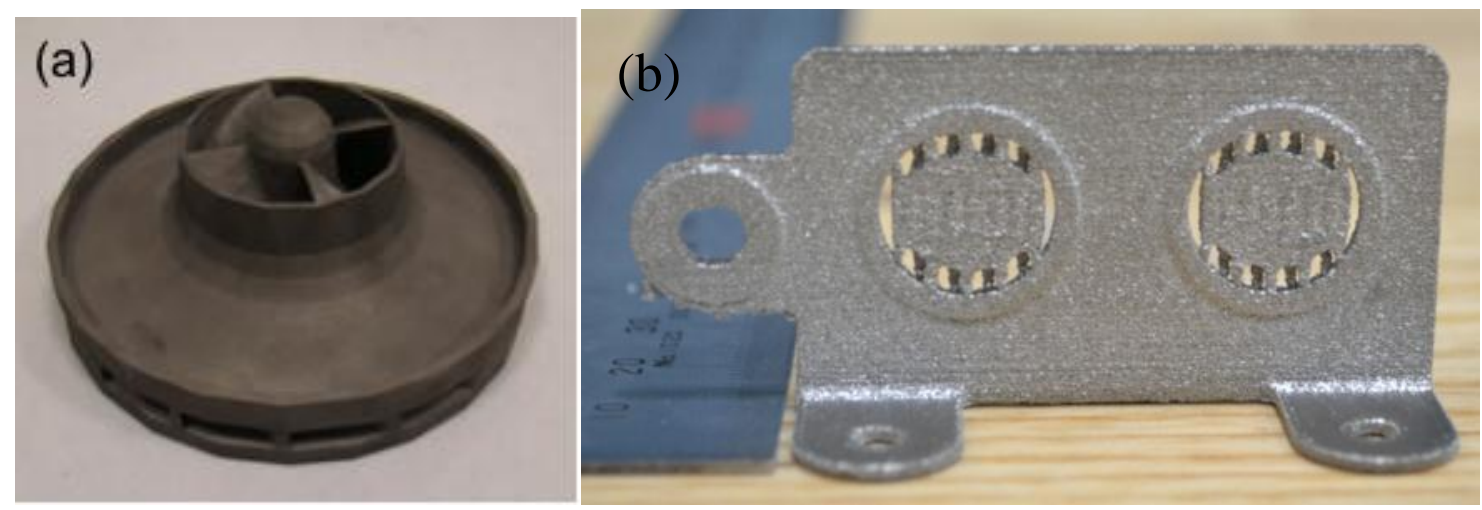

Figure 86. Preliminarily fabricated products of (a) an impeller, and (b) a T-bracket for aircraft components fabricated by additive manufacturing.

The Ti-bracket for F-35 component was fabricated by solid-state powder metallurgy (press, sinter, and HIP). The numbers of the same shape components have been fabricated with various process conditions, in order to evaluate processing route, machinability, and mechanical properties of the final components. Brackets fabricated via EBM technology were assessed with Lockheed Martin. The results indicated the mechanical properties of the brackets were adequate when fabricated by EBM. A detailed study of the mechanical property evaluation conducted by Lockheed Martin and ORNL was previously reported.

\subsubsection{Additive manufacturing impeller}

The previous impeller was built to specification for manufacturing the impeller through the casting process. However, the geometric flexibility afforded by additive manufacturing allowed the impeller to be redesigned for function rather than limiting the design because of the manufacturing process. The wall thickness of the impeller was determined by the casting process limitations and was significantly thicker than necessary for the optimized function of the impeller in service. Stress analysis modeling packages proprietary to the impeller manufacturer was used to determine the maximum stresses on the impeller during operation and the wall thickness of the impeller was minimized to satisfy this stress condition. The new impeller design using the additive manufacturing technology decreased the component weight by $55 \%$ while performing a similar function. A comparison of the impeller wall thickness is shown in Figure 87.
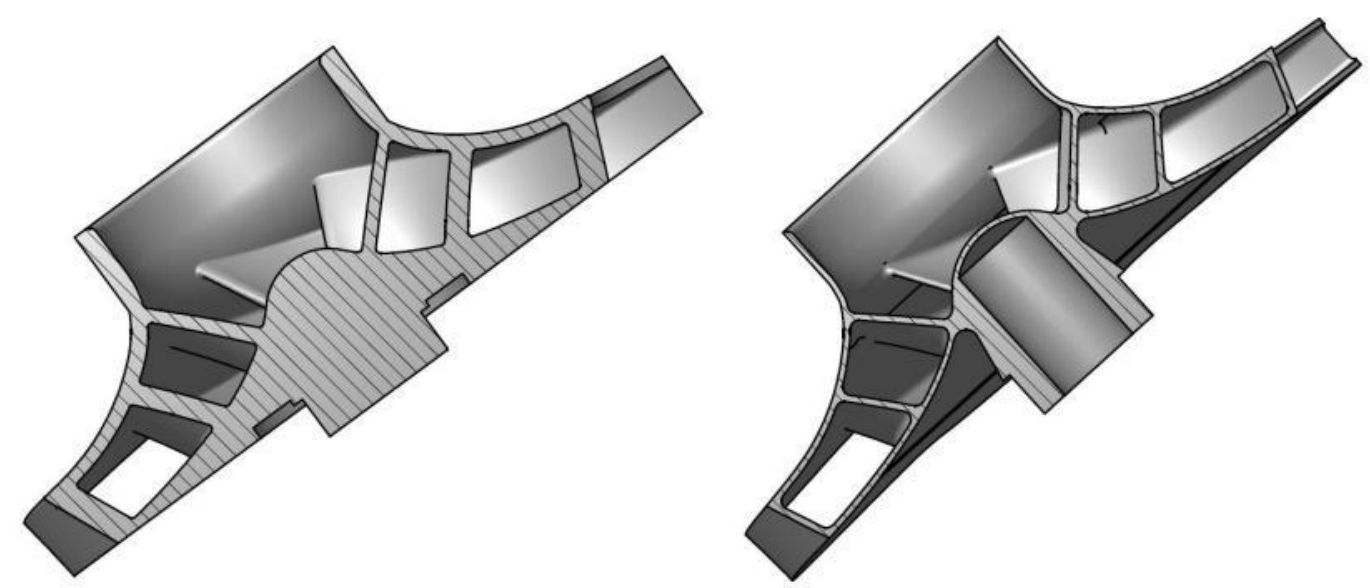

Figure 87. Cross section of impeller fabricated through casting (left) and newly designed impeller using electron beam melting. A $55 \%$ weight savings was observed while maintaining similar function. 
The new impeller model was fabricated using the electron beam melting technology and sent to the industrial partner for evaluation. Inspection revealed that the geometric accuracy of the impeller was not sufficient to machine and test a final component. Figure 88 illustrates the measurement of the fluid passages for the optimal case (a) and for the fluid passage that does not meet the geometrical tolerances required (b). Only 1 of the fluid passages of the 6 total passages failed to meet the geometric accuracy required. It was determined that the thermal supports on the EBM technology were not sufficient. The support material for the component that did not meet the geometric accuracy was square while the impeller contained 3 -fold rotational symmetry. The supporting structure was changed to a radial support theme and the distance between thermal supports was decreased. ORNL verified the geometric accuracy of the new impeller and sent it to the industrial manufacturer for inspection. The new support method greatly improved the geometric accuracy of the additively manufactured impeller. The new impeller was machined and evaluated in field trials.
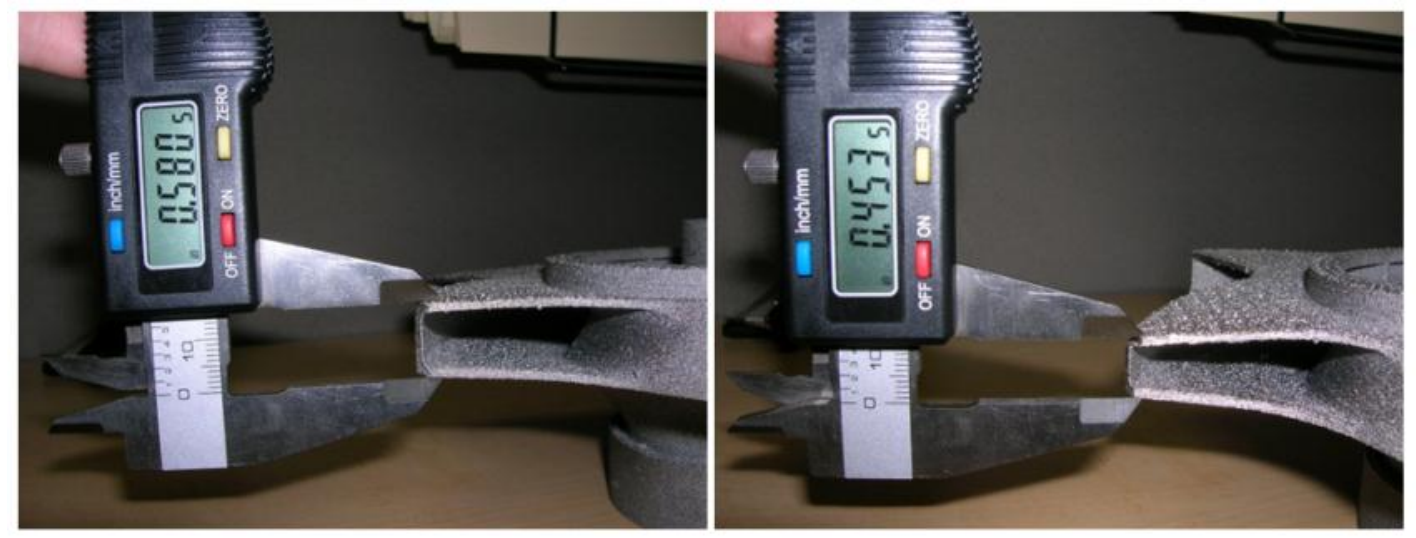

Figure 88. Measurement of an adequate fluid passage and for the fluid passage that failed to meet the geometric accuracy required for machining. Only 1 of the 6 fluid passages failed to meet the required geometric accuracy.

Upon conclusion of the work, the impeller manufacturer stated a 55\% weight reduction based on improved manufacturing process. There was also $75 \%$ less machining due to the high geometric accuracy of the electron beam melting process. This resulted in $75 \%$ less energy consumed during the machining cycle as well as decreased machining time that leads to improved production efficiency. The impeller manufacturer also concluded the process allows for limitless possibilities for hydraulic passageways that could allow hydraulic efficiency increases up to $5 \%$ using novel features which cannot be applied using a casting.

\subsubsection{Additive manufacturing bracket}

The second trial component was designed in conjunction with a major aerospace manufacturer (Lockheed Martin) to examine the potential of electron beam melting for fabrication of complex aerospace brackets. These brackets typically have an extremely high buy to fly ratio. Lockheed Martin has identified nearly 20 different geometry components that fall into a similar geometric family as the bracket identified in Figure 86. ORNL has fabricated several of the bracket geometries and demonstrated the ability to accurately fabricate these geometries. However, these brackets are not shown because they are not cleared for public release. These brackets were examined for microstructure and mechanical properties. Based on these results, a larger study was conducted to examine the commercial feasibility of manufacturing these brackets using the electron beam melting technology. It was concluded that an extensive mechanical evaluation would need to be conducted as a function of sample location within the build chamber. In addition to mechanical test specimens, build containing the brackets will also be fabricated. The brackets will be machined and evaluated. 
ORNL utilized the EBM technology to fabricate a sample test bed designed by Lockheed Martin. Various geometry samples were included in the build including tensile samples, fracture toughness samples, and witness coupons. The layout was designed to understand the effect of properties on the location of the sample in the build (near the center or edges), the effect of building an individual sample or machining the sample from a larger block, and to verify there is no residual porosity when building overhung geometries. Samples were hot isostatically pressed at Bodycote and machined into mechanical test specimens at Lockheed Martin. Samples were then tested at Lockheed Martin. The build layout is shown in Figure 89. Microstructural evaluation demonstrated no residual porosity was present in the material after the hot isostatic pressing cycle. The mechanical tests indicated the material met the ASTM specification for wrought Ti-6A-4V in terms of strength, ductility, and chemical composition.

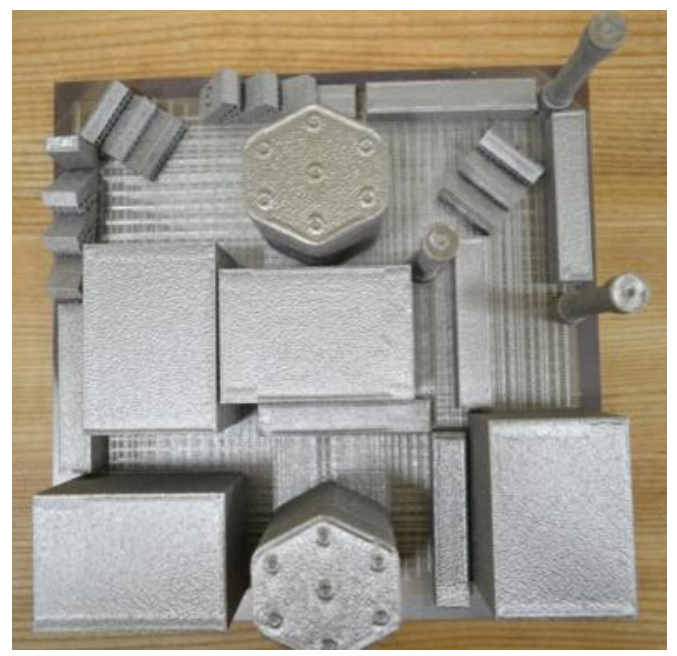

Figure 89. Lockheed Martin designed specimen layout containing both blocks of samples and individual samples along with witness coupons.

A similar build was designed to specifically examine the effect of sample location and orientation of a Lockheed Martin bracket Bleed Air Leak Detect (BALD) brackets and three tensile test bars as "witness" bars. The BALD brackets were selected due to their classification as tertiary structure and light loading which would simplify acceptance on the program. ORNL fabricated two identical builds using two different powder lots. One set of brackets was fabricated using new powder that had not been previously used in the EBM process and another build was fabricated with powder that had been utilized for a period of over 3 months in the EBM process and was known to not comply with AMS4911 chemical profile. The mechanical test results indicated that although the powder did not meet the chemical requirements of the ASTM standard, the mechanical strength and elongation did meet the ASTM requirements for Ti-6Al-4V. The mechanical testing results demonstrated the potential for powder recycling during the process and help understand material utilization rates and powder chemistry effects on properties over time. It is expected that despite the mechanical properties being sufficient, powder that does not meet the chemical requirements will not be used due to liability issues. A more extensive evaluation is needed to determine the fatigue properties of higher impurity material. The samples underwent a similar hot isostatic pressing cycle as the mechanical test specimens and tested on a testing apparatus specifically designed by Lockheed Martin. The layout of the builds is shown in Figure 90 and includes several brackets as well as several tensile samples for comparison to bulk samples. 

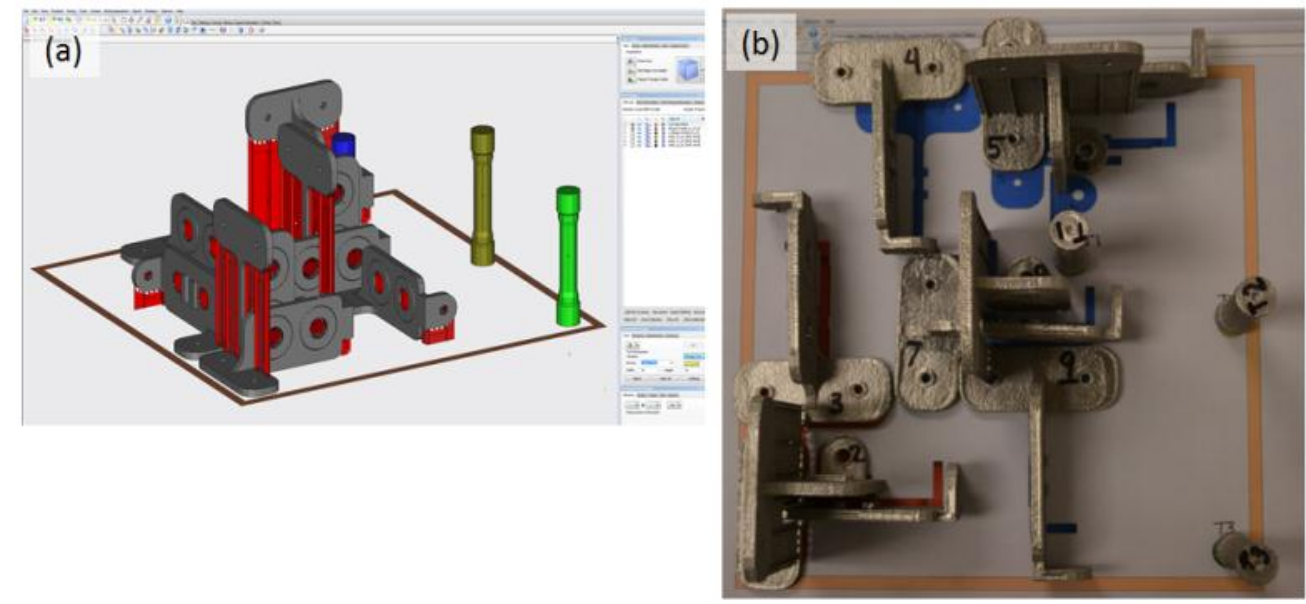

Figure 90. Layout of LM bracket to test mechanical strength as a function of location and orientation within the build chamber; (a) drawing of the component layout, and (b) the as-build components.

Lockheed Martin did have some difficulty machining the BALD Brackets after the HIP process. However, this project has sufficiently demonstrated the ability to fabricate complex geometric components that meet the materials specifications for aerospace components in the designated service environment.

\subsubsection{Powder Forging, Machining, and Joining}

Direct net shape tube fabrication from Armstrong processed Ti-6Al-4V powder was performed via extrusion. A steel can with tube shape was prepared and filled with milled Ti-6Al-4V powder, vacuum sealed, and then extruded at $925^{\circ} \mathrm{C}$ with an extrusion ratio of 3.2:1, which resulted in consolidating the loose powder (44\% theoretical density) before extrusion, to more than $99.8 \%$ after extrusion (shown in Figure 91a and Figure 91b). This single-step fabrication process could be equivalent to the combination of cold compaction, sintering at high temperature $\left(\sim 1300^{\circ} \mathrm{C}\right)$ in a vacuum, and hot isostatic pressing to make a fully consolidated near net shape titanium component, indicating a potential for energy and cost savings by reducing the numbers of the manufacturing steps. The nature of this fabrication process would be analogous for both pure titanium and titanium alloy powders. The tube diameter and its wall thickness can be controlled by using a combination of different sized extrusion dies and mandrel, or following piercing process. The outer/inner steel tubes can be removed by using an acid solution, without harming the titanium tube, realizing very high yields (Figure 91c).
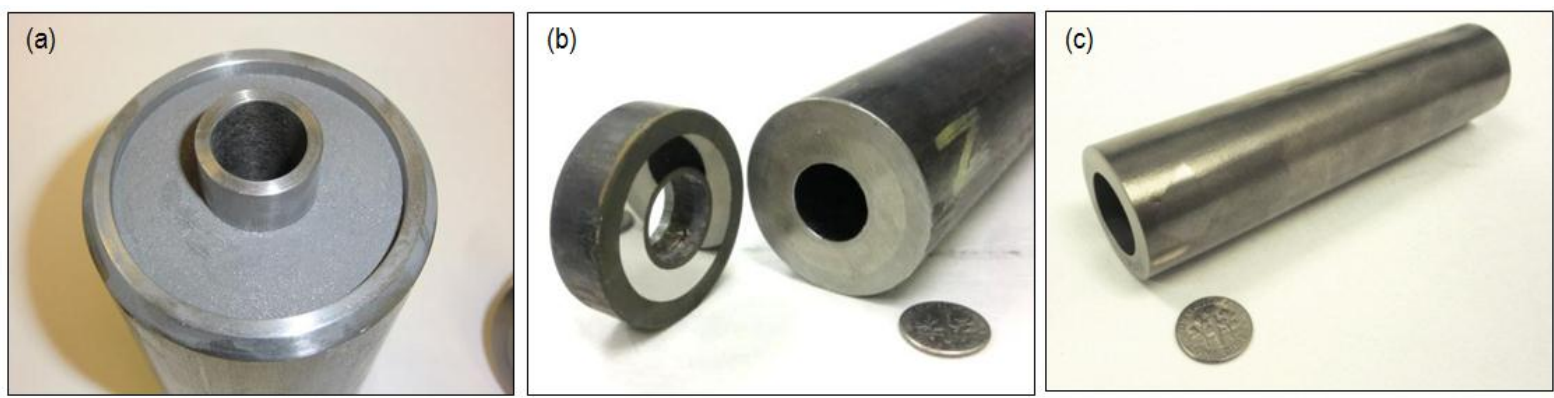

Figure 91. Each process of direct tube fabrication from Ti-6Al-4V powder; (a) Armstrong processed ti-6Al-4V powder in a steel can (OD:3"), (b) after hot extrusion (Sectioned), and (c) after can removal. 
Trial of near net shape hot extrusion was attempted with an $\mathrm{H}$-shape extrusion die built from e-beam deposition. A commercial wrought Ti-6Al-4V billet with 3 inch diameter and 4.5 inch length was used for the first attempt (shown in Figure 92a). The extrusion was successful without any problem during the process, and the cross sectional views showed uniform and symmetrical $\mathrm{H}$-shape as expected (Figure 92b). Microstructure characterization of H-shape extruded Ti-6Al-4V bar indicated no internal defects due to the irregular extrusion die shape, as shown in Figure 93, although the elongated grain morphology indicated that anisotropic stress was applied during extrusion process. However, the variation of the grain morphology and size were relatively small so that very little effect on the mechanical properties would be expected.
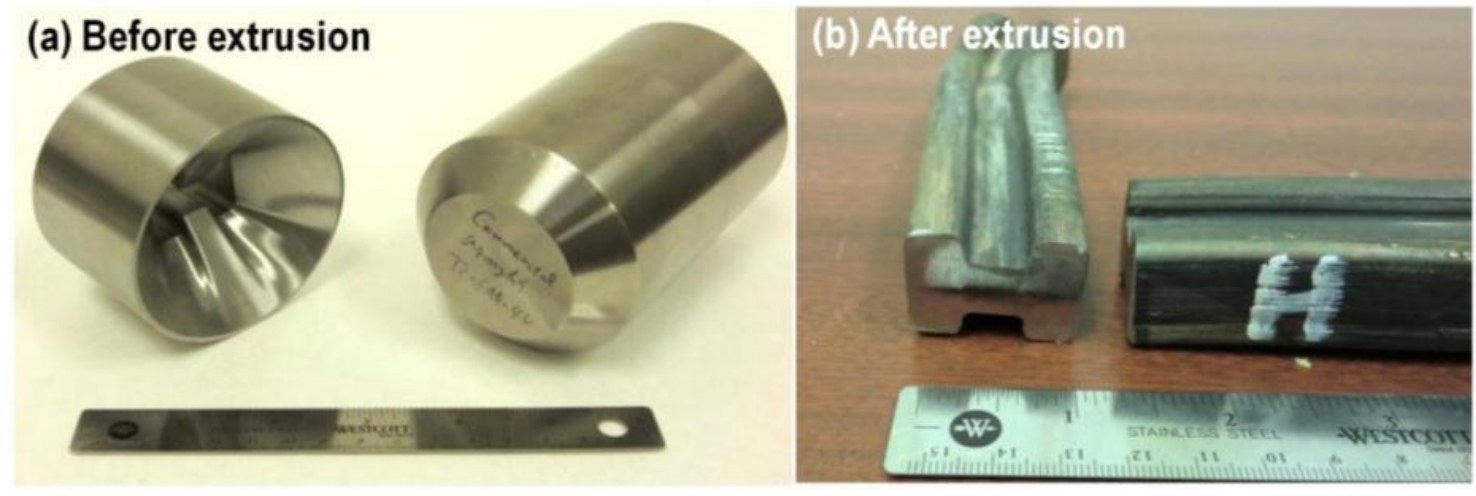

Figure 92. (a) the H-shape die made by additive manufacturing and a wrought Ti-6Al-4V billet before hot extrusion, and (b) a section of the extruded bar showing the H-shape.

By combining the two extrusion processes extrusion of complicated shapes directly from powder is feasible. In order to minimize the fabrication steps, a canless powder extrusion was proposed by using press and sinter technology. The extrusion process can apply very high pressure to the materials, so that relatively easy consolidation can be expected. This requires careful atmosphere control to minimize the contamination.
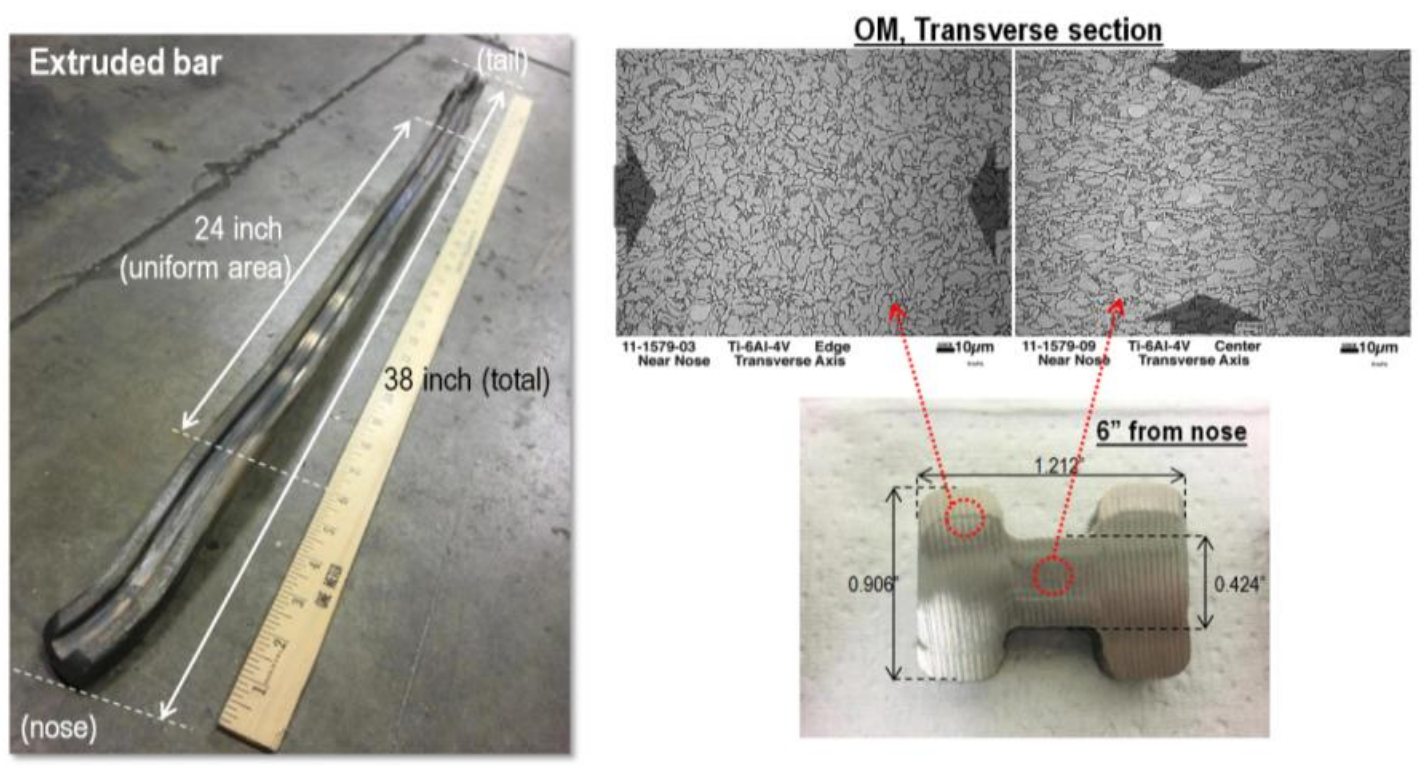

Figure 93. Picture of the $\mathrm{H}$-shape extruded commercial Ti-6Al-4V bar, together with crosssectional microstructure obtained from two different portions. The elongated grain morphology in the microstructure indicated anisotropic stress applied to the material during extrusion. 


\section{BENEFITS ASSESSMENTS}

The obvious advantage for consideration of producing components via powder metallurgy is to increase the efficiency of part manufacturing. Given the same raw material source, increasing efficiency occurs by lowering the energy input, reducing the labor, and improving the yield. An evaluation is made below on energy considerations with the most significant factor being the buy to fly ratio. There is a scarcity of information on labor and yield for any of these processes as those areas are where competitors in the industry gain advantages. The HDH process considered under this assessment assumes that the source of the CP-titanium is from Kroll sponge; for HDH Ti-64 the source is scrap from Kroll based component manufacturing whereby bulk scrap goes through the HDH process. Although other sources are available they are less mature. These two sources were used in this study. For Armstrong Process TM material that has yet to be evaluated at a production scale, there is a significant promise in efficiency improvement. Powder output at the newly designed Ottawa, IL plant is designed for 500 pounds per hour, of either Ti-64 or CP-Ti. The making of CP-Ti via the Armstrong Process ${ }^{\mathrm{TM}}$ is more energy efficient than making CP-Ti powder via the HDH process from Kroll sponge. The energy savings on final part yield for Ti-64 has moderate projected energy efficiency; however significant efficiency comes from continuous output with a smaller infrastructure and lower labor input.

\subsection{KROLL PROCESSING}

The Kroll process utilizes $\mathrm{TiCl}_{4}$, most of which is produced for the paint industry, where purified $\mathrm{TiCl}_{4}$, substantially free of other metals is used to make $\mathrm{TiO}_{2}$ paint pigment. The Kroll process utilizes pigment quality $\mathrm{TiCl}_{4}$ as feed in a batch process that produces metallic titanium by utilizing the following exothermic reaction (known as the Kroll reaction):

$$
\mathrm{TiCl}_{4}+2 \mathrm{Mg}=2 \mathrm{MgCl}_{2}+\mathrm{Ti} . \Delta \mathrm{H} \approx-97.5 \mathrm{kcal} / \text { mole Ti }(-2.37 \mathrm{kWh} / \mathrm{kg} \mathrm{Ti})[39]
$$

To accomplish the reduction, purified $\mathrm{TiCl}_{4}$ is fed into a closed stainless steel reactor vessel that contains a small heel of molten magnesium. Over approximately 4 days, $\mathrm{TiCl}_{4}$ and molten magnesium are co-fed into the reactor at controlled rates that maintain the reactor vessel wall at approximately $1100{ }^{\circ} \mathrm{C}\left(2000^{\circ} \mathrm{F}\right)$. Inert gas fills the head space of the reactor; avoiding back reactions with air caused by any potential leaks in the system. The reaction rate and temperature is controlled by the feed rate of $\mathrm{TiCl}_{4}$ and $\mathrm{Mg}$ and is regulated by metering the two feeds. Periodically, during the reduction, liquid $\mathrm{MgCl}_{2}$ is removed from the vessel to allow space for continued filling. After the 4 day reaction cycle, residual $\mathrm{Mg}$ and $\mathrm{MgCl}_{2}$ remain intermixed with the porous titanium reaction product (sponge) inside the reaction vessel. In modern plants a distillation cycle is employed after the reduction is complete where the reaction vessel is externally heated to approximately $1000^{\circ} \mathrm{C}$ $\left(2000^{\circ} \mathrm{F}\right)$ and evacuated over approximately 4 days to remove most of the $\mathrm{MgCl}_{2}$ and $\mathrm{Mg}$ residues. After distillation, another 4 days of reactor vessel cooling is typically required. Once the 12 day cycle is complete, the vessel is cut open and the sponge agglomerate is removed, and sectioned into portions. Sponge adjacent to the reactor wall is high in contaminants including corrosion products from the reactor vessel, and is utilized in less critical applications. Sponge metal on the bottom of the mass is rejected. Approximately $75 \%$ to $85 \%$ of the mass of titanium sponge produced is suitable for subsequent processing into metallic components.[40,41]

The reaction by-product $\mathrm{MgCl}_{2}$ captured during reaction progression and as a vacuum distillate is electrochemically converted to $\mathrm{Mg}$ and $\mathrm{Cl}_{2}(\mathrm{~g})$ and reintegrated for process economy. Approximately $60 \%$ to $70 \%$ of the energy associated with the Kroll sponge process is attributable to magnesium recovery. [40,41] 
A process flow diagram from Kobelco, Kobe Steel Group [42] is shown in Figure 94. This diagram begins with Kroll process sponge and follows the numerous processing steps required to make the full range of products. The stepwise batch processing and low material yield are significant contributors to the high cost of titanium.

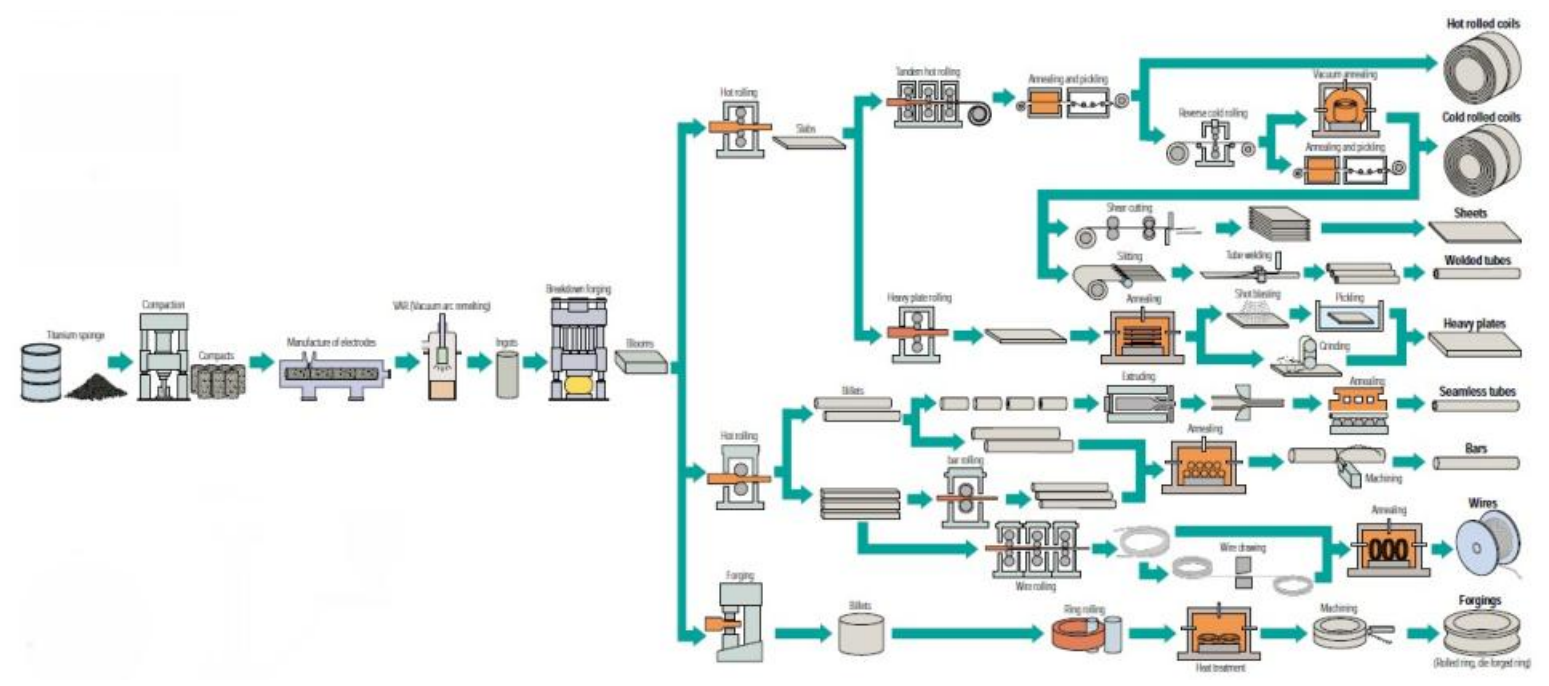

Figure 94. A process flow diagram depicting Kroll processed titanium into various metallic forms (Kobelco [42]).

The energy required for the Kroll process to make 2,200 pounds (1 MT) of usable titanium sponge from $\mathrm{TiCl}_{4}$, recover the magnesium from the reaction by-product $\mathrm{MgCl}_{2}$, and cull the sponge to remove low purity undesirable sponge portions is estimated at 74MBtu (21,500 kWh). From the Kroll reaction one mole of titanium (47.55 g) is produced along with two moles of $\mathrm{MgCl}_{2}(95.2 \mathrm{~g}$ ), consuming 2 moles of $\mathrm{Mg}$ (48.6 g). The electrolytic recovery of $\mathrm{Mg}$ from $\mathrm{MgCl}_{2}$ is essential for process economy and is the substantive energy consumer attributed to the Kroll reduction process and is estimated at 20,500 Btu/ lb magnesium $(13,200 \mathrm{kWh} / \mathrm{MT}$ of $\mathrm{Mg}){ }^{6}$

To produce 1MT of CP-Ti bar it is necessary to process approximately 33,100 pounds $(15,000 \mathrm{~kg})$ of $\mathrm{TiCl}_{4}$ to yield 8,400 pounds $(3,800 \mathrm{~kg})$ of raw metallic titanium sponge of which 6,380 pounds $(2,900$ $\mathrm{kg}$ ) has acceptable purity for conversion into metallic bar. The 6,380 pounds $(2,900 \mathrm{~kg})$ are pressed into an electrode, melt processed via double vacuum arc remelting (VAR) followed by forging /hot rolling, annealing and surface conditioning to yield a clean 2,200 pound (1000 kg) bar. The energy required to produce 2,200 pounds (1 MT) of CP-Ti bar is estimated at $240 \mathrm{MBtu}(70,400 \mathrm{kWh})$.

To convert the CP-Ti sponge to Ti-64 alloy bar and machine it to a 2,200 pound finished component with a $10: 1$ buy to fly ratio requires 261,000 pounds $(118,600 \mathrm{~kg})$ of $\mathrm{TiCl}_{4}$, to yield 66,000 pounds $(30,000 \mathrm{~kg})$ of metallic titanium sponge of which 61,250 pounds $(27,800 \mathrm{~kg})$ is of acceptable purity for subsequent processing. Master alloy granules containing aluminum and vanadium are blended with crushed titanium sponge and pressed into a first melt electrode for the initial VAR melt. Once the master melt is completed two more VAR melts are performed to homogenize and purify the alloy. Following melting, castings are forged to bar which includes several reheating steps. Once forged the bar is final annealed and surface finished to produce to a smooth regular shape. The 10:1 buy to fly ratio is calculated using the regular machined shape as the start point, and machining removes $90 \%$ of the bar as turnings. The energy required to produce a 1MT finished component machined from a Ti64 bar with a $10: 1$ buy to fly ratio is estimated at $1,987 \mathrm{MBtu}(582,100 \mathrm{kWh})$. It is recognized that a vacuum arc melted ingot sufficient to produce a 2,200 pound (1MT) final component with a 10:1 buy 
to fly ratio, forged and machined from a single billet, needs to be larger than 20,000 pounds $(9,100$ $\mathrm{kg}$ ) and is beyond the normal infrastructure for making titanium alloy billet; however for energy discussions no limit to infrastructure is considered. A 2,200 pound (1MT) finished component with a buy to fly ratio of 10:1 is rare, but this size is used for consistency in comparison and scales linearly with smaller pieces.

\subsection{KROLL HDH POWDER}

The Kroll HDH (Hydride Dehydride) process uses sponge produced by the Kroll process. However instead of melting the crushed sponge, the sponge is chemically cleaned to remove residual magnesium compounds, and is reacted with hydrogen to form titanium hydride by the reaction:

$$
\mathrm{Ti}+\mathrm{H}_{2}(\mathrm{~g})=\mathrm{TiH}_{2}
$$

$\mathrm{TiH}_{2}$ is brittle and has a low propensity to react at room temperature with either water or air. These characteristics allow the $\mathrm{TiH}_{2}$ to be crushed, ground, and attritted at room temperature with little risk of unstable oxidation (low pyrophoricity potential), or pick-up of undesirable interstial elements $\left(\mathrm{O}_{2}\right.$, $\mathrm{N}_{2}$ ). The crushed $\mathrm{TiH}_{2}$ is screened to achieve a desirable size distribution for subsequent solid state compaction. Once screened, a batch thermal process is used to heat the particulate in vacuum and convert the $\mathrm{TiH}_{2}$ back into Ti. Table 36 shows the reaction thermodynamics where below $775^{\circ} \mathrm{C}$ the reaction; $\mathrm{Ti}+\mathrm{H}_{2}(\mathrm{~g})=\mathrm{TiH}_{2}$ is favored [39]. Above $775^{\circ} \mathrm{C}$ the reaction $\mathrm{TiH}_{2}=\mathrm{Ti}+\mathrm{H}_{2}(\mathrm{~g})$ is favored and proceeds rapidly in vacuum. Currently the $\mathrm{H}_{2}$ is not recovered. Figure 95 shows a schematic of the Kroll HDH process, with a depiction of the morphology of the particulates. For mill forms, cladding the cold pressed powder in a steel can, followed by hot isostatic pressing (HIP) to achieve full density and /or hot wrought processing by batch operations are required.

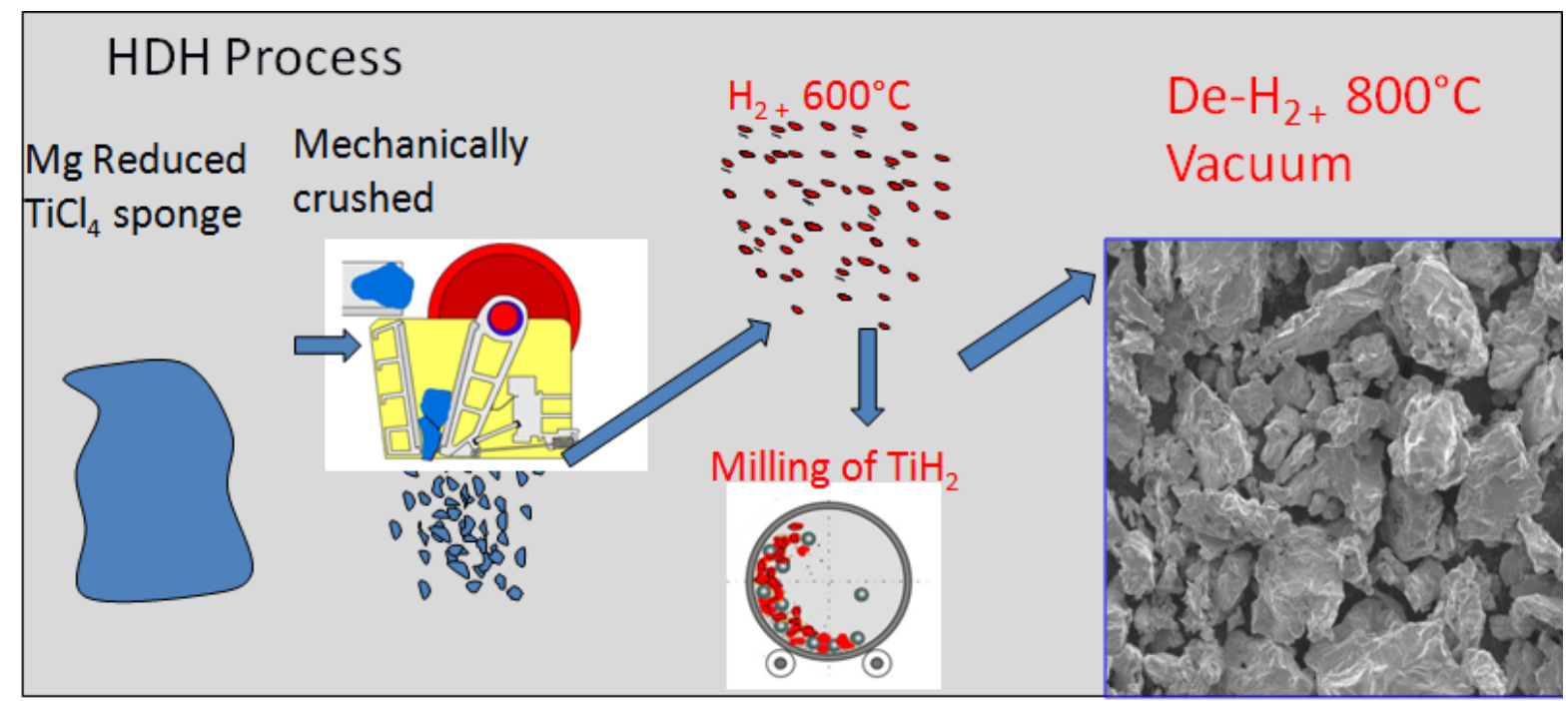

Figure 95. Depiction of the Kroll HDH process with a scanning electron microscope image of the produced powder. 
Table 36. Thermodynamic data on the Titanium Hydride reaction [39]

\begin{tabular}{|c|c|c|c|}
\hline \multicolumn{4}{|l|}{$\mathbf{T i}+\mathbf{H 2}(\mathbf{g}) \mathbf{T i H 2}$} \\
\hline $\mathbf{T}$ & Delta $\mathbf{H}$ & Delta $\mathbf{S}$ & Delta G \\
\hline \hline${ }^{\circ} \mathbf{C}$ & kcal & cal/K & kcal \\
\hline 600 & -35.31 & -33.70 & -5.89 \\
\hline 610 & -35.30 & -33.69 & -5.55 \\
\hline 620 & -35.29 & -33.67 & -5.21 \\
\hline 630 & -35.28 & -33.66 & -4.88 \\
\hline 640 & -35.26 & -33.64 & -4.54 \\
\hline 650 & -35.25 & -33.63 & -4.20 \\
\hline 660 & -35.24 & -33.62 & -3.87 \\
\hline 670 & -35.22 & -33.60 & -3.53 \\
\hline 680 & -35.21 & -33.59 & -3.20 \\
\hline 690 & -35.20 & -33.58 & -2.86 \\
\hline 700 & -35.19 & -33.56 & -2.52 \\
\hline 710 & -35.17 & -33.55 & -2.19 \\
\hline 720 & -35.16 & -33.54 & -1.85 \\
\hline 730 & -35.15 & -33.53 & -1.52 \\
\hline 740 & -35.14 & -33.52 & -1.18 \\
\hline 750 & -35.13 & -33.51 & -0.85 \\
\hline 760 & -35.12 & -33.50 & -0.51 \\
\hline 770 & -35.11 & -33.49 & -0.18 \\
\hline 780 & -35.10 & -33.48 & 0.16 \\
\hline 790 & -35.10 & -33.48 & 0.49 \\
\hline 800 & -35.09 & -33.47 & 0.83 \\
\hline
\end{tabular}

The energy consumption for making of 2,200 pounds (1MT) of Kroll HDH particles is approximately $62,400 \mathrm{Btu} / \mathrm{lb}$. (40,246 kWh/MT Ti) and is almost double that required by the conventional Kroll sponge due to the added hydrogen demand that requires an additional 3,900 Btu / lb. (2,500 kWh/ MT of Ti), and is also coupled with some additional losses due to fines. The need for a hydrogen plant detracts from the promise of a low capital investment for the Kroll HDH process.

When considering a 2,200 pound (1MT)) finished product output a mill form bar requires an estimated $222 \mathrm{MBtu}(64,900 \mathrm{kWh})$ an $8 \%$ saving over Kroll processing via liquid metal / wrought processing due to improved yields. A Ti-64 machined component with a buy to fly ratio of 5:1, requires $1,076 \mathrm{MBtu}(315,100 \mathrm{kWh})$ a $12.5 \%$ increase in energy consumption over Kroll liquid metal wrought processing. Energy advantages will occur when the buy to fly ratio exceeds $7: 1$. The near parity on energy is due to the fact that the source material for the HDH Ti-64 comes from the Kroll triple melting process in this energy analysis, in contrast to all solid state processing in the case of CP-Ti.

\subsection{ARMSTRONG PROCESS TM PROCESSING}

An alternative to the Kroll process, the Armstrong Process ${ }^{\circledR}$, is being reduced to practice by Cristal US's, International Titanium Powder (ITP) division in Ottawa, IL. Like the Kroll route, the Armstrong Process ${ }^{\circledR}$ uses $\mathrm{TiCl}_{4}$ as a feed material; however sodium is used as the reductant instead of magnesium. The Armstrong Process ${ }^{\circledR}$ plant that is now in commissioning is designed to produce 2,000 ton / year of titanium powder.

The reduction of $\mathrm{TiCl}_{4}$ takes place in a continuous flow pipe reactor where excess sodium absorbs the exotherm of the reaction: 


$$
\mathrm{TiCl}_{4}+4 \mathrm{Na}=4 \mathrm{NaCl}+\text { Ti. } \Delta \mathrm{H} \approx-203 \mathrm{kcal} / \mathrm{mole} \mathrm{Ti,} \mathrm{(-4.93} \mathrm{kWh/kg} \mathrm{Ti)} \mathrm{[39]}
$$

Using excess liquid sodium as the carrier fluid, titanium product, and sodium chloride by-product are transferred to a solids separation step, followed by a distillation / evaporation step to remove excess sodium. The sodium chloride is removed via a water wash and the remaining titanium is dried and consolidated. The process is schematically depicted in Figure 96 along with an example of the particulate morphology.

\section{Armstrong}
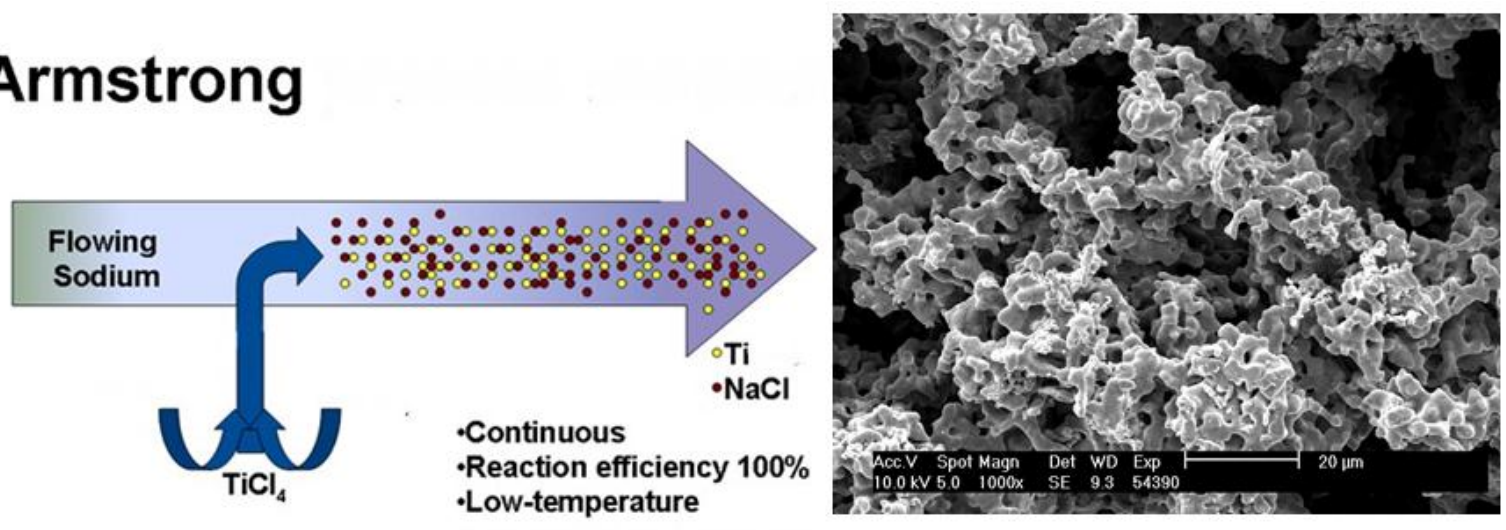

Figure 96. Schematic depiction of the Armstrong Process ${ }^{\circledR}$ from International Titanium Powder with a scanning electron microscopy image of the powder morphology.

An energy analysis when considering the recycling of the sodium chloride back into sodium metal shows the titanium reduction process to be more energy intensive than Kroll at 58,600 Btu/lb of Ti $(37,800 \mathrm{kWh} / \mathrm{MT}$ of Ti), due to the high energy demand for electrolytic recovery of sodium from sodium chloride. Four moles of sodium $(92 \mathrm{~g})$ are required and 4 moles of sodium chloride $(234 \mathrm{~g})$ are produced for each mole $(47.9 \mathrm{~g})$ of titanium and the electrolytic recovery of the sodium from sodium chloride is $17,000 \mathrm{Btu} / \mathrm{lb}$ of sodium $(11,000 \mathrm{kWh} / \mathrm{MT} \text { of } \mathrm{Na})^{12}$. Mill product energy calculations reveal 94,900 Btu /lb (61,200 kWh /MT), 21\% less than Kroll, and $6 \%$ less than CP-Ti $\mathrm{HDH}$ process. Even though reduction to powder is more energy intensive, the reduced surface conditioning requirements and lower material losses associated with processing in a steel can, still makes Armstrong Process TM slightly more energy efficient. Although the energy advantage is slight, the promise of continuous output with lower labor cost is thought to be compelling.

A Ti-64 machined PM Armstrong component with a buy to fly ratio of 5:1 consumes $856 \mathrm{MBtu}$ $(250,700 \mathrm{kWh})$ a $12 \%$ energy savings over Kroll wrought processing, and 26\% over Kroll HDH Ti-64 processing. The savings comes from not having the hydrogen cost in the case of Kroll HDH and in not having to triple melt the raw material to make Ti-64. The Armstrong Process ${ }^{\mathrm{TM}}$ for Ti-64 is solid state. In Figure 97, the percentage of energy that can be potentially saved has been compared to the improvements in yield (or the decrease in buy to fly ratios) for powder metallurgy components. 


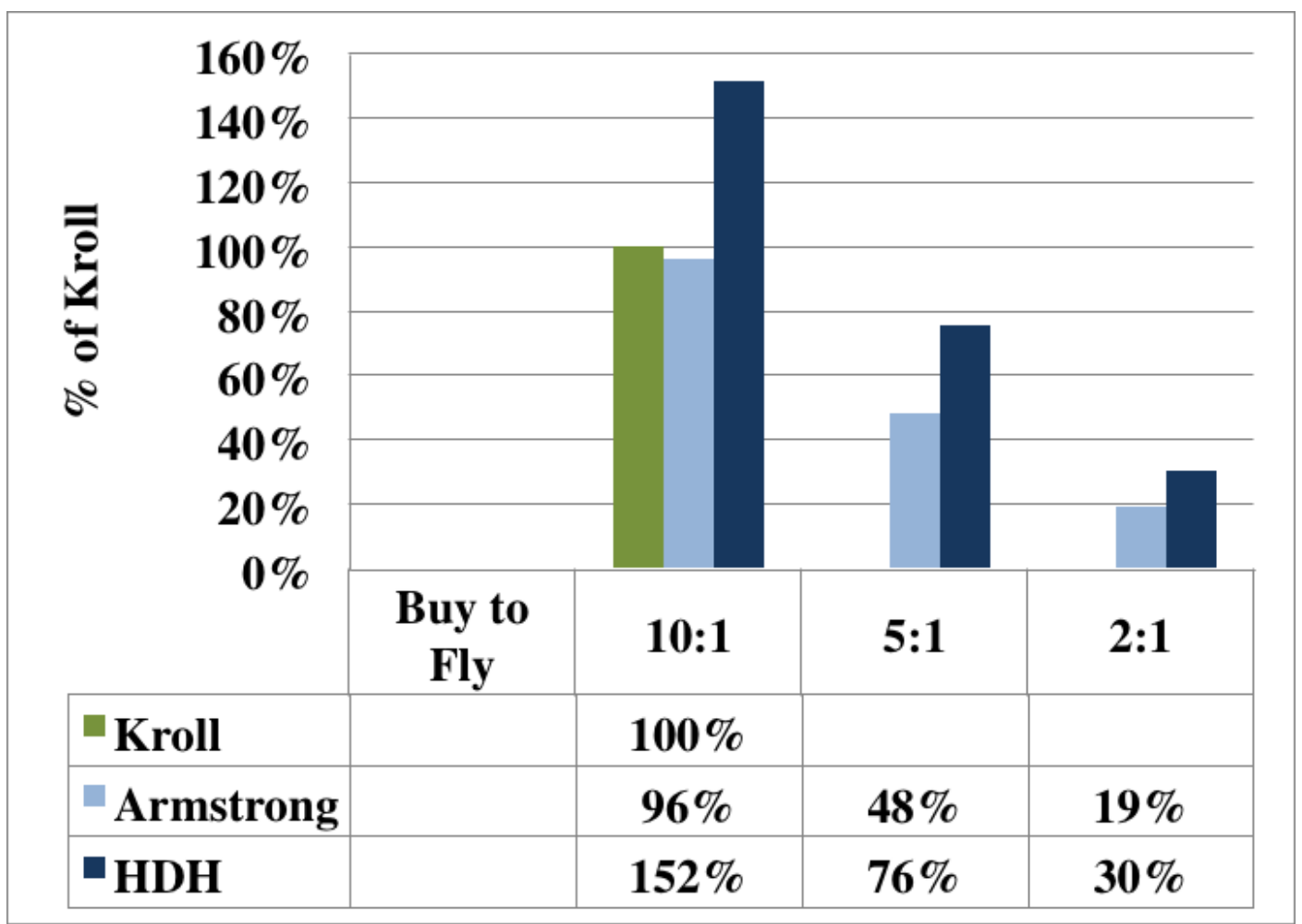

Figure 97. Comparing energy requirements to produce Ti-6Al-4V component by powder metallurgy using 10:1, 5:1, and 2:1 buy to fly ratio versus a 10:1 buy to fly ratio for wrought product.

\subsection{ENERGY BENEFITS IN APPLICATION}

The largest potential energy savings can be obtained in the downstream energy savings by using a net shape titanium component low in weight. These savings can be found in many forms. In aircraft, the increased use of titanium and carbon composites in the Boeing 787 decreased the weight of the aircraft by $20 \%$ compared to conventional aircraft of similar size. Based on the ATKINS feasibility study, "reducing the weight of long range aircraft by $100 \mathrm{~kg}$ results in a $1.3 \mathrm{MtCO}_{2} \mathrm{e}$ overall lifetime of the aircraft, the equivalent of saving $\$ 2.5 \mathrm{M}$ worth of fuel" $" 43$. In a similar context, replacing steel components with titanium alloy components in automotive applications has the potential to decrease the overall weight of components up to $40 \%$ based on strength to weight ratios. For every $10 \%$ weight reduction in automotive, a 6\% savings in fuel can be realized. In the area of pumps and impeller design, a 5\% savings in hydraulic efficiency could be realized by utilizing the ability to fabricate net shape desired geometries.

\subsection{COST COMPARISON OF POWDER METALLURGY, ADDITIVE MANUFACTURING, AND WROUGHT PRODUCT}

Significant material inefficiencies are associated with titanium aircraft components. Most aeronautic components, including defense applications, require buy-to-fly ratios (weight of material purchased versus weight of finished component) of 8 to 1 or higher using conventional processing. New aircraft platforms generally have larger inefficiencies or material approaching 10 to 1 or 11 to 1 . For each F22, 110,239 lbs of material are purchased, but only 10,043 lbs of components are installed on the jet per a briefing by the Defense Logistics Agency $\left[{ }^{24}\right]$. Machining is costly in titanium and its alloys due to the slow speeds required. Typically machining costs can be up to half of the final component costs. Figure 98 shows a cost stack up of the individual stages for producing a final part as well as 
the cumulative cost. Parts from plate are illustrated on the left where 20 randomly chosen aircraft components were averaged, and forging is on the right where 10 randomly selected aircraft components were averaged. Often titanium is quoted for price per pound in the milled product form. As is apparent in the figure, mill product can be below $\$ 20 / \mathrm{lb}$, but when the costs are compared to the final weight of the part, the cost can be over $\$ 1,000 / \mathrm{lb}$.

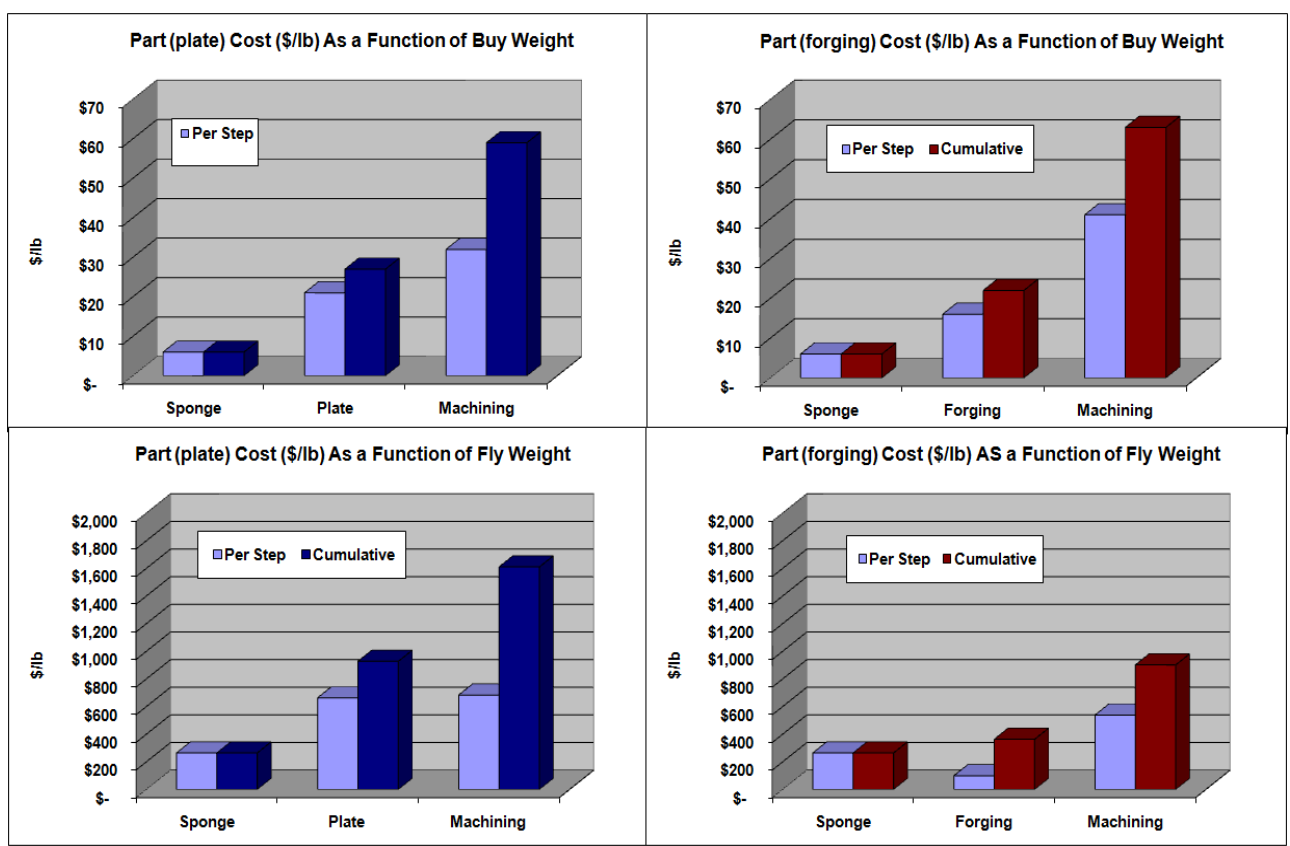

Figure 98. The cost breakout of titanium parts machined from plate (left) and forged stock (right) as a function of buy weight (top) and fly weight (bottom).

In order to compare the potential cost savings of powder metallurgy or additive manufacturing to conventional wrought plate machined, the team has obtained commercial costs associated with the press and sinter, additive manufacturing, and hot isostatic pressing of the BALD aircraft brackets. We have compared the costs to relative bracket values of $\$ 330$ per bracket, $\$ 430$ per bracket, and $\$ 530$ per bracket. A commercial press and sinter company provided quotes for the pressing and sintering of brackets for 20 parts, 500 parts, and 1,000 parts. The quotes did not include material/powder, HIPing, or machining. Estimates for these values (as a per bracket value) were included based on recent quotes for the respective service. In addition, an additive manufacturing firm was asked to provide a quote for 20 components; their quote includes powder and e-beam deposition. Once again, HIP and machining estimates were made. Table 37 shows the results of these calculations. While both technologies have the opportunity to save significant costs (above $50 \%$ ) significant quantities of parts or large volume parts have to be manufactured via powder metallurgy in order to obtain large savings. In the case of additive manufacturing, small part counts even with small parts can result in significant savings. A F35 jet fighter has only a limited number of the same bracket, but contains many brackets in different configurations. This line of reasoning has led to the interest of Lockheed Martin to evaluate the fabrication of aircraft brackets by additive manufacturing. In contrast, there is interest in looking at the forging of powder metallurgy titanium for large components with high buy to fly ratios. 
Table 37. Potential Cost Savings for Fabricating Brackets via Powder Metallurgy or Additive Manufacturing as Compared to Conventional Machining of Plate

\begin{tabular}{|c|c|c|c|c|c|c|c|c|c|}
\hline \multicolumn{10}{|c|}{ Powder Metallurgy Approach to Fabricate Bracket } \\
\hline & $\begin{array}{c}\text { Weight of } \\
\text { Material } \\
\text { (lb) }\end{array}$ & $\begin{array}{l}\text { Powder } \\
\text { Cost }(\$) \\
\end{array}$ & $\begin{array}{c}\text { Commercial } \\
\text { Press and } \\
\text { Sinter Costs } \\
\text { per Bracket }\end{array}$ & $\begin{array}{c}\text { HIP } \\
\text { Costs per } \\
\text { Bracket } \\
\end{array}$ & $\begin{array}{c}\text { Machining } \\
\text { per } \\
\text { Bracket } \\
\end{array}$ & $\begin{array}{c}\text { Cost / } \\
\text { Bracket }\end{array}$ & $\begin{array}{c}\% \text { Decrease } \\
\text { If } \$ 330 \\
\end{array}$ & $\begin{array}{c}\% \text { Decrease } \\
\text { If } \$ 430 \\
\end{array}$ & $\begin{array}{c}\% \\
\text { Decrease If } \\
\$ 530 \\
\end{array}$ \\
\hline PM 20 Parts & 0.2 & 6 & 290 & 9 & 200 & 505 & -53.0 & -17.4 & 4.7 \\
\hline PM 500 Parts & 0.2 & 6 & 21.33 & 3.6 & 150 & 180.93 & 45.2 & 57.9 & 65.9 \\
\hline PM 1000 Parts & 0.2 & 6 & 18.33 & 1.8 & 150 & 176.13 & 46.6 & 59.0 & 66.8 \\
\hline \multicolumn{10}{|c|}{ Additive Manufacturing Approach to Fabricate Bracket } \\
\hline & $\begin{array}{c}\text { Weight of } \\
\text { Material } \\
\text { (lb) }\end{array}$ & & $\begin{array}{c}\text { Commercial } \\
\text { AM Costs } \\
\text { Including } \\
\text { Powder } \\
\end{array}$ & $\begin{array}{c}\text { HIP } \\
\text { Costs per } \\
\text { Bracket } \\
\end{array}$ & $\begin{array}{c}\text { Machining } \\
\text { per } \\
\text { Bracket } \\
\end{array}$ & $\begin{array}{c}\text { Cost } \\
\text { /Bracket } \\
\end{array}$ & $\begin{array}{c}\% \text { Decrease } \\
\text { If } \$ 330 \\
\end{array}$ & $\begin{array}{c}\text { \% Decrease } \\
\text { If } \$ 430 \\
\end{array}$ & $\begin{array}{c}\% \\
\text { Decrease If } \\
\$ 530 \\
\end{array}$ \\
\hline AM 20 Parts & 0.1 & & $\$ 112$ & 9 & 100 & $\$ 221$ & 33.0 & 48.6 & 58.3 \\
\hline
\end{tabular}




\section{COMMERCIALIZATION}

Two sets of technologies were evaluated for production of near net shape titanium powder metallurgy parts and further developed in this project, powder metallurgy and additive manufacturing. The results of the tasks associated with these technologies have been captured in Section 3. Both technologies result in a net shape component fabricated from powder, but the technologies presently utilize different powder sources/feedstocks. Between the differences in the current status of the technology, and the use of different powder morphologies, the commercialization plan will be addressed separately for powder metallurgy and additive manufacturing, and then a commercialization plan associated with Lockheed Martin Aero's BALD brackets will be discussed.

\subsection{POWDER METALLURGY}

In the area of powder metallurgy, this project looked at the use of titanium powders consolidated by solid-state methodologies to make aircraft components and other industrial componentry. Almost all titanium today is fabricated using VAR melting to produce ingots followed by thermo-mechanical processing to make mill product forms. In certain high expense parts, conventional titanium powders (plasma rotating electrode process (PREP) or $\mathrm{HDH}$ ) have been consolidated via powder metallurgy to make components. However, these components have been limited and do not represent high production parts due to the historical high cost of the feedstocks and the required mechanical properties. This project looked at the powders fabricated utilizing new reduction technologies (e.g., Armstrong Process), and the advancements in conventional powder development (e.g., HydrideDehydride processing of Kroll Sponge) to determine if powder metallurgy was ready to make a large impact in the titanium industry.

Many of the new powders have unique powder morphologies that have significant effects on the process methodology and can also represent a whole new set of manufacturing challenges. In addition, data, cost information, and processing criteria is required for companies to make the business decisions as to the commercialization of titanium powder metallurgy components. Adding to the complexity, most high strength applications require Ti-6Al-4V or other Ti alloys, and can affect the overall cost structure to the fabrication of PM components.

The project effectively developed and demonstrated how to make complex fully dense components from titanium and titanium alloy powder with a range of morphologies. Press and sinter components/samples were exhibited. The cost effective means to fabricate net shape components from powder must be gauged on a part-by-part basis. The infrastructure required to consolidate the powders exists in commercial vendors today. However, the largest current limitation for commercialization is the availability of low cost prealloyed titanium powders. While research quantities of new powders have been available for laboratory consolidation and evaluation, commercial quantities are not available in pre-alloyed titanium powder that have met the cost requirements of the end users. Since the start of the project, new reduction technologies have been delinquent in producing commercial quantities of powder, and the costs of the powders have been greater than preliminary estimates. In looking at small components with small lot sizes, the cost of dies, cost of developing the required specifications, and other required infrastructure can outweigh the cost savings obtained in using less material. ORNL has worked with multiple airframe companies that have recognized large structural components that they would be interested in moving forward into commercialization if low cost powders were available and could meet the required specifications. 


\subsection{ADDITIVE MANUFACTURING}

Lockheed Martin - Aero was the project's main industrial partner with the largest industrial contribution. Through this project, Lockheed Martin identified aircraft components with high buy-tofly ratios that could benefit from powder metallurgy and/or additive manufacturing. In future commercialization efforts, the aircraft brackets fabricated via electron-beam deposition have the highest technology readiness level per Lockheed Martin. Lockheed Martin is interested in pursuing commercialization of this series of components. Aircraft brackets were evaluated for commercialization, and cost estimates were developed and evaluated for both powder metallurgy and additive manufacturing. Additive manufacturing was down selected by Lockheed Martin due to the economic, yield, and versatility benefits. The selected component fabricated by additive manufacturing could decrease the cost by half based on commercial estimates. Components and mechanical specimens for a wide range of testing and validation were then fabricated. Lockheed Martin performed the tests, and looked at a wide range of variables. The tested data was favorable for commercial implementation. The report and data were delivered by Lockheed Martin separately.

Successful commercialization and adoption of powder bed direct manufacturing technology is reliant on three elements. Two elements necessary for adoption are technical and the third is economic. All materials utilized in industry, and in particular the aerospace industry, are dependent on stringent standards to provide consistency for both chemical and physical properties. The aerospace industry relies almost exclusively on standards controlled by the Society of Automotive Engineers (SAE) to provide Aerospace Material Standards (AMS). Due to the length of time and complexity involved in approving SAE-AMS specifications an alternative approach for incorporating new materials and processing methods could be the use of internal company specifications. These specifications can be approved in months versus the year or more normally required for an industry wide specification.

In preparation for writing a specification some limited mechanical testing will need to be performed to establish material property baselines. The minimum tests normally involve those listed in the Metallic Materials Properties Development and Standardization (MMPDS) matrix for S-Basis allowables and include tensile, compression, shear and bearing tests [43]. The details of the tests can be found in Table 9.2.4.1 Chapter 9 of the MMPDS but the total tests required is 260. The use of this minimal data set imposes significant penalties on the material allowables due to the limited statistical base involved. To take full advantage of the new material a B-Basis allowable test program would need to be performed which carries a cost of approximately $\$ 50 \mathrm{~K}$ for only the static tests. To include fatigue data the cost of testing can easily approach $\$ 1$ million dollars, however this type of database allows the designer and stress analyst to take full advantage of the materials' capability. The primary issue is in justifying the expense of conducting this level of testing versus the potential payoff of using powder bed based direct manufactured material.

The issue of payoff brings us to the final and most important factor in the commercialization of powder bed direct manufacturing and that is the business case. Each part that is considered for conversion from conventional machining to powder bed direct manufacturing will require a business case that shows lower cost than the current method of manufacture. Normally the business case analysis focuses primarily on non-recurring engineering (NRE) reduction including tooling, numerical control (NC) programming and tool path proofing. Any reductions in material cost, machining time, or manufacture methods are also taken into account and compared against the current methodology to calculate a return on investment (ROI). With the entry of additive manufacturing the issue of inventory cost and savings offered by the ability to offer just in time delivery and order quantity flexibility enter the equation with the more difficult problem of calculating the cost of money and inventory added to the equation. Additive manufacturing eliminates the set up time normally associated with traditional machining and multiple unique parts can all be run in the same batch with 
no unique set up. In addition revisions can be made to a part with no need to alter an NC program or tooling. The new part configuration is merely downloaded from the CAD system and converted into the required file format for build using the material and direct manufacture machine of choice. These savings in both inventory and span time need to be added to the business case analysis to be able to move forward with the powder bed manufacturing technology. 


\section{ACCOMPLISHMENTS}

The following technical accomplishments were made in the project:

1) Ti-6Al-4V Armstrong powder was consolidated to more than $98 \%$ of theoretical density by press and sinter technology. HDH Ti-6Al-4V powder achieved densities that were around $80 \%$ of theoretical.

2) $\mathrm{HDH}$ and Armstrong (CP Ti and Ti-6Al-4V) powders have been fully consolidated by more than one post sinter process. Direct hot isostatic pressing (HIP) and pneumatic isostatic forging (PIF) of Armstrong powder without canning achieved full consolidation with densities as low as $78 \%$ theoretical before isostatic pressing.

3) A consolidation model was developed for evaluation of press and sinter components.

4) High strain rate plate compaction by using electro-magnetic actuator achieved full consolidation of Armstrong CP-Ti powder at a stage velocity of $\sim 140 \mathrm{~m} / \mathrm{s}$. It was found that the density increased with increasing the strain rate up to $\sim 140 \mathrm{~m} / \mathrm{s}$, and then decreased gradually.

5) High strain rate tubular compaction of Armstrong Ti-6Al-4V powder combined with subsequent sintering process created fully consolidated titanium tube components, without HIP/PIF process.

6) Mechanical properties (i.e. fatigue crack growth rate, FCGR) of HIP/PIFed titanium powder were comparable to the wrought materials.

7) A chemical pump component was designed and built using electron beam deposition that decreased the component weight by $56 \%$ compared to conventional casting techniques currently used. In-field testing by the company illustrated a 5\% efficiency increase in the first iteration.

8) A T-shape bracket made by PM technology reduced buy-to-fly ratio from 33:1 down to 4:1.

9) Electron beam deposition of same bracket further brought down buy to fly ratio to between 2:1 and 1:1 (may not require further machining).

10) Based on evaluations of additive manufactured brackets, Lockheed Martin is interested in pursuing specifications of electron beam deposited bracket.

The obtained results based on the effort of this project were presented/ published into open literatures as listed below:

Publications (5 journals and 5 proceedings)

1. Peter, William H., et al. "Current Status of Ti PM: Progress, Opportunities and Challenges." Key Engineering Materials v. 520 (2012), pp. 1-7.

2. Sabau, Adrian S., et al. "Numerical Simulation of Cold Pressing of Armstrong CP-Ti Powders." Proceedings in the TMS 2012 Annual Meeting \& Exhibition, 521-528, 2012.

3. W. Chen, Y. Yamamoto, W.H. Peter, M.B. Clark, S.D. Nunn, J.O. Kiggans, T.R. Muth, C.A. Blue, J.C. Williams, and K. Akhtar, "The investigation of die-pressing and sintering behavior of ITP CP-Ti and Ti-6Al-4V powders”, Journal of Alloys and Compounds, v. 541 (2012) pp. 440-447.

4. Sarma B. Gorti, Adrian S. Sabau, William H. Peter, Stephen D. Nunn, Yukinori Yamamoto, and Wei Chen, "Process Simulation of Cold Pressing and Sintering of Armstrong CP-Ti Powders", proceedings in TMS 2011 Annual Meeting \& Exhibition, February 27-March 3, 2011, San Diego, CA.

5. W. Chen, Y. Yamamoto, W.H. Peter, S.B. Gorti, A.S. Sabau, M.B. Clark, S.D. Nunn, J.O. Kiggans, C.A. Blue, J.C. Williams, B. Fuller, and K. Akhtar, "Cold compaction study of 
Armstrong Process ${ }^{\circledR}$ Ti-6Al-4V powders", Powder Technology, Vol. 214 (2011) pp. 194199.

6. Yukinori Yamamoto, William H. Peter, Adrian S. Sabau, Gorti B. Sarma, Jim O. Kiggans, Stephan D. Nunn, Michael B. Clark, Craig A. Blue, John E. Barnes, Chad Henry, Joe A. Capone, Muktesh Paliwal, Brian Fuller, and Kamal Akhtar, "Low Cost Titanium Near-NetShape Manufacturing Using Armstrong and/or Hydride-Dehydride CP-Ti and Ti-6Al-4V Powders", proceedings in the 2010 International Conference on Powder Metallurgy \& Particulate Materials, PowderMet 2010, June 27-30, Hollywood, FL.

7. Adrian S. Sabau, James O. Kiggans, William H. Peter, and Donald L. Erdman III, "Material Properties for the Simulation of Cold Pressing of Titanium Armstrong CP-Ti/Ti-6Al-4V Powders", proceedings in the 2010 International Conference on Powder Metallurgy \& Particulate Materials, PowderMet 2010, June 27-30, Hollywood, FL.

8. Adrian S. Sabau, Sarma B. Gorti, William H. Peter, and Yukinori Yamamoto, "Process Simulation of Cold Pressing and Sintering of Titanium Armstrong CP-Ti/Ti-6Al-4V Powders", proceedings in the 2010 International Conference on Powder Metallurgy \& Particulate Materials, PowderMet 2010, June 27-30, Hollywood, FL.

9. Y. Yamamoto, J.O. Kiggans, M.B. Clark, S.D. Nunn, A.S. Sabau, and W.H. Peter, "Consolidation Process in Near Net Shape Manufacturing of Armstrong CP-Ti/Ti-6Al-4V Powders", Key Engineering Materials Vol. 436 (2010) pp. 103-111.

10. W. Chen, Y. Yamamoto, and W.H. Peter, "Investigation of pressing and sintering processes of CP-Ti powder made by Armstrong Process", Key Engineering Materials Vol. 436 (2010) pp. 123-130.

Oral presentation (total 13 presentations)

1. Chen, Wei, et al. "The effect of powder morphology on the sintering behavior of $\mathrm{Ti}$ and $\mathrm{Ti}$ alloy powders." In TMS 2012, Orlando, Florida, USA, March 11-15, 2012.

2. Adrian S. Sabau, et al. "Numerical Simulation of Cold Pressing of Armstrong CP-Ti Powders." Presentation in the 2012 TMS Annual Meeting \& Exhibition.

3. Peter, William H., et al. "Processing and Properties of Commercially Pure Ti and Ti-6Al-4V Made by Two Different Powder Metallurgy Methods." Powder Processing, Consolidation and Metallurgy of Titanium, Brisbane, Australia, December 05-07, 2011.

4. Peter, William H., et al. "Netshape Fabrication of Titanium Components." Titanium 2011, San Diego, California, USA, October 02—05, 2011.

5. W. Chen, Y. Yamamoto, W.H. Peter, M.B. Clark, S.B. Gorti, A.S. Sabau, S.D. Nunn, J.O. Kiggans, C.A. Blue, J.C. Williams, B. Fuller, and K. Akhtar, " Cold compaction and sintering study of Armstrong Process ${ }^{\circledR}$ CP-Ti and Ti-64 powders", oral presentation in TMS 2011 Annual Meeting \& Exhibition, February 27-March 3, 2011, San Diego, CA.

6. Y. Yamamoto, W. Chen, S.D. Nunn, J.O. Kiggans, M.B. Clark, R.L. Swain, A.S. Sabau, T.R. Muth, R.R. Dehoff, W.H. Peter, C.A. Blue, J.C. Williams, B. Fuller, and K. Akhtar, "Effect of milling process on mechanical properties of fully consolidated titanium and titanium alloy powders made by Armstrong Process ${ }^{\circledR}$ technology”, oral presentation in TMS 2011 Annual Meeting \& Exhibition, February 27-March 3, 2011, San Diego, CA.

7. Sarma B. Gorti, Adrian S. Sabau, William H. Peter, Stephen D. Nunn, Yukinori Yamamoto, and Wei Chen, "Process Simulation of Cold Pressing and Sintering of Armstrong CP-Ti Powders", presentation in TMS 2011 Annual Meeting \& Exhibition, February 27-March 3, 2011, San Diego, CA. 
8. Thomas R. Muth, William H. Peter, Yukinori Yamamoto, Craig A. Blue, David Harper, John E. Barnes, Chad Henry, Joe A. Capone, Muktesh Paliwal, and Kamal Akhtar, "Affordable Titanium Sheet Fabrication Via Roll Compaction", presentation in the 2010 International Conference on Powder Metallurgy \& Particulate Materials, PowderMet 2010, June 27-30, Hollywood, FL.

9. Yukinori Yamamoto, William H. Peter, Adrian S. Sabau, Gorti B. Sarma, Jim O. Kiggans, Stephan D. Nunn, Michael B. Clark, Craig A. Blue, John E. Barnes, Chad Henry, Joe A. Capone, Muktesh Paliwal, Brian Fuller, and Kamal Akhtar, "Low Cost Titanium Near-NetShape Manufacturing Using Armstrong and/or Hydride-Dehydride CP-Ti and Ti-6Al-4V Powders", presentation in the 2010 International Conference on Powder Metallurgy \& Particulate Materials, PowderMet 2010, June 27-30, Hollywood, FL.

10. Adrian S. Sabau, James O. Kiggans, William H. Peter, and Donald L. Erdman III, "Material Properties for the Simulation of Cold Pressing of Titanium Armstrong CP-Ti/Ti-6Al-4V Powders", presentation in the 2010 International Conference on Powder Metallurgy \& Particulate Materials, PowderMet 2010, June 27-30, Hollywood, FL.

11. Adrian S. Sabau, Sarma B. Gorti, William H. Peter, and Yukinori Yamamoto, "Process Simulation of Cold Pressing and Sintering of Titanium Armstrong CP-Ti/Ti-6Al-4V Powders", presentation in the 2010 International Conference on Powder Metallurgy \& Particulate Materials, PowderMet 2010, June 27-30, Hollywood, FL.

12. Y. Yamamoto, J.O. Kiggans, M.B. Clark, S.D. Nunn, A.S. Sabau, and W.H. Peter, "Consolidation Process in Near Net Shape Manufacturing of Armstrong CP-Ti/Ti-6Al-4V Powders", presentation in symposium "Cost-affordable Titanium III" in TMS 2010 Annual Meeting \& Exhibition, February 14-18, 2010, Seattle, WA.

13. W. Chen, Y. Yamamoto, and W.H. Peter, "Investigation of pressing and sintering processes of CP-Ti powder made by Armstrong Process", presentation in symposium "Cost-affordable Titanium III" in TMS 2010 Annual Meeting \& Exhibition, February 14-18, 2010, Seattle, WA. 


\section{CONCLUSIONS}

The objective of this study was to develop near net shape manufacturing processes of new, and potentially low cost, titanium components for industry, which directly contribute to reduce industrial energy intensity, especially on downstream of the manufacturing process compared to conventional wrought titanium components, and to impact the potential industrial market of low-cost, corrosion resistant, and light weight structural components. Comprehensive powder consolidation studies of $\mathrm{CP}-\mathrm{Ti}$ and Ti-6Al-4V powders made by the Armstrong process and the hydride-dehydride (HDH) process have been conducted.

Consolidation modeling predicted pressure and density distributions of pressed Armstrong titanium powders in a cylindrical die, as well as shape changes during sintering process, as a function of aspect ratio of the pressed samples. The calculated density distribution and shape changes were consistent with those of the actual die-pressed and sintered samples.

Milling process improved the tap density drastically of Armstrong titanium powders from 6-8\% (asreceived) to nearly $30 \%$ (ball-milled in ethanol for $90 \mathrm{~min}$ ). The milling showed little effect on the pressed density, but improved the sintered density of Ti-6Al-4V significantly to achieve full consolidation. However, the milling process with extended period of time or in improper atmosphere resulted in powder contamination (e.g. high oxygen) which caused degradation of ductility of fully consolidated samples.

Traditional press-and-sinter technology achieved nearly full consolidation of the Armstrong processed titanium powders. CP-Ti powder was consolidated up to $96.4 \%$ theoretical density by uniaxial die pressing at $100 \mathrm{ksi}$ and vacuum sintering at $1300{ }^{\circ} \mathrm{C}$ for $1 \mathrm{~h}$. Ti-6Al-4V powder, after milling process, achieved more than $99.8 \%$ theoretical density after die-pressing at $50 \mathrm{ksi}$ followed by vacuum sintering at $1300{ }^{\circ} \mathrm{C}$ for $1 \mathrm{~h}$. These densities were very high compared to those of the HDH $\mathrm{CP}-\mathrm{Ti}$ and Ti-6Al-4V powders which pressed and sintered at the same process consolidations (93.3\% and $71.3 \%$, respectively). Blending two different powders (Armstrong and HDH) was attempted, but did not result in increasing the as-pressed and sintered densities.

Fabrication of near net shape components made from the Armstrong titanium powders was successfully conducted by using press-and-sinter technology with optimized process conditions. A Tshape bracket, tubes, coins, and sheets were die-pressed in the shapes and some of them were coldisostatically pressed without any significant difficulty.

Pneumatic isostatic forging (PIF) and hot isostatic pressing (HIP) of the press-and-sintered samples successfully achieved full consolidation of both Armstrong and HDH powders. Armstrong powders were fully consolidated without the use of cans, since the press-and-sinter process eliminated open porosity as well as inter-connected pores inside the samples. The HIP process combined with the press-and-sinter was mainly used for preparing the full consolidated titanium specimens for the mechanical property screening.

High strain rate powder compaction was systematically investigated under collaboration with the Ohio State University. Tube shape components were successfully pressed by utilizing electromagnetic compaction methods, which achieved full consolidation after sintering process using milled Armstrong Ti-6Al-4V. The relationship between the green density and actuator velocity, controlled by the stored energy prior to the compaction, on plate-shape compaction of Armstrong powders was also determined. The optimized compaction methods achieved nearly full consolidation of CP-Ti in as-pressed condition. 
Mechanical properties of fully consolidated titanium powders at room temperature, including tensile, fracture toughness, fatigue crack growth, and high cycle fatigue, were evaluated. Armstrong CP-Ti and Ti-6Al-4V samples exhibited lower tensile ductility and less fracture toughness than the minimum requirements of commercial grade 2 (CP-Ti) and grade 5 (Ti-6Al-4V) titanium products, although these results are expected due to high oxygen content of the initial powders. More efforts to optimize the full consolidation process with less contamination and better microstructure control will be required once Armstrong powders are available. Additional research could also be of interest where new methods of minimizing oxygen pickup during the consolidation and sintering steps are investigated. The Armstrong powder samples showed improved fatigue crack growth resistance (CP-Ti and Ti-6Al-4V) and extended high cycle fatigue limit (CP-Ti) compared to wrought titanium products. Fully consolidated HDH powders showed similar results compared to commercial wrought products in most of the properties, except for fracture toughness of CP-Ti. Further development of anneal treatments may improve fracture toughness, but the industrial team members of the project were more interested in titanium alloy versus commercially pure titanium. Therefore, resources were focused on near term commercial interests, such as additive manufacturing. Once again, a reevaluation of powder metallurgy titanium components should be evaluated when or where affordable powders meeting low interstitial content are available.

Additive manufacturing (electron beam melting and deposition system) was utilized to build near net shape titanium components from gas-atomized titanium powders. An impeller for chemical industry and a T-bracket for aircraft were selected for the demonstration, which were successfully built without any technical issues. The HDH CP-Ti and Ti-6Al-4V powders were also utilized in the ebeam melting system, which resulted in adequate flow properties to be utilized in the EBM machine without alteration to the current powder raking method. Anisotropic tensile properties were observed in as-deposited materials, which would need to be eliminated by optimizing deposition conditions and/or subsequent heat treatments.

The two components were evaluated in field trials. In future commercialization efforts the aircraft brackets fabricated via electron-beam deposition have the highest technology readiness level. Lockheed Martin is interested in pursuing commercialization of this series of components. Aircraft brackets were evaluated for commercialization and proprietary cost estimates were developed and evaluated for both powder metallurgy and additive manufacturing. Additive manufacturing was down selected due to the economic, yield, and versatility benefits. The selected component fabricated by additive manufacturing could decrease the cost by half based on commercial estimates. Components and mechanical specimens for a wide range of testing and validation were fabricated. Lockheed Martin performed the tests, and looked at a wide range of variables. The results were favorable for commercial implementation. The next step towards commercialization is qualification, and development of a specification. Lockheed Martin is evaluating the class of qualification that will provide the best return on investment (limited use allowables or extensive allowables). 


\section{RECOMMENDATIONS}

The following recommendations are being made for the areas of powder metallurgy and additive manufacturing of titanium powders.

\section{In General}

- Commercially viable reduction technologies for winning titanium metal from ore is still an area of development that is required to enable significant penetration of titanium and titanium alloys into new industrial and energy applications.

For powder metallurgy

- Follow up research to improve PM process to reduce contamination and to control microstructure in order to improve mechanical properties of fully consolidated Armstrong titanium powders.

- Collaboration with commercial PM makers for scale-up efforts.

For additive manufacturing

- Development of optimized melting conditions and subsequent thermo-mechanical processing (e.g. HIP) for the materials built by additive manufacturing. 


\section{REFERENCES}

[1] Lutjering G., William J. C. Titanium. Springer, 2007. pp. 1-14

[2] Montgomery J. S. et al. JOM 49, 5, 1997. pp. 45-47

[3] Hurless, B.E. et al. The AMPTIAC Quarterly, Volume 6, Number 2, pp. 3-9

[4] China's Impact on Metals Prices in Defense Aerospace, Department of Defense, Office of the Deputy Under Secretary of Defense (Industrial Policy), December 2005.

[5] Luckowski, S. The Application of Titanium in Army Armament Systems, Presentations at TMS 2003 Meeting

[6] Froes, S. Kirk-Othmer Encyclopedia of Chemical Technology. Titanium and Titanium Alloys. John Wiley \& Sons, Inc. 2001

[7] Savage, N. A Cleaner, Cheaper Route to Titanium. Technology Review: An MIT Enterprise. 2006. http://www.technologyreview.com/printer_friendly_article.aspx?id=16963

[8] Hartman, A.D. et al. JOM 50, 9, 1998. pp.19

[9] H. Friedrich et al., "Titanium in Automotive Applications -Nightmare, Vision, or Reality, "Proceedings 10thWorld Conference on Titanium, ed. G. Lutjering (Weinheim, Germany; Wiley-VCH, 2003), pp. 3393-3402.

[10] http://en.wikipedia.org/wiki/Aluminum

[11] Crowley, G. AM\&P 161, 11, 2003. pp. 25-27

[12] Montgomery J. S. et al. JOM 49, 5, 1997. pp. 45-47

[13] Hurless, B.E. et al. The AMPTIAC Quarterly, Volume 6, Number 2, pp. 3-9

[14] China's Impact on Metals Prices in Defense Aerospace, Department of Defense, Office of the Deputy Under Secretary of Defense (Industrial Policy), December 2005.

[15] Luckowski, S. The Application of Titanium in Army Armament Systems, Presentations at TMS 2003 Meeting

[16] Savage, N. A Cleaner, Cheaper Route to Titanium. Technology Review: An MIT Enterprise. 2006. http://www.technologyreview.com/printer_friendly_article.aspx?id=16963

[17] Hartman, A.D. et al. JOM 50, 9, 1998. pp.19

[18] H. Friedrich et al., "Titanium in Automotive Applications -Nightmare, Vision, or Reality," Proceedings 10thWorld Conference on Titanium, ed. G. Lutjering (Weinheim, Germany; Wiley-VCH, 2003), pp. 3393-3402.

[19] Kraft E. TI-METAL: The Global Titanium Metal Industry, A multi-client study by TZ Minerals International and EHK Technologies, TZ Minerals International Pty Ltd., May 2007.

[20] EHK Technologies, Industrial Markets for Titanium Manufacturing Energy Consumption And Impact of Lower Cost Processing, A Study Performed for US Department of Energy and Oak Ridge National Laboratory. 2007

[21] McCormack, Titanium in Military Airframes, GKN Aerospace, ITA Conference 2007 Presentation, Orlando, FL

[22] National Materials Advisory Board, "Titanium: Past, Present, and Future”, National Academy Press, Washington, D.C. 1983

[23] Lutjering G., William J. C. Titanium. Springer, 2007. p. 81

[24] "Titanium Procurement Lessons Learned", Col. John Kusnierek, Briefing by the U.S. Air Force, DLA, August 4, 2008

[25] Rivard J.D.K. et.al., "The Thermomechanical Processing of Titanium and Ti-6Al-4V Thin Gage Sheet and Plate," JOM, Vol. 57, Issue. 11, page 58 (2005)

[26] Seong S., Younossi O., Goldsmith B. W., Lang T., and Neumann, M. Titanium: Industrial Base, Price Trends, and Technology Initiatives. Prepared for the United States Air Force. Rand Corporation, 2009. pp.1-2

[27] Kraft E. TI-METAL: The Global Titanium Metal Industry, A multi-client study by TZ Minerals International and EHK Technologies, TZ Minerals International Pty Ltd., May 2007. 
[28] A Thintri Market Study, The Titanium Age: Supply Constraints and New Markets, Thintri Inc, NY. 2005.

29 Gambogi, J. 2010 Minerals Yearbook: Titanium [Advance Release \}. U.S. Department of the Interior. U.S. Geological Survey. June 2012. Pg 78.15.

[30] Aero: Boeing's Quarterly Publication, Issue 24, Quarter 04, 2006. (boeing.com/commercial/aeromagazine)

[31] Chapman, P.F.; Roberts, F. Metal Resources and Energy. Butterworths \& Co., 1983. pp.114 and 138

[32] Hurless, B.E. et al. The AMPTIAC Quarterly, Volume 6, Number 2, pp. 3-9

[33] Blue C.A. and Peter W.H. Final CRADA Report for CRADA No. ORNL05-0702, Alloy Design and Thermomechanical Processing of a Beta Titanium Alloy for a Heavy Vehicle Application, www.osti.gov/bridge, July 2010

[34] W. Chen, Y. Yamamoto, and W.H. Peter, "Investigation of pressing and sintering processes of CP-Ti powder made by Armstrong Process", Key Engineering Materials Vol. 436 (2010) pp. 123-130.

[35] Robertson I.M. and Schaffer G.B., Metall . Mater. Trans. A, 40, p. 1968, (2009)

[36] R. Panelli, F. Ambrozio Filho. A compacting equation and its use to describe the powder consolidation behavior. Powder Metall. 41 (1998) 131-133

[37] V.A. Livanov, A.a. Bukhanova, and B.A. Kolachev, Hydrogen in Titanium, Israel Program for Scientific Translation Ltd. (1965): translated a Russian book published in Moscow, 1962.

[38] R. Boyer, G. Welsch, E.W. Collings, Materials Properties Handbook: Titanium Alloys. ASM International, Materials Park, OH, 1994.

[39] Outotec, HSC Chemical Reaction and Equilibrium Software, 2010, calculation

[40] Kosemura et al, Technology Trend of Titanium Sponge and Ingot Production, Nippon Steel Technical Report, No 85, January 2002

[41] Subramanyam R. B., Some Recent Innovations in the Kroll Process of Titanium Sponge Production, Bulletin of Material Science, Vol. 16, No. 6 December 1993, pp 433-451

[42] (2011) Manufacturing Process, Retrieved August 10, 2011 from Kobelco Kobe Steel Group Web Site http://www.kobelco.co.jp/english/titan/files/process.pdf

[43] ATKINS feasibility study. Downloads, 2008. [Online]. Available from: http://atkinsproject.com/web/atkins/pdf/ATKINSfeasibilitystudy.pdf. 